Fall 2019

\title{
2019 Miracle Yearbook
}

Cedarville University

Follow this and additional works at: https://digitalcommons.cedarville.edu/yearbooks

Part of the Higher Education Commons, Organizational Communication Commons, and the Public Relations and Advertising Commons

\section{Recommended Citation}

Cedarville University, "2019 Miracle Yearbook" (2019). Yearbooks. 100.

https://digitalcommons.cedarville.edu/yearbooks/100

This Book is brought to you for free and open access by DigitalCommons@Cedarville, a service of the Centennial Library. It has been accepted for inclusion in Yearbooks by an authorized administrator of DigitalCommons@Cedarville. For more information, please contact digitalcommons@cedarville.edu. 


\section{Miracle Yearbook moments}







\section{Contents}

Fall Divider

Winter Divider

Spring Divider

Student Life Divider

Global Outreach Divider

Sports Divider

Freshman Divider

Sophomore Divider

Junior Divider

Senior Divider

Fac/Staff Divider 


\section{opening}

This year at Cedarville was a compilation of millions of moments. It began with masses of students in matching T-shirts screaming with banners and pool noodles in hand, welcoming all of us home, whether it felt like home yet or not. Then, all the "firsts" came - first dinner in Chucks, first overwhelming syllabus, first Rip run, first Rinnova latte. We started digging into our classes and hoping for survival.

On a typical week, we spent our Tuesday nights at Stingers downing boats of curly fries and laughing at scarily accurate memes. We cheered on the volleyball team alongside our buff new mascot to earn T-shirts, and we tried not to get hit by motorized longboards on our walk back to our dorms, whether we lived in the brand-new Walker Hall or the long-standing Faith. We got struck with Cedar Plague, yelled at CedarPrint, and shook our fists at the wind as we were tossed past Cedar Lake to chapel, Though the year was filled with triumphs and tragedies, we shared the common experiences that made our campus one of a kind.

This book is an attempt to capture those moments. If you find yourself laughing, shaking your head, or saying, "I completely forgot that happened," we have accomplished our goal. This is a chronicle of the student experience, a tribute to all things Cedarville. Join us to relive every second that makes Cedarville University our home. 


\section{Dedication}

James Leightenheimer is an alumna and Associate Professor of Communication, as well as the advisor for the student-run radio station, Resound Radio. He has been married for 40 years to his wife Beth, and they have five children: Jesse, Jenny, Johannah, Jay, and Jacob. His hobbies include baking, reading, stained glass work, hiking, and hunting. He is a member of Grace Baptist Church and serves on the security team, and he ran sound there as well. He has worked at Cedarville since the fall of 1982 and has changed countless students' lives during his time here.

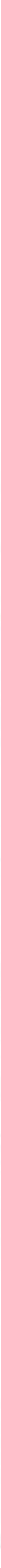




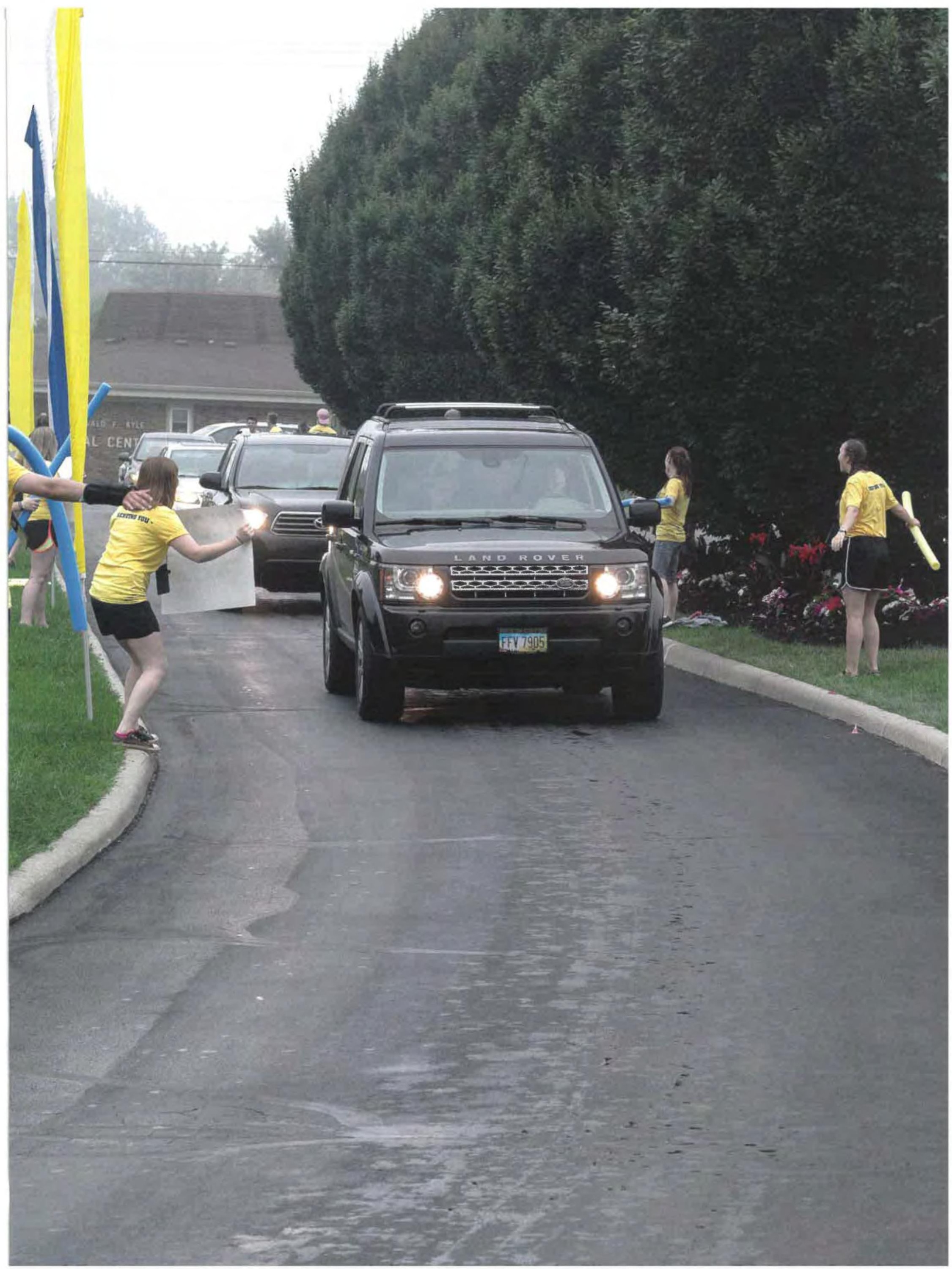




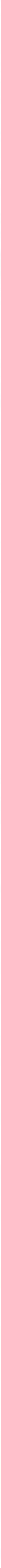




\section{Getting Started}

Hours before Jacket Fest's start time, students in

Campus Experience had to execute their rain plan

and set up all the inflatables and activities inside the

Fieldhouse. This was the first time the freshman party would be held inside, so it was a toss-up of whether it would work well or flop. Luckily, an impromptu, student-initiated dance broke out next to the SGA poster-signing table. "As groups began to finish their main activities, they started the dance party," Whitney O'Brien, a STING leader, said. "Before I knew it, our group had joined, and nearly everyone at the Jacket Fest was jumping up and down to the beat." O'Brien said the party led to lasting connections in her group; one girl even signed up to be in her D-group this year.

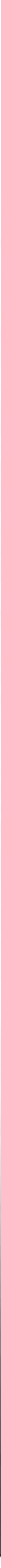


1: Isaac Wood, an RA, stands outside Brock Hall, ready to meet, greet, and help freshmen into their new home.

\section{2: Mariah Mayse and Madeline Stouffer wave} signs, welcoming freshman girls to Johnson Hall and reassuring parents that their students are in good hands.

3: Zachary Skaer gets high-fived during the Jacket Jaunt, a Cedarville freshman tradition. The Jaunt started at the courtyard outside the SSC after the freshman picture and led to chapel, featuring Dr. White's welcome message in the DMC.

4: Breanna Hamilton hauls a freshman's belongings to her unit in Printy. Hamilton was a STING group leader, which meant she helped move in freshmen.

5: Dr. White parks his golf cart outside the Fieldhouse. He was in charge of handing out water to the STING leaders and RA's who were helping move in new students.

6: Summer Lange jogs toward the DMC after the freshman class picture. 


\section{Fall Bible Conference}

Students kicked off the school year with a much-loved speaker and an impactful message at the annual Fall Bible Conference. Morning and evening, Sam Allberry taught core truths about Jesus Christ through his series, "(Re)Introducing Jesus," which encouraged students to reconsider their perceptions of $\mathrm{Him}$. "Each and every student needed a fresh vision of Jesus," Allberry said. "I know this is the case because I also needed a fresh vision of Him." During the conference, dozens of students made the decision either to come to Christ or rededicate their lives to the Lord. Those few days were a time of revival and of a discovery of Christ.

1: Members of HeartSong sing "The Lion and the Lamb" in chapel.

2: Ariana Brooks plays keys during HeartSong's set.

3: Josiah Winey plays guitar and leads in worship.

4: Kristen Doyle harmonizes with the other singers, adding in an alto part.

5: Sam Allberry delivers his sermon on the second day of the conference. 


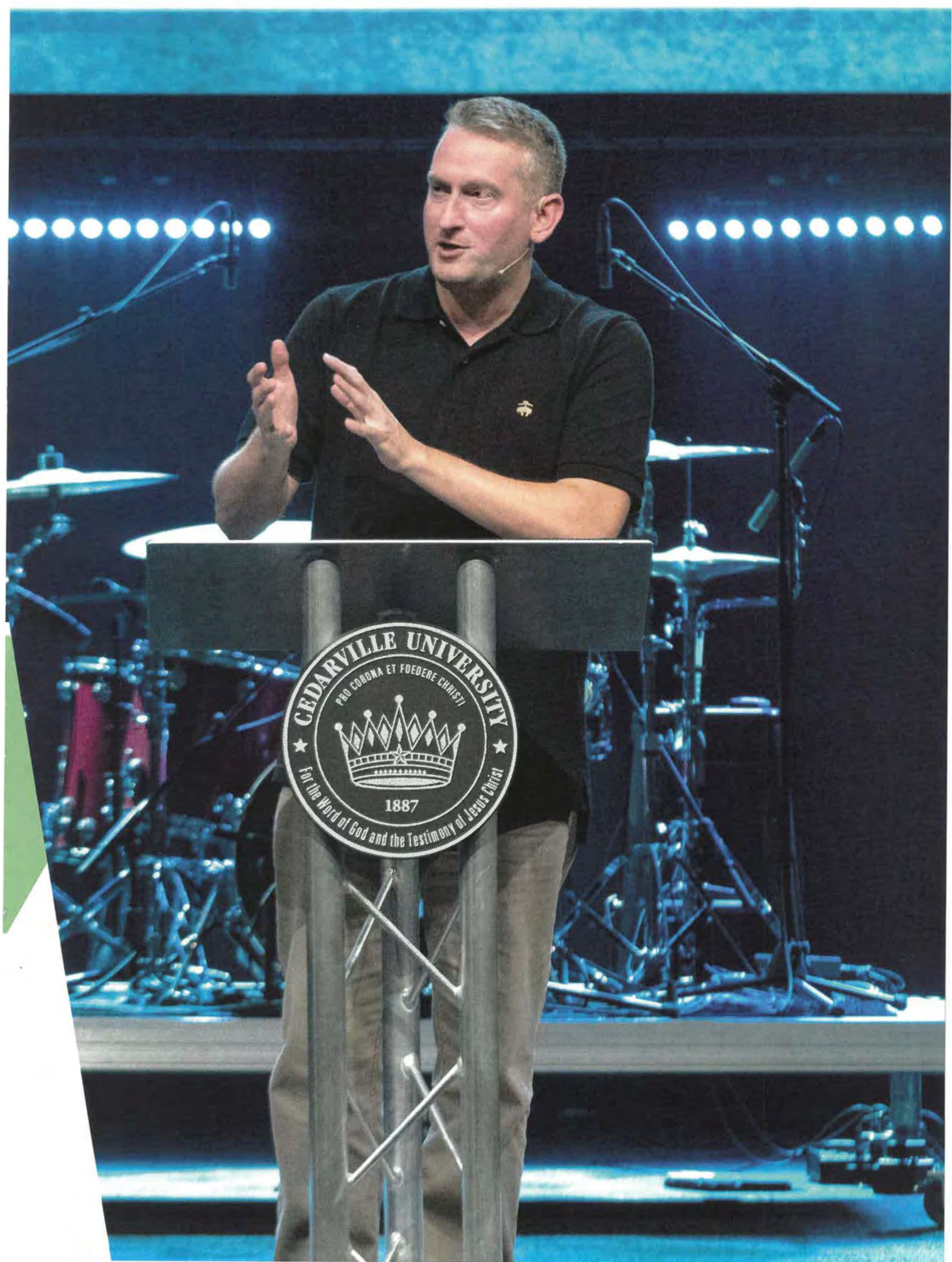




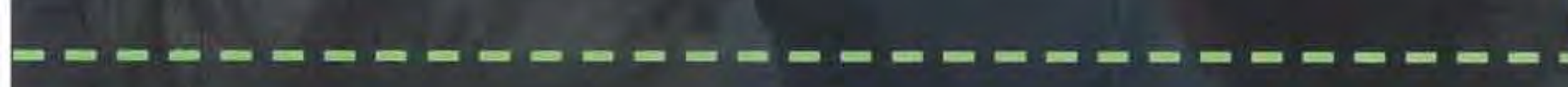

1: Students sit by the edge of Cedar Lake to watch the annual cardboard canoe race.

2: Dawson Tso and Steven Sweeney compete in the cardboard canoe race.

3: Ray Tiell and Kimmy Powell ride down Main Street during the Homecoming parade. They were elected as Mr. and Miss Cedarville and received a place of honor during the parade.

4: Dr. Chris Miller reads Scripture during a musical interlude in "The Light, a Night of Worship." He reminded the audience that Christians are to be lights in the world.

5: Kylie Beste blows bubbles while walking down Main Street during the Homecoming Parade. She was dressed up for her float's "Under the Sea" theme.

6: Jeremiah Vroegop leads students and guests in song during "The Light, a Night of Worship."

7: Nathan Johnson pulls his canoe out of the water as he finishes the cardboard canoe race.

8-9: (Left to right) Hope Hesterman, Ben Coleman, Andrew Fretwell, Ethan

Ooms, and Natalie Steenwyk recreate a yearbook photo from the 1980's for Throwback Thursday. The photo below (9) is the one they recreated.

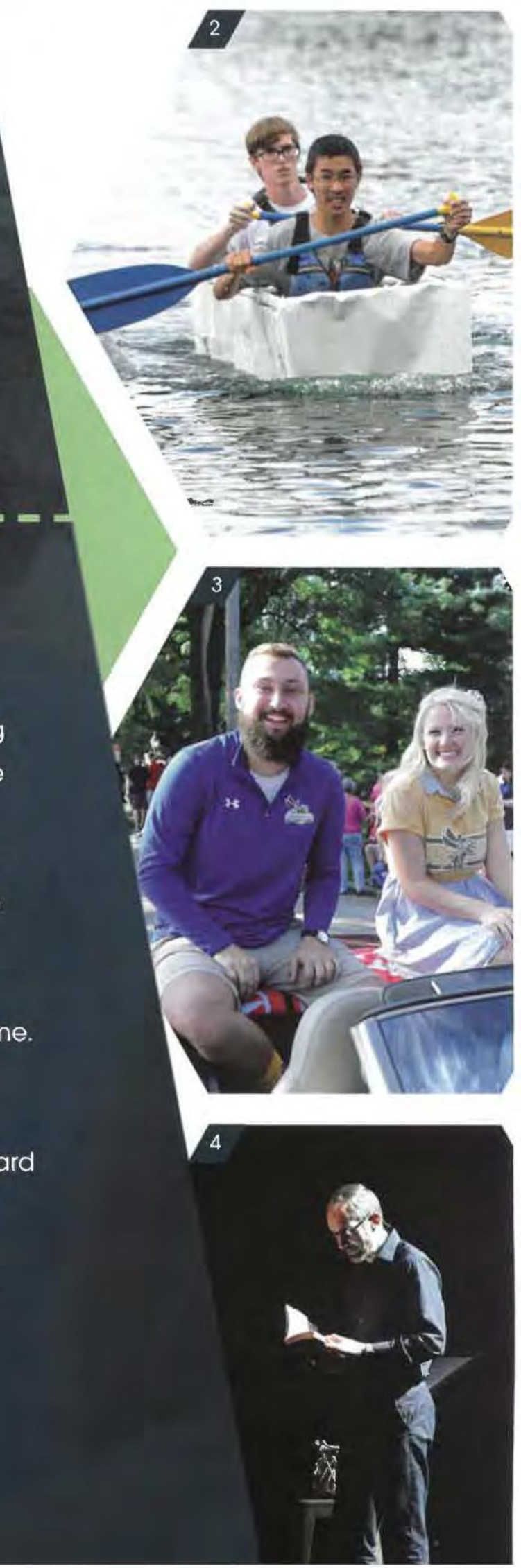




\section{Homecoming}

Nearly 2,000 guests visited campus on Oct. 5-6. A mixture of alumni, parents, and friends gathered to visit students, reminisce on past college days, and participate in a multitude of campus events like the Homecoming parade and cardboard canoe races. "The Light, a Night of Worship" capped off Homecoming Weekend in an awe-inspiring finale. "All the hard work we did certainly paid off," soloist Macy McClain said. "It was very powerful, and I heard that a parent came to Christ that night." At the event, Dr. Chris Miller read passages of Scripture between worship songs performed by the choir, orchestra, and praise band. The chapel was packed out with students and family members who used light-up bracelets to wave during the last song, symbolizing that believers are to be lights in the world that emulate Jesus Christ.

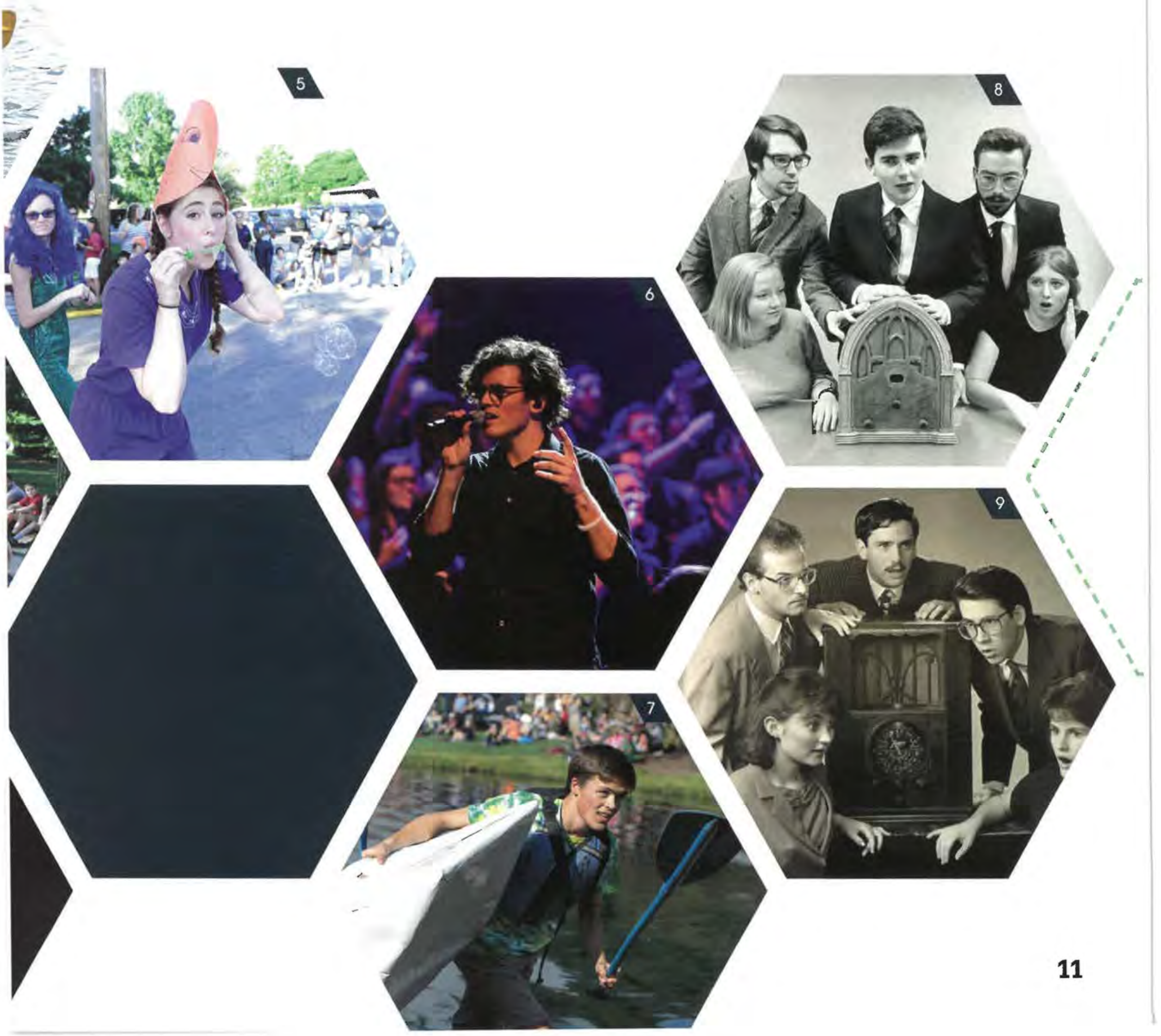




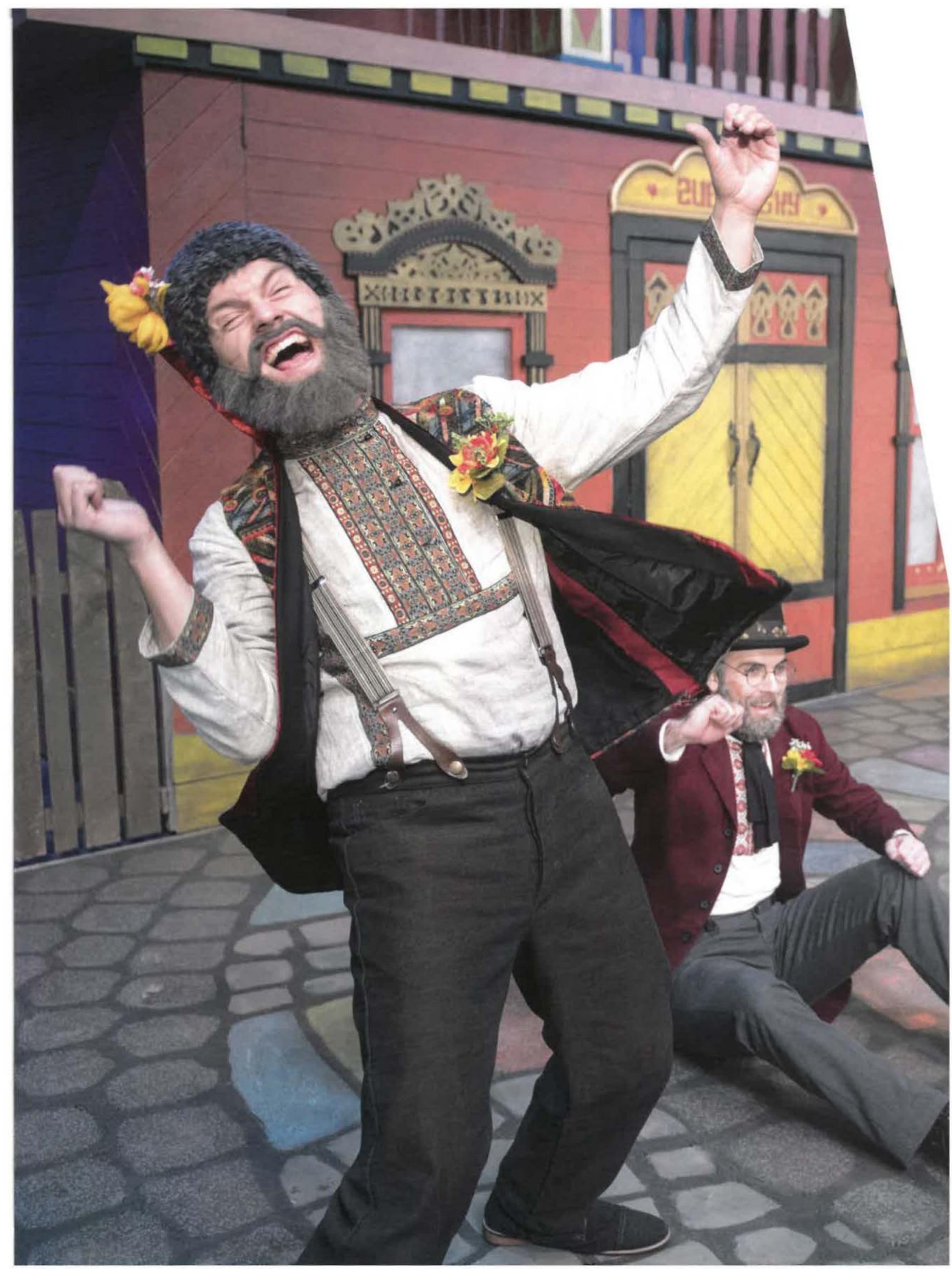




\section{Fools}

The cast of the fall play took to the stage on Oct. 4-14 to perform "Fools" by Neil Simon. The play is about a young schoolteacher who gets a job in a Ukrainian town called Kulyenchikov, not knowing that the locals are under a curse that makes them incredibly foolish. Although the play is lighthearted, the cast went through rigorous preparation to perform it skillfully. They had rehearsals for three hours a day, four days a week, to immerse themselves in their roles. "I really liked rehearsals because I learned so much just about theater in general and how professional theater works," Beth Oldham, the female lead, said. "You know, going to theater rehearsal for the show, we weren't allowed to wear logos on our shirts or anything that would take us out of the world of Kulyenchikov." They even had a dialect coach come in and train them on how to perform in a Ukrainian accent. Their intense study of the characters allowed them to put on a professional performance.

1: Snetsky, played by Andrew Standley, discovers that he can spell words again and that the curse of stupidity has been broken.

2: Leon Tolchinsky, the lead character played by Jeremy Smith, pretends to have trouble getting the bride's ring on Sophia Zubritsky's finger, played by Beth Oldham.

3: The cast of "Fools" prepares to bow during their curtain call.

4: As an outsider, Jeremy Smith's character tries to reason with the cursed townspeople but cannot break thorugh their confusion.

5: Gregor Yousekevitch, played by Blake Hansher, describes his hatred for his father.

6: Lenya Zubritsky, played by Ranae Haskins, eats a flower, giffed to her by Leon, as a way of thanking him.
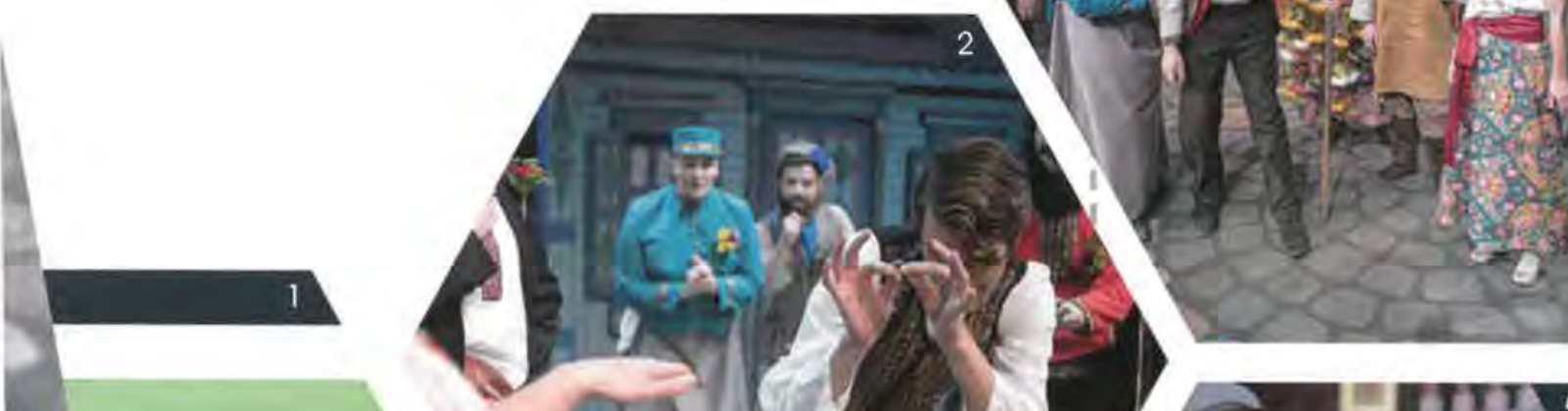

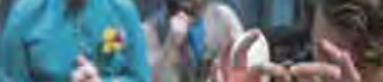
9 (4) 2. कर 3 $\mathrm{H}_{\mathrm{F}} \mathrm{x}$

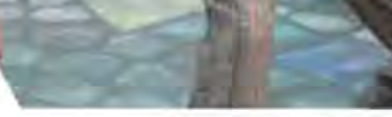

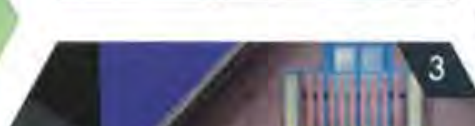
3 


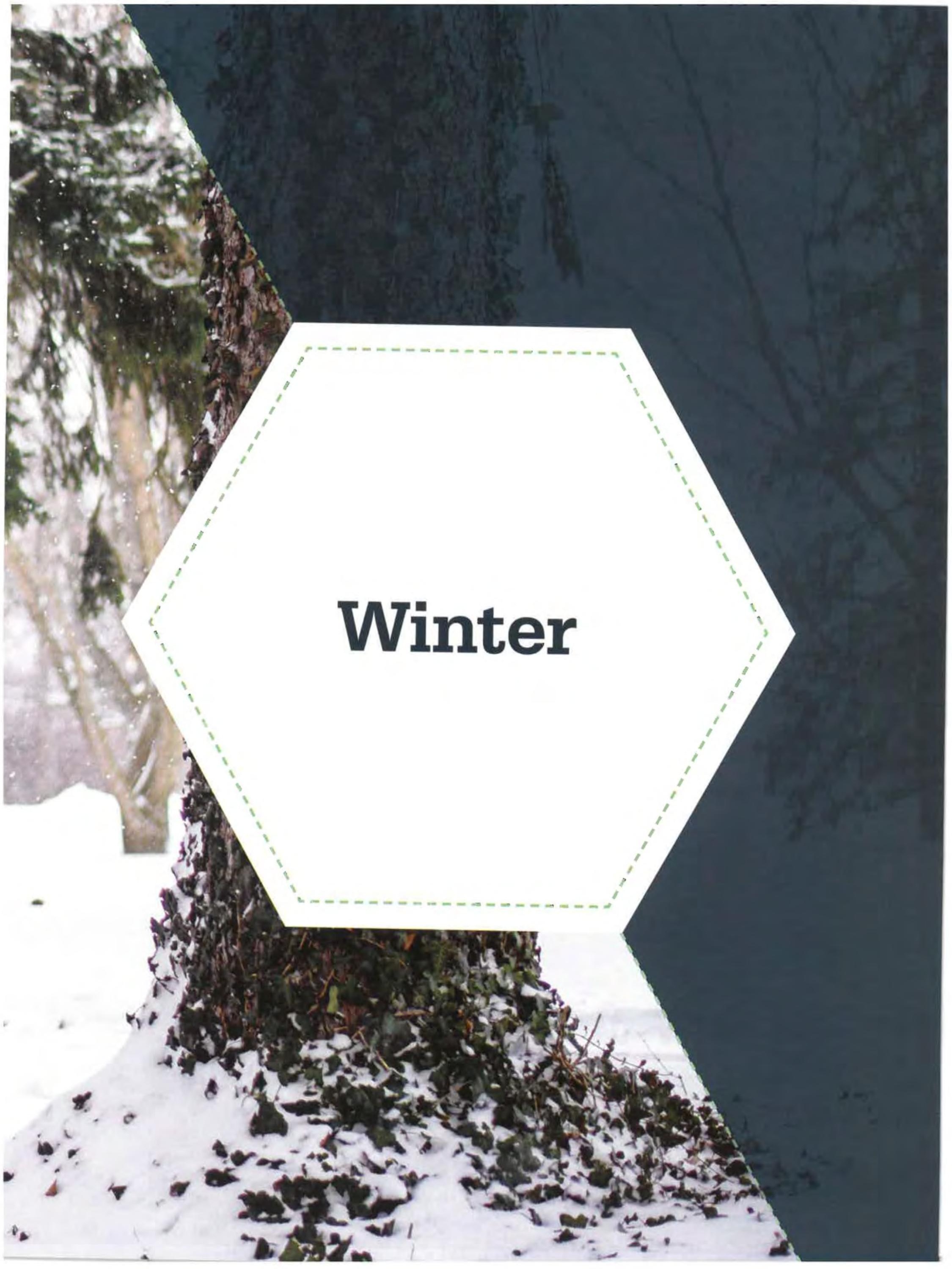


1: Olivia Deyaert pops out from behind a tree during open dorms. Her hall was Narnia-themed.

2: Hannah Lucas waves pool noodles, pretending to be a STING leader welcoming students to campus.

3: Megan Whitney, Timberly Kreiner, and Emily Talento serve ice cream, dressed up as Young's Dairy employees.

4: Isaac Wagner runs an "Oregon Trail" room in Rickard. His hall's theme was Arcade Games.

5: Weston Mountz pretends to be Aslan on the Stone Table during open dorms.

6: Andrew Harshbarger peeks out of a cardboard box during open dorms. He was acting as the mole in whack-amole.

7: Tanner Kunz sings "Mary Did You Know" during karaoke night in Chuck's.

8: A SuperGames employee drives a train around Chuck's. Students were invited to ride in the train as one of the activities.

9: BriAnn Stokes and Kaitlyn Antle act as hippies for their hall's theme, Christmas in the ' 70 s. 


\section{Campus Christmas}

All through the Fall semester, students anticipated

Campus Christmas: a weekend chock-full of

celebrating, activities, and fun. Friday, December 7

kicked off the event with Campus Christmas Open

Dorms. Students decorated their halls in different,

creative "themes," such as "Mary Poppins" or "Printy

House Cinemas," and then opened up the halls

- for tours. The tours ran from late afternoon until

midnight, and the day was a blast for everyone involved. On Saturday Evening, the Stevens Student Center hosted a giant Christmas party that included cookie decorating, pictures with Stinger, and showings of "The Polar Express." From 9-11 pm, the Dining Hall offered a late-night breakfast, karaoke, and even train rides. The weekend gave students a much-needed break from finals and provided them the opportunity to celebrate the season.
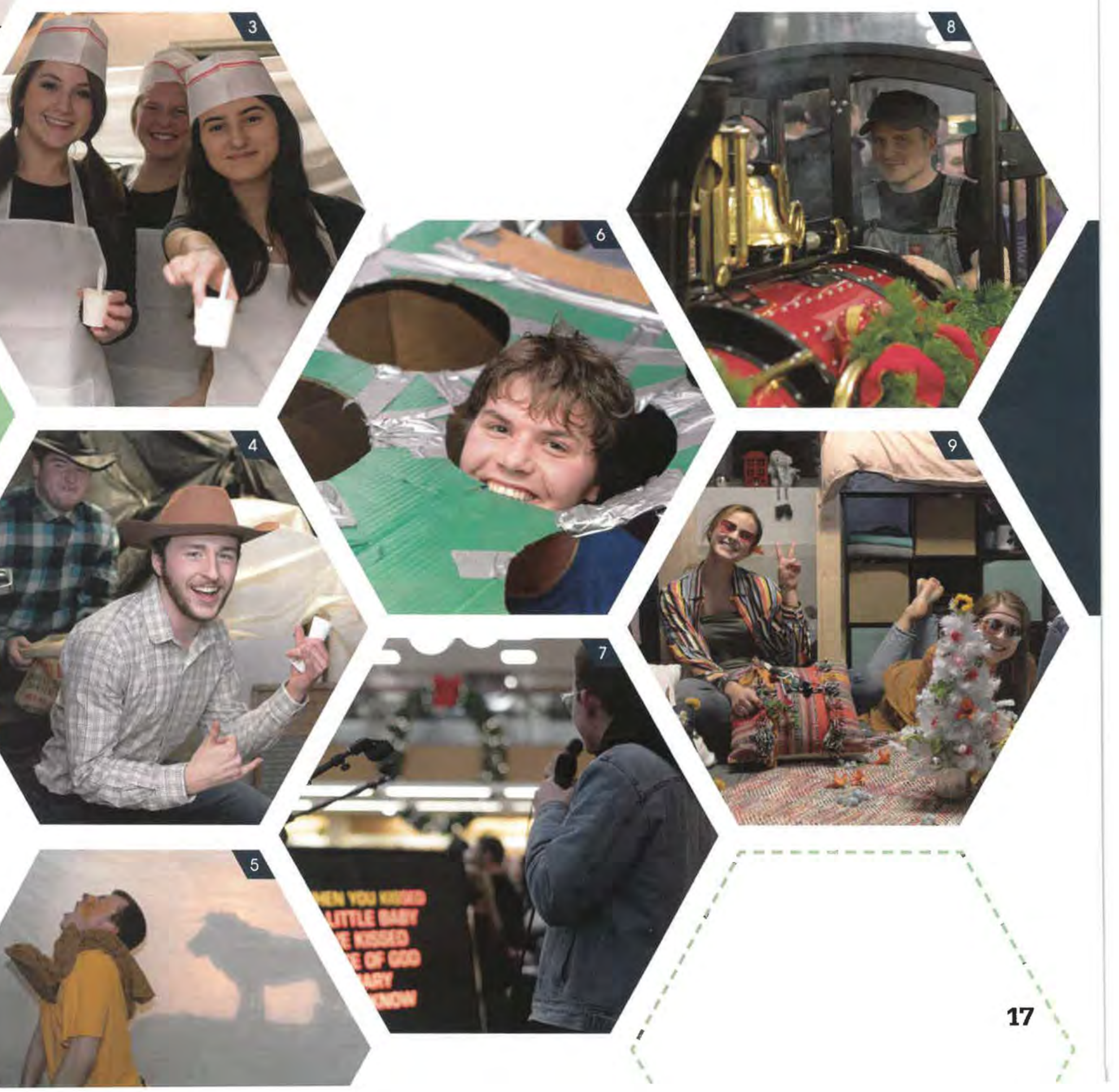


\section{Missions Conference}

Dr. Kevin Ezell, the president of the North American Mission Board, and Dr. Matt Bennett, Assistant Professor of Missions and Theology, led Cedarville's annual Missions Conference on Jan. 8-10. This year, the university hosted the largest conference in its history, with 100 missions organizations and over 50 missionaries in attendance. During the conference, students participated in workshops and visited various displays to learn how they could use their skills to make an impact on the world. The event emphasized the point that students should learn to carry the gospel with them wherever they end up going, not necessarily just to other nations. Dr. Ezell spoke at the four main sessions, and Bennett wrapped up the conference. "If the Lord does have you here for a season of preparation," Bennett said, "let me encourage you that $\mathrm{He}$ is sovereign, and $\mathrm{He}$ is going about the accomplishing of His tasks around the world while $\mathrm{He}$ has you here preparing."

1: Ariana Brooks plays the keys and sings.

2: Kayla Welch leads in worship.

3: Caleb O'Neel plays guitar and leads in worship.

4: Brandon Haynes plays electric guitar with Joshua Ratlift on the drums.

5: Dr. Kevin Ezell gives a sermon on missions during the conference. 


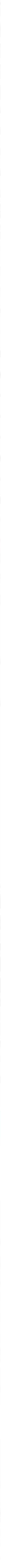




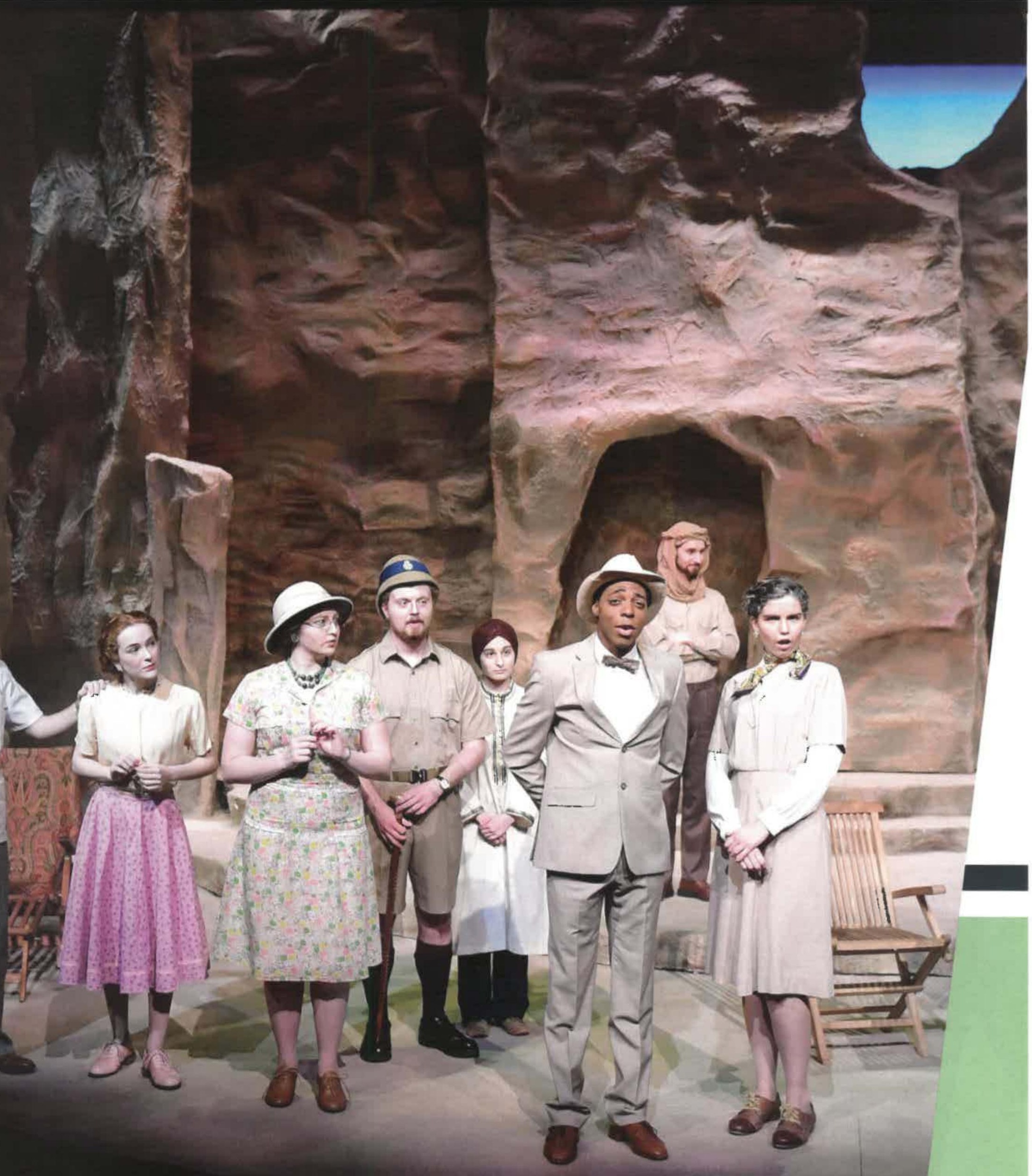




\section{Appointment With Death}

1: Alderman Higgs (DaVonte Cassidy) tells the group of his connection to Lady Westhome (Teagan Bolin).

2: Dr. Gerard (Thomas Folkerts) listens in to the Boynton family's conversation.

3: Alderman Higgs (DaVonte Cassidy) holds a conversation with the ltalian girl (Beth Oldham).

4: Mrs. Boynton (Abigail Krakora) manipulates the mind of her son, Lennox Boynton (Evan Ellis).

5: Sarah King (Ssubi Arango), Lennox Boynton (Evan Ellis), Nadine Boynton (Emma Waywood), and Raymond Boynton (Hunter Johnson) watch as events uncover the truth behind Mrs. Boynton's death.

6: Ginevra Boynton (Lauren Jacobs) ho!ds up a knife and contemplates what to do with if

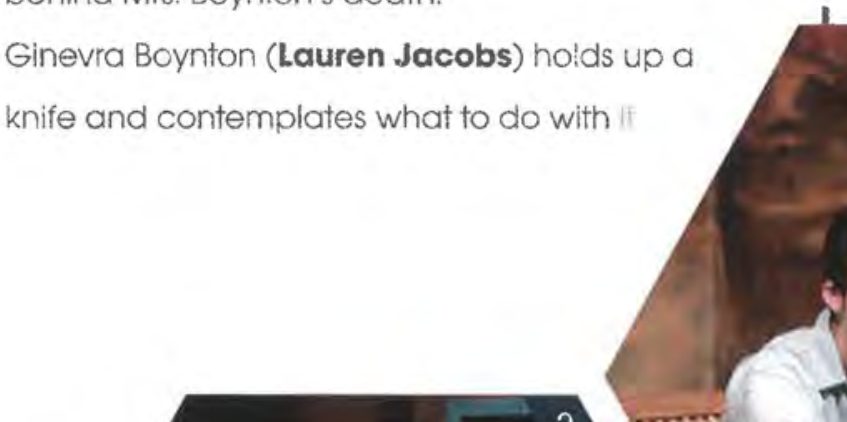

"Appointment with Death," a play that ran from Jan. 31 - Feb. 10, is set in Petra, Jordan during the 1940s. A tourist group settles into a hotel and gets to know one another in preparation for their outing the next day. However, it is not long before a death unsettles the group and casts suspicion upon several characters. This play was directed by Dr. Dawn Schluetz, who was in her second year as an assistant professor of theatre. The play featured a cast from a variety of years and majors, allowing them to gain skills for their future school and work. A variety of cast members explained their experience with the play to be helpful in expanding their worldview and beliefs in Christianity.

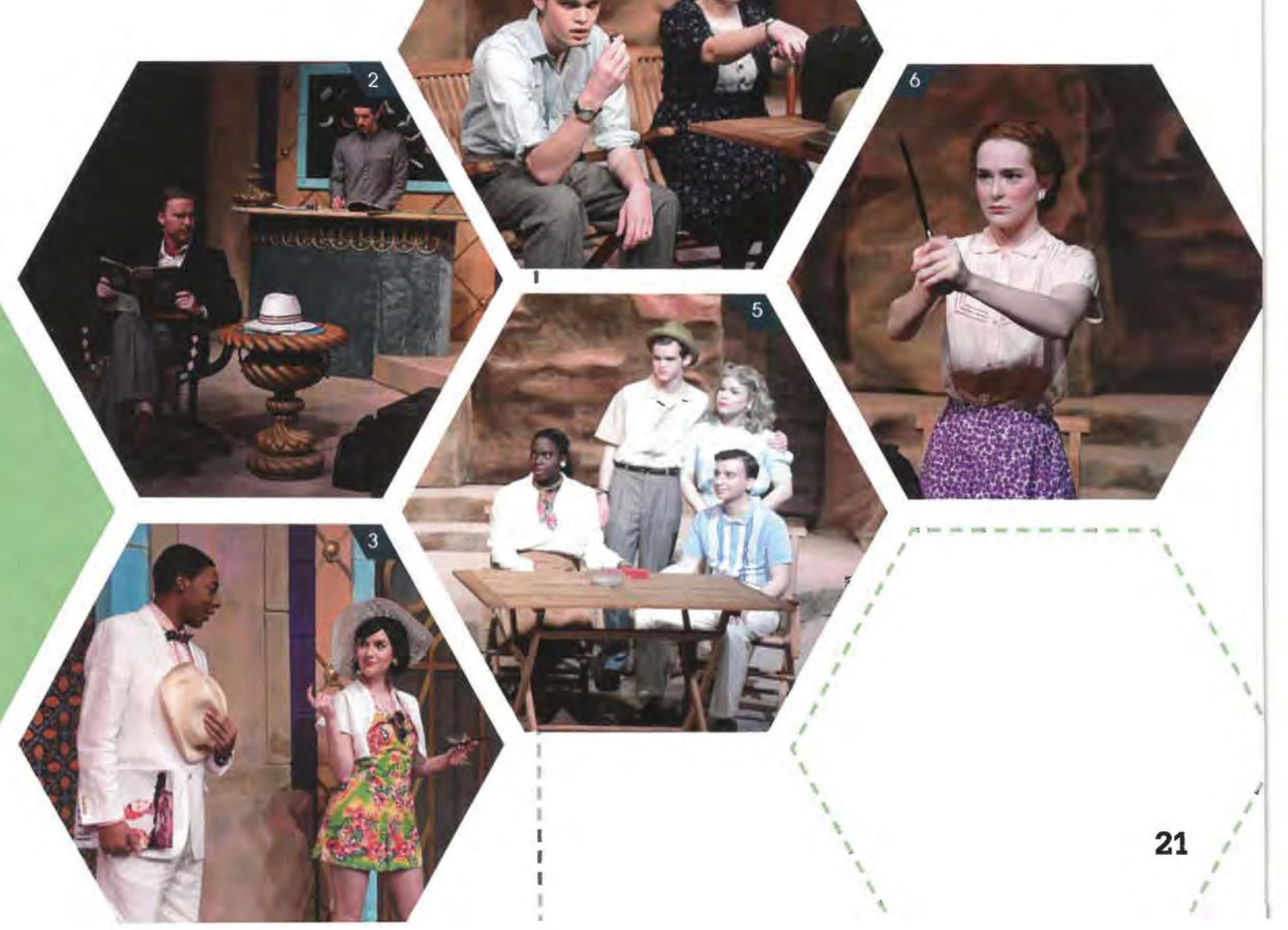




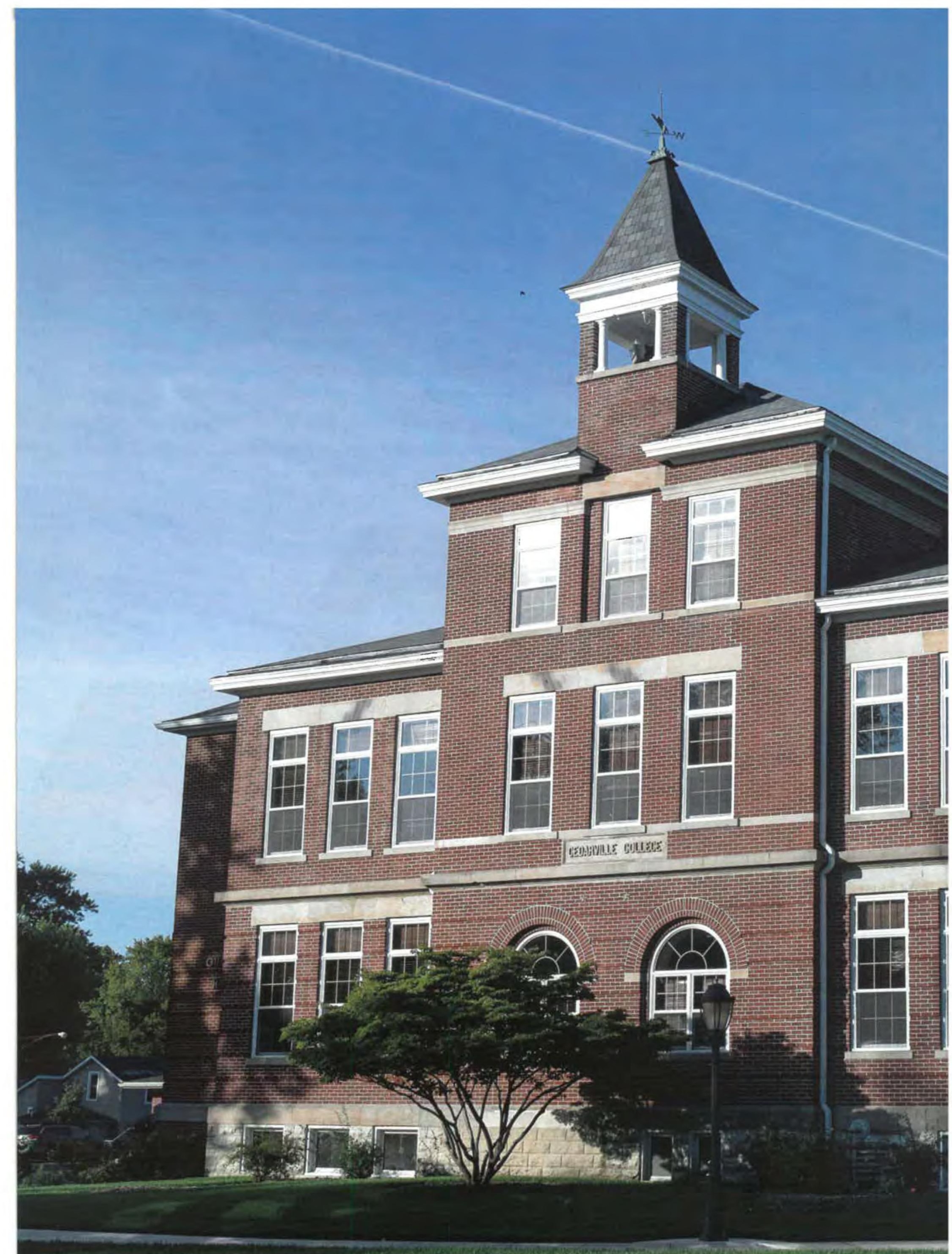




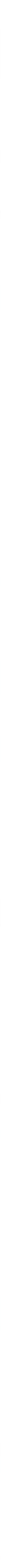





\section{Chapel}

From weekly series to one-time events, chapel is a place where students daily hear from God's Word. As just one example, in February, Cedarville welcomed Ken and Tara Winter who spoke in chapel as a husband and wife team. Ken is the lead pastor of Heritage Fellowship Church in Springfield, $\mathrm{OH}$, and Tara serves alongside Ken and provides care to women at the Pregnancy Resource Center in Springfield. The couple told the story of their relationship, how they navigated their spiritual lives through rocky times, and how God ultimately used their circumstances to draw others to Himself. Tara said, "Our hope is that whatever life circumstances students at Cedarville will encounter, they will always know of God's unconditional love and grace that $\mathrm{He}$ has for them and that our $\sin$ does not define us, but our identity rests in God's redemptive work to be more like Him."

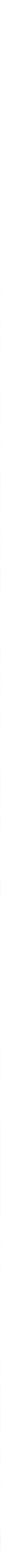




\section{Spitfire Grill}

The Spitfire Grill, Cedarville's spring production, was a musical based off the original movie made in 1996.

This heartwarming story follows Percy Talbott, played

by Emily Hunnemeyer, who travels to a small town after her release from prison. At first, Percy is the one who needs the town for a fresh start, but it turns out that the town itself needs Percy just as much, if not more. "To put on a whole show in just two months took a lot of hard work, but it was the kind of hard work that you look forward to doing," Connor Haynes, who played Shelby Thorpe, said. "Through tough classes and long days, I always knew that I would have a goal outside of myself to go to, to forget about this life awhile and focus on the life of another person, my character." Each character in the play finds some redemption by the end, which mirrors the gospel message of God's

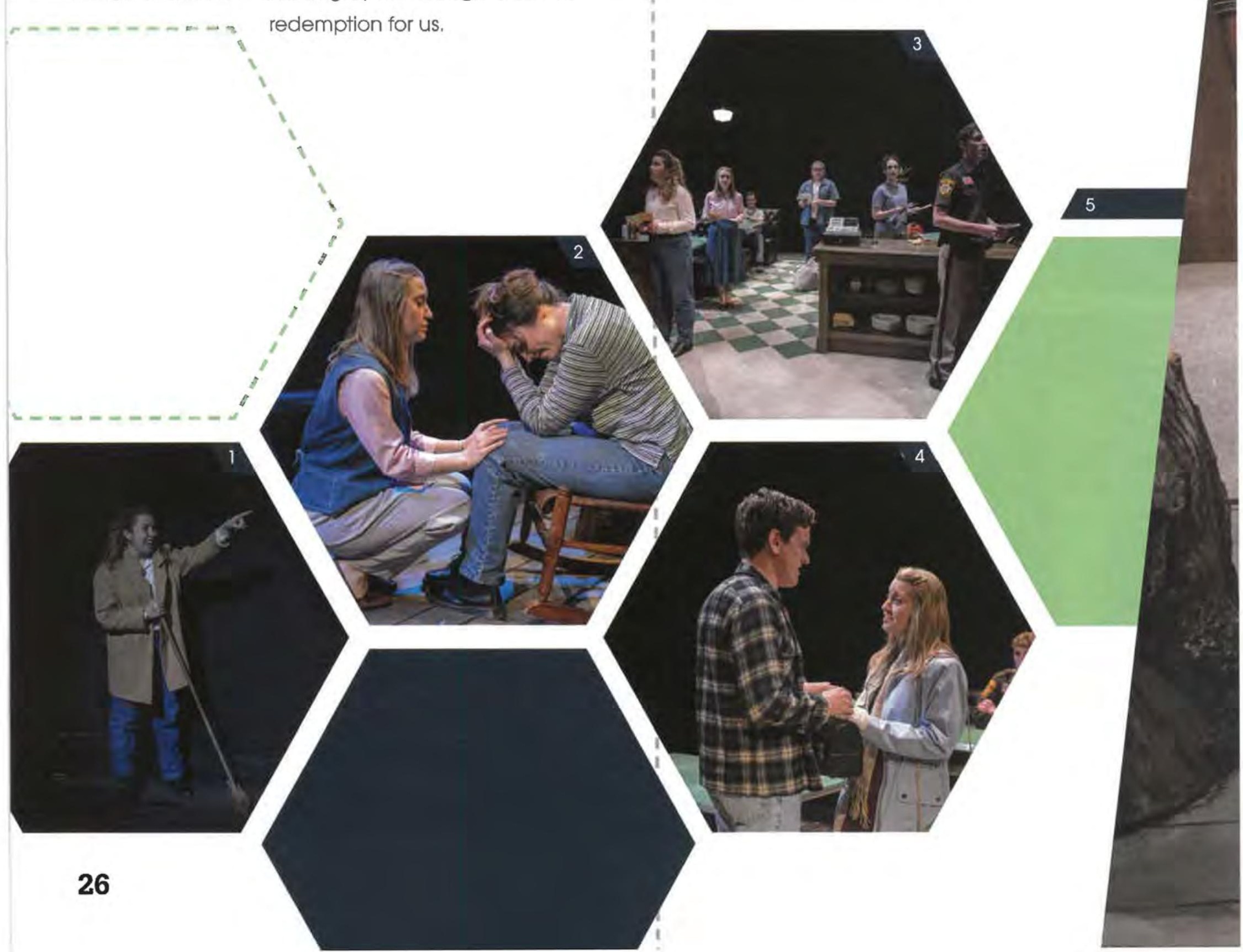




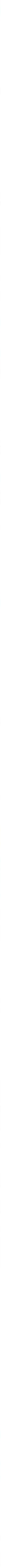




\section{Moonlight Madness}

1: Ryan Smith, the SGA president, announces this year's basketball players.

2: A judge panel gives a unanimous $10 / 10$ during the men's slam dunk contest. Even Stinger joined in with his vote!

3: Lexi Moore (44), Isabelle Bolender (20), and Emily Chapman (0) give a group dance performance as their names are announced.

4: Ashlyn Huffman (5) dodges Kelly Poole (14) during the Lady Jackets' mock game between upper- and underclassmen

5: Andrew Tuttle, Nick Mahek, and Christian Brandt pose with Stinger on the bleachers.

6: Quinton Green (55) throws the ball under his leg as he leaps to make a slam dunk.

7: Lindsey Seals, one of the Cedarville cheerleaders, raises her arms in victory while performing a daring stunt.

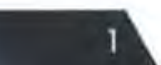

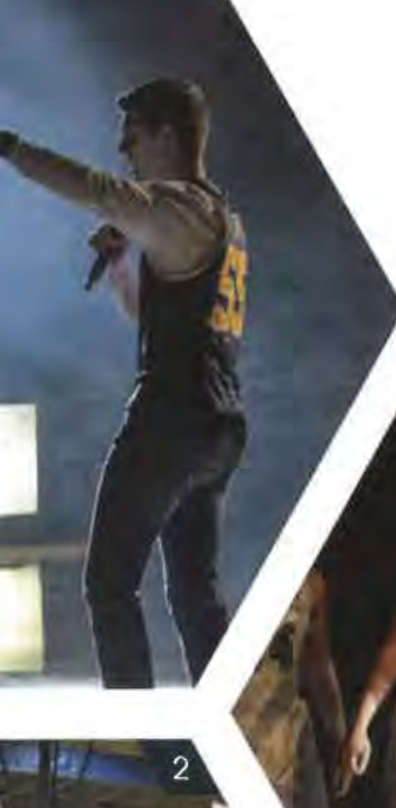
(a)

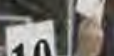
10. P.

She

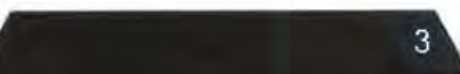
Q. A (1)

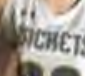
СHETS sile N PNo

s 


\section{JS}

1: Laurel Bryant, Abby Snow, Victoria Christenson,

Stephanie Brimer, William Tomlinson, Kaitlyn Ring,

and Angie Bobe pose in a gazebo for a group picture.

2: Steven Wormald, Angie Bobe, and Cameron

Smith pose for a group photo.

3: Nathan Harris holds Gabe Sallstrom in his arms to pose in the gazebo with their friends Bert LaChance, Jack Higgens, and Kaileb O'Neil.

4: Josh Ratliff prepares to take pictures with his friends on the BTS patio.

5: Jake Kenniv, William Tomlinson, Victoria Christianson, Jon Larson, and Mark Holland pose for a group picture.

6: JS took place at the Savannah Center in Cincinnati.

7: Julianna Mitten, Kaitlyn Ring, and Taylor Leeds pose for a group photo.

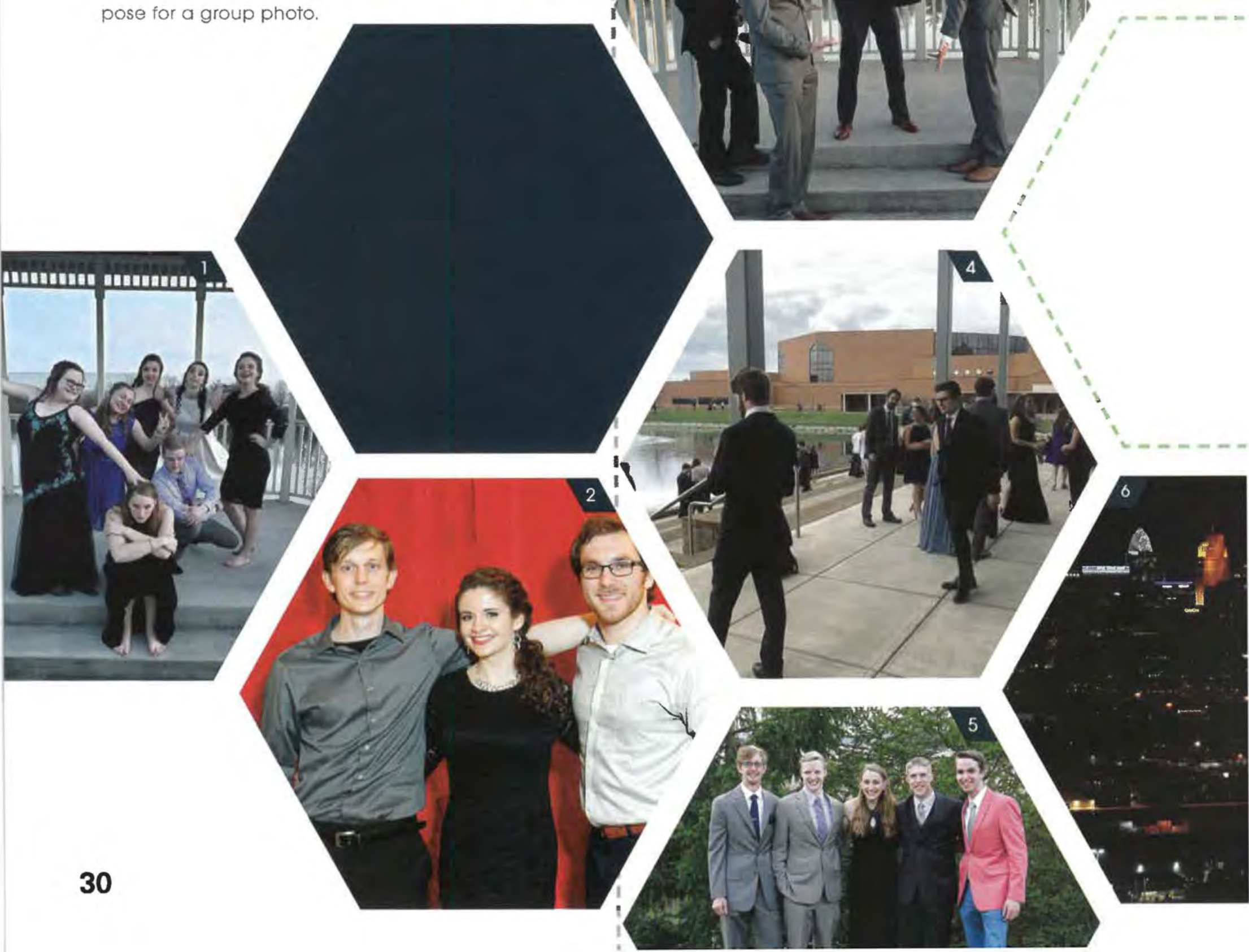




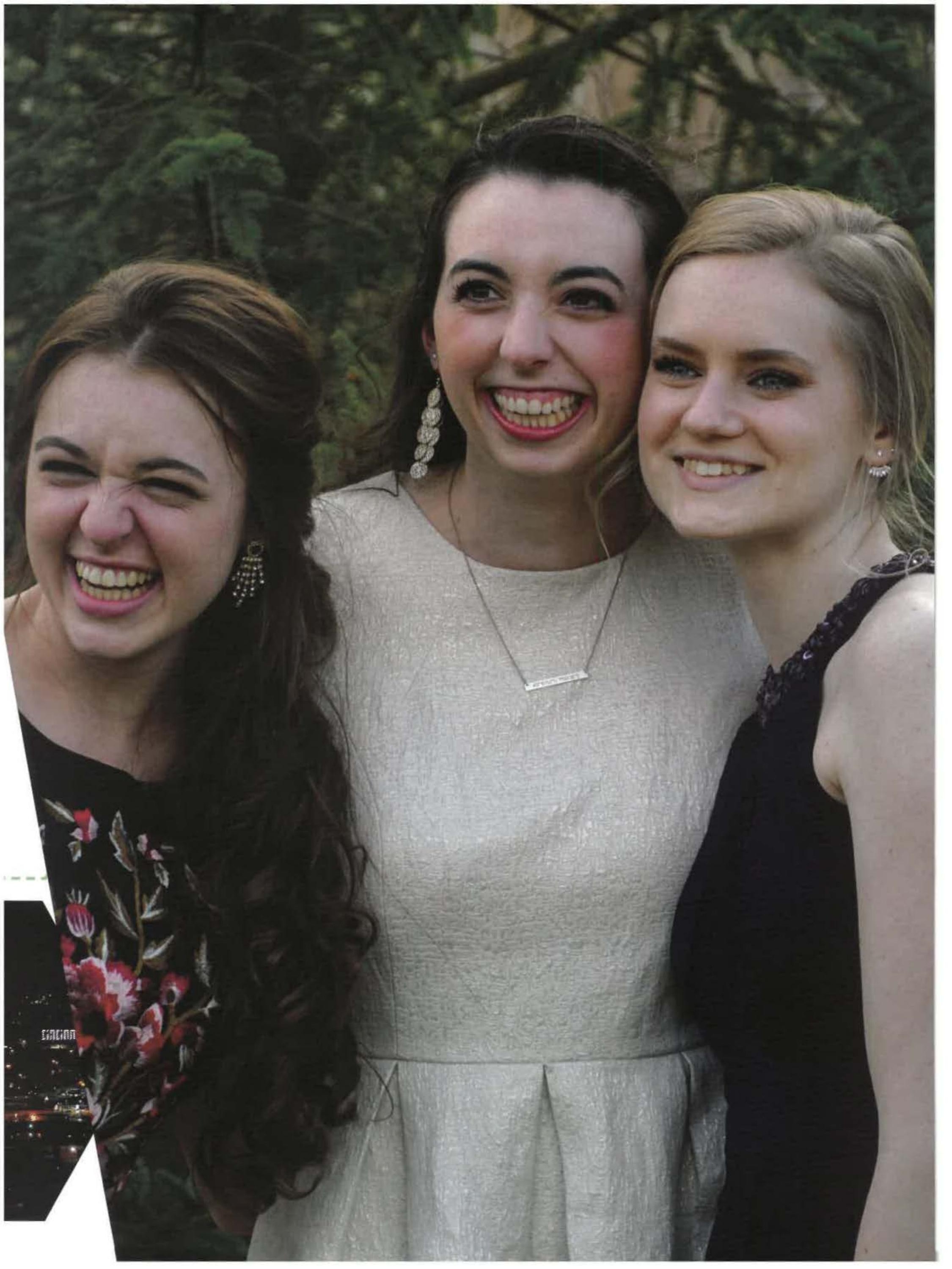


No

2. 240 .

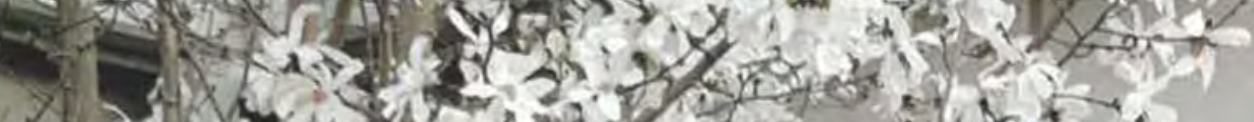

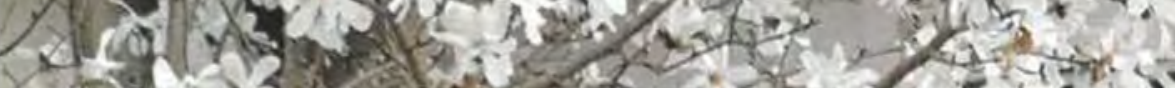

$\rightarrow 2$ ale 1 .

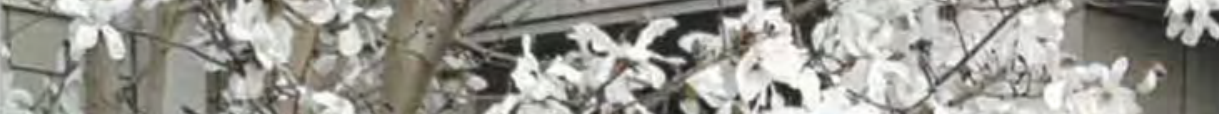

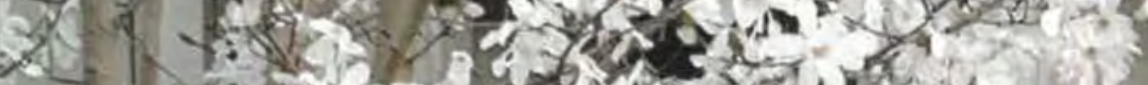

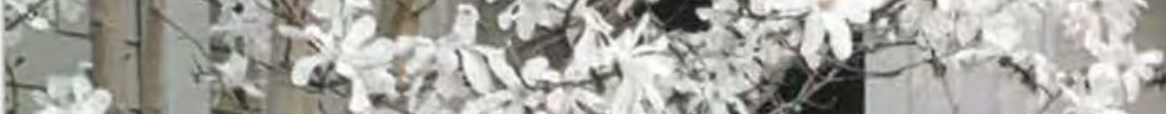

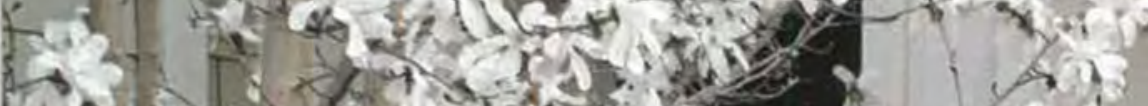

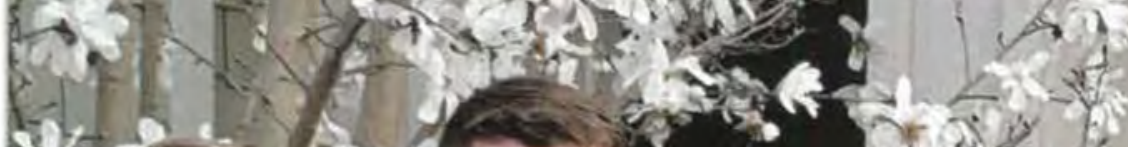

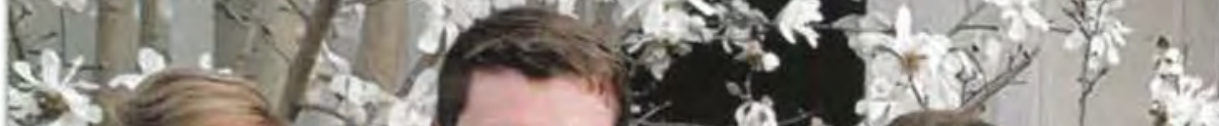

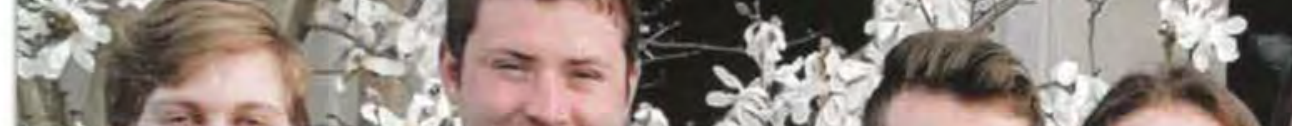

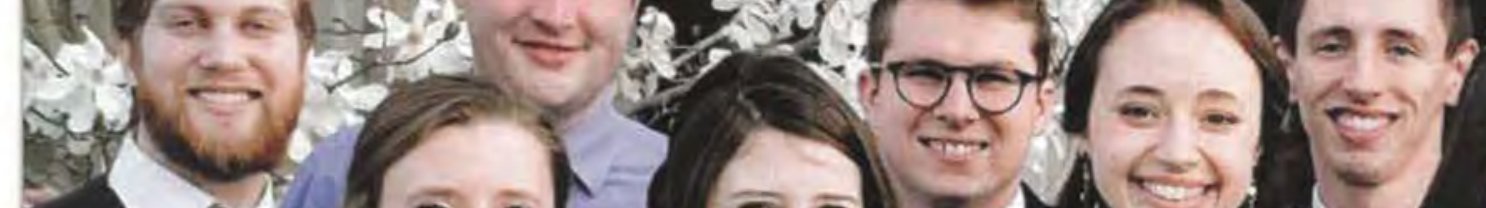

1

- -5

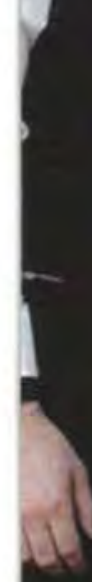

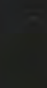

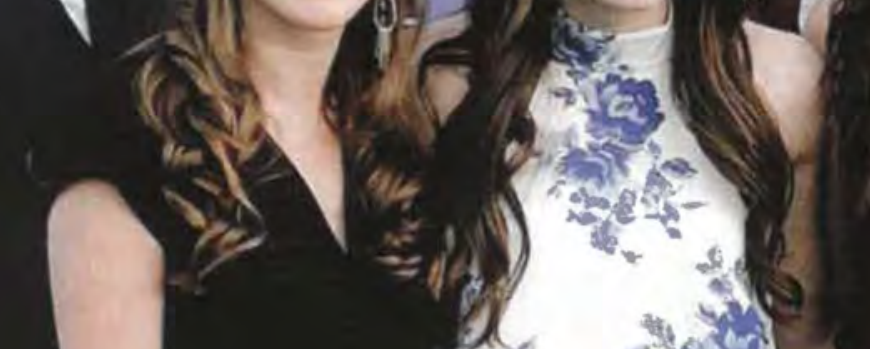

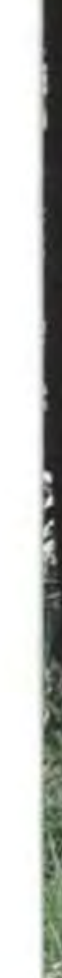


1: Jake Russo, Michael Wilt, Josh Ratliff, Aaron Lynn, Adam Gardner, Anna Espling, Danielle Lynn, Autumn Hankins، Emily DeCeglie, and Michaela Carpenter pose together for a picture during JS.

\section{2: Nate Osborne, Katie Wingert, Natalie}

Steenwyk, and Ethan Ooms enjoy their night at JS.

3: Beka Jamison, lan Woodall, Janessa Krueger, and Marcus Waterman pose for pictures at JS.

4: Students pose with their JS tickets during the event. The theme this year was Our Story.

5: Lauren Stieferman and Tim Vander Have pose for pictures during the event.

ó: Laura Mihelc, Theresa Jones, and Lydia Jacobsen enjoy their night and the beautiful setting.

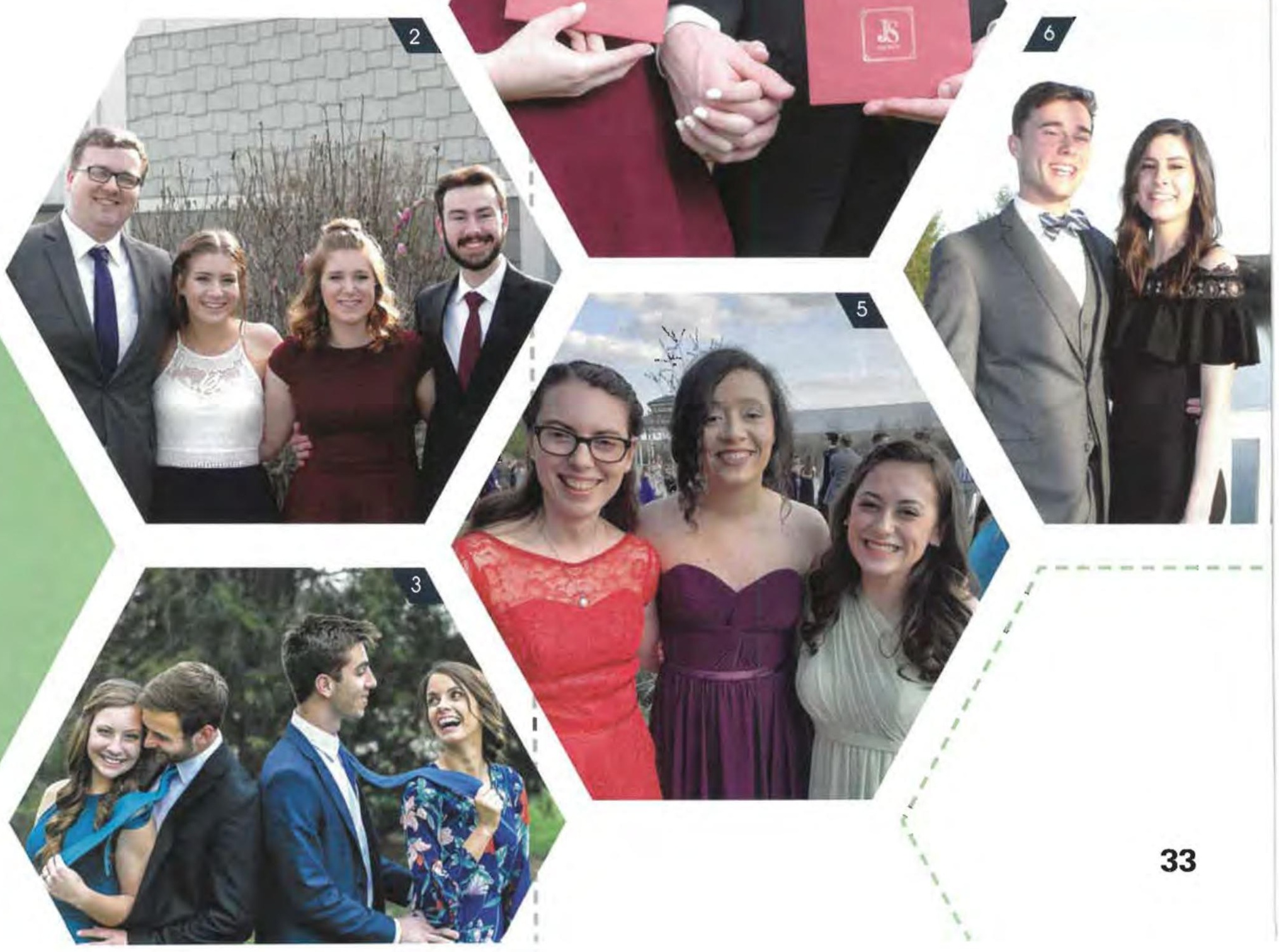




\section{Elliv}

Hosts Ranae Haskins and Jake Johnson reveal the

answer to their guessing game. The quote, "through

the birth canal of death." was an inside joke among

the students from a chapel speaker earlier in the

year.

2: Caleb O'Neel sings "Life is a Highway" by Rasca Flatts.

3: The Chinese Dragon wins the costume contest. The winner was decided based on a Kahoot (online quiz) that the entire audience was invited to participate in

4: Noah Daznell sings "High Hopes" by Panic! At The Disco.

5: Jake Johnson showcases his musical talent.

b: Silas Rea plays the trumpet.
Elliv is one of the biggest events of the school year, and this year, SGA put a new spin on it. The theme was "Timeless," and everything about the night represented the classics: black and white, campus jokes that never got old, and songs everyone could sing along to. 


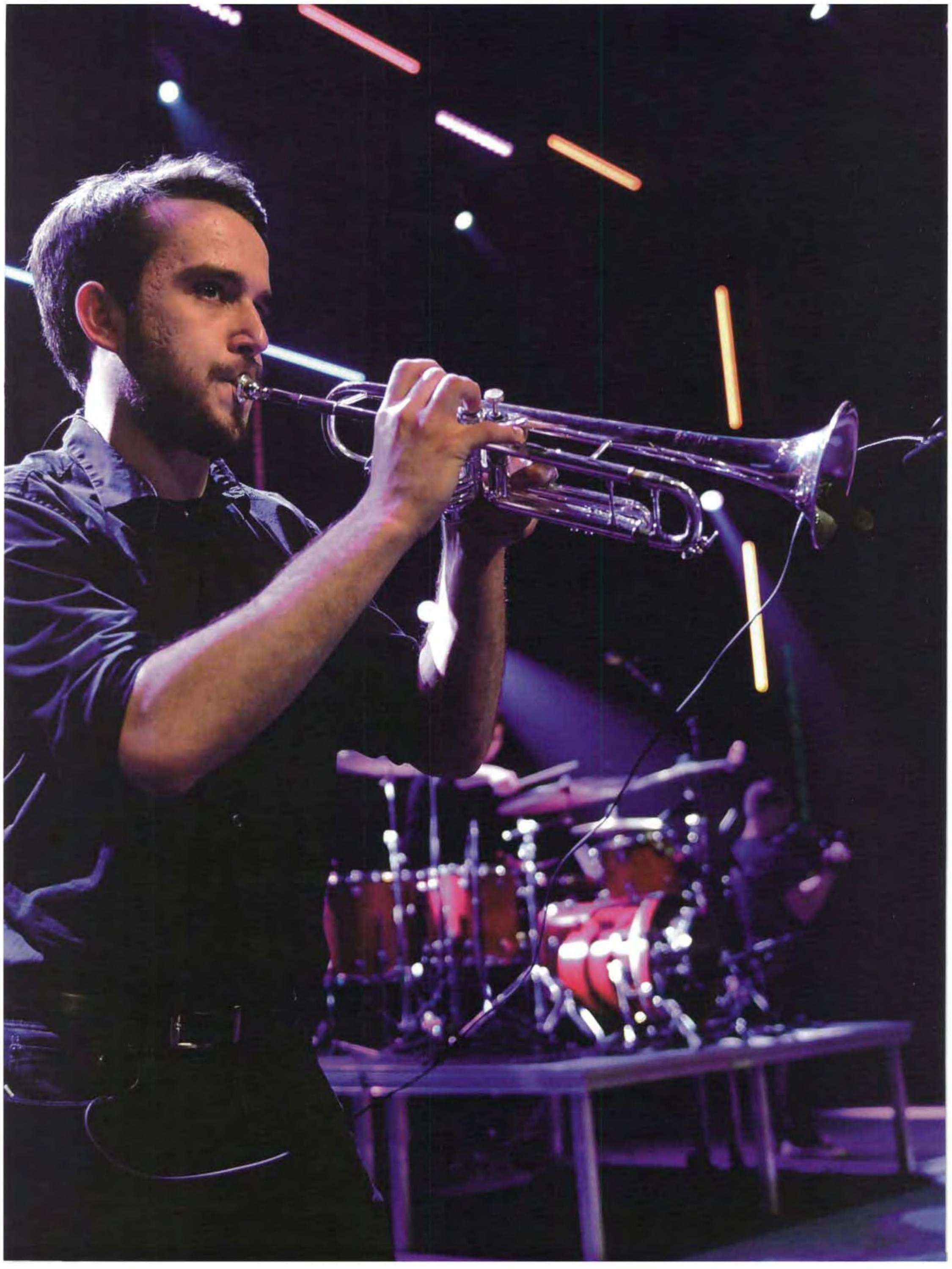




\section{Commencement}

1: Dr. White speaks to the graduates, offering a final word of inspiration before they become alumni.

2: Madison Werling, Emily Broadwick, and

Jennifer Tyson take a picture with the "Class of 2019 " frame.

3: Parents buy flowers for their graduating children.

4: Students pose with communications professor

Derrick Green for a selfie.

5: Rafael Lopez signs for his diploma.

6: Dr. White takes a selfie with the graduating class, commemorating the end of their 1,000 days.

Graduating seniors filled up the Callan Athletic Center early on May 4 for Cedarville's 123rd commencement ceremony. "There was a nervous but eager energy in the gym before we walked to the field house," Mariah Shull recollected. "Then at the end there were bittersweet and final goodbyes from good friends or even just acquaintances. We all just wanted to see one another succeed after working so hard for our degrees." Now these graduates will continue to be salt and light in the world, wherever God takes them. 


\section{Commencement}

After a time of worship, Dr. White gave a speech

for all the seniors as they prepared to move out into the world. Later, students walked across the stage to get their diplomas, shake hands with Dr. White, and receive Bibles from Dr. Wood. They had succeeded.

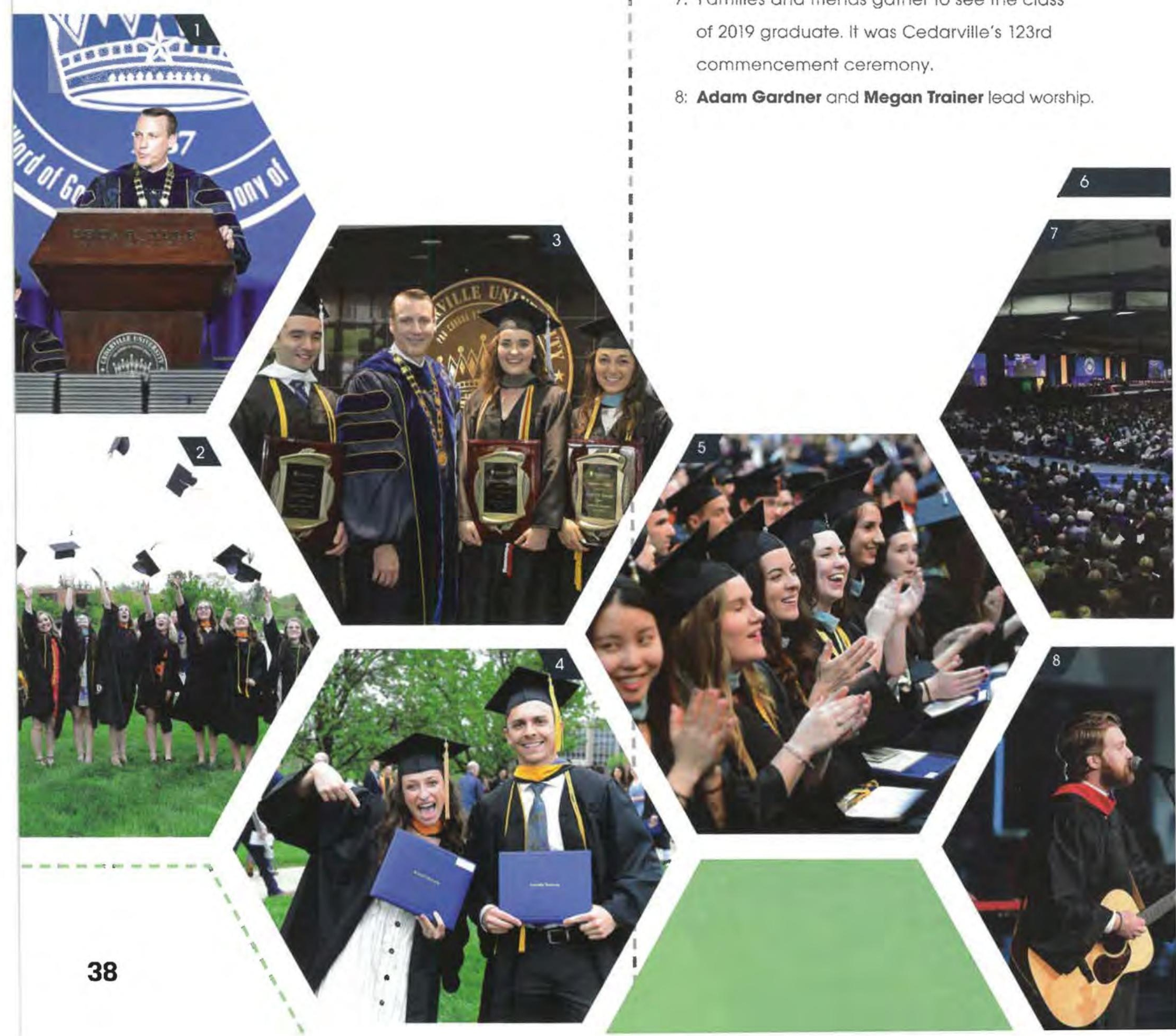

2: Graduates toss their caps into the air.

3: Justin Lough, Clara Costello, and Jocelyn Quirple pose with Dr. White. All three of them earned the President's Trophy.

4: Graduating students pose with their diplomas.

5: Graduates applaud as their classmates' names are announced.

6: Savannah Hart and Ranae Haskins pose with their diplomas.

7: Families and friends gather to see the class of 2019 graduate. It was Cedarville's 123rd commencement ceremony.

: Adam Gardner and Megan Trainer lead worship. 


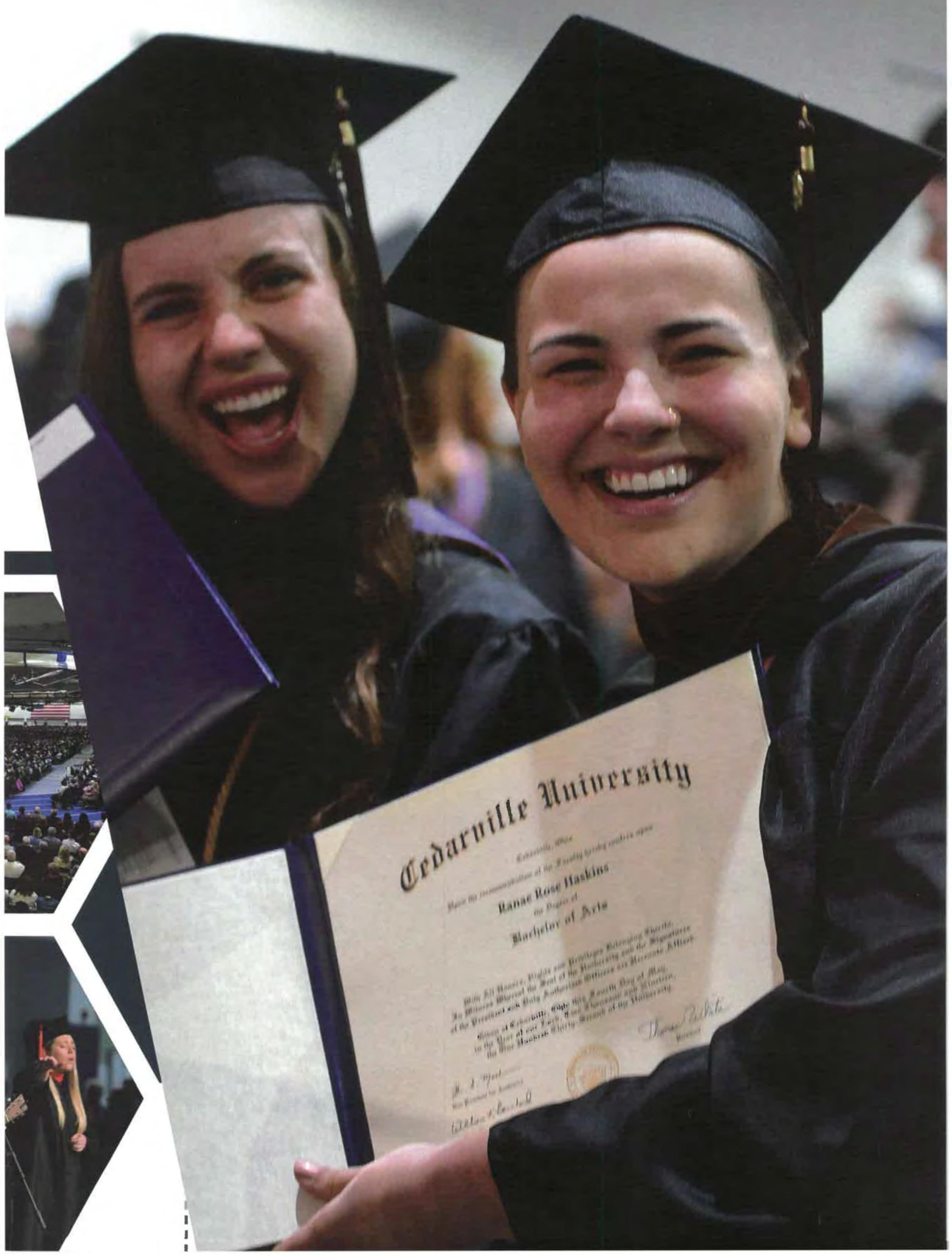




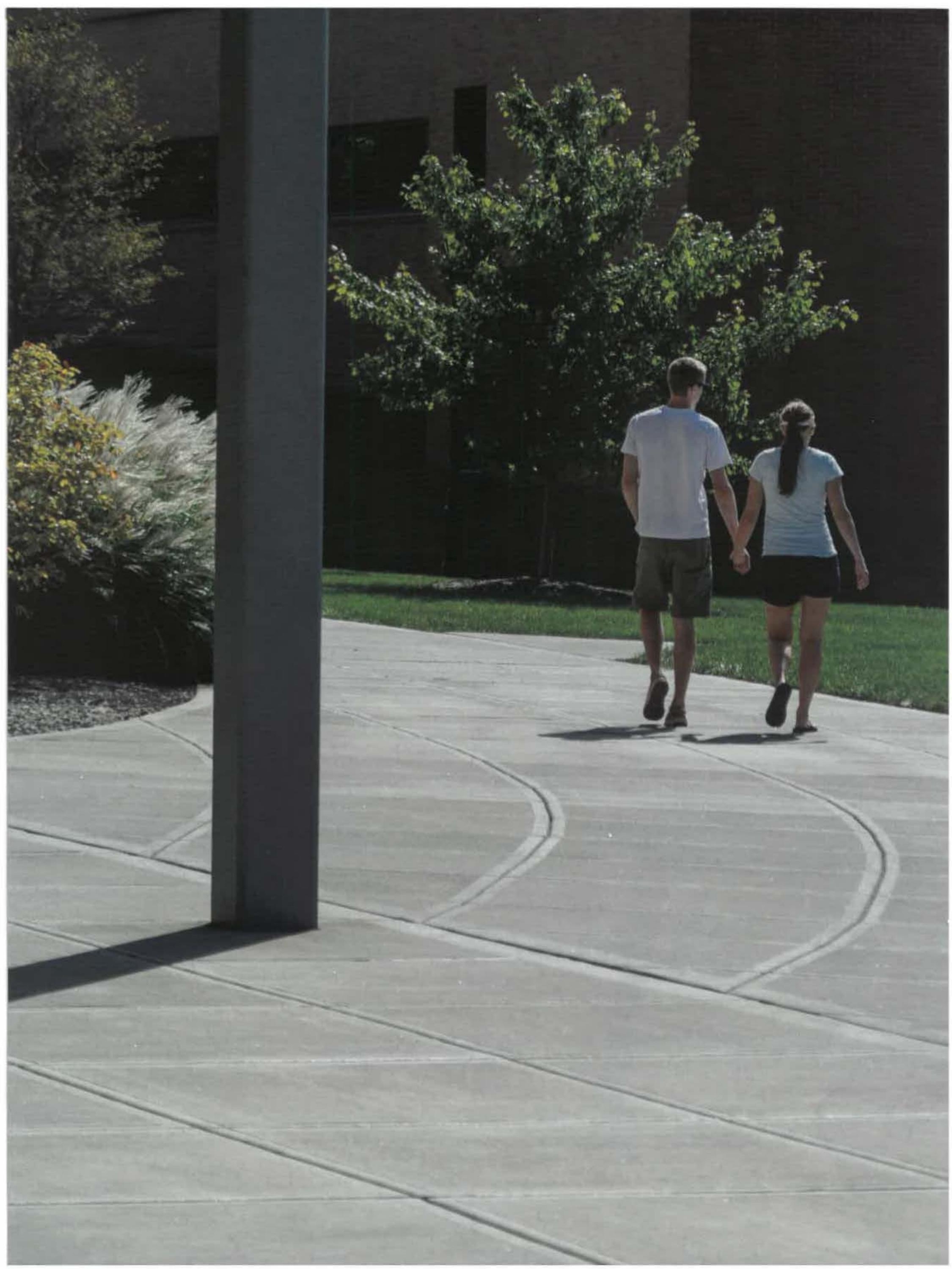


का

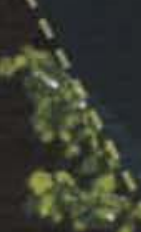

- is risos

$x$ a $3 x$

Pry

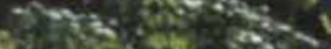

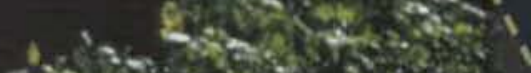

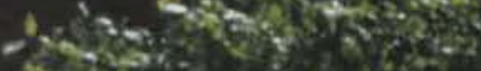

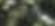

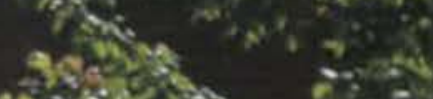

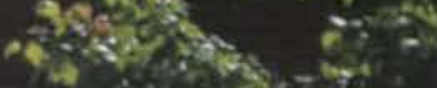

300 the

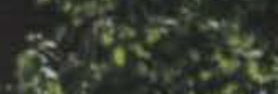

and 0 stey

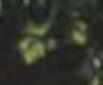

Student

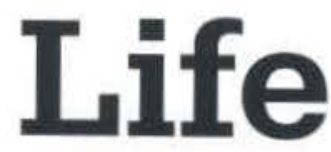




\section{Dorm Life}




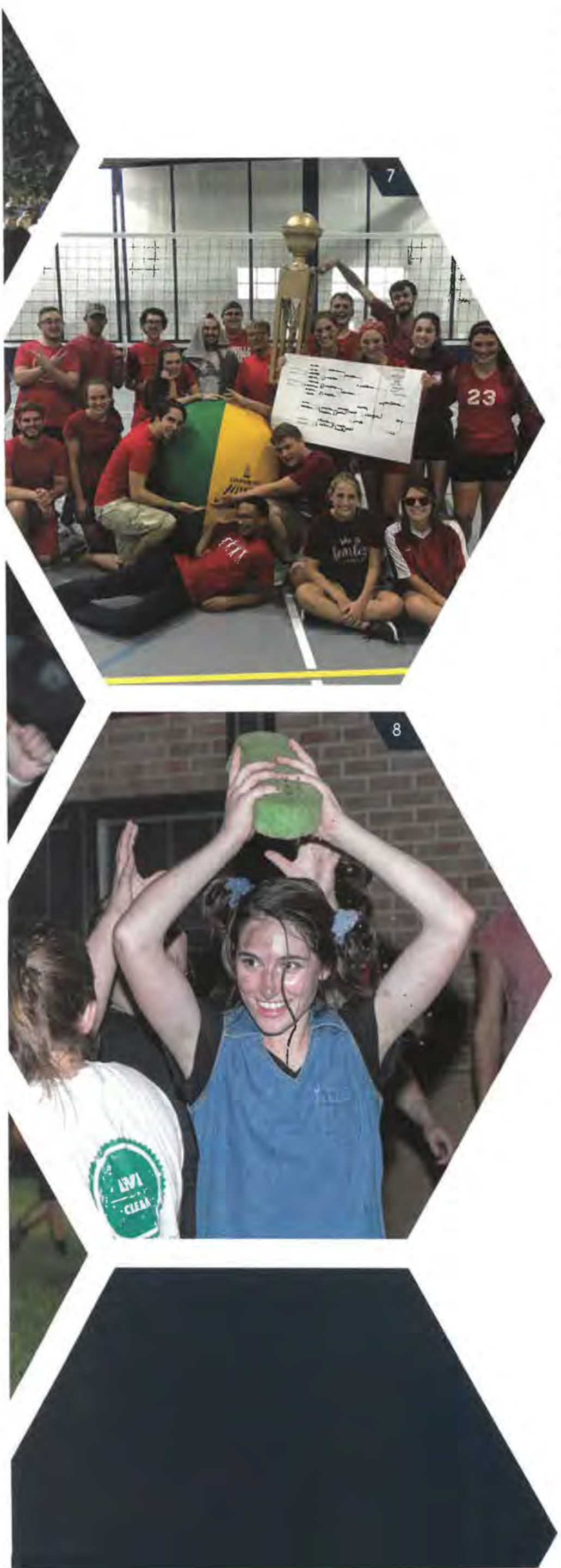

1: Brevin Henninger flips a tire for one of Rickard's Man

Week competitions.

2: Rachel Moore and McKayla Bauer watch units 18, 20, 22

and 24 compete in Printy Wars. Their theme was Shrek.

3: Lawlor Units 14, 16, 18 and 20 cheer on their sister units during Printy Wars.

4: Units 14, 16, 18, and 20 hold hands for a game during

Lawlorpalooza. They had to pass a large loop of rope around the circle without breaking hand contact.

5: Kevin Symonette, Grant Jones, and Ryan Merk prepare for Man Week at Rickard Hail.

6: Austin Land braces himself to flip a tire during Man Week.

7: McChesney Upper Middle and McKinney Lower Back display their trophy after the Beach Ball Volleyball tournament. Their bro/sis was the undefeated winner of the championship. and their theme was Moses parting the Red Sea.

8: Sara Beste passes a sponge over her head to her teammate for a game during Printy Wars. Their team had to pass the sponge over their heads and under their legs while draining as little water as possible from it.

All across campus, student dorms participated in a variety of events and competitions. Units battled against each other during Printy Wars and Lawlorpalooza, each determined to create the best costumes and win the most games. Rickard stepped up to the plate during Man Week, where men competed in feats of strength, stamina, and resilience, such as flipping giant tires. McChesney/ McKinney and St. Clair/Johnson participated in a beach ball volleyball tournament, where bro/ sis halls teamed up in a game of elimination. McChesney Upper Middle and McKinney Lower Back happily took home the trophy after an intense battle. "I was really proud of our team," Andrew Nussbaumer, a McChesney resident, said. "We had to give it our all, and we had to take it one set at a time. It was a good team win, and it was overall enjoyable." 


\section{Student Life}

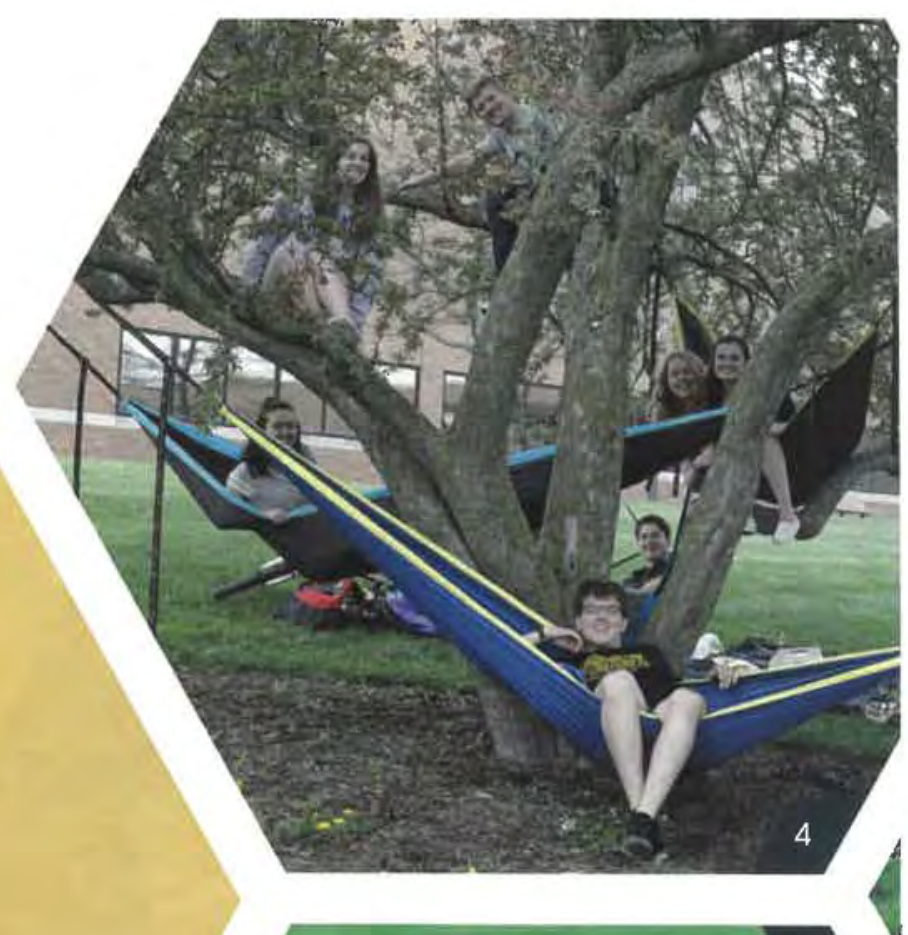

in

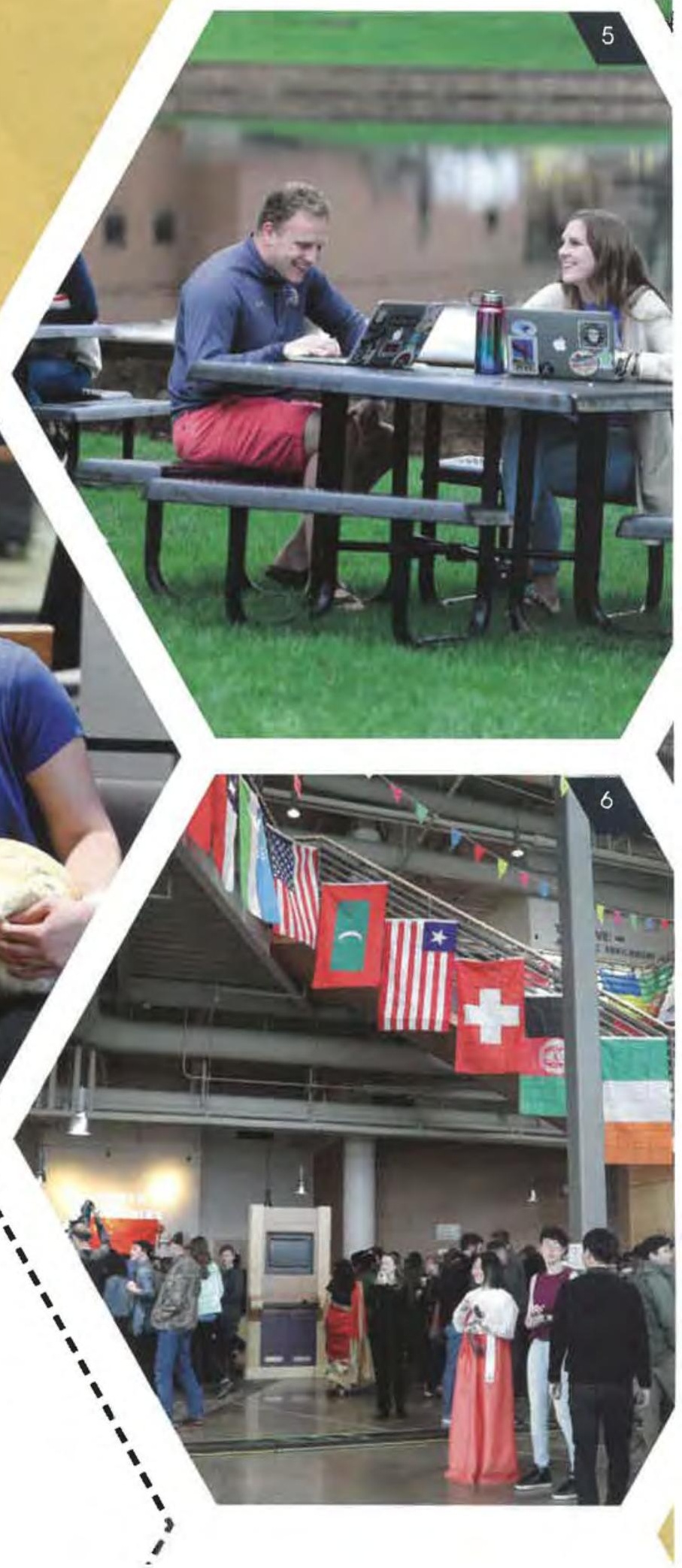





\section{Orgs}

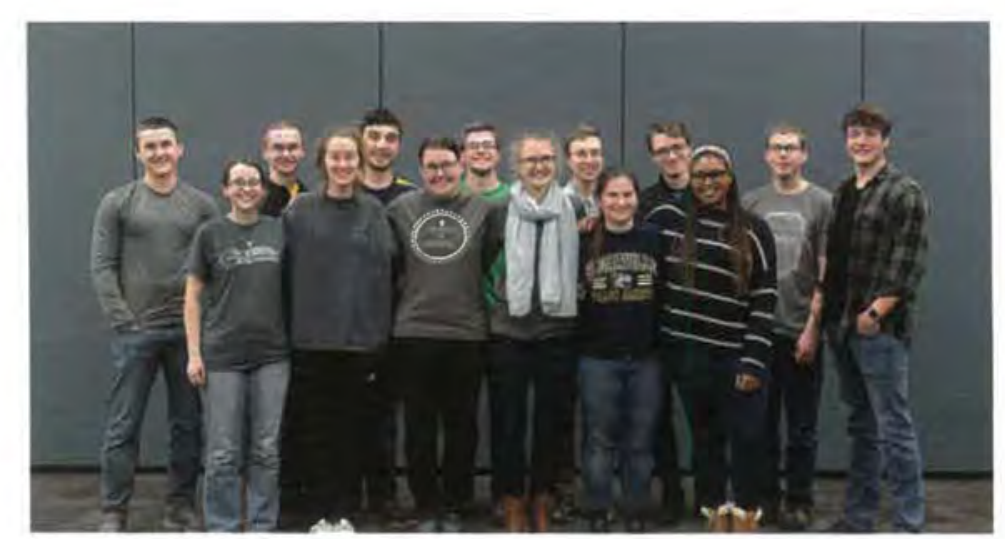

Society of Engineers Aiding Missions

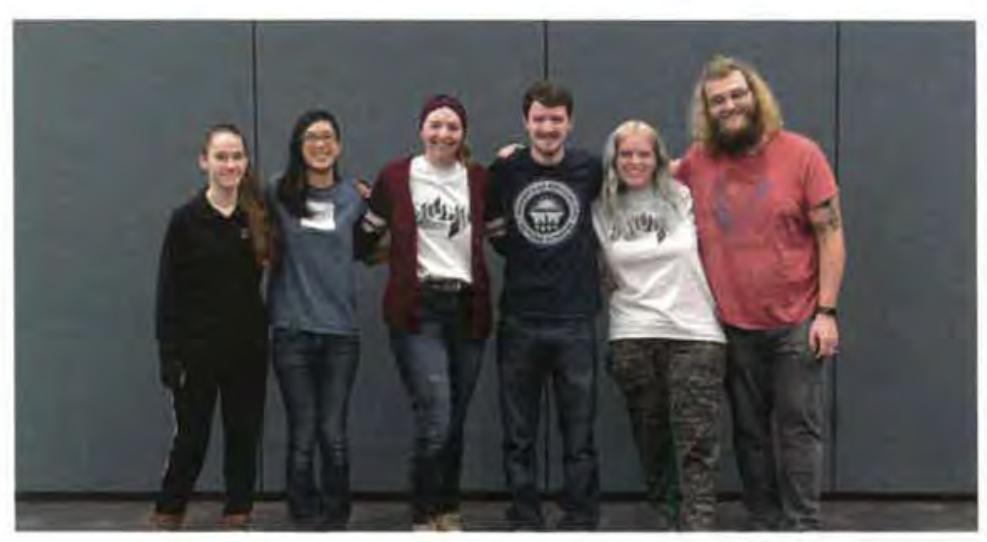

The Studio

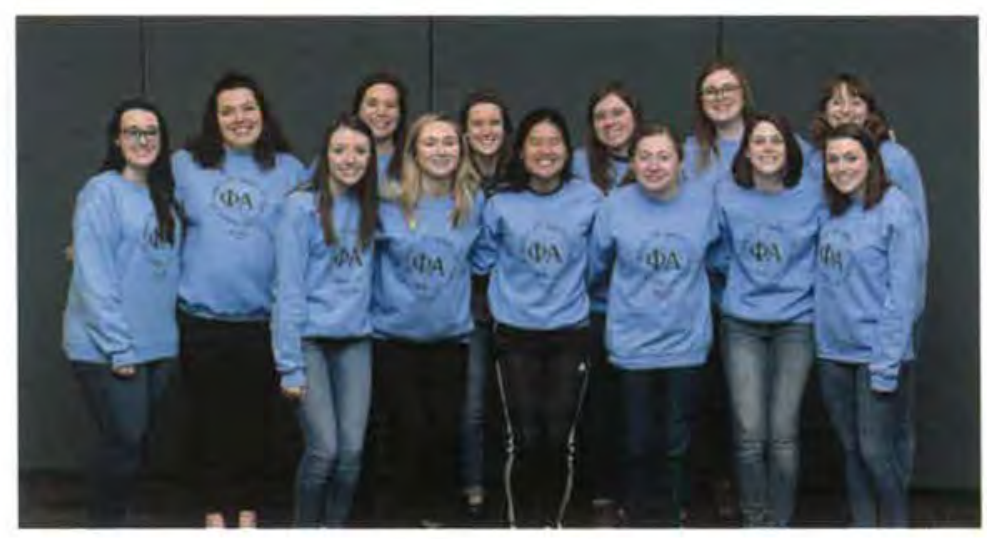

Phi Alpha

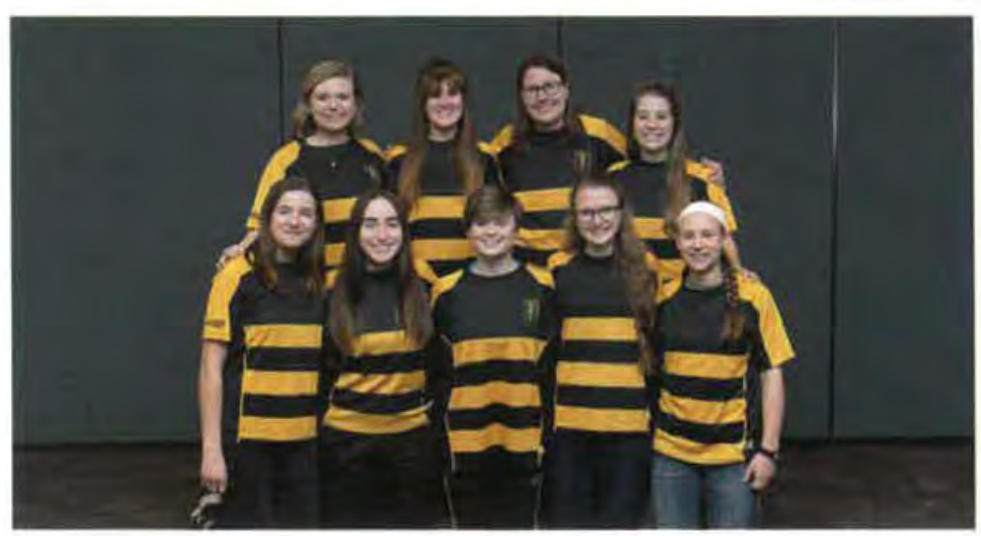

Women's Rugby

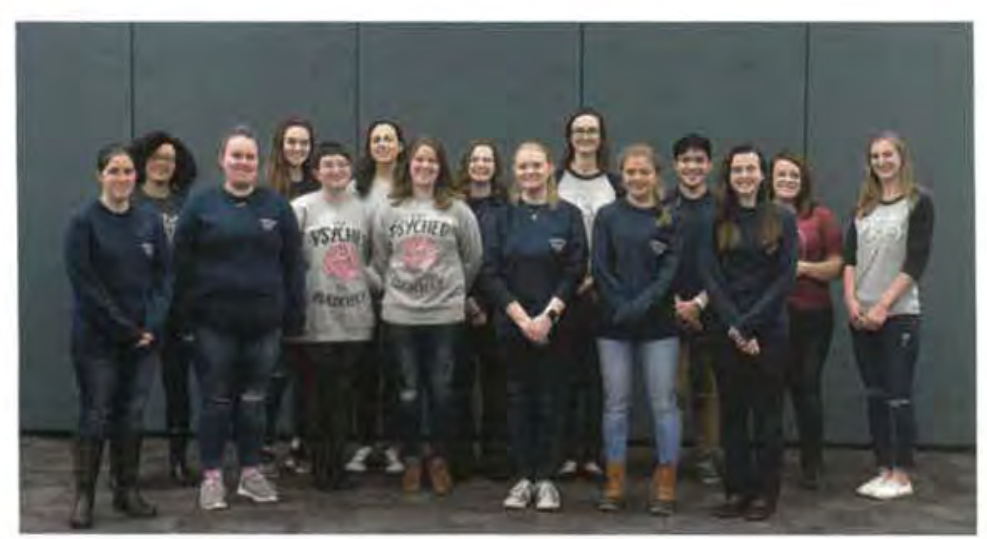

Psi Kappa Theta

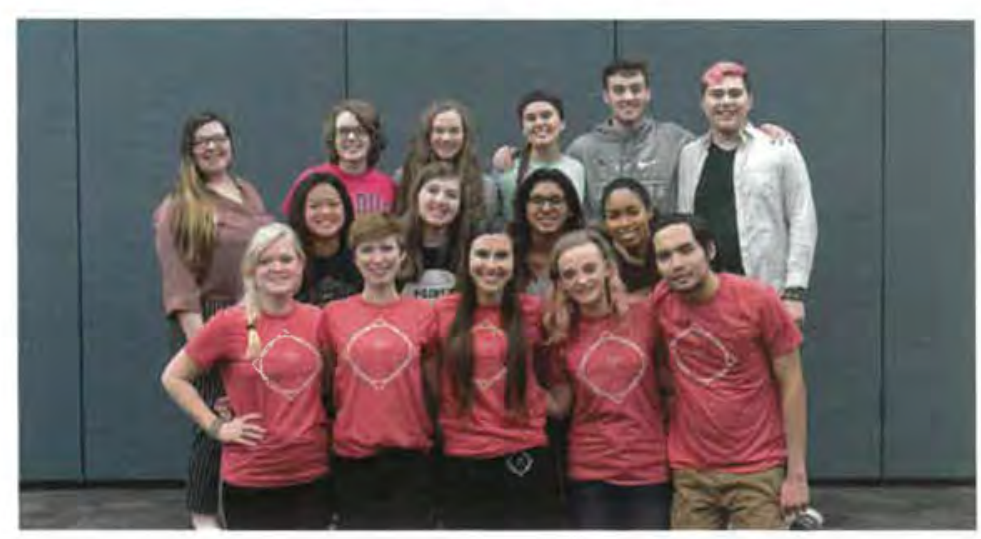

Ayo Dance Company

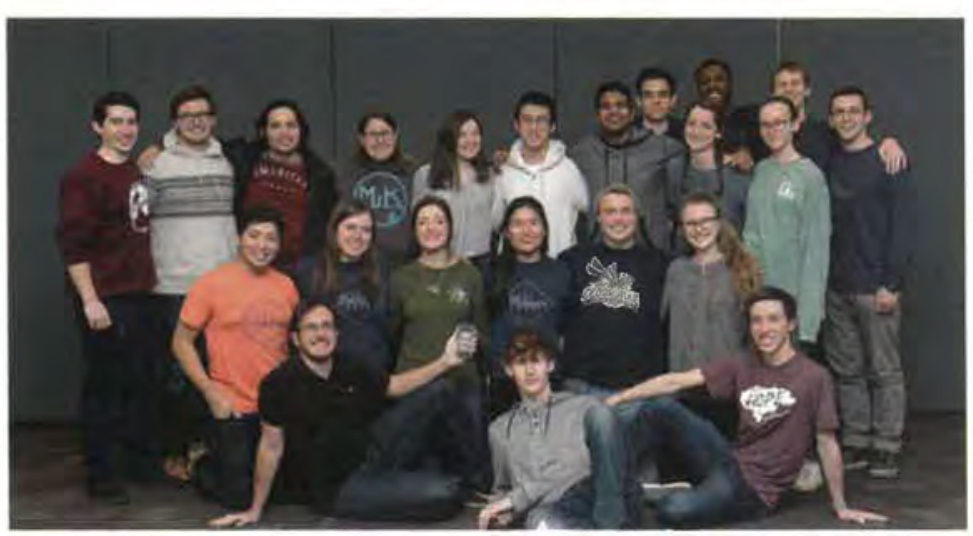

MuKappa

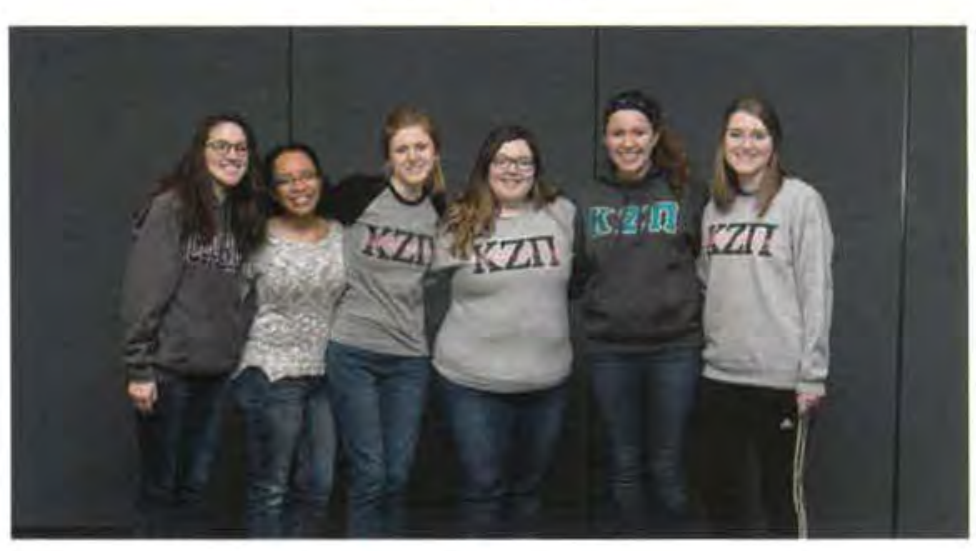

Kappa Zeta Pi 


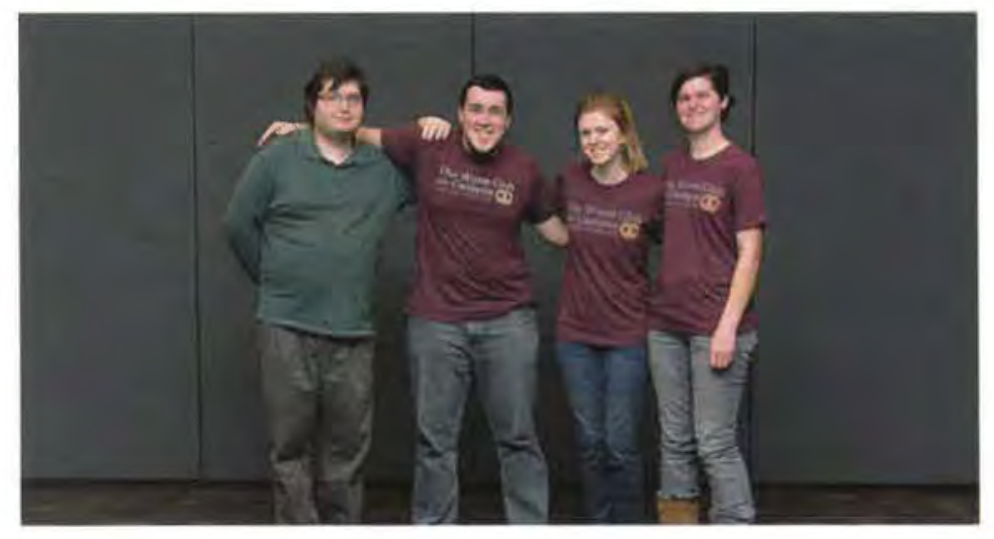

German Club

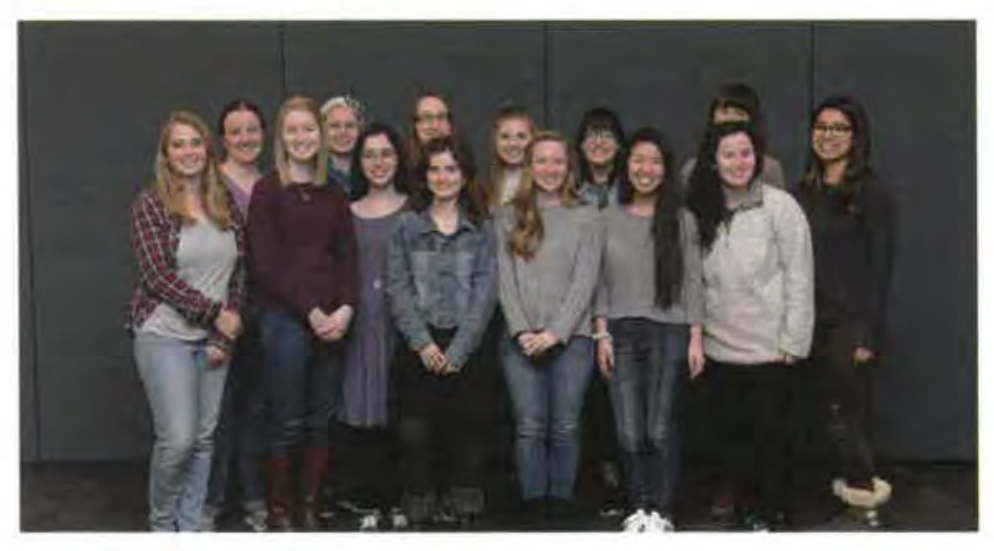

Society of Professional Writing

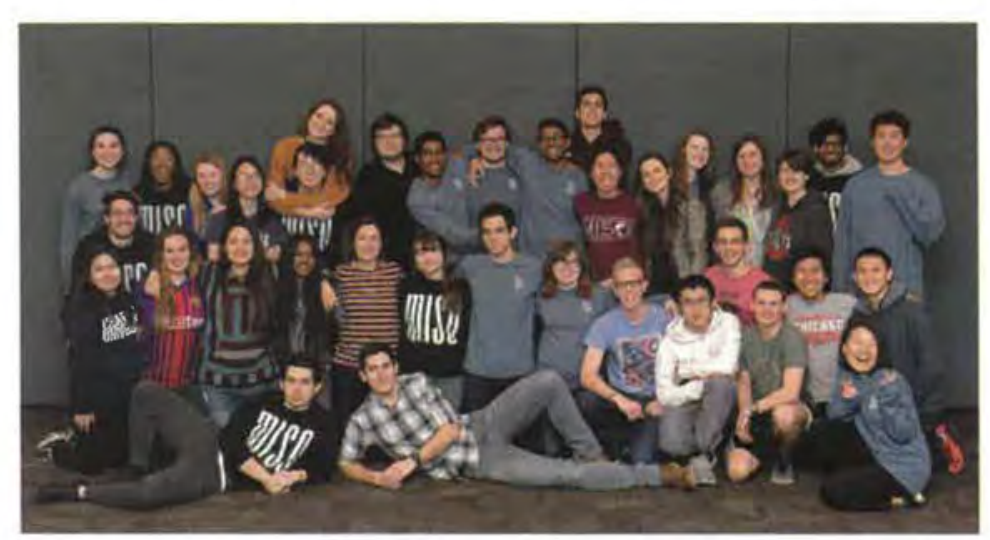

MISO

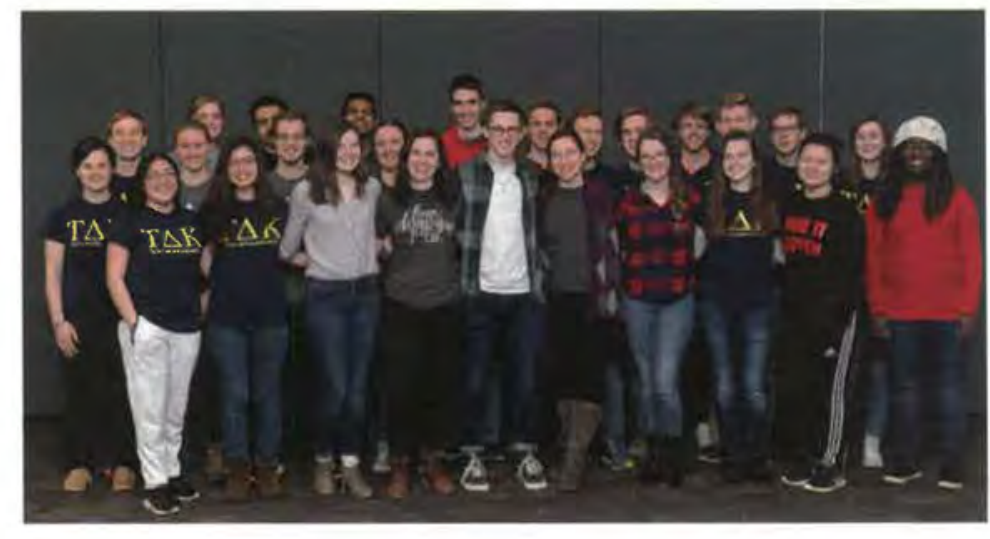

Tau Delta Kappa

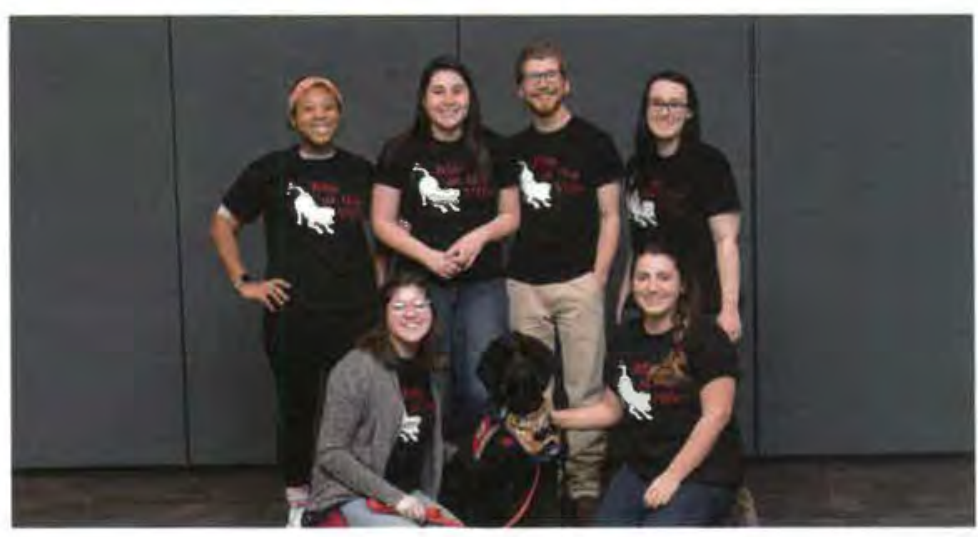

K9's at the Ville 

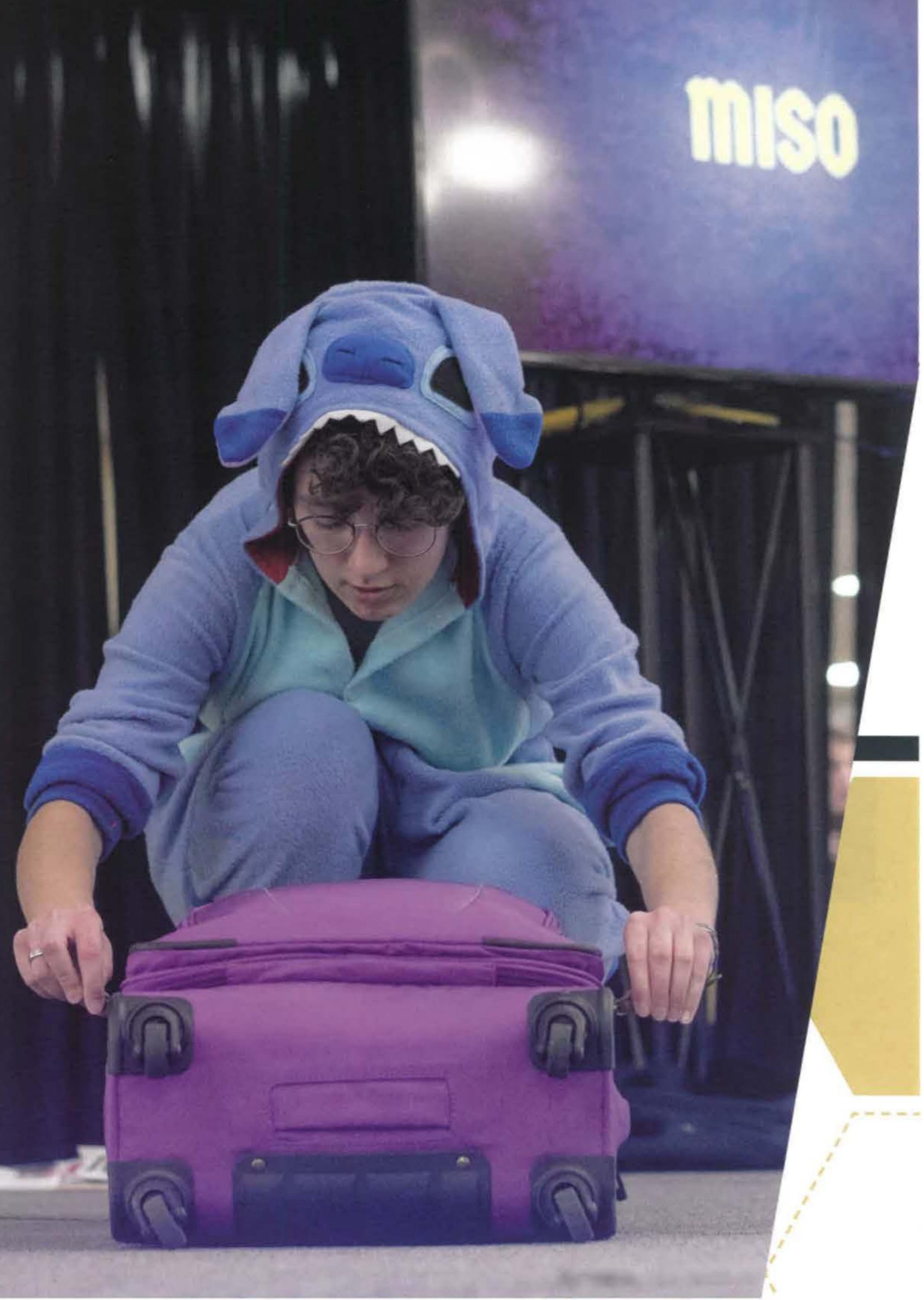


\section{King of the Ville}

I: Megan Marrie unzips her suitcase during MISO's performance in the lip sync battle. The org chose "Party in the USA" by Miley Cyrus, acted out an international student moving to the US for the first time, and won the competition.

2: Kamen Rogers performs as a Chinese warrior with his bro/sis in "1"l Make a Man Out of You" from "Mulan."

3: Sarah Burgoon dances to "Umbrella" by Rihanna with PEB.

4: Emily DeCeglie votes for PEB, a student org, to win the lip sync battle.

5: Zachary Reeder shrugs his shoulders to "Whis My Hair" by Willow Smith. He maintained the same dance move with a straight face as his bra/sis danced around miry
King of the Ville was a new, two-night event that allowed bro/sis groups to compete in a series of challenges alongside student organizations. It featured an opening ceremony, service projects, and a gauntlet that included a trivia contest, a cooking competition, and a 60-second throwdown. "This year was orgs and bro/sis halls, so that was a new addition, because this used to be org wars, and we kind of evolved it into this," Zachary Rubosky said. "It was definitely an experimental year... but the turnout Friday night was really great." Almost 1000 students came to the opening ceremony, and nine teams competed in the gauntlet. MISO, the organization for missionary and international students, emerged as the champions. 


\section{Concerts}

In addition to the numerous concerts throughout the year, Christian artist Andrew Peterson performed in concert in the Jeremiah Chapel on February 12. For almost twenty years, Peterson has been writing music, produced 11 albums, and been nominated for the Dove Award. He decided to kick off his 2019 tour with a performance at Cedarville University which highlighted his newest album, "Resurrection Letters Vol. 1." The crowd was thrilled to hear one of his most popular new songs, "Is He Worthy," which involved audience participation. "I frequently talk about faith, art, and community and the way my interaction with art and imagination is one of the chief ways that God has spoken to me over the years," Peterson commented to Natalia Kirychuk in a public relations interview. Peterson was also invited to speak in chapel the next day and share some of his journey through music.

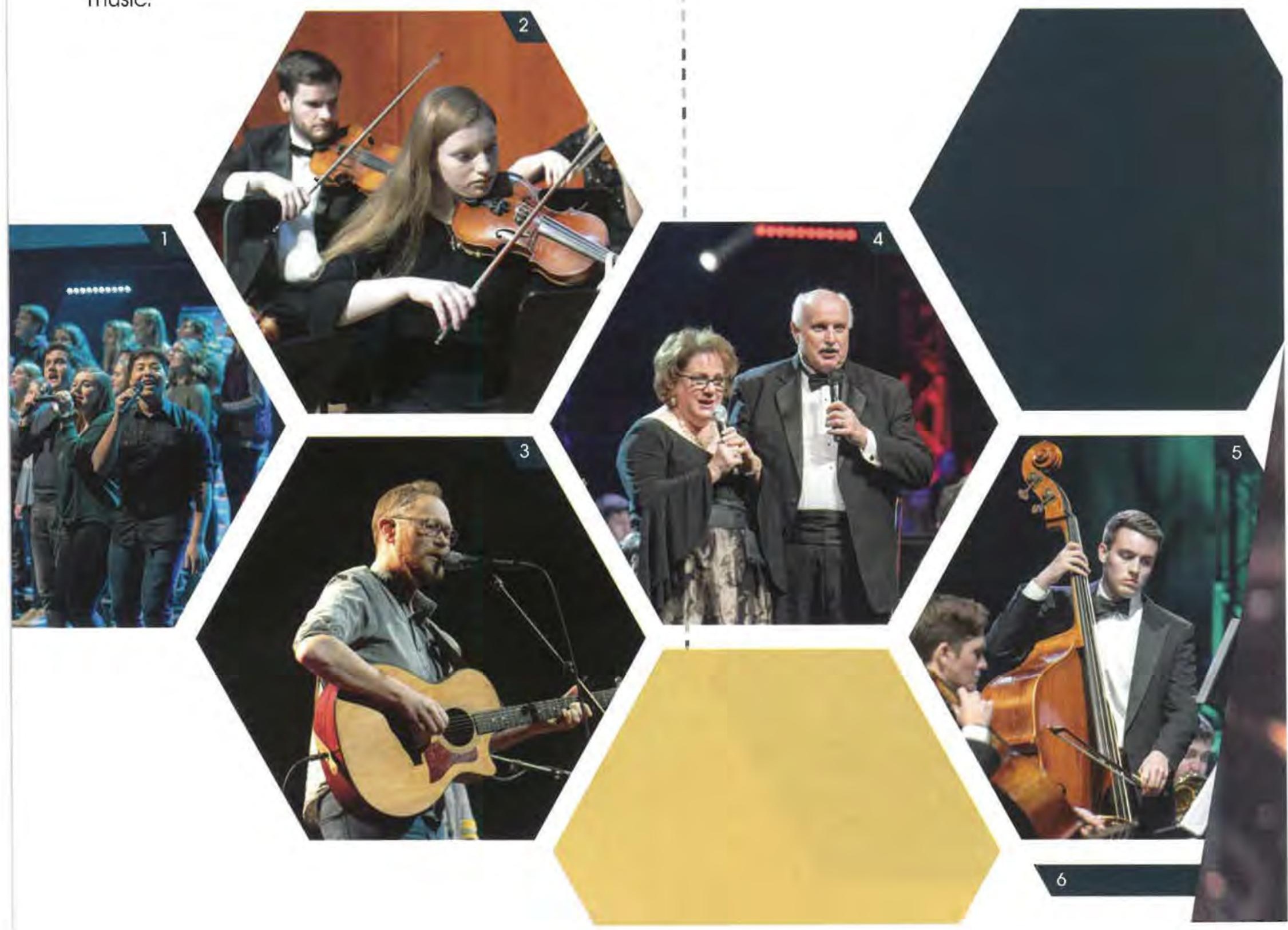





\section{Campus Experience}

Once a month, groggy members of Campus Experience (which included SGA, Class Council, Info, SCAB, Finance, Media, Rinnova, Ops, and the Executive Team) gathered at 7 a.m. on Friday mornings to listen to Brian Burns speak about something he called Bravo Zulu culture. Bravo and Zulu are two nautical radio signals, and together they mean "well done." By giving Bravo Zulu coins to the students, hanging flags in his office, and awarding students at the end of the school year, Burns drilled into Campus Experience members' minds that excellence in effort was supposed to

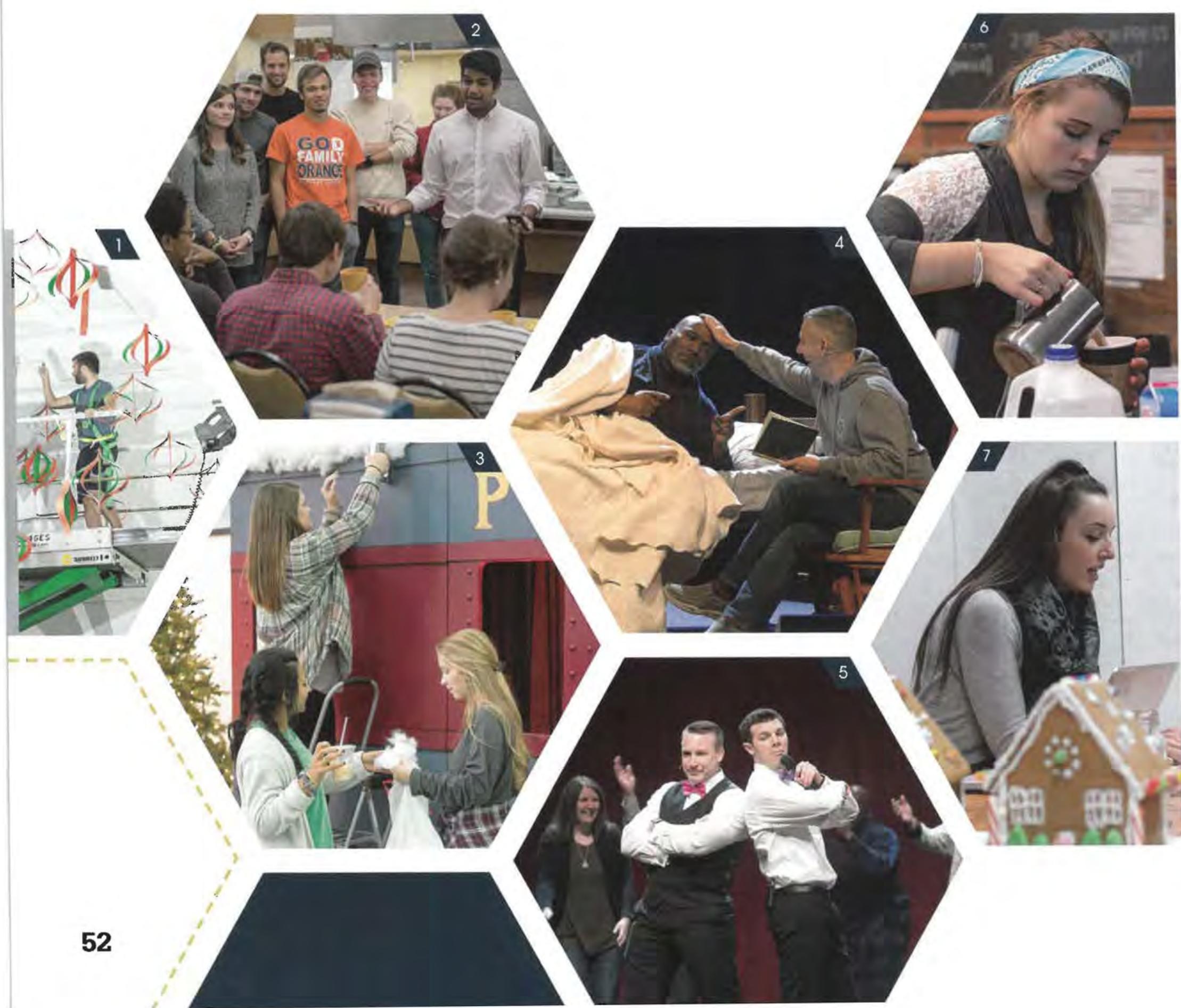

encompass their lifestyle. "I think one of the biggest things that I have gotten from Bravo Zulu is the idea of 'extraordinary effort, not extraordinary results," Clara Costello, SGA vice president, said. "Learning how to serve faithfully and to trust the Lord with my efforts and know that He controls the results has brought so much more excitement into my work, but also freedom in what I do, knowing that I control my effort, but the rest is left up to the Lord." This training helped Campus Experience members transform their mindsets so they could help Cedarville become all it could be. 



\section{ALT Nights}

Among the biggest events thrown on campus, Cedarville's ALT nights did not fail to please this past year. With popular pre-released movies, food, and games, students were able to take the night off and just go have fun with friends. A variety of movies held something for every audience - from Disney films such as "Coco" and "The Incredibles 2," to "A Quiet Place," a teeth-clenching thriller. "I always have really enjoyed ALT nights," Kaitlyn Ring said, "My favorite part is always hanging out in line with friends before the showing, playing games, or just talking before the mad rush to get a good seat." During the last ALT night of the year, characters from the movie "Mary Poppins Returns" showed up in the SSC, making the night even more memorable.

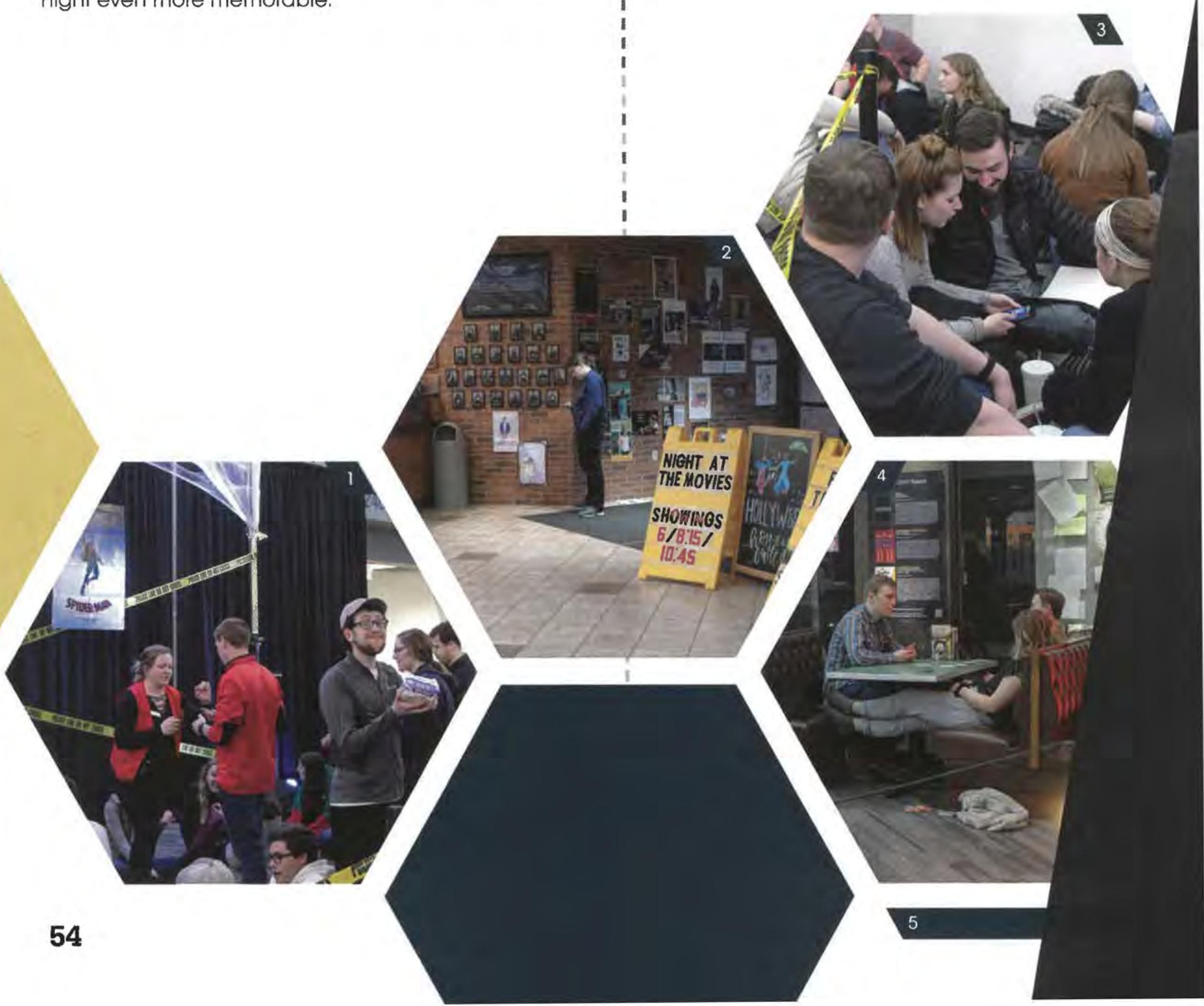

1: Abby Carraher, a member of Campus Experience. scans students into the movie "Spider-Man: Into the Spider-Verse,"

2: Kirsten Sommers waits at Rinnova while the baristas make her a signature drink.

3: Ethan Ooms and Natalie Steenwyk wait in line for a movie showing.

4: Students chat in some Hollywood-style booths set up outside the DeVries Theater.

5: Emily Hunnemeyer and Blake Hansher enter as Mary Poppins and Bert for the ALT night showing "Mary Poppins Returns."

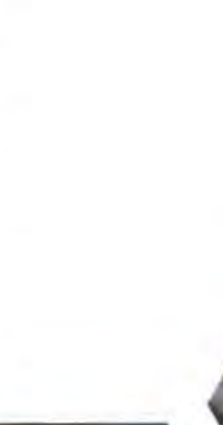



$=5$

(6)

(n)

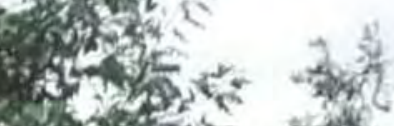

W.

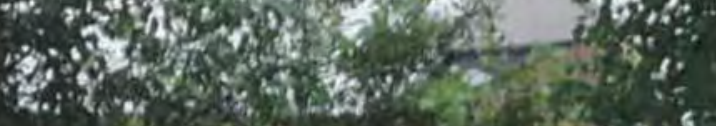

1. $x^{2}, 2 x$

it

er.

1 inewe

and 0 :

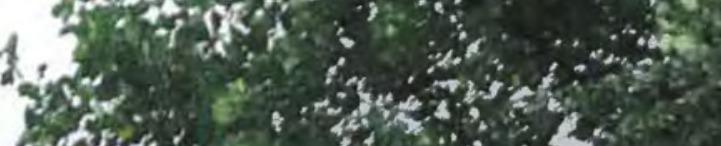

is

4.ion

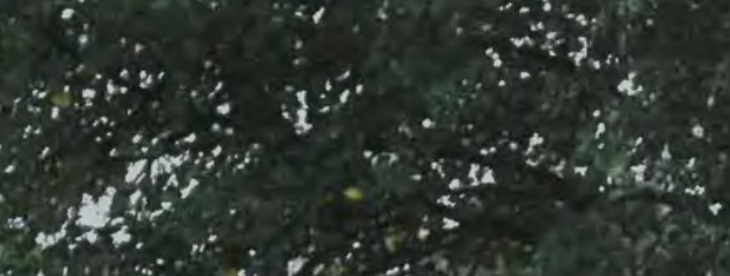

कीस

$\therefore \rightarrow \frac{30}{406}$ 


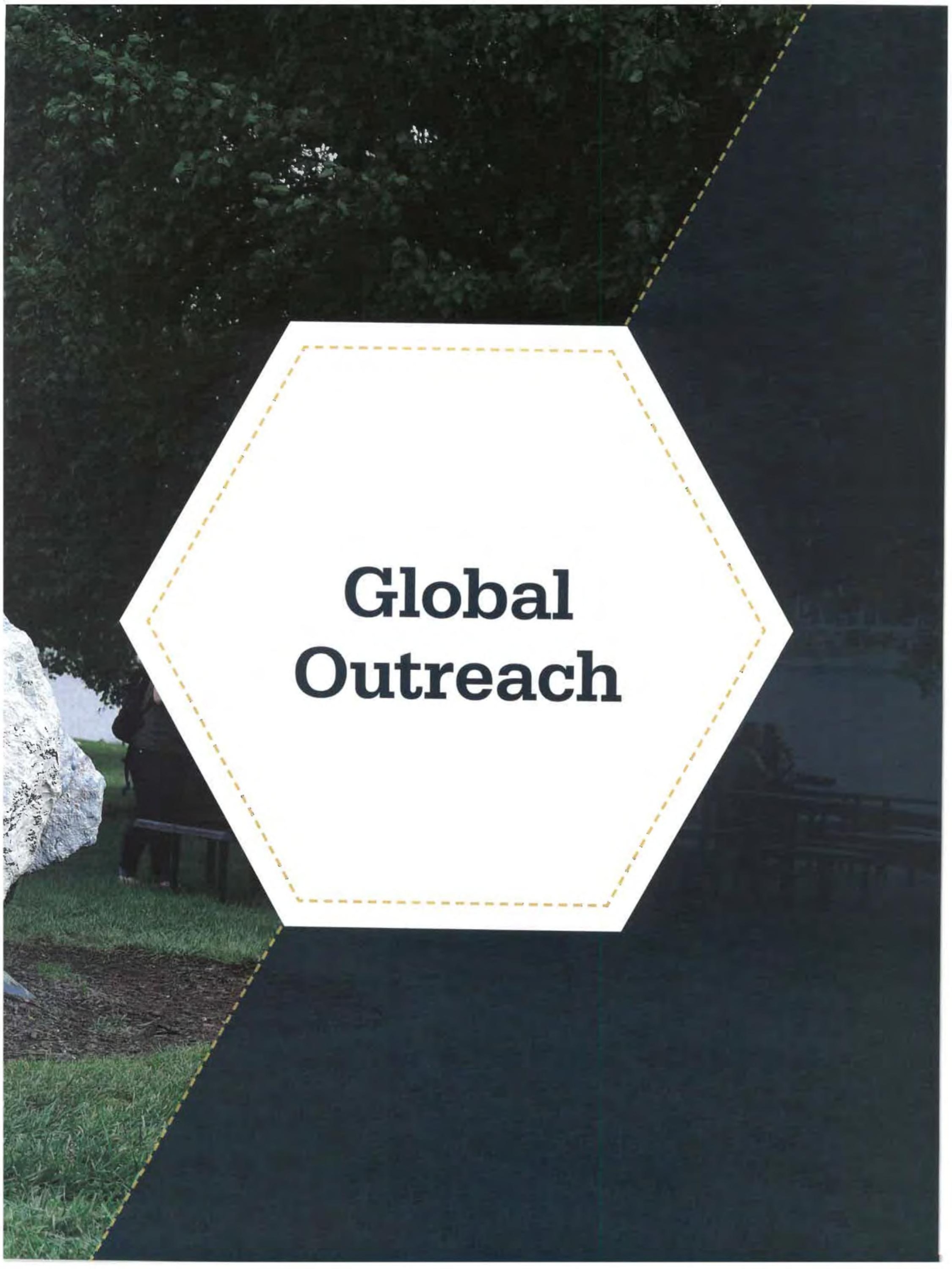




\section{Summer and Fall Trips}

From Costa Rica to the Czech Republic, Cedarville students spread all over the globe on a mission to proclaim God's Word and aid those in need. Global Outreach teams worked alongside locals in their schools, camps, and sport teams during the summer, fall, and spring. Not only are communities uplifted by these hardworking volunteers, but the students are also impacted through their service. They learn better how to share the gospel and get a fuller understanding of the world. Some may even make a decision to serve full-time after graduation. Whether serving on missions means bringing fresh water to a third-world country or helping a family on the next street get a decent meal, Global Outreach students are dedicated to proclaiming the Gospel everywhere.

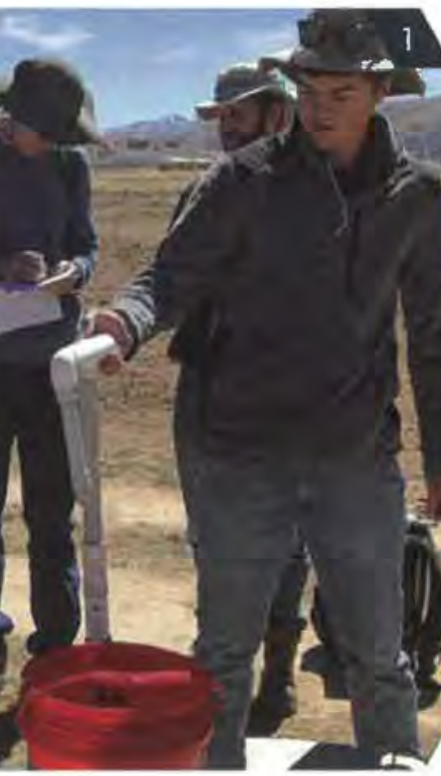

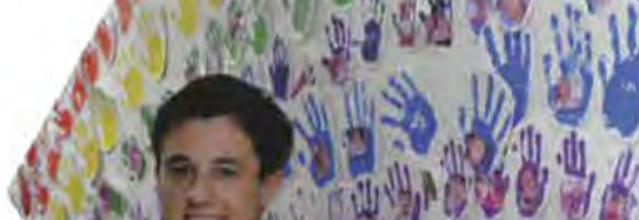
(vi) ${ }^{3}$

1 Jared Klimek works outdoors in the heat

2: A Global Outreach team walks down a path.

3: Jacob Sanders stands in front of a wall with painted handprints

4: Ian Waltz, Bailey Pitcher, and Elizabeth Bassette stand outside a church in Zomba, Malawi, Africa with a group of playful village children.

5: Troy Coates gives a piggyback ride to a Navajo child during recess at Immanuel Mission School in Arizona. $\mathrm{He}$, along with the Discipleship Council, helped out at the Navajo reservation school in Teec Nos Pos, gave gospel messages, and did manual labor.

6: Makenzie Mayse gives a child an immunization during a cross-cultural nursing internship in Honduras. She volunteered at a clinic and helped distribute immunizations and medication.

7: A group of children play outside. 


\section{Spring Trips}

1) Two dressed-up alpacas pose with a team of students

in a plaza in the middle of Huaraz, Peru.

2: A Global Outreach team poses in Brooklyn, New

York, where they taught English as a second

language to immigrants.

3: A group of children are gathered around a student worker.

4. A Globai Outreach team helps an old woman with her shoes.

5: A team witnesses to London college students.

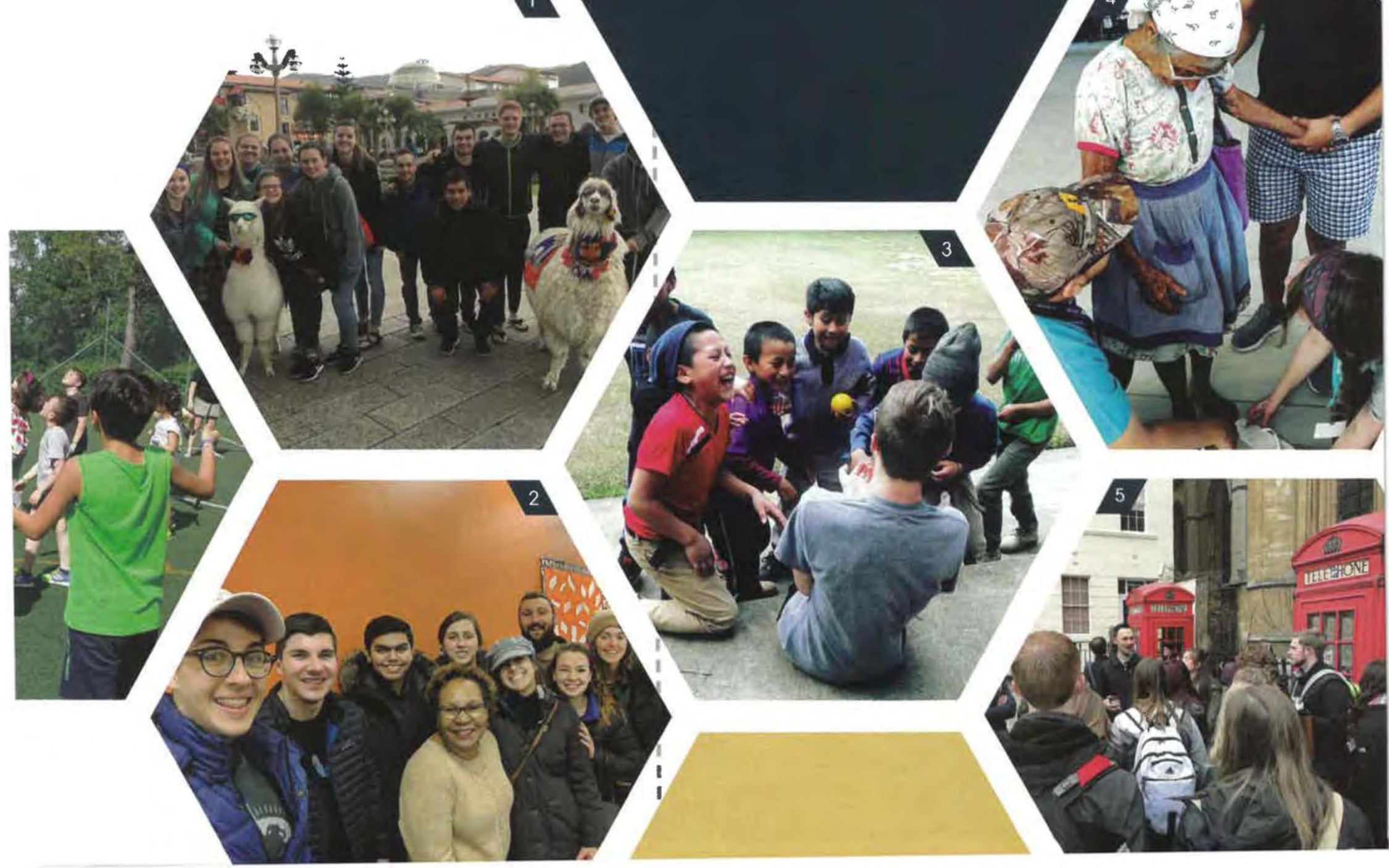




\section{Domestic Global Outreach}

1: Brian Nester, Keith Holcomb, Ellen Hanson, and Vicky Hines pose for a photo.

2: International Friendships celebrates Diwail at Wright State,

3: Xavier Halder and friends enjoy dumplings as they celebrate Chinese New Year.

4: International Friendships poses for a group photo.

5: The Clark County Jail team prays before having spiritual conversations with the inmates.
King's Kids tutoring is just one of many programs supported by Global Outreach's domestic focus. This program is designed to assist refugee kids with math homework. At least once a week, students from Cedarville University travel to Dayton, where a local church hosts these refugee kids and the Cedarville students. The students build relationships with the kids and help them understand English terms related to math and science. Anna Ward, a Mollecular and Cellular Biology major here at Cedarville, says, "I like King's Kids best because it reaches outside the walls of Cedarville...I like that I can work with people from literally all over the world right in Dayton."

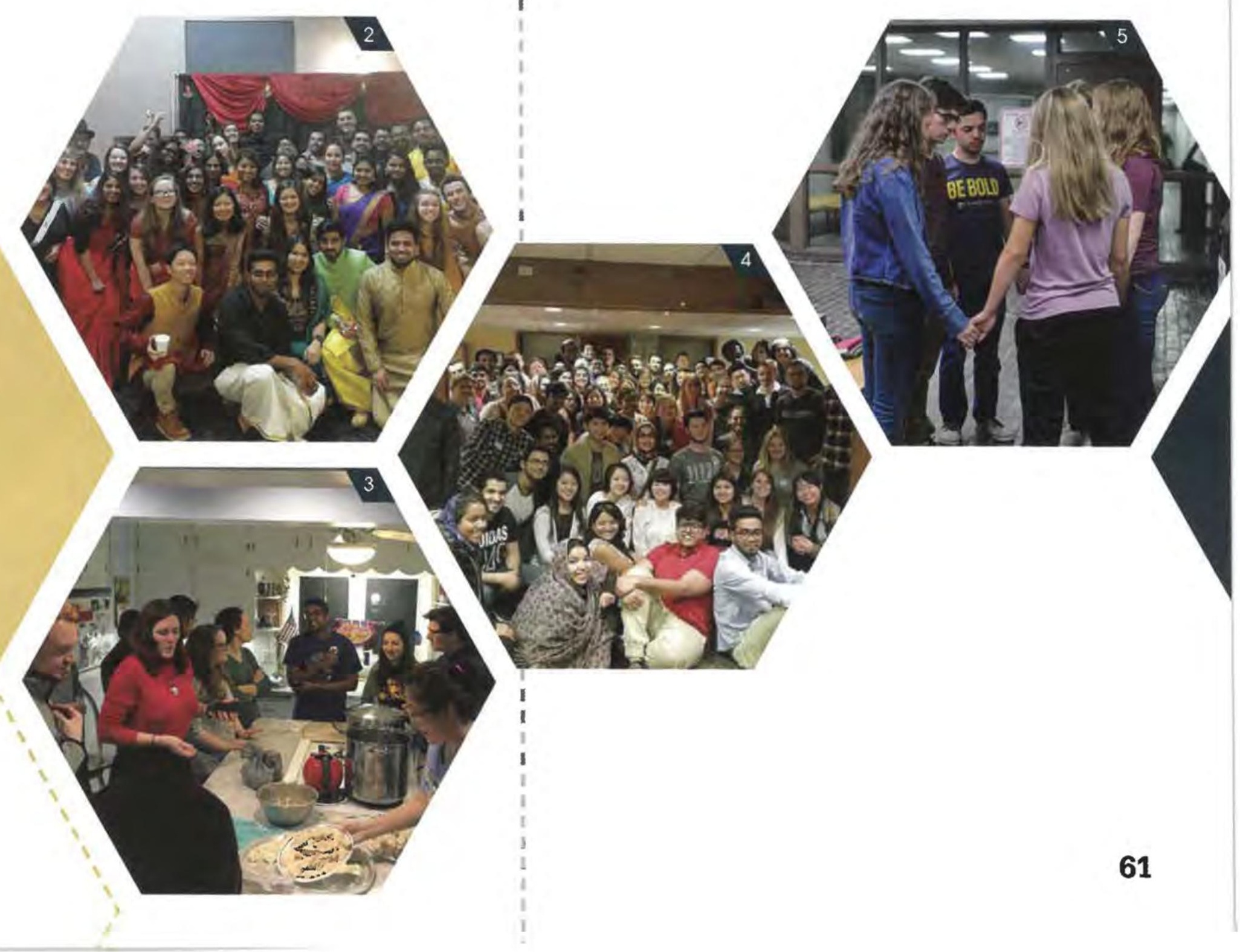




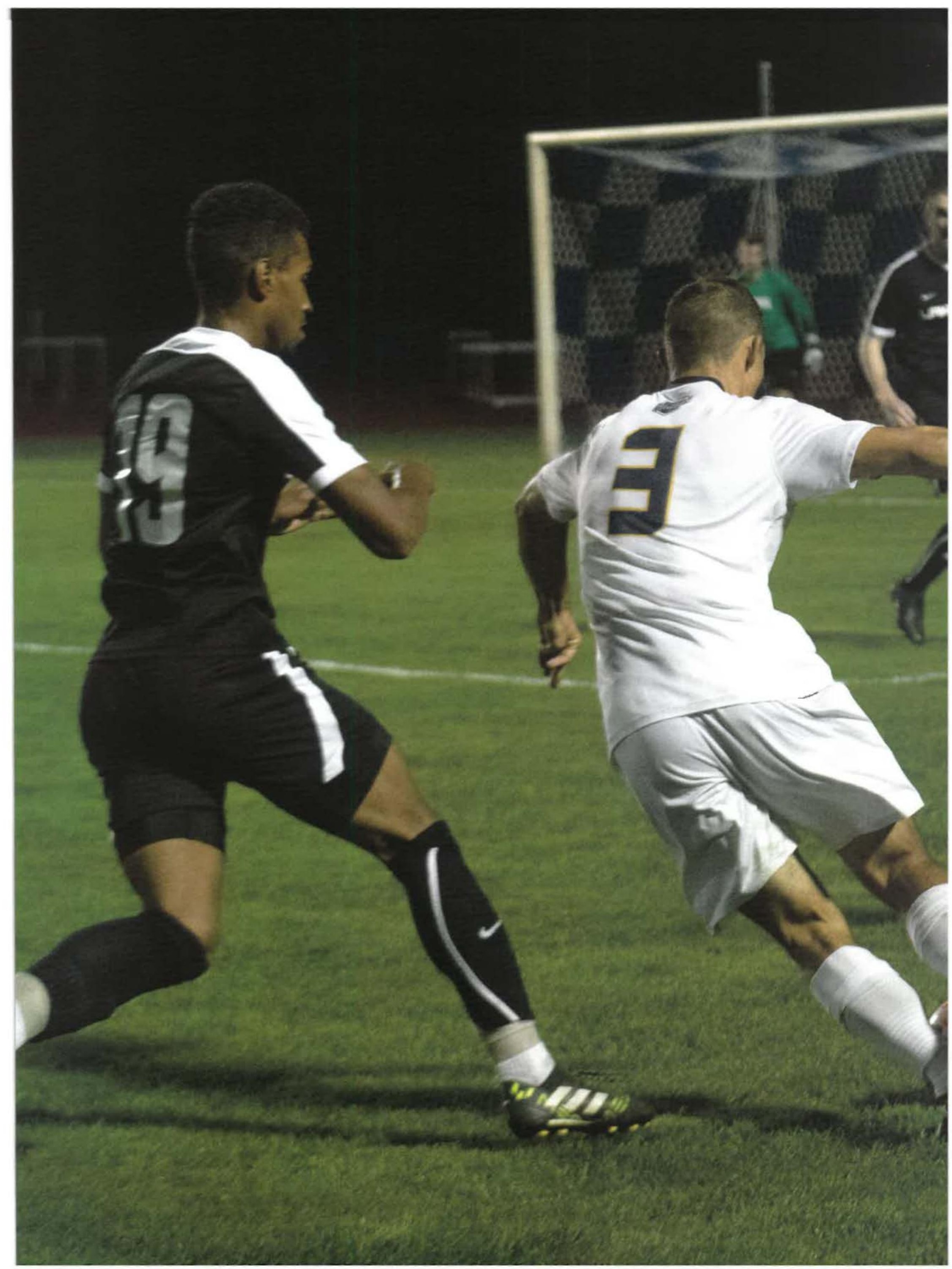




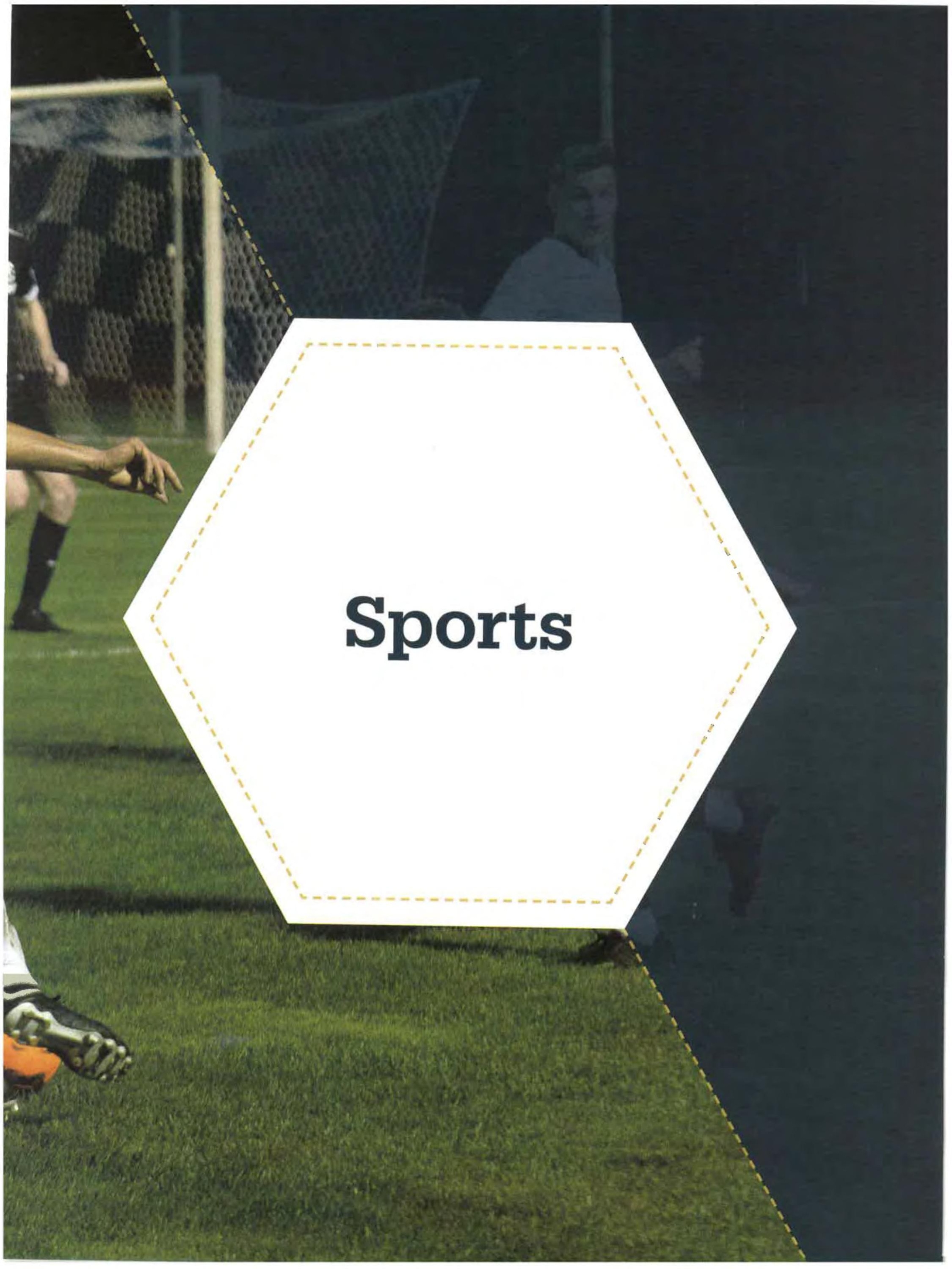




\section{Men's Soccer}

1: Midfielder Sammy Killimann (9) strikes for the goal as Cole Butaud (16) supports his teammate.

2: Cole Butaud (16) drives up the field, heading in toward the goal.

3: Greg Williams (24) dribbles past the opposing player. shielding him forward off the ball.

4: Conner Hughes (12) looks to drive up the field with the ball, hoping for a chance at the goal.

5: Derek Braak (7) contests for a headball at the end of the field.

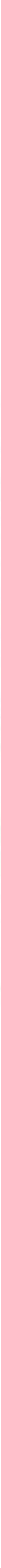




\section{Women's Soccer}

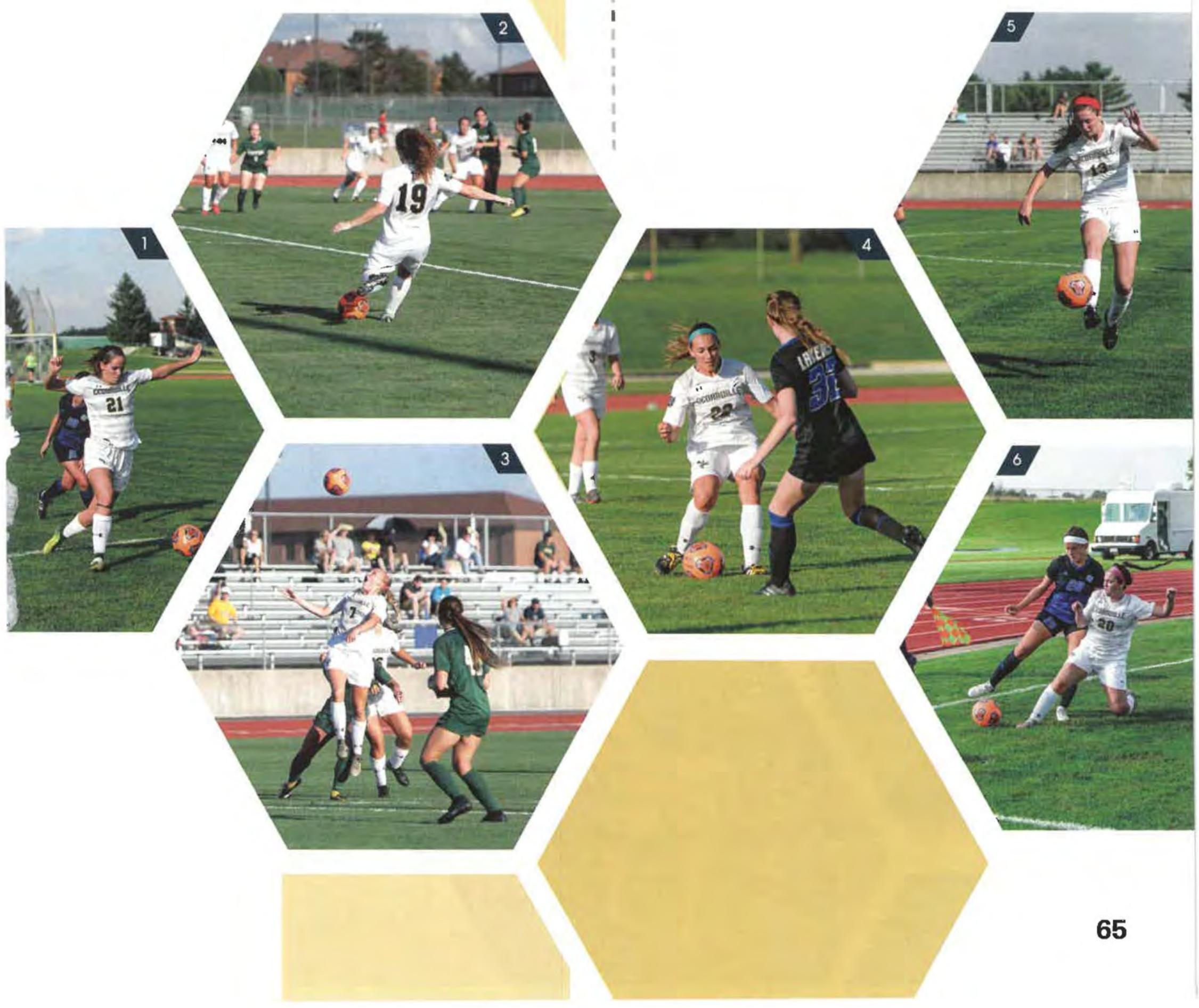




\section{Men's Cross Country}

Queen 5K:

5 of 15

Friendship 8K:

1 of 16

All-Ohio 8K:

5 of 39

Wilmington $8 \mathrm{~K}$ :

6 of 36

Rock 8K:

4 of 29

G-MAC 8K:

3 of 13

NCAA MW 10K:

5 of 32

NCAA DII 10K:

24 of 34

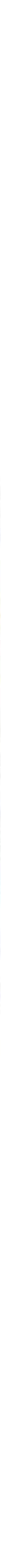

of runners broke from their box at the start line.

2: Andrew Sholl runs down the homestretch at the

end of Cedarville's $8 \mathrm{k}$ race at the 2018 Friendship

Invitationa

3: Andrew Testas closes the gap on a group of runners in

front of him during the 2018 Friendship Invitational.

4: Alec Weinhold competes in the Friendship Invitationa

5: Ethan Sullivan is the first Cedarville runner to finish at

the Friendship invitational. He finished 2 nd overall

2 INVITATIONA5

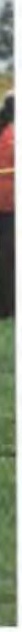




\section{Women's Cross Country}

Christy Jesson comes into the finish line of All Ohio. I

She was second for CU and 14 th overall for the meet

2. Kayla Casaleito comes into the finish line of All Ohia

(hosted at Cedarville) She was 3rd for CU and 23rd

overall

3. Kayla Casaletto heads toward the finish line of All

Ohio.

4. The CU women's Cross Country runners pose for a

team phoio

5. A pack of CU runners, Krista Greene, Rachel

Davidson, and Gabby Johnson work as a team in

midrace

6. Skyler Farrand is midrace at All Ohio

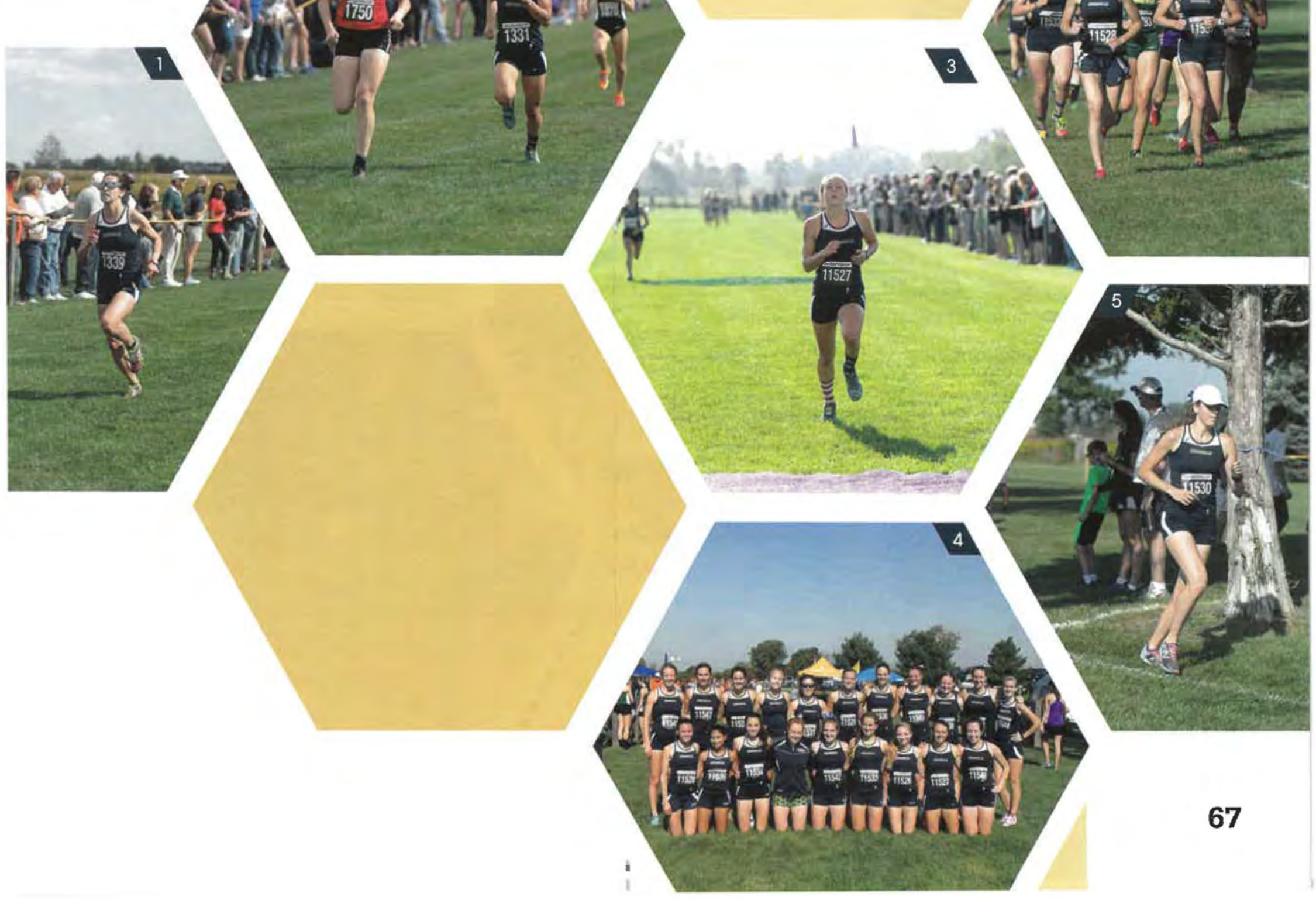




\section{Men's Golf}

1: Mitch Creamer surveys the siope of the green.

2: The men's golf team poses for a group photo.

3: Cody Cogdill hits an approach shot from the fairway

4: Isaac Wood lines up a putt.

5: Mitch Creamer hits a drive.

6. Coach Ryan Bowen helps Cody Cogdill pick the right club.

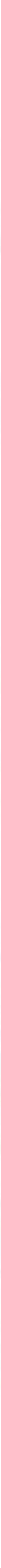




\section{Men's Basketball}

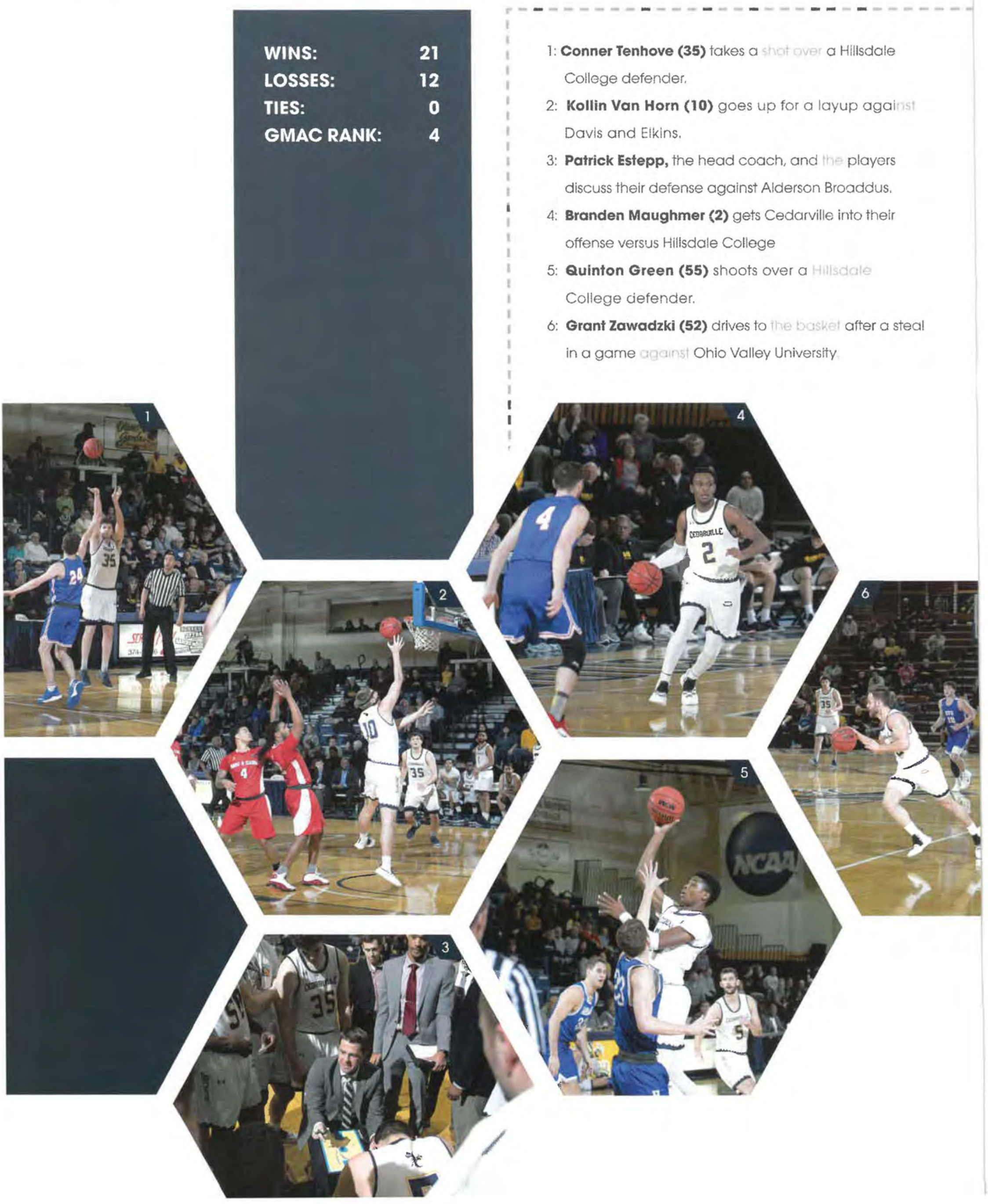




\section{Women's Basketball}

1: Abigail Wolford (3) drives to the basket in a game against Hillsdale.

2: Kari Hoffman, the head coach, tells her players to get in a stance on defense and not let their girl go right. Cedarville University was playing Ohio Valley

3: Allison Mader (24) dribbles up the court in transition against Ohio Christian

4: Cameron Peek (23) shoots a layup as Cedarville plays the University of Findlay.

5: Ashlyn Huffman (5) dodges Kentucky Wesleyan to attack the basket.

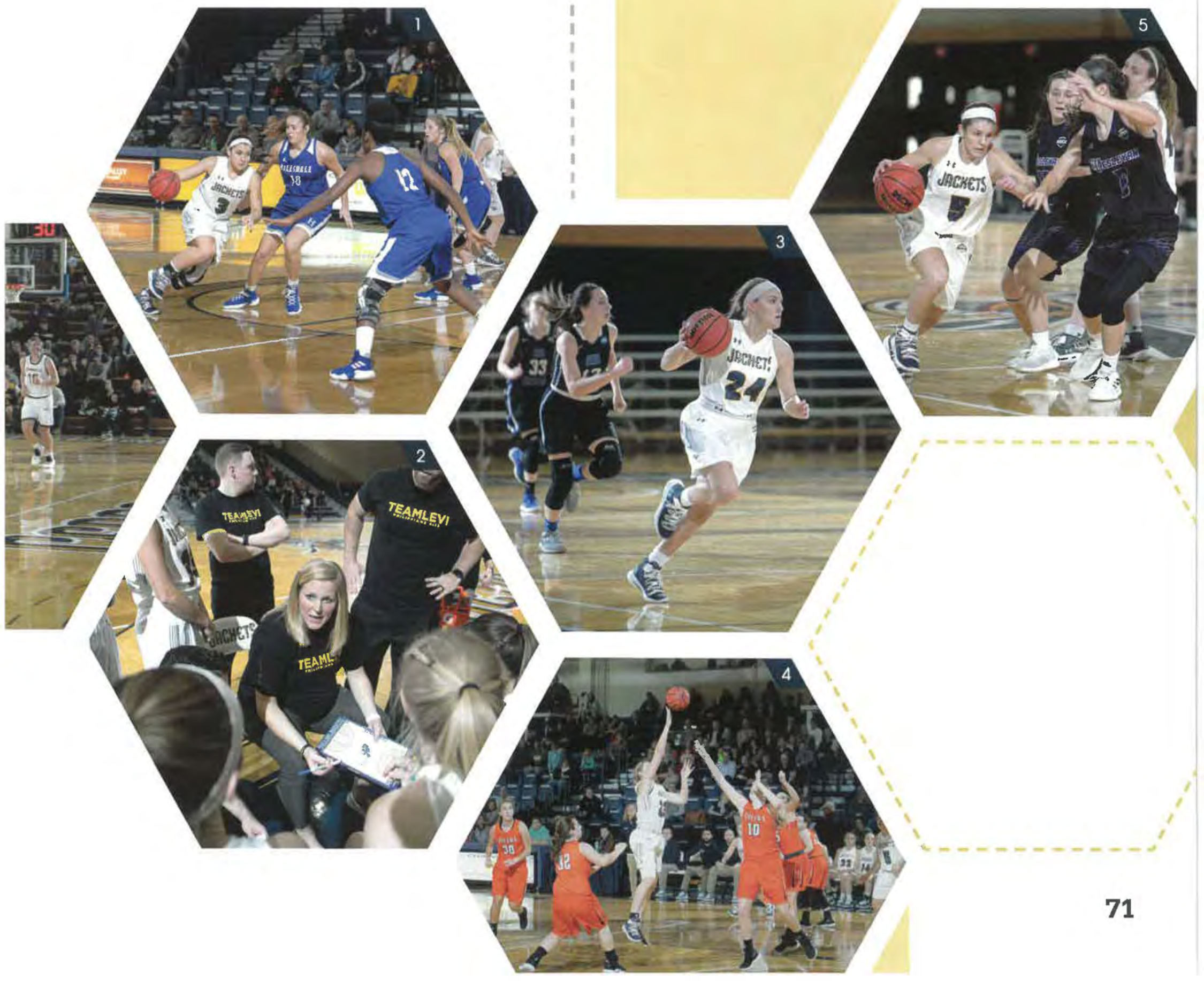




\section{Men's Tennis}

I: Dawson Poling and Cole Moss ploy in a $\$ 2$.

doubles match,

2: Matthew Brumbaugh prepares to hit o forehand volley.

3: Timothy O'Brien prepares to hit a volley.

4: Timothy O'Brien hits a forehand. He and Philip

Brumbaugh were playing a match at $\# 3$ doubles.

5: Philip Brumbaugh serves the bail in a doubles match

against West Virginia State.

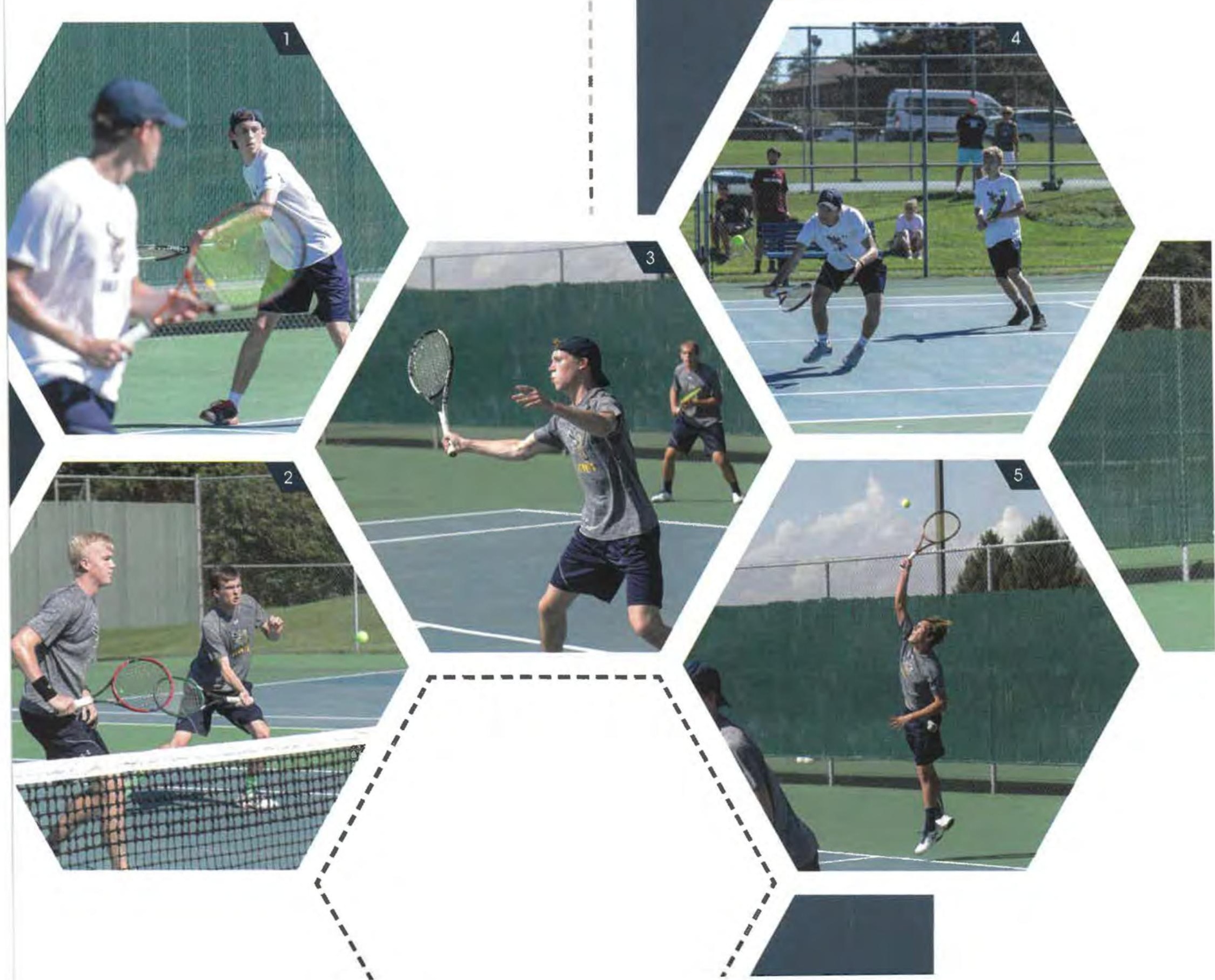




\section{Women's Tennis}

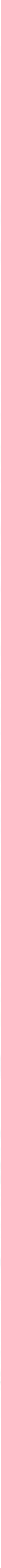




\section{Men's Track}

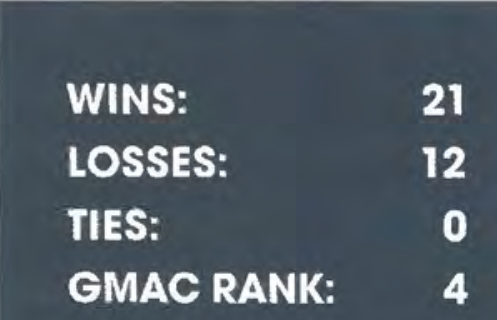

1: Jonathan Scouten throws the shot put

2: Caleb Carrico runs the 110-meter hurdles.

3: Noah Errichetti throws the javelin,

4: Tyler Reinhard does the high jump.

5: Josh Brown runs the 200-meter dash.

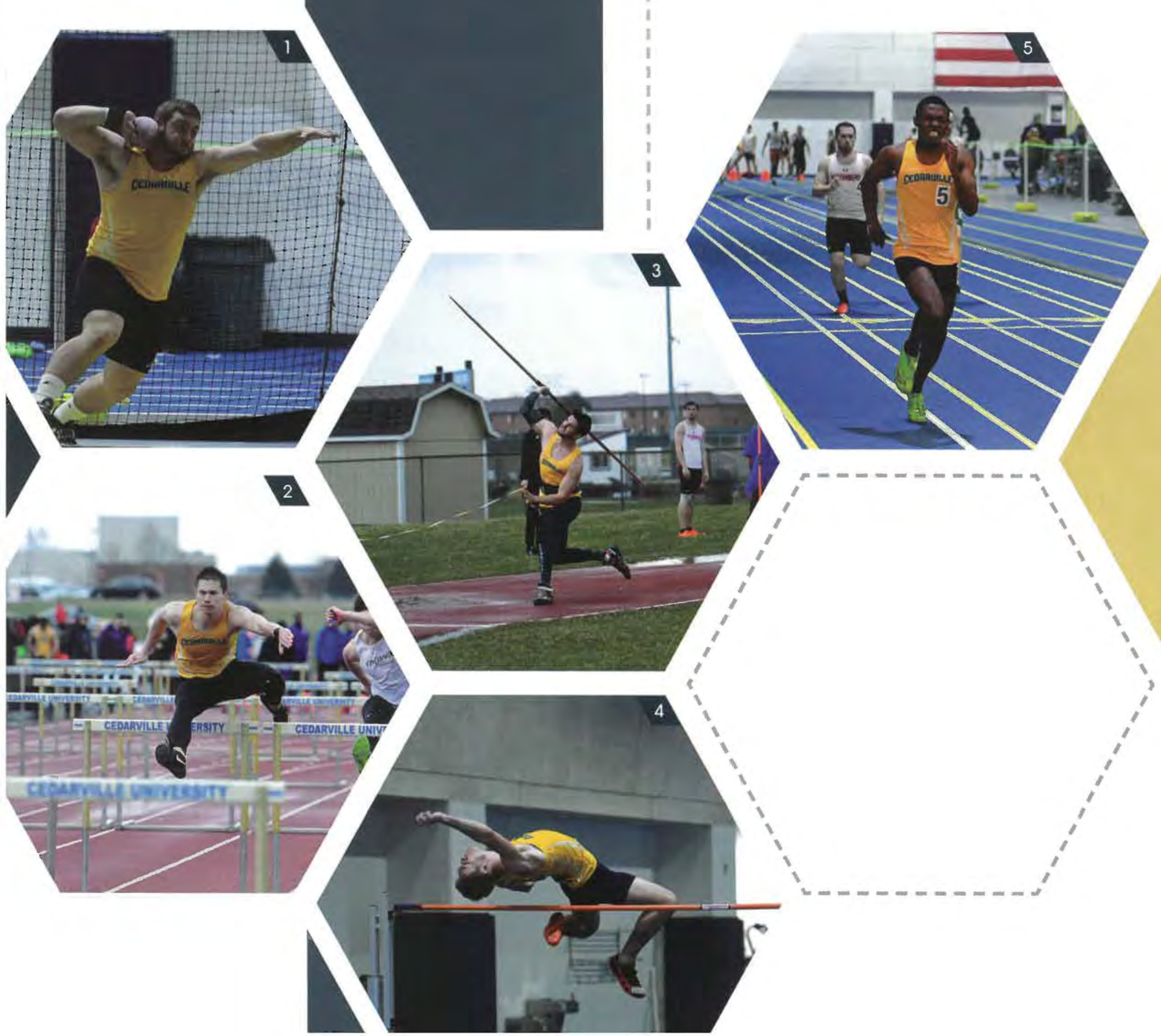




\section{Women's Track}

1. Lauren Willow jumps over a hurdle.

2. Lauren Willow high jumps.

3. Emily Kosker passes the baton to Hannah Johnson in a relay race.

4. Madeline Barnes pole vaults.

5. Abigail Pullins sprints in the 100-meter dash.

6. Grace Norman runs a distance race.

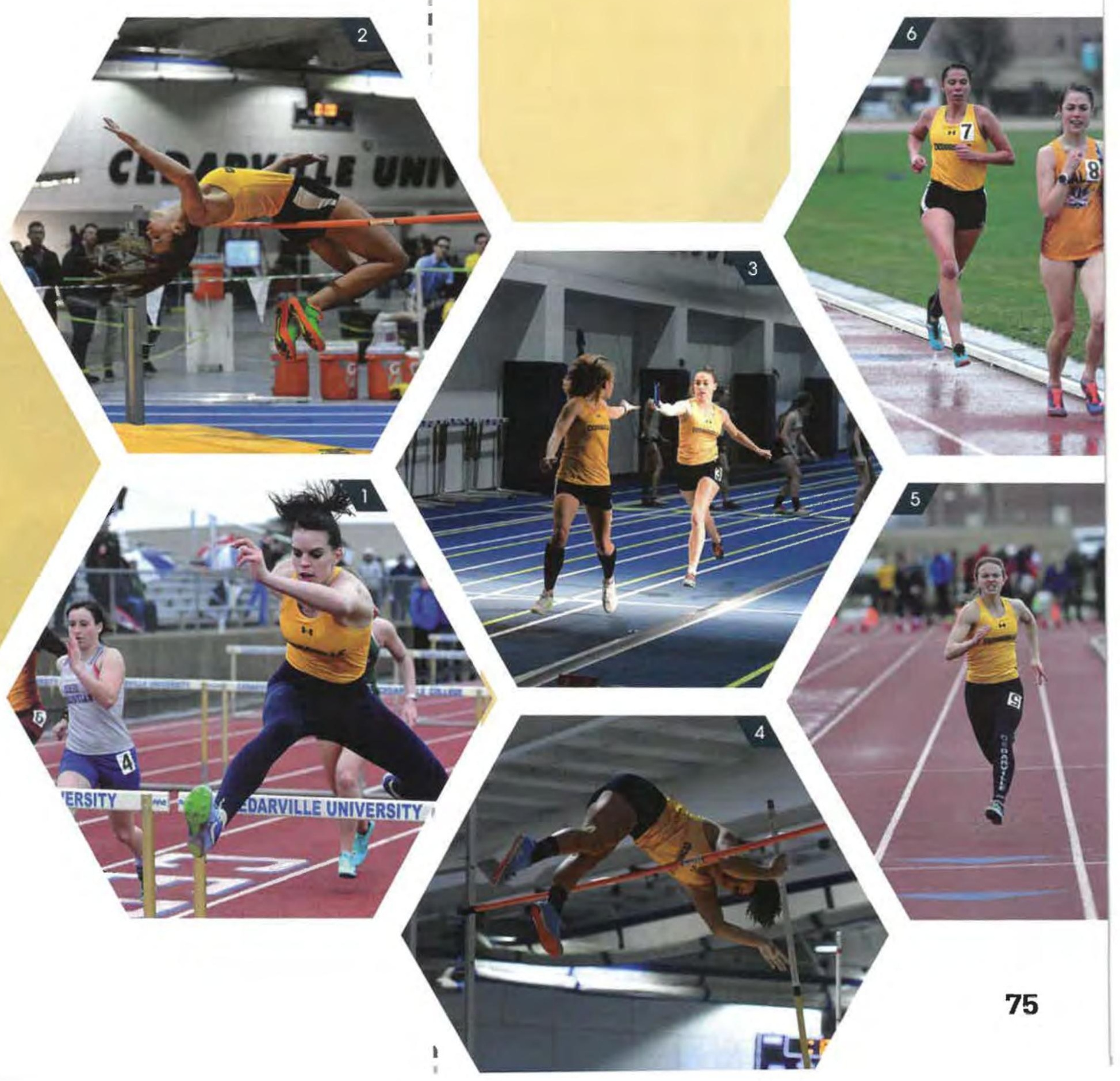




\section{Baseball}

1: Ross Melchior throws the ball to first base.

2.: Elijah Sanchez prepares to hit the ball.

3: The players congratulate each other after a game.

4: Brendan Toungate throws the ball to second base.

5: Peyton Eeles fields a ground ball.
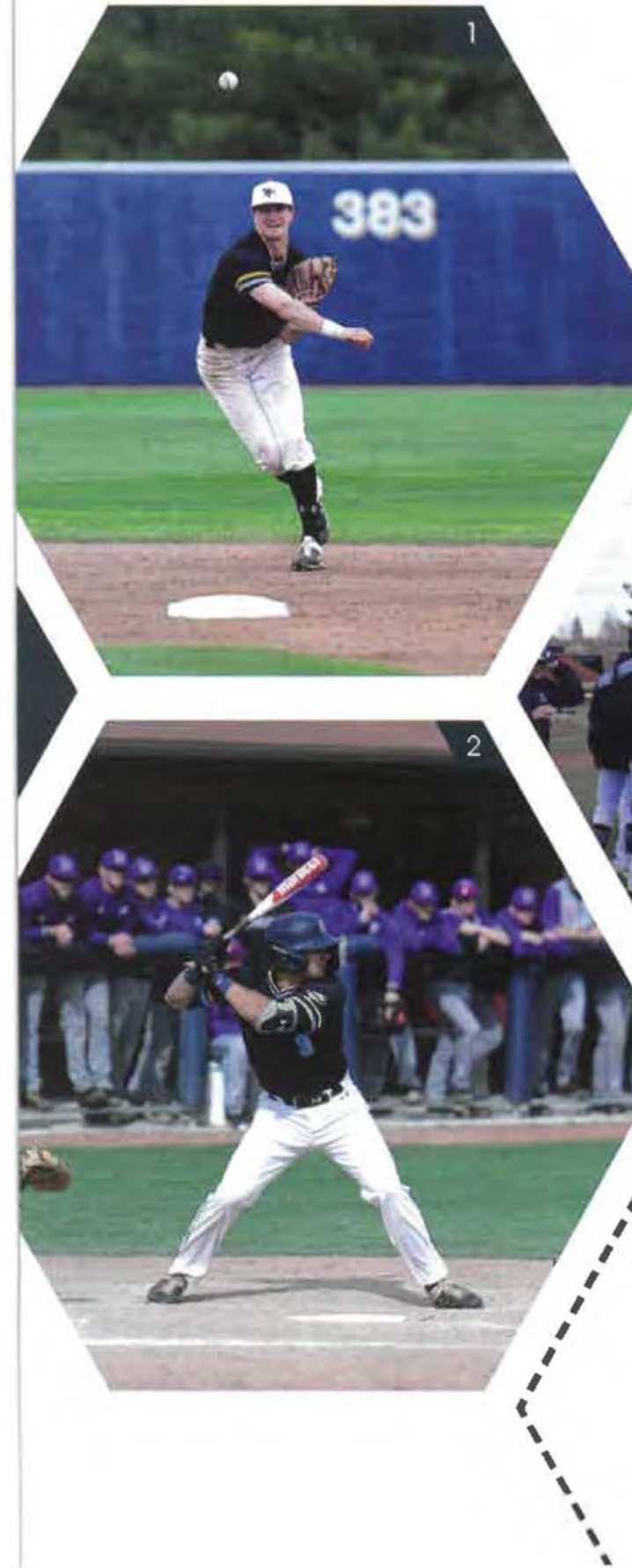

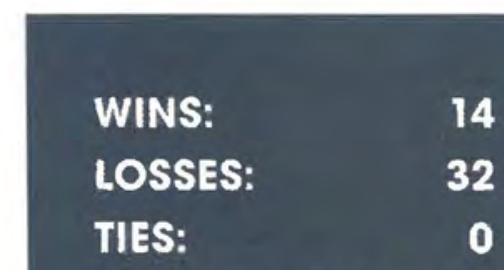

BATTING RANK: 11 PITCHING RANK: 10 FIELDING RANK: 9 


\section{Softball}

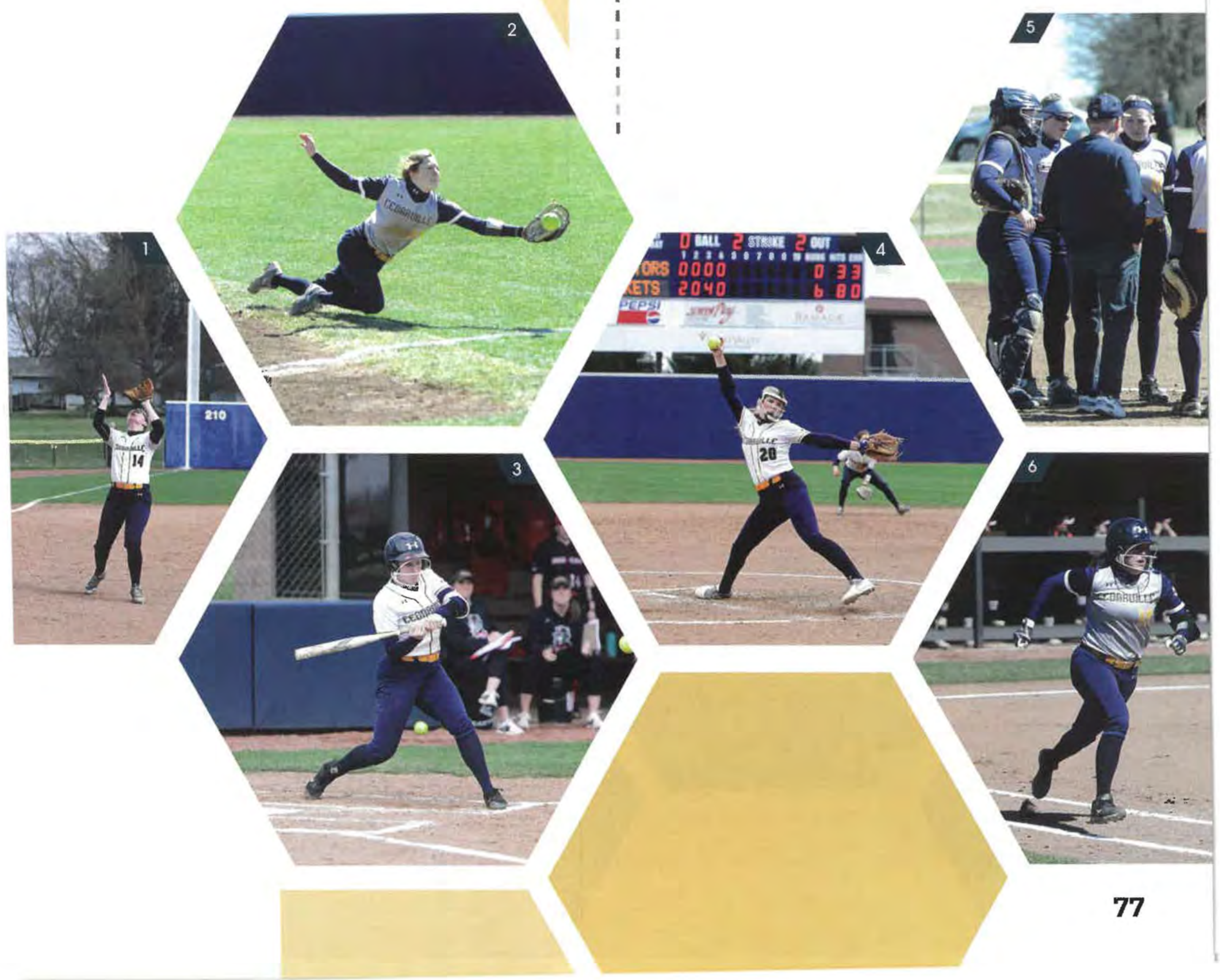




\section{Cheerleaders}

The cheerleading team faced some unexpected losses this school year when several members left the team and the squad shrank- a big struggle in cheer, where every member is required to accomplish their stunts. Due to this change, they had to rearrange all of their group mounts and stunts, but they tackled the challenge with ambition, renewing the old stunts and adding some new ones. "One of my favorite parts about cheering this year was our small but mighty team," Kori Beal said. "The remaining teammates were so enthusiastic and committed to making it a great year that we were actually able to try some mounts that we had never imagined. Two of our seniors are graduating this year, but they left us knowing that no matter what size our team is, we can do great things."

1: The cheerleading squad executes a tabletop during a time out.

2: Courtney Eppard cheers on a basketball player as he shoots a free throw.

3: The cheerleading squad performs a double table top.

4: Evan Hunnemeyer cheers on the basketball team.

5: Aaron Johnston and Kori Beal perform the "whoo h, CU" cheer after a free throw shot.

6: Kori Beal does a dance on the sideline during $a$ time out.

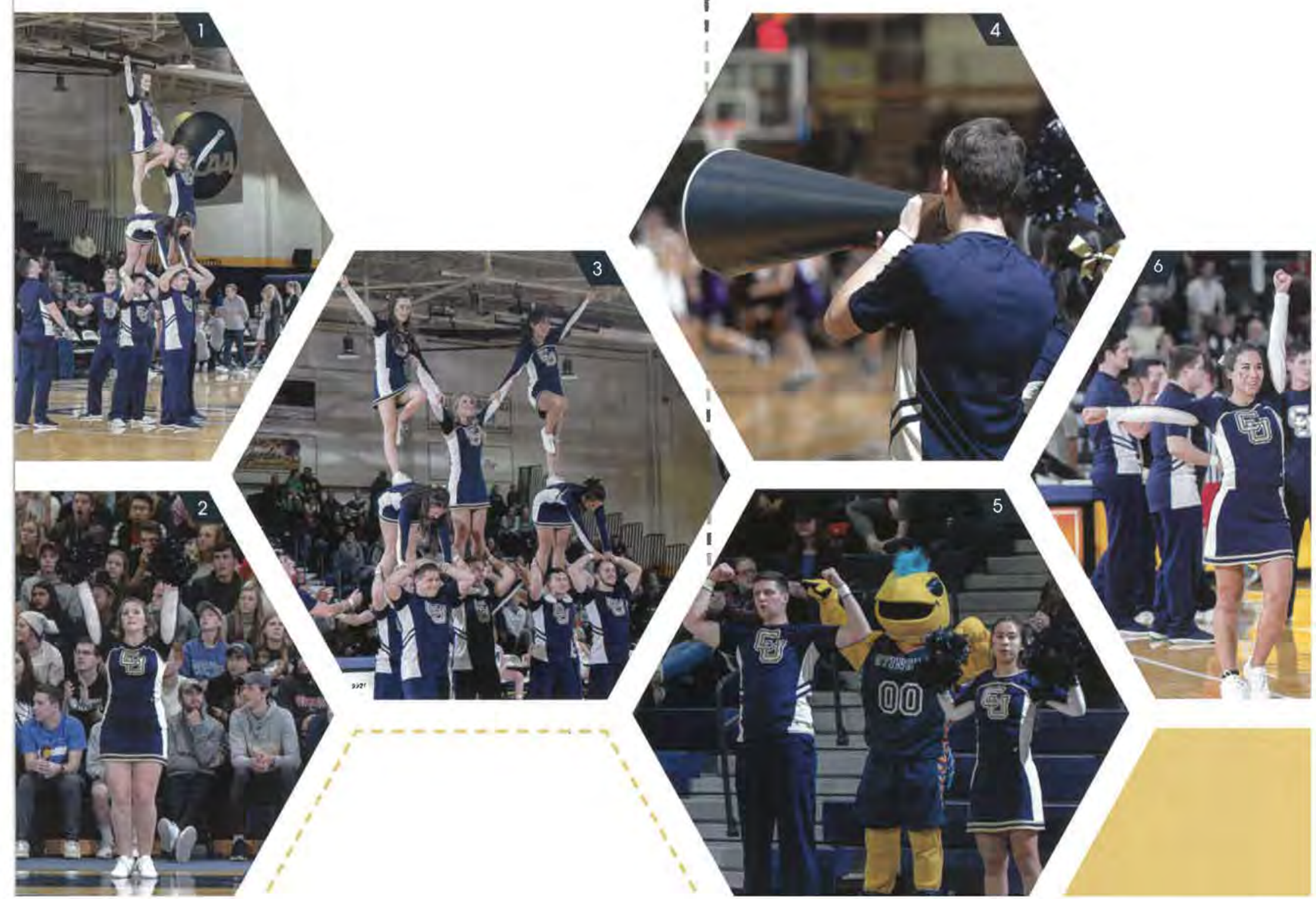




\section{Intramurals}

Philip White throws a disc into the basket during a

game of disc golt.

2: Team Name 4.0 poses for a plature after winning the flag footbalf championship Their leam started oul with the name "Team Name" freshman vear, and they added a number at the end of the name each year until they graduated.

Jessica Steger, Abby Woodard, and Natalie Wright pose for a plcture after winning in the intramural beach vollevball toumament

4: Chris Keener, Zoe Steigerwald, Kailynn Pike, and Jack Yeager pose together on the volleyball court

5: Go Harden the Paint, an intramural basketball team, poses for a plicture after winning the 3 on 3 toumament.

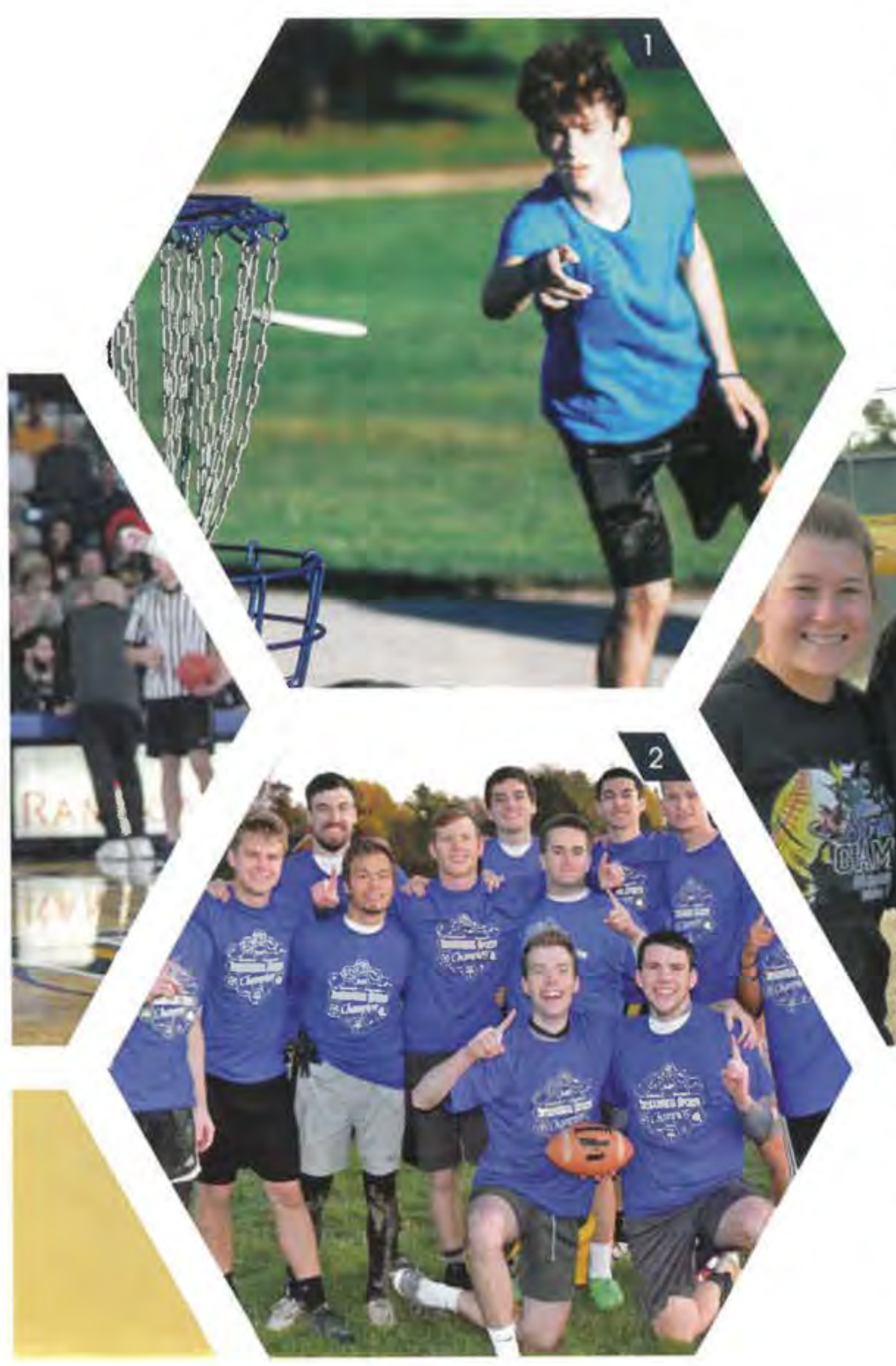

Most intramural teams take their sport seriously and play to win in an attempt to rise to the top. This year, one team decided to incorporate a little humor into their gameplay. A men's intramural basketball team dressed up in a variety of crazy costumes for every game. Some dressed themselves like nuns, some wore tropical Hawailan outfits, and one player even arrayed himself in a full suit. During every game, the players kept the crowd laughing with their ridiculous stunts and horseplay. "They just dressed up and memed the whole time," Andrew Peterson said. "(They) just scored on the basket in the middle, shot behind their backs, didn't play defense." Sometimes it is good to let go and let your crazy side loose for a little while, as this team happily demonstrated. 


\section{Club Sports}

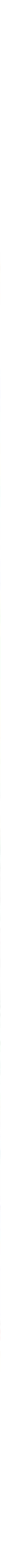




\section{Academic Teams}

1 The aero design team poses for group pinct

2: The aero design team inonks then pliot for flying ther

3: Mae Dewhurst, Alex Hentschel, and Caleb Jackson

are in a tenge disclission with cother ctelegutes in

at

DAYMUDC. Mae Dewhutel was the CU MUN tear

and Caleb

4: Maury Funez addresses delegates at the Dayton Model

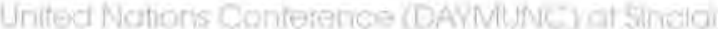

Community College at the beginning of February. $\mathrm{He}$ represented Kazakhstan in the UNICEF committee.
Model United Nations is a simulated international negotiation team comprised of students from many different majors at Cedarville. Cedarville's team travels and competes against other teams of students from around the world. Each team usually represents a country, and these countries work pass policies from start to finish. While none of these policies actually are implemented, it gives the students experience in collaboration, diplomacy, presentation, and professionalism. Cedarville's team finished off its year at a competition in New York. Olivia Patterson, from the Cedarville team said, "My favorite memory from this year was at the end of the week when we were able to visit the United Nations building in New York. To have our final assembly in the halls where so many major decisions were made was incredible. Decisions that impacted our world and changed history were made in these rooms." The Cedarville Model UN team capped off their award-filled year by winning the Outstanding Delegation award in New York, which is the highest team award given in Model UN.

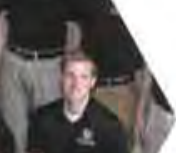

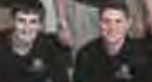
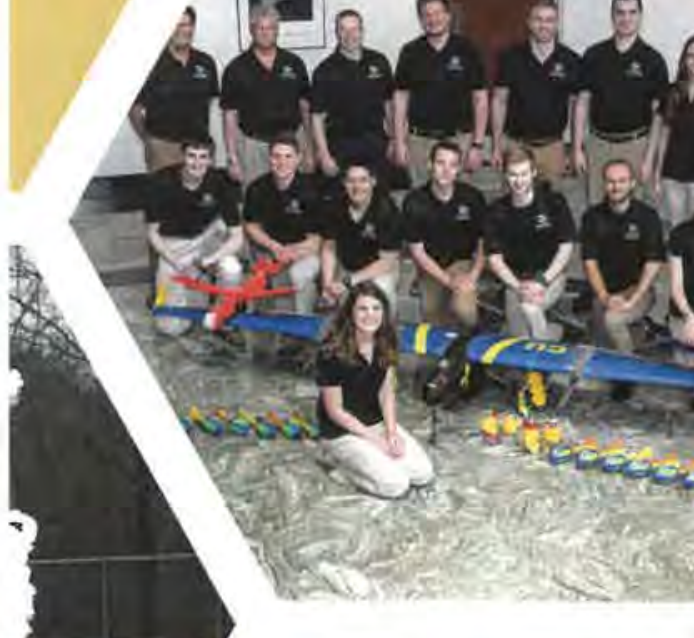


\section{International Center for}

\section{Creativity Juniors \& Seniors}

Chad Benninger

Brie Driver

Marcus Gowin

William Haskins

Anita Hayden

Luke Henig

Naomi Lynch

Tamara Marques

Ben Martin

John Minier
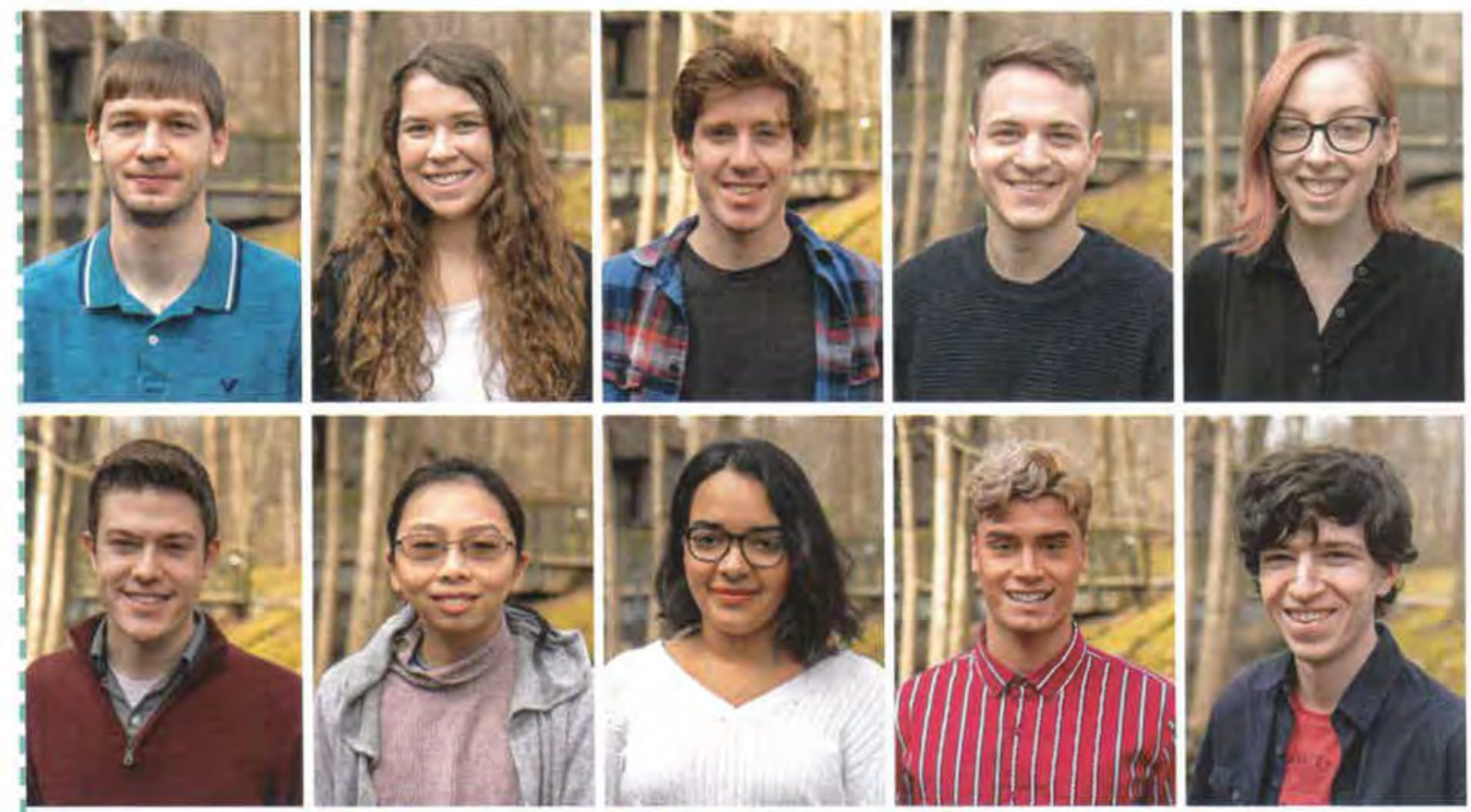

Rebecca Murch

Nathan Osborne

Anna Pizarro

Nathan Pomles

Allison Ramsey
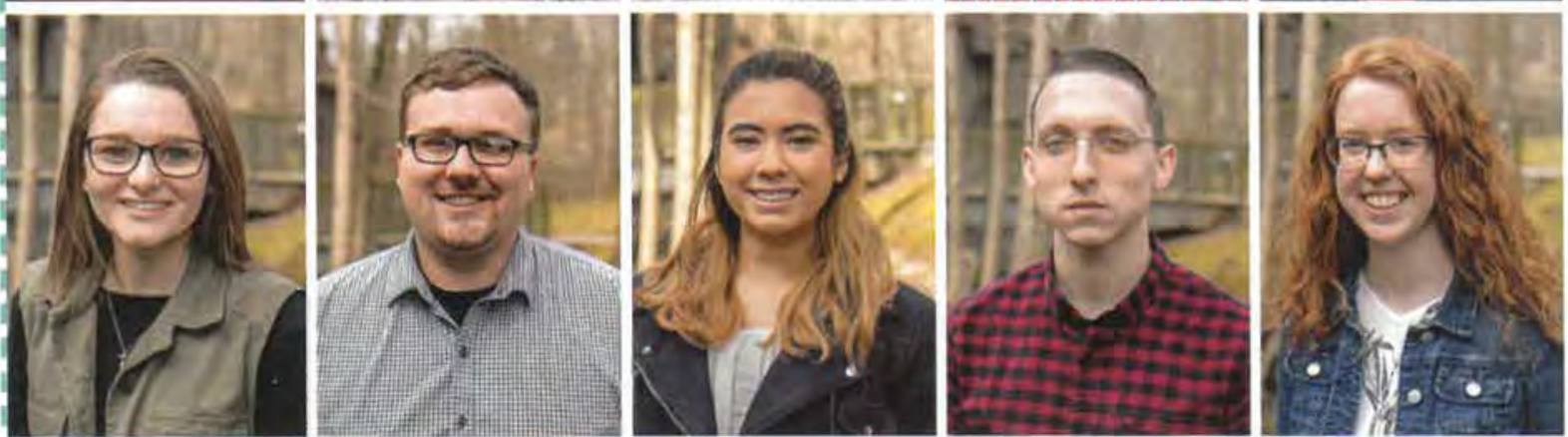

Andrew Renner

Robert Saieg

Olivia Taylor

Isaac Thomas

David Watson
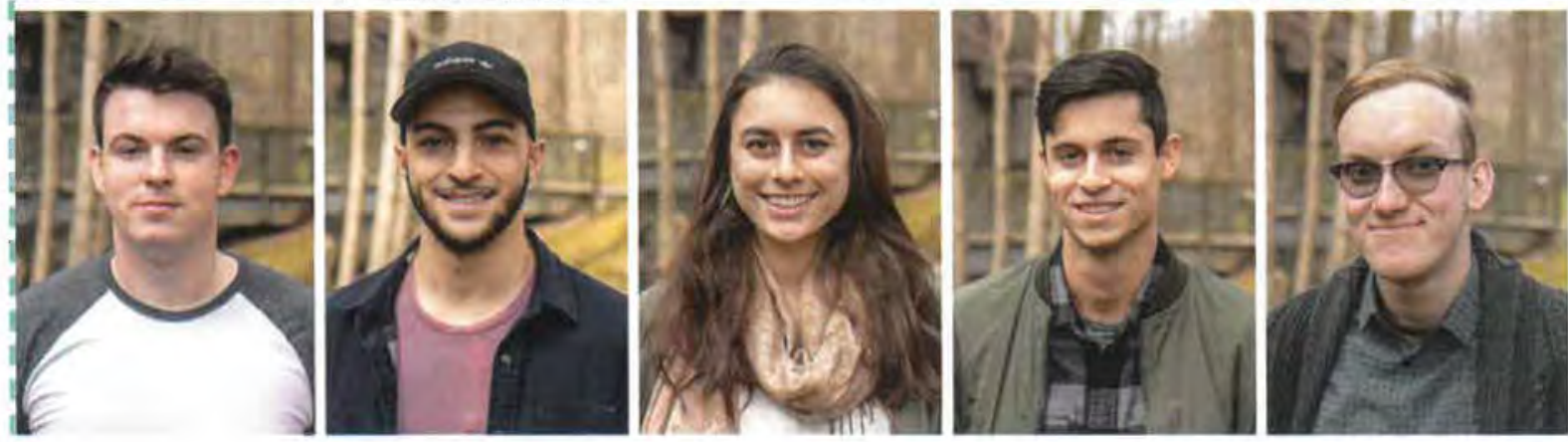
Jennifer Barber Garett Beaudette

Rachel Bragg

Kristin Calderone

Cori Concepcion

Rory Emrich

Jacob Fiere

Jared Finley

Caleb Hanson

Savannah Hovingh

Ye-Chan Jeoung

Tracy Jerschina

Braden Leenerts

Michael Leitch

Sarah Lewis

Benjamin Luckhof

Vitaliy Lukyanov

Cara Matheson

Josiah Parson

Andrew Plunkett

Drayton Santavicca

Blake Scanlan

Julia Shaffer

Hannah Sitle

Alex Spangle

Rosie Thompson

Jennifer Yosinsk
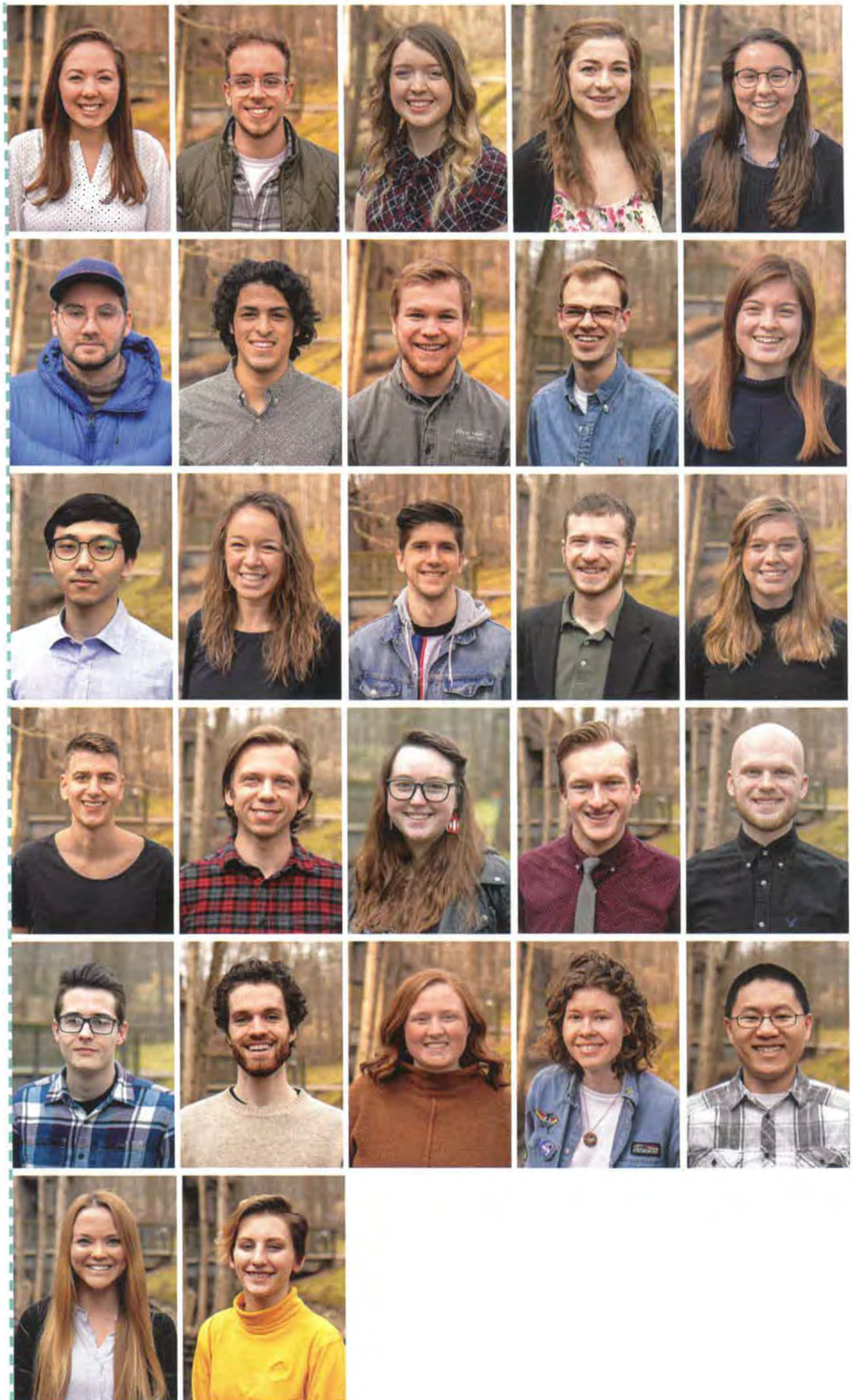


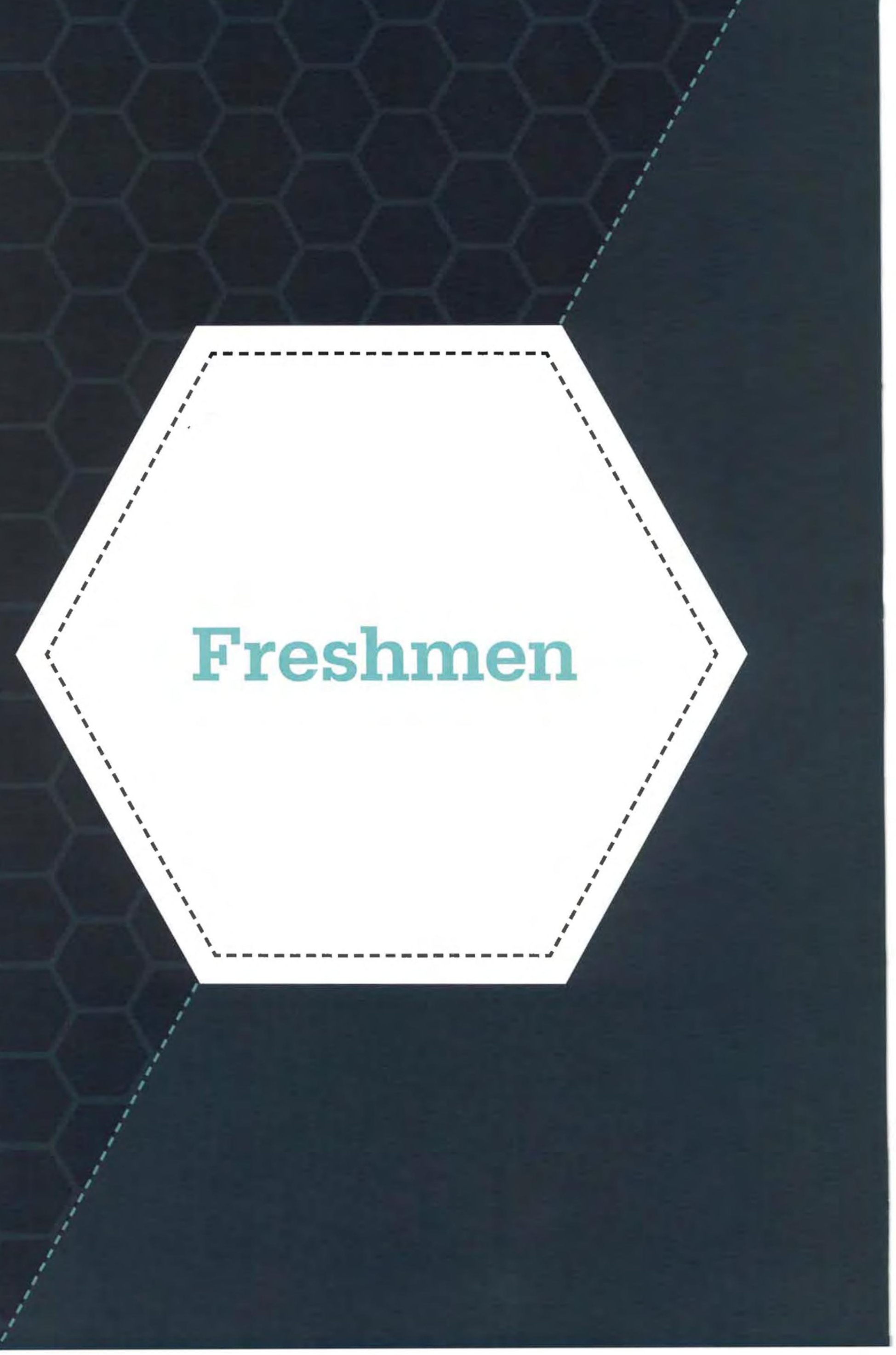




\begin{abstract}
Timothy Abbott
Grant Abramowitz

Alayna Ackley

Kathryn Adams

David Adewole

Daniel Alber

Caleb Amundson Julia Anderson

Kaitlyn Antle

Hope Arango

Samuel Arblaster

Ashley Armour
\end{abstract}

Kailee Armstrong

Amelia Arthur

Nathanael Atkins

Pieter Ausema

Brooke Bailey

Abigail Baker

Benjamin Baker

Josiah Balk

Logan Ball

Emma Barker

Stacey Barker

McKenzie Barlow

\section{Madelyn Batka \\ Peter Beck \\ Hope Beckloff \\ Justin Ben \\ Rebecca Bennett \\ Jenna Beremand}

Sara Beste

Madison Bevin

Lindsey Bishop

Josiah Bitner

Abigail Blain

Dawson Block

Cameron Blubaum

Jason Blunt

Isabelle Bolender

Kirsten Boner

Jesse Boomstra

Jared Bowden
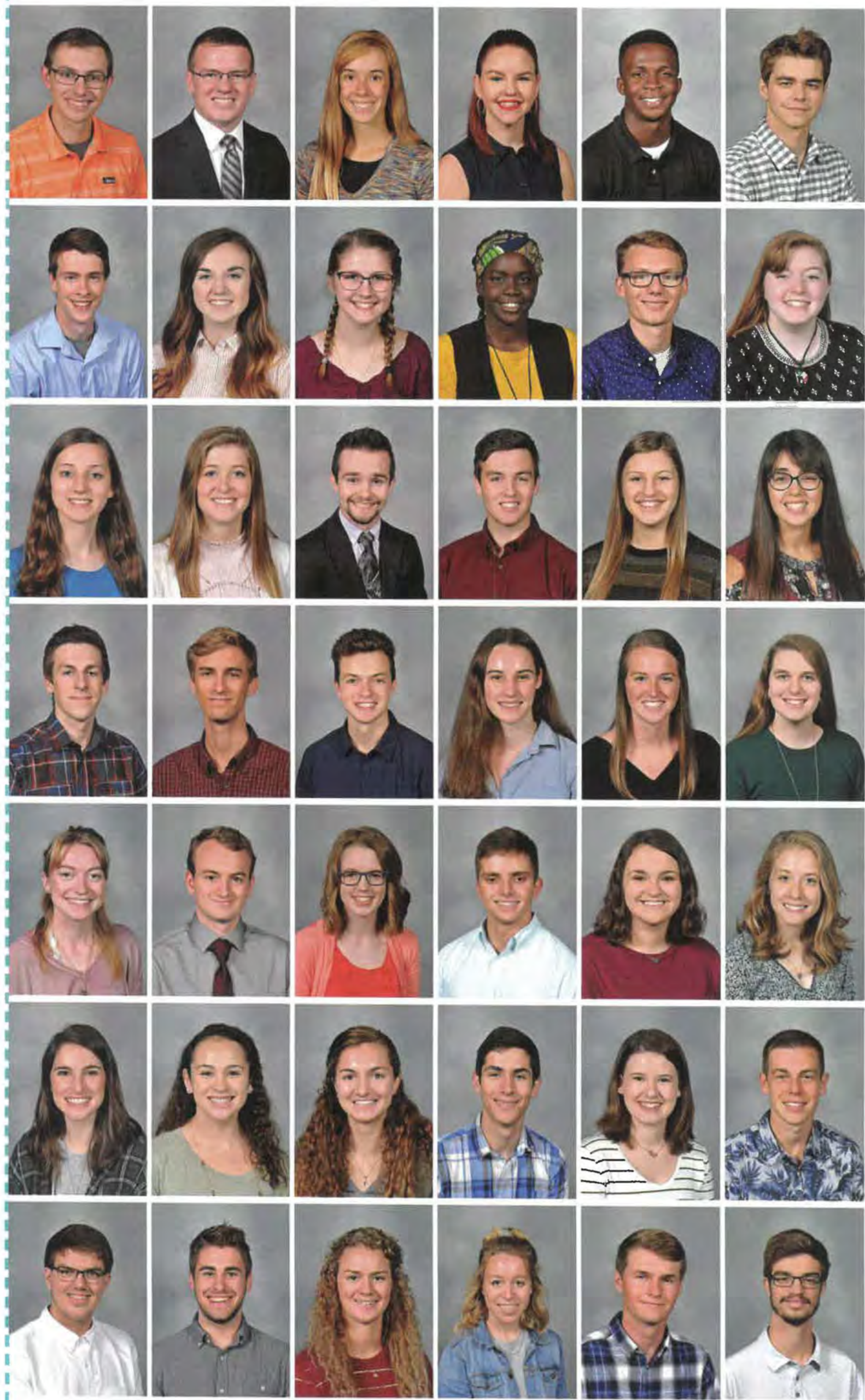
Cayla Bowles Mitchell Bowser

Lydia Bradley

Lia Branch

Abigail Brandner

Nehemiah Branson

Alyssa Brennan

Isaac Brenneman

William Brethaue

Kayla Brimner

Allison Brosius

Ruth Brouwe

Austin Brown

Dana Brown

Isaac Brown

Morgan Bryant

Claire Burke

Alexis Burket

Abigail Burr

Callie Burt

Avery Bush

Delaney Bynum

Isabel Byrd

Grace Cain

Faith Callahan

Aaron Campbe

Savannah Carmack

Emily Carman

Mario Castillo Diaz

Madeline Chairvolotti Christa Charles

Alise Cheeseman

Asia Childress

Carly Cinberg

Cole Cinberg

Cameron Clark Christopher Clark

Kaelin Clemens

Kaylee Clemen

Joshua Cochran

Makenzie Cochran
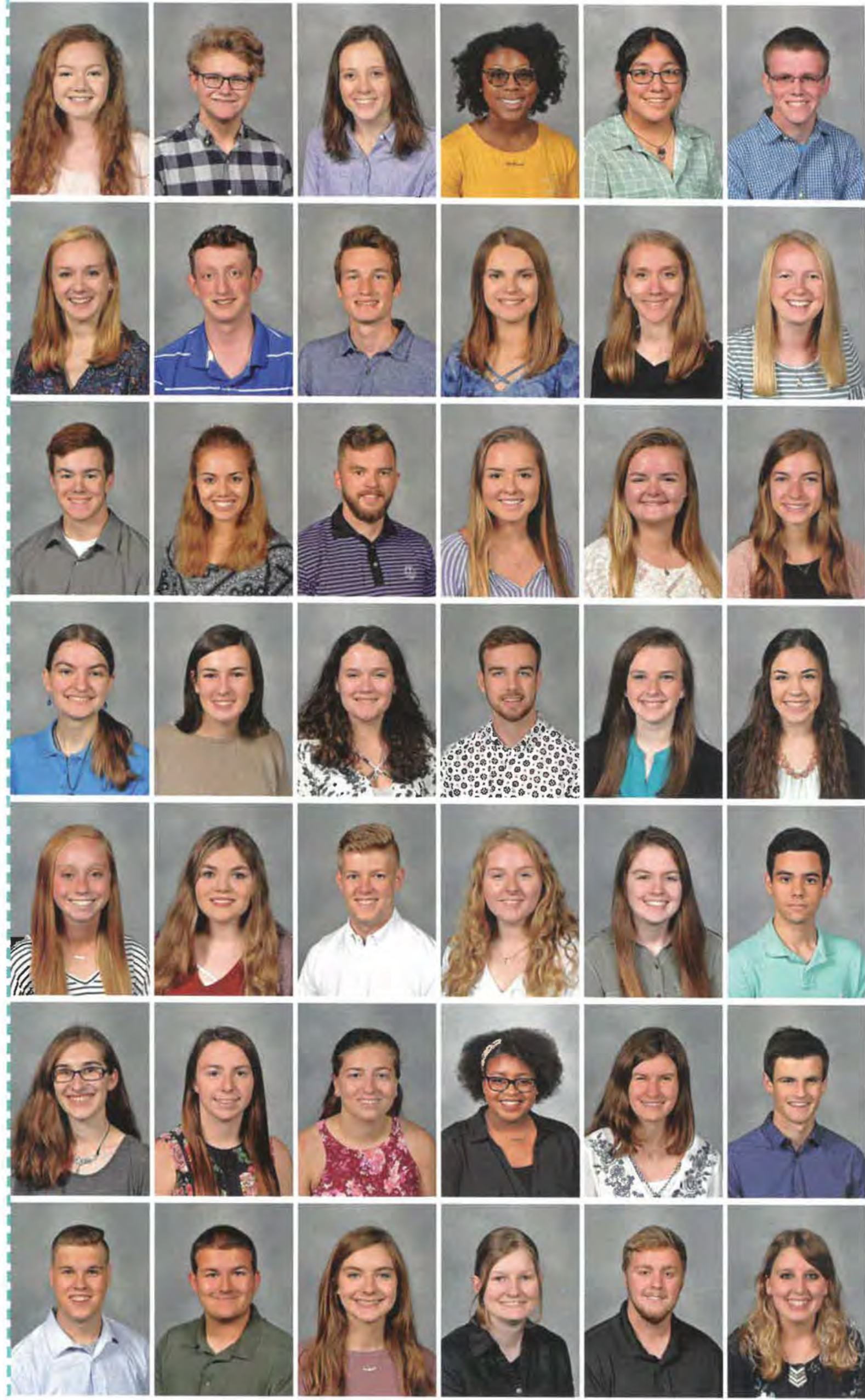
Zachary Conoboy Corinna Cooper

Grace Cooper Joshua Counts Braden Cowell Colin Cramer

Kameron Crandell Sarah Creditt Tiana Curley Jacob Curran Joshua Curran Wilson Daghfal

Noah Davidson MacLaren Dawson Kathryn De Vries Hannah Deane Natalee Deaton Joshua Decker

Nathaniel Dentel Joshua Depinto Timothy Dibert Bradley Diller Natasha Dobson Sarah Doddridge

Colin Dowd Fiona Downey Maria Drollinger Anna Dubols Lauren DuBois Grant Dupler Delaney Dykema Matthew Eari Payton Eeles Micah Eisman Jordan Elam

Rita Elgersma Lauren Ellis Rebekah Ellis Julia Elmers Nathaniel Emory Elijah Engle
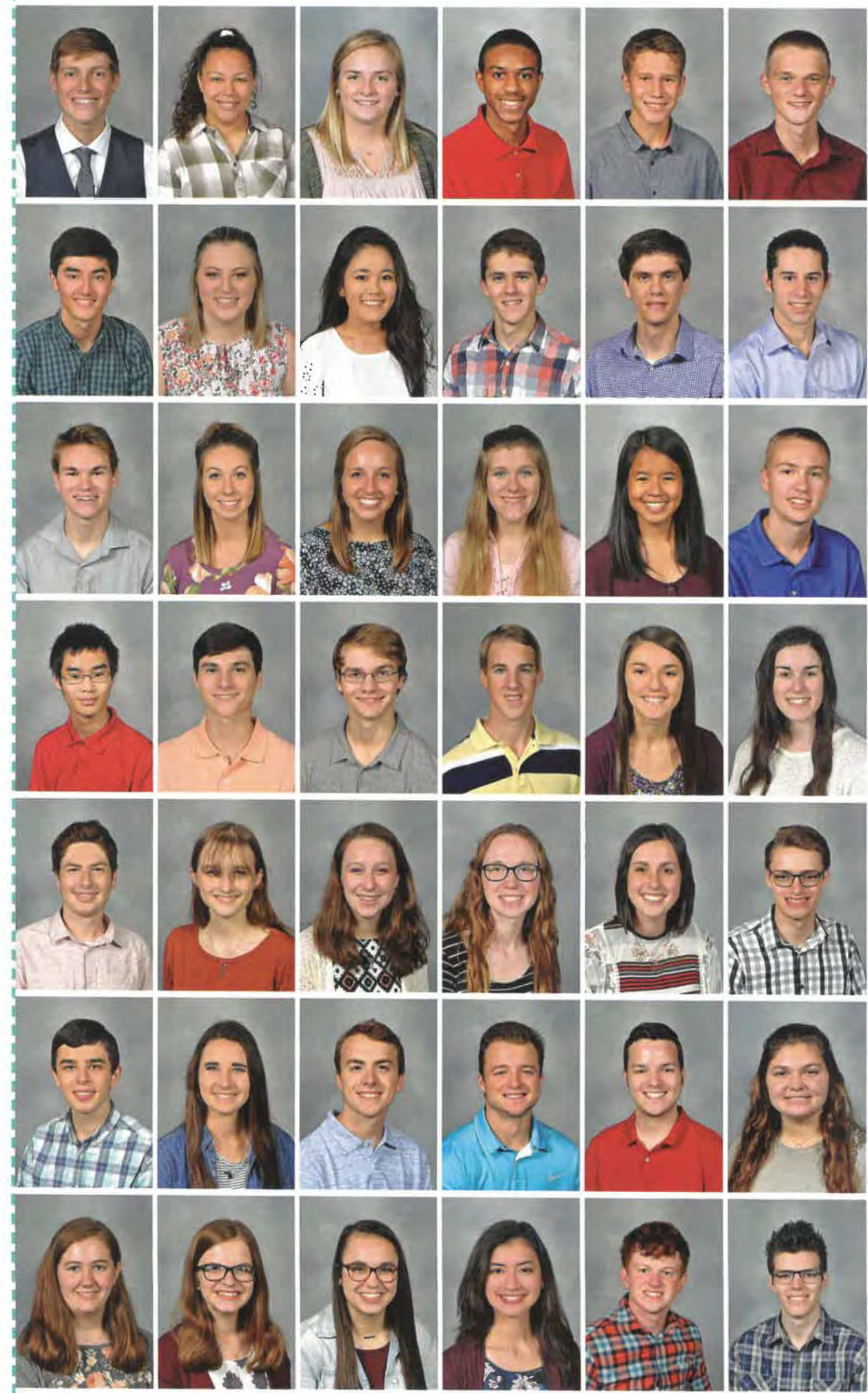
Abigail Enloe Abraham Enns

Tanner Esselburn

Mark Everhart

Cayla Exline

Erika Faison

Caleb Fasnacht

Katelyn Fausko

Kaitlyn Ferguson

Cecelia Ferris

Brandon Fisher

Stephanle Fisher

Maxwell Fletcher Ethan Flint

Thomas Folkerts

Charley Fortener

Joshua Foss

Abigail Fox

Alison Franz

Yukl Funakosh

Phillip Gammie

Jesse Gard

Jacob Gayman

Michaela Gentry

Jessie Gerakinis

Collin Gibson

Wesley Glaze

Katie Gosman

Kurtis Gould

Aidan Graef

Benjamin Graeff

Clara Gra

Madison Greathouse

Emily Greenhouse

Allison Griffith

Sarah Grover Andrew Hackler Jennifer Halder

Erika Hall

Amber Haney Luke Hannay
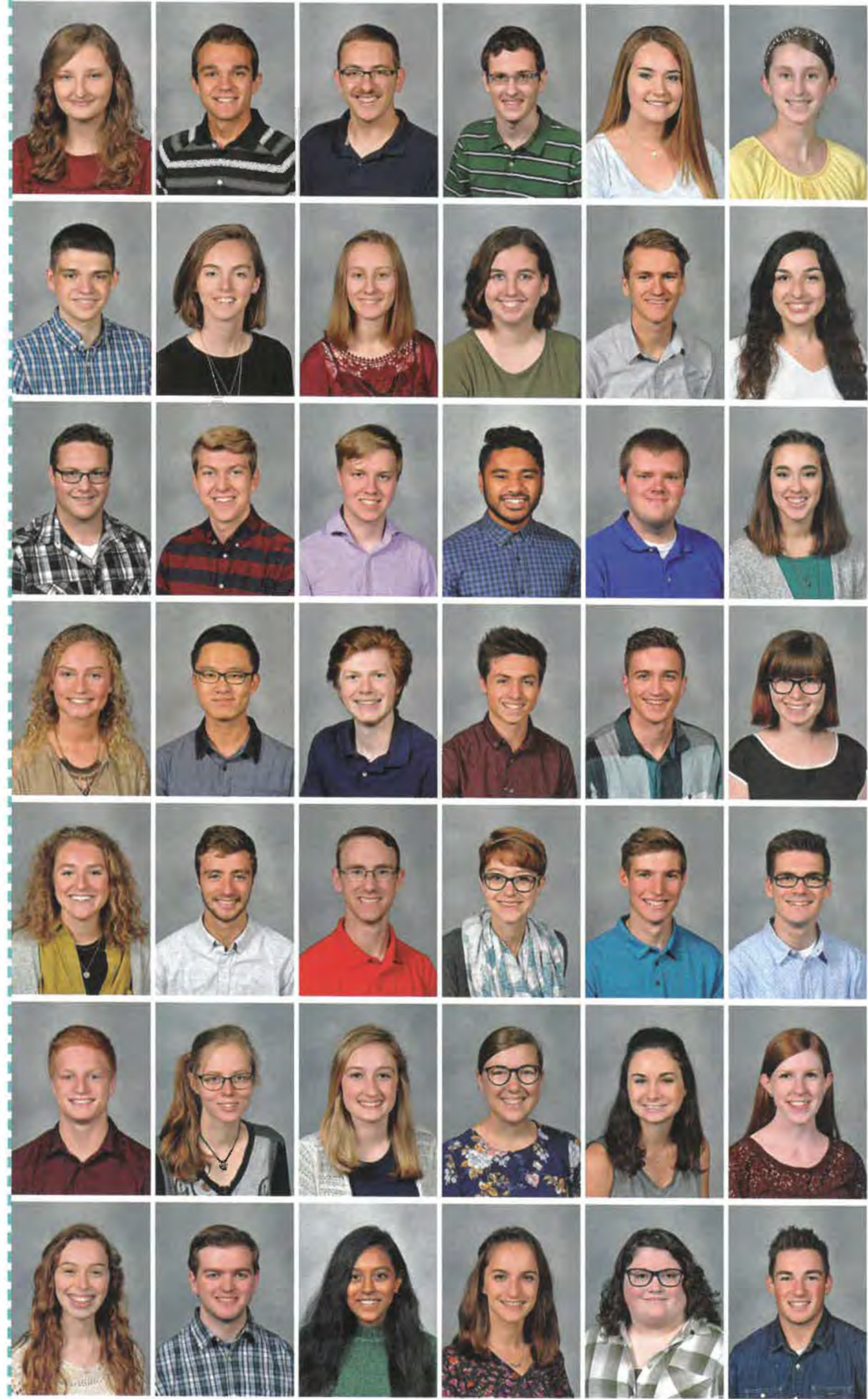

$$
\text { i }
$$$$
1
$$ 
Elizabeth Harmon

Heidi Harris

Robert Harris

Connor Hart

Noah Hatfield

Margaret Hayes

Haley Heeter

Hallie Heideman

Dalton Herron

Rachel Hershey

Joel Hess

Heather Hicks

Nicolas Hill Noah Hill

Josiah Hirschler Madlson Holsey

Andrew Holsinger Gabriel Holsinger

Avery Hopkins Morgan Hopkins

Shayalay Horn

Kaylee Howell

Lily Hoyt

Trent Huelskamp

Cheyenne Jarvis

Abigail Jenks

Ethan Jepma

Carrie Jespersen

Binyang Jiang

Jebediah Johnson

Micah Johnson

Nathan Johnson

Jenna Johnston

Marquise Jones

James Jordan
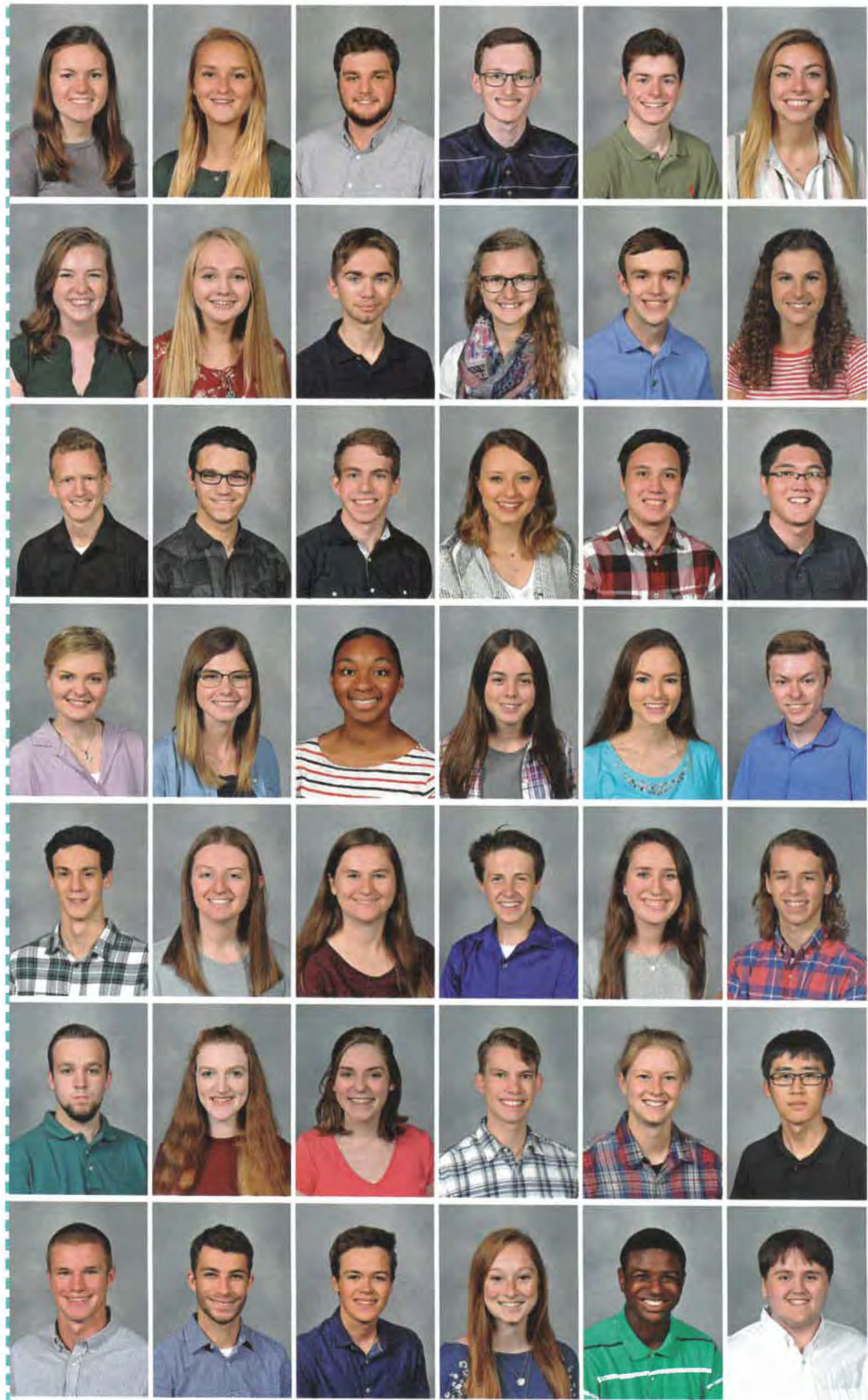


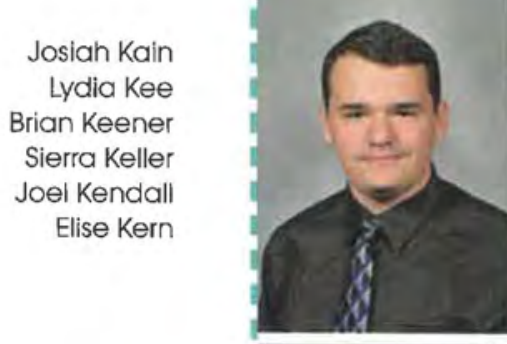

Alexander Kidd

Kevin Kijak

Celeste Kimmel

Hannah Kitchen

Elianna Kniegge

Kenneth Knight

Madalyn Knowles Nicolas Knowiton Timothy Kohl

Katherine Korwan

Brent Krisovitch

Sarah Kroger

Mary Kronk

Valerie Kuczynsk

Katherine Kuzma

Bethany Laird

Summer Lange

Daniel Lantz

Jenna Lawless

Breanna Lawrence

Allanna Ledford

Nathan Lee

Hannah Lehman

Courtney Leszczynski

Karissa Lewis

Yuan Liang

Grace Lockwood

Amanda Loger

Tyler Lollis

MacKenzie Lord

raylen Luke

Andrew Lund

Yimiao Luo

Timothy Lyall

Kiara Lyford

Jason Magnuson
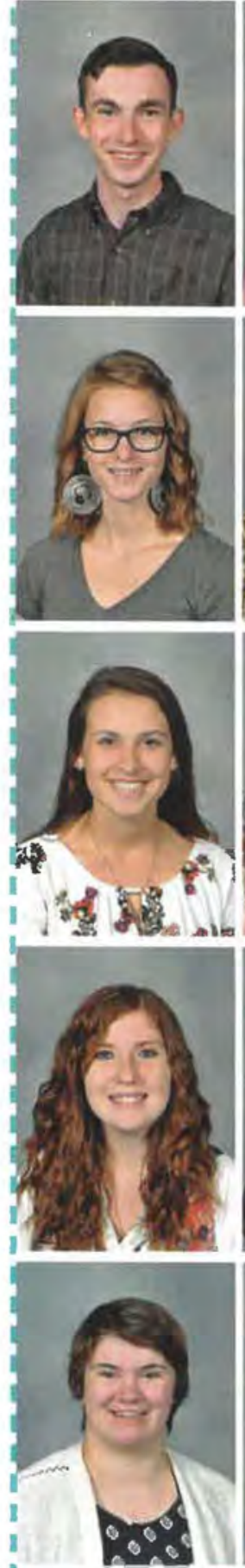
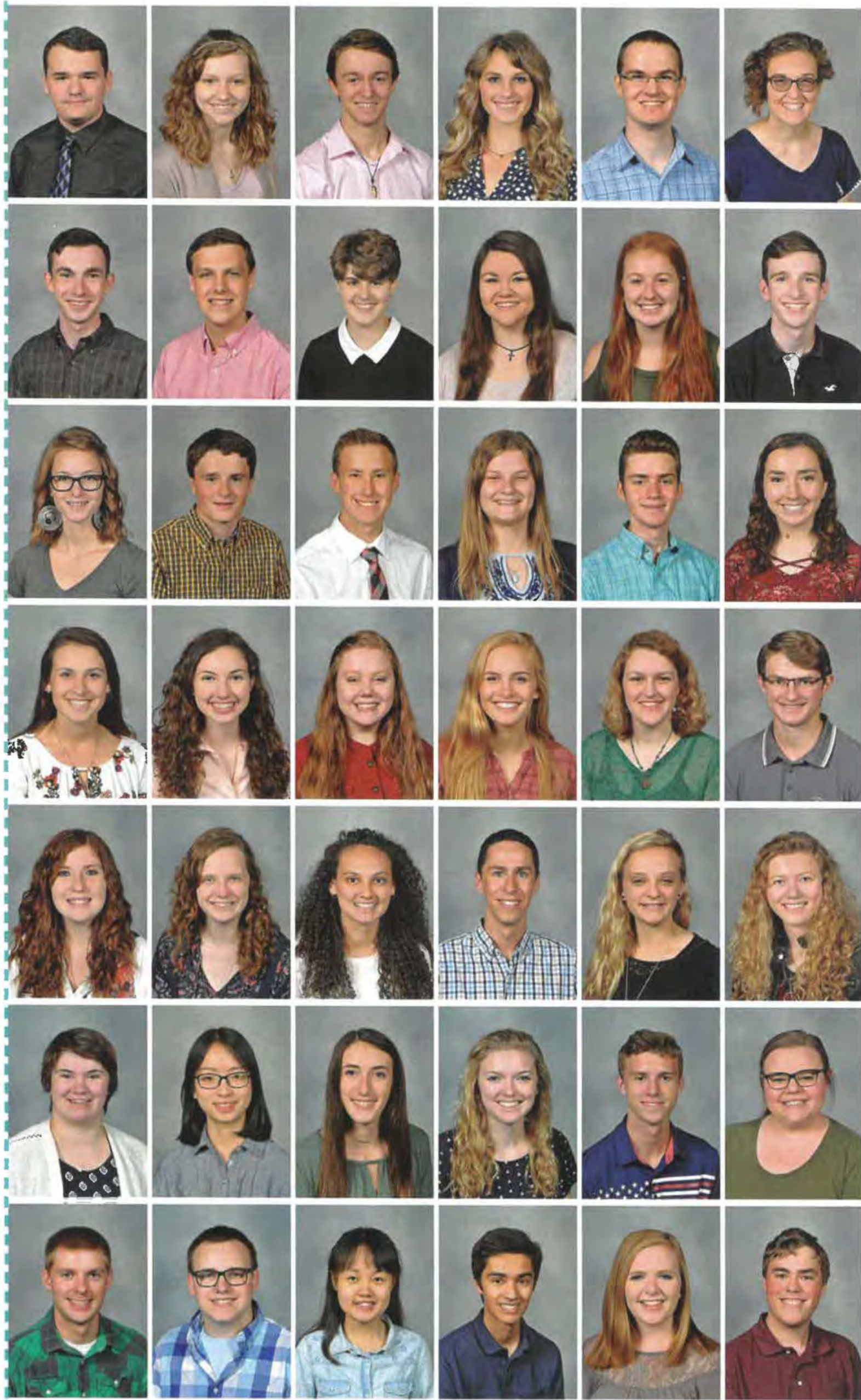
Atticus Mahaffey

Kristen Mantek

Rayna Markle

Katherine Marks

Isaiah Martin

Aleah Martone

Adam Marvin

Daniel Mason

David Mate

Rufus Mathew

Makayla Matthews

Sarah Maue

Allison May

Madison Maynard

Elizabeth McClain

Dominic McClung

Matthew McCormick-

Nerlinger

Alexander McDole

Katelyn McGinnis Nathan McGuffey

Katherynn McKay

Jana Merkel

Justin Merrick

Griffin Messer

Micah Metcalf

Caleb Miller

Joshua Miller

Sarah Miller

Matthew Miskimen

Sarah Mobed

Michael Moldenhauer Jana Molinar

Rachel Moore

Brooklyn Morrison

Tallon Mount

Joshua Mundell

Jesse Musgrave Madison Naugle

Laura Neer

Luke Neikirk

Abigail Nelson

Natalie Nemni
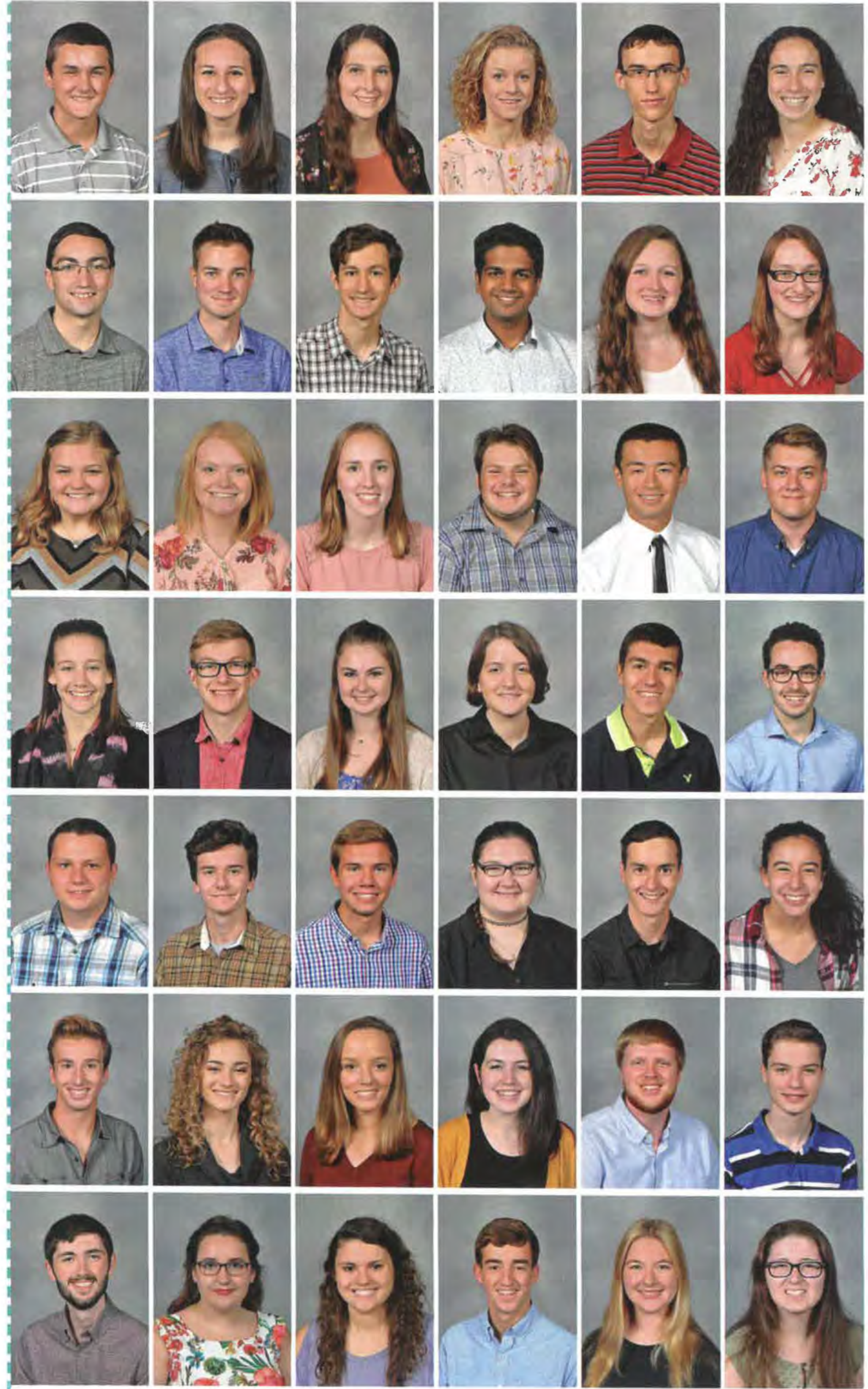
Elizabeth Nevarez Benjamin Nevels Joshua Nevin Nguyen Nguyen Hannah Nichols Hannah Nohrer

Danielle Norman Torrie Norman Jillian Norris Andrew Nussbaumer Lucas O'Brien Madeline O'Brien

Erica Oakley Alicia Ochoa Jillian Ogden Ozichukwu Ojukwu Joyce Otakasongo Nikolas Otto

John Parker Nicole Parsons Julianne Pataky Jillian Patrick Rebekah Patterson Amar Payton

lan Pessoa Katriona Peterson Mark Petrin Kailynn Pike Autumn Pisarsky Nicklis Pitman

Amy Plank Dawson Poling Daniel Posecznick Kasey Pot Jennifer Powell Mia Printz

Hannah Quandt Rebekah Quinter Deborah Raczykowski Luciano Raffa Nathan Reinhard Catherine Riley
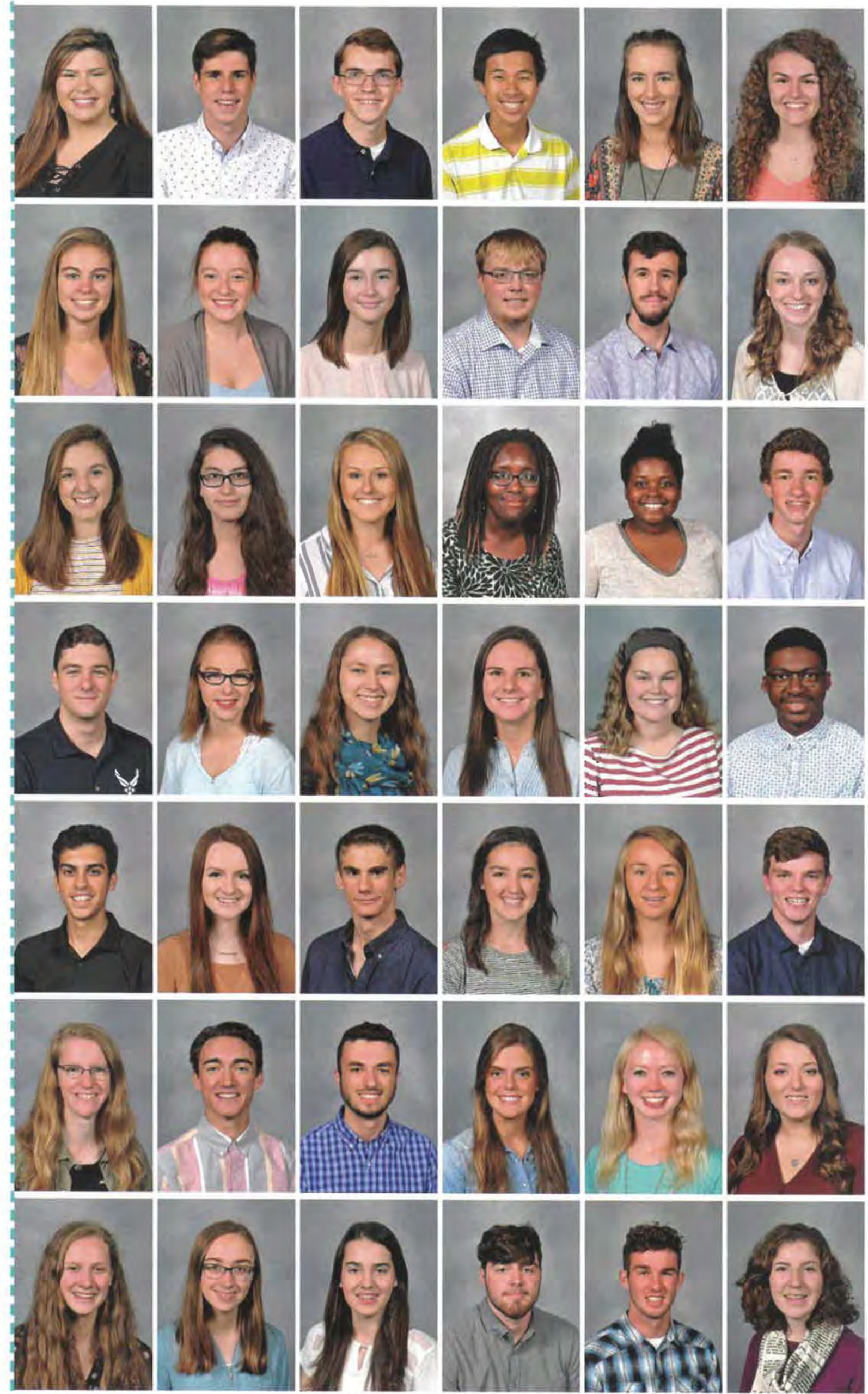
Rachel Ring

Samantha Rivera

Jared Robey

Logan Rockich

Kamen Rogers

Cameron Roseman

Madison Rosenbalm Caroline Roth

Trey Roudebush

Abbey Salomon

Maria Salow

Chad Sanderson

Danielle Sareno Lauren Schaefer Justin Schlabach

Russell Schultz

Michelle Schuman Kimberly Schwelbold

Sarah Schweppe Joel Scott

Blake Senseman

Steven Shade

Malaya Shepard

Travis Shinabery

Victoria Slefert

Kristina Sinkonis Joseph Skidmore

Sarah Slater

Taylor Smart

Benjamin Smid

Andrew Smith

Cassidy Smith

Josian Smith

Rebekah Smith

Sophia Snow

Timothy Solokha

Kristin Solomon

Isaac Sparks

Reed Spencer

Chase Springmeyer

Lane Stanford

Jonathan Stanhope
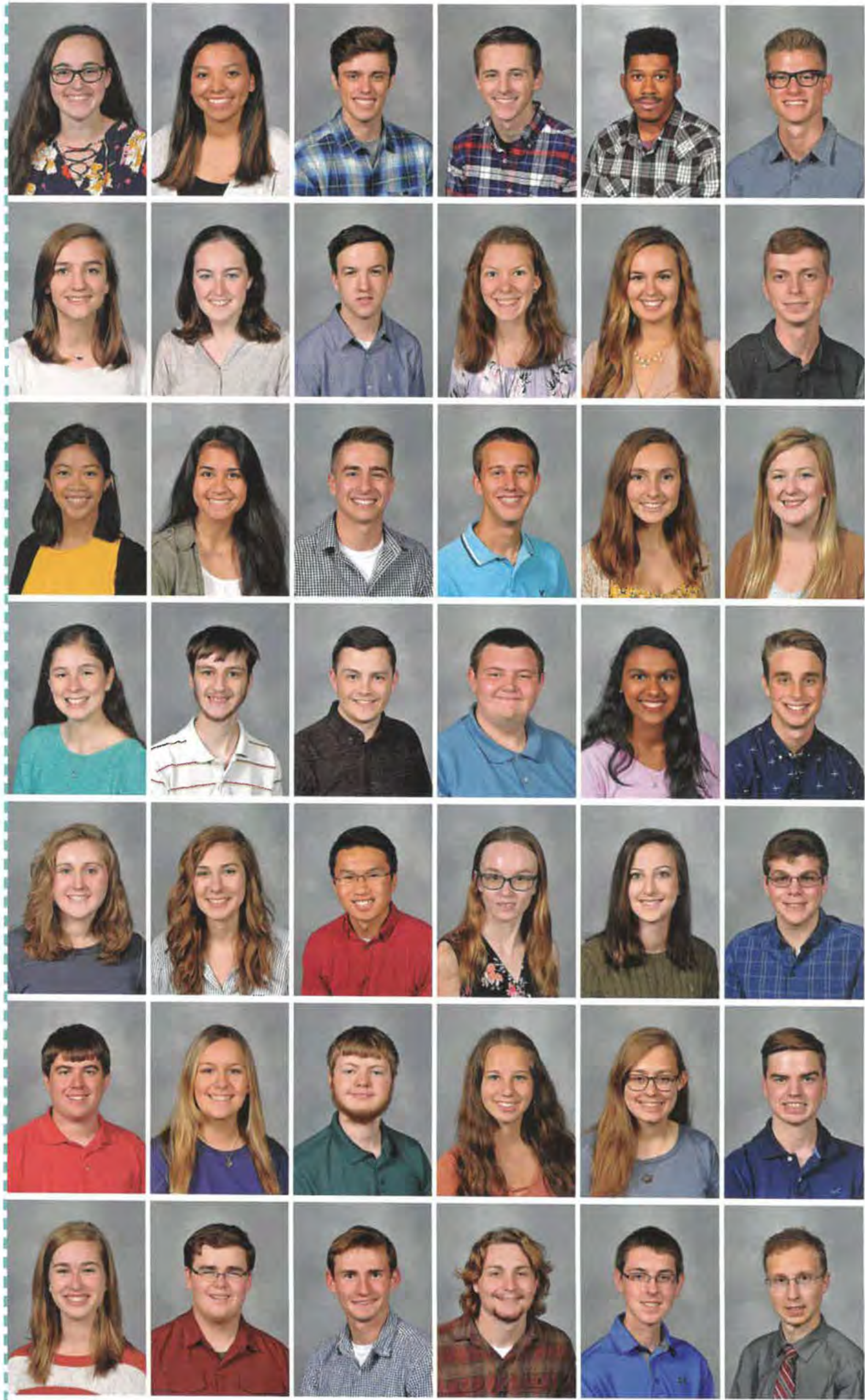
Zoe Stelgerwald

Grace Stevenson

Morgan Stewart

Noah Stimpson

Ethan Stoneberg

Hannah Stuercke

John Sullivan

Emmel Summy

Jonathan Sutherland

Steven Sweeney

Abigail Swieringa

Lydia Switzer

Elizabeth Tan

Claire Terhaar

Gabriel Thomas

Samuel Thompson

Austin Thorsen

Max Thullen

Anna Tomic

Caleb Toth

Rachel Tracy

Rachel Turner

Brooke Twitchel

Craig Van Demark

Alex Van Dromme

Gerrit Van Dyne

Joshua Van Patten

Emma Van Veldhuizen

Caleb Vance

Alyssa Vandegrift

Brianna Verhey

Elise VerSchneide

Keerthi Vethanayagam

Macy Wade

Joshua Wagner

Bethany Wagner

Joseph Wagoner

Emily Walker

Leslle Wallace

Michael Waliace

Jenna Wallenbeck

Elizabeth Walter
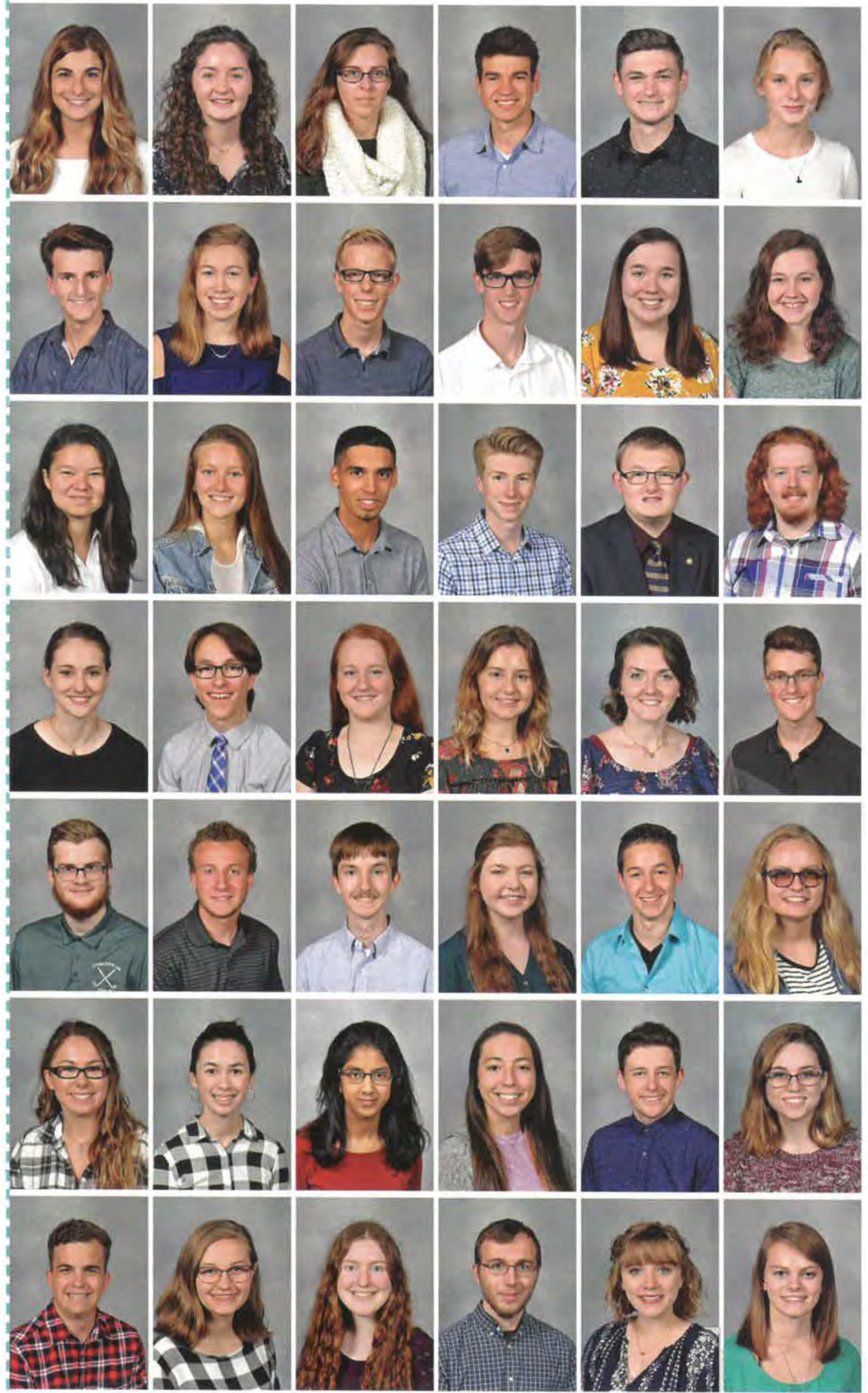
Nicholas Ward Samuel Watkins

Carl Weaver

Liana Webb

Kelly Weeks

Hudson Wellin

Daniel Wells

Mariah Weston

Kaylynn Whittaker

Drew Williams

Ethan Wilson

Chi Hang Wong

Moriah Woodall

Macey Wymer

Joshua Yee

Annalynn Yerkey

Jeffrey Yoder

Sarah Zahoransky

Micah Zell

Faith Ziamba

Emily Zichi

Allison Zieg

Katelyn Zook
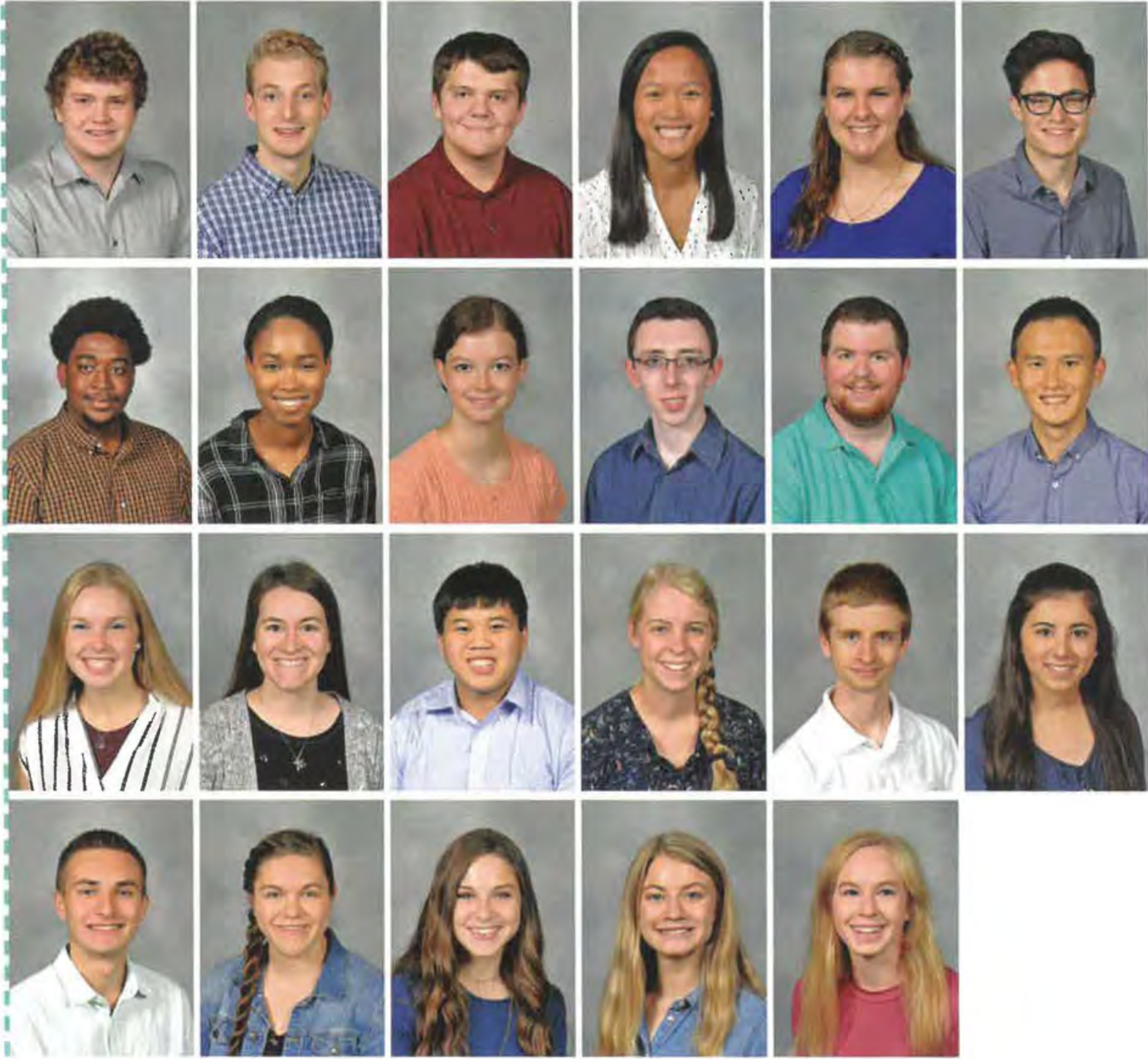


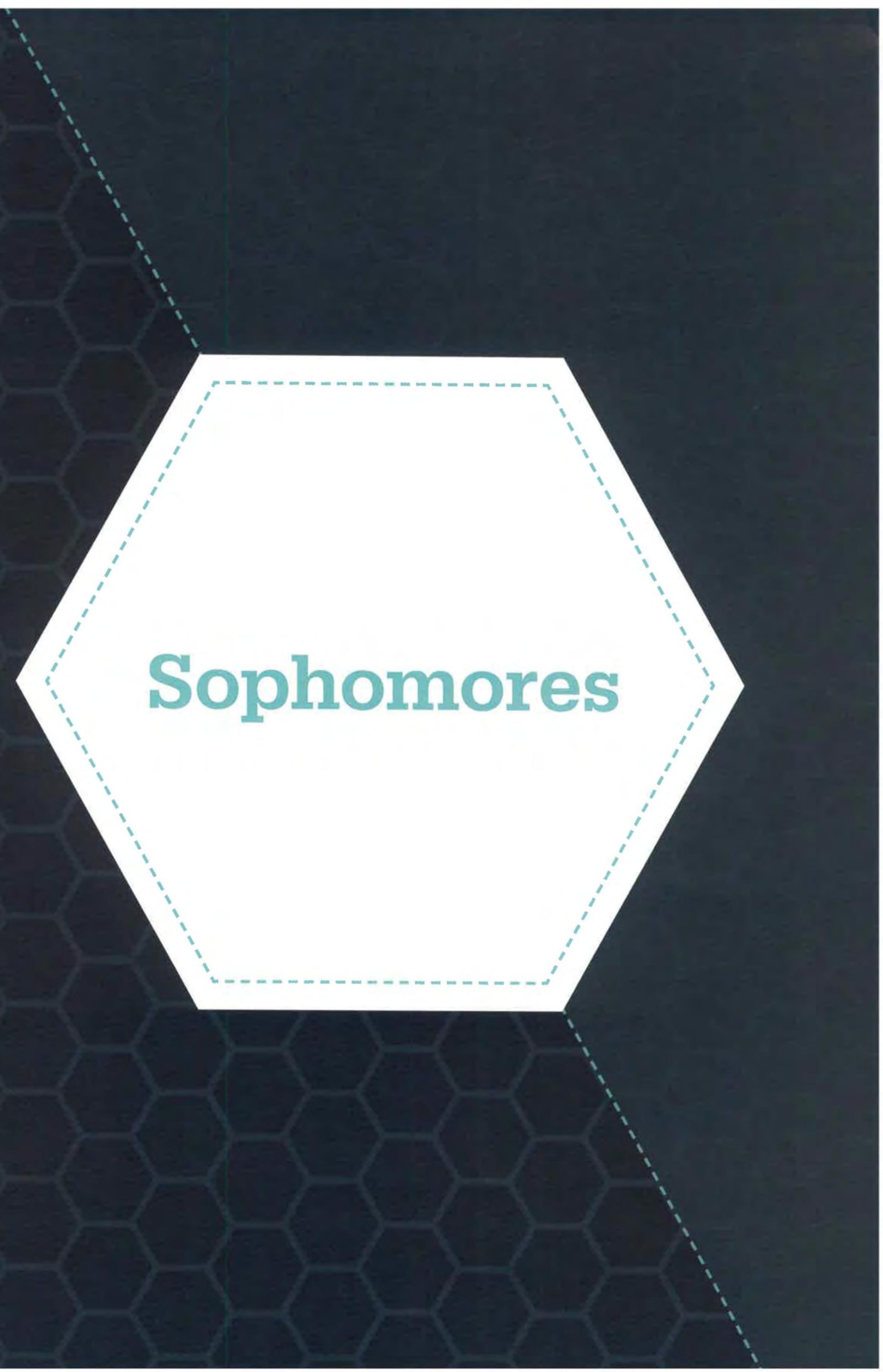


Emily Aaserud Johnathon Adelhardt Katelynn Allwood Thomas Ansiel Zachary Ashley Emily Aubrey

Jonah Bahorik Aaron Bapst Lorin Barnes McKaylalynn Bauer Samuel Bautista Sarah Bean

Jillian Black Hannah Board Noah Board Teagen Bolin Chloe Boucher Megan Boyle

Tyler Brenner Kyle Brewer Emily Brubaker Eleanora Burrows Zachariah Byrum Magalie Chapman

Landon Cina Maggie Colson Jackson Crisi Owen Cummins Deborah Curran Wesley Darst

Noah Davis Nathaniel DeRochie Dylan Dixon Noah Duncan Benjamin Dunning Jolie Elzahaby

Madison Ensign Isaiah Erway Hannah Fellenbaum David Fenneran Emily Fitts Emma Foster
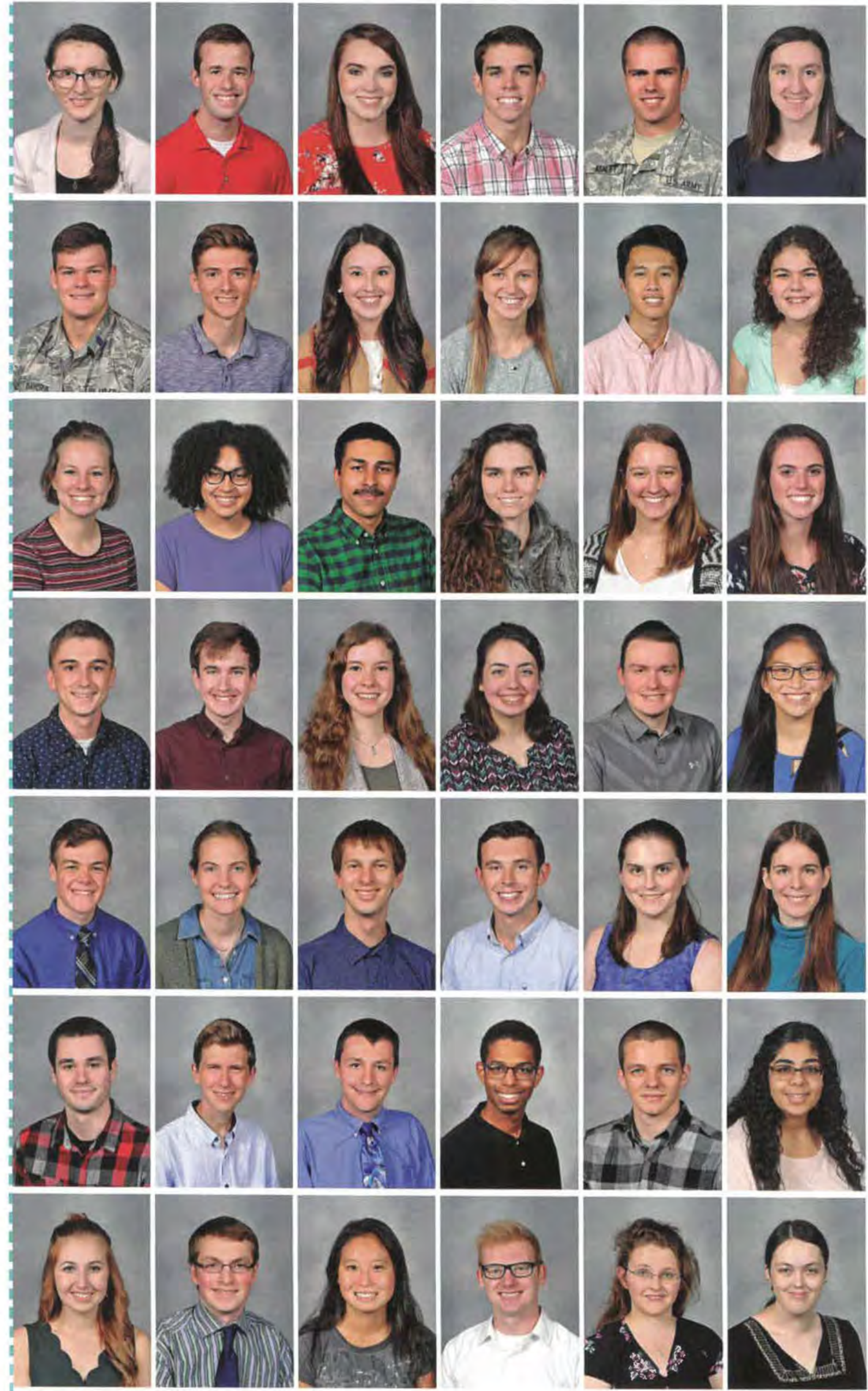
Haley Foster

Katherine Fry

Joelle Gallardo

Philip Gebauer

Alex Gessner

Emily Gifford

Ashley Gosman

Jonathon Grunenwald

Alexis Hall

Andrew Halverson

Ethan Hand

Mark Handel

Wright Harvey

Nicholas Heist

Brevin Henninger

Michael Hess

Madeline Hurst

Rachel Ingram

Alex Istrate

Daniel Jagod

Shamin Jegan

Yein Jo

Hunter Johnson

Jeremy Johnson

Kyrie Eleyson Johnston Kendall Jones

Sadie Kemp

Ye Eun Kim

Anna King

Colin King

Ryan Klimek

Kaylie Klotzbach

Nathanael Knowlton

Zachary Koehler

Janelle Kovacs

Eva Kramer

Emily Kuhn Kelsey Laing

Laura Lasich

Abigail Lebs

Lauren Lightbody

Katie Linville
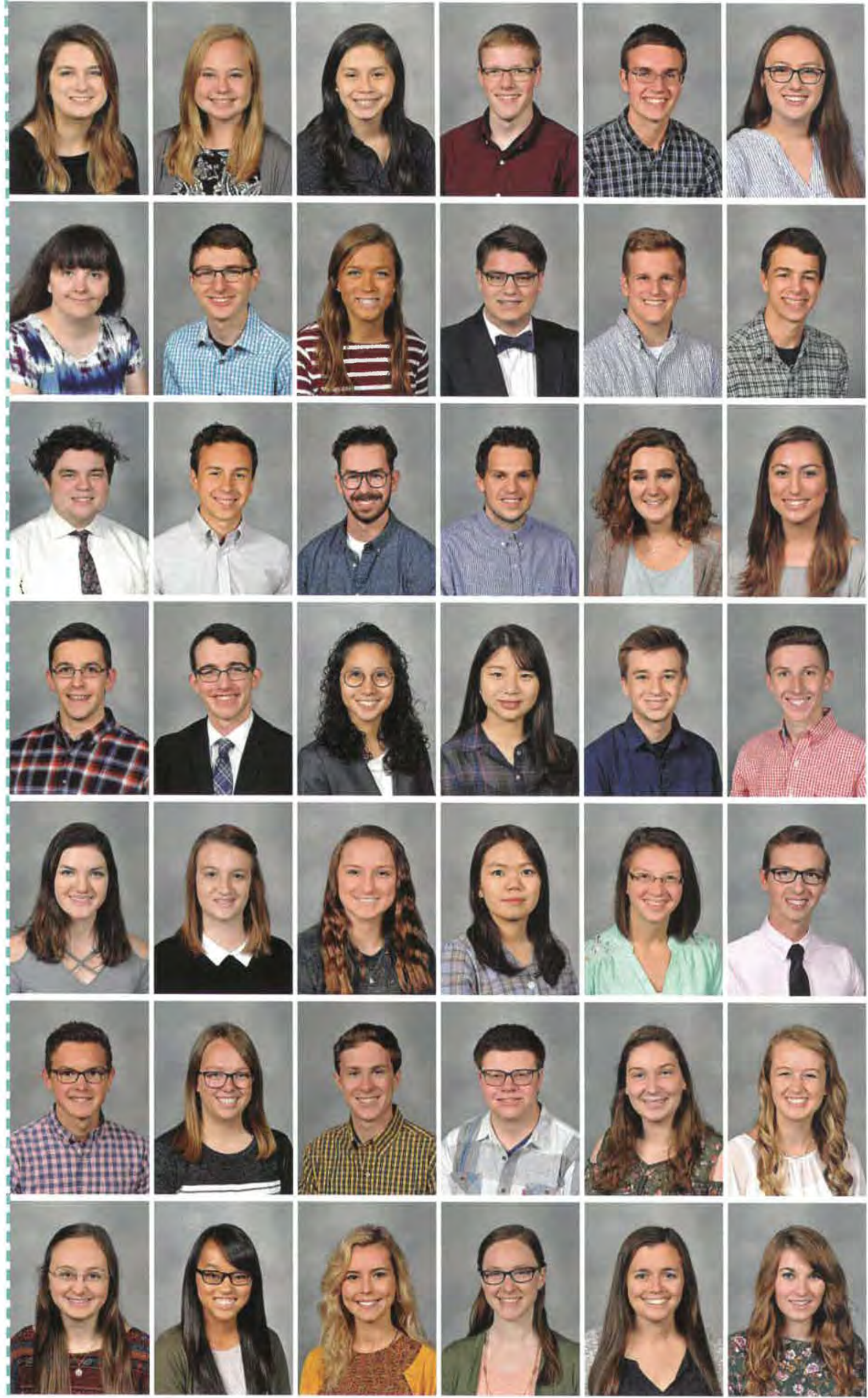
Nathan Litteral Daniel Lively

Trevor Loula

Thomas Lowry

Andrew Luiken

Emma Luman

Valeryia Malashevich Ethan Manley Noah Maurer Catherine McGill Micah McKanna Laura McKenna

Matthew McMahon Ahna Mellinger Stephen Mentzer Katelyn Miller Katie Milligan Kristina Mills

Gretchen Milstead Molly Moses Byron Mrowiec Juan Munoz William Naegeli Ariana Nelson

Meredith Nelson Madeline Neumann Rachel Newman Joshua Noel Maya Norris Richard Nyquist

Nathanael Olander Beth Oldham Brittney Oliver Samuel Osborne Alexandra Paris Shelby Parschauer

Jeremy Patricca Jason Paulus Kristina Petersen Monica Plank Breanna Potts Celine Przypek
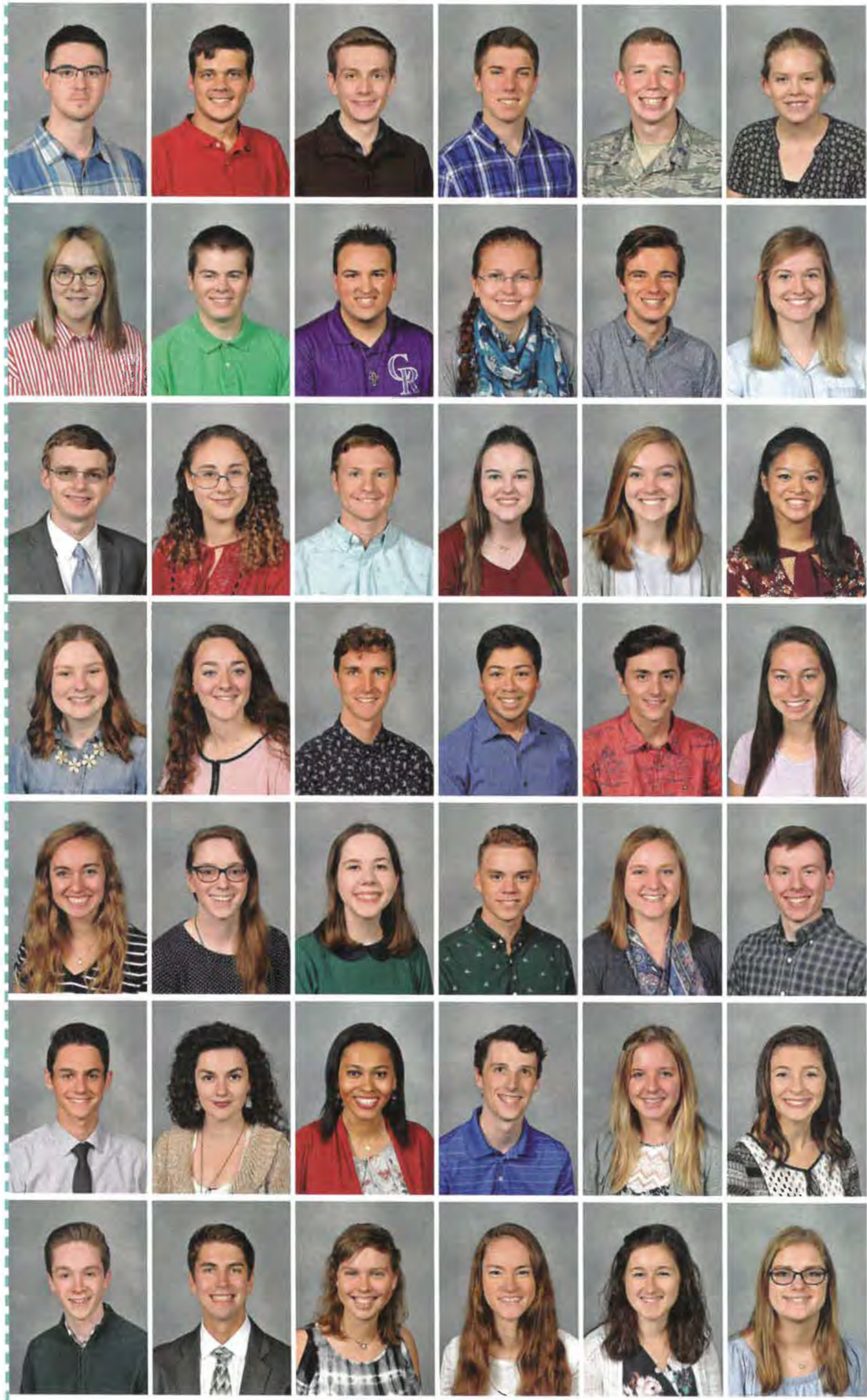
Lydia Quandt

Austin Ragan

Ryan Rager

Abby Reed

Benjamin Richmond

Ashley Riddle

Jake Ringstrand

Daniel Ripperger

Madison Roberts

Aaron Ross

Andrew Ross

Mary Ann Rouland

Anna Rowell

Carolyn Russo

Brianna Saucier

Julia Schantz

Jacob Schlichtmann

Emilie Schulze

Katara Scott

Kayla Seabra

Kyle Semmelroth

Abigail Shaffer

Hannah Shaffer

Rachel Shaffer

Caleb Shepherd Lauren Simmons

AnnaMarie Skoczen

Benjamin Smith

Kaitlyn Smith

Chloe Sodonis

Ian Steptoe

Ryan Stikeleather

Leah Swinford

Mya Taylor

Kyle Tillinghast

Hannah Timmons

Noah Timmons

Jonathan Tomlinson

Christopher Tsibouris

Katrina Tucker

Allison Turnbull
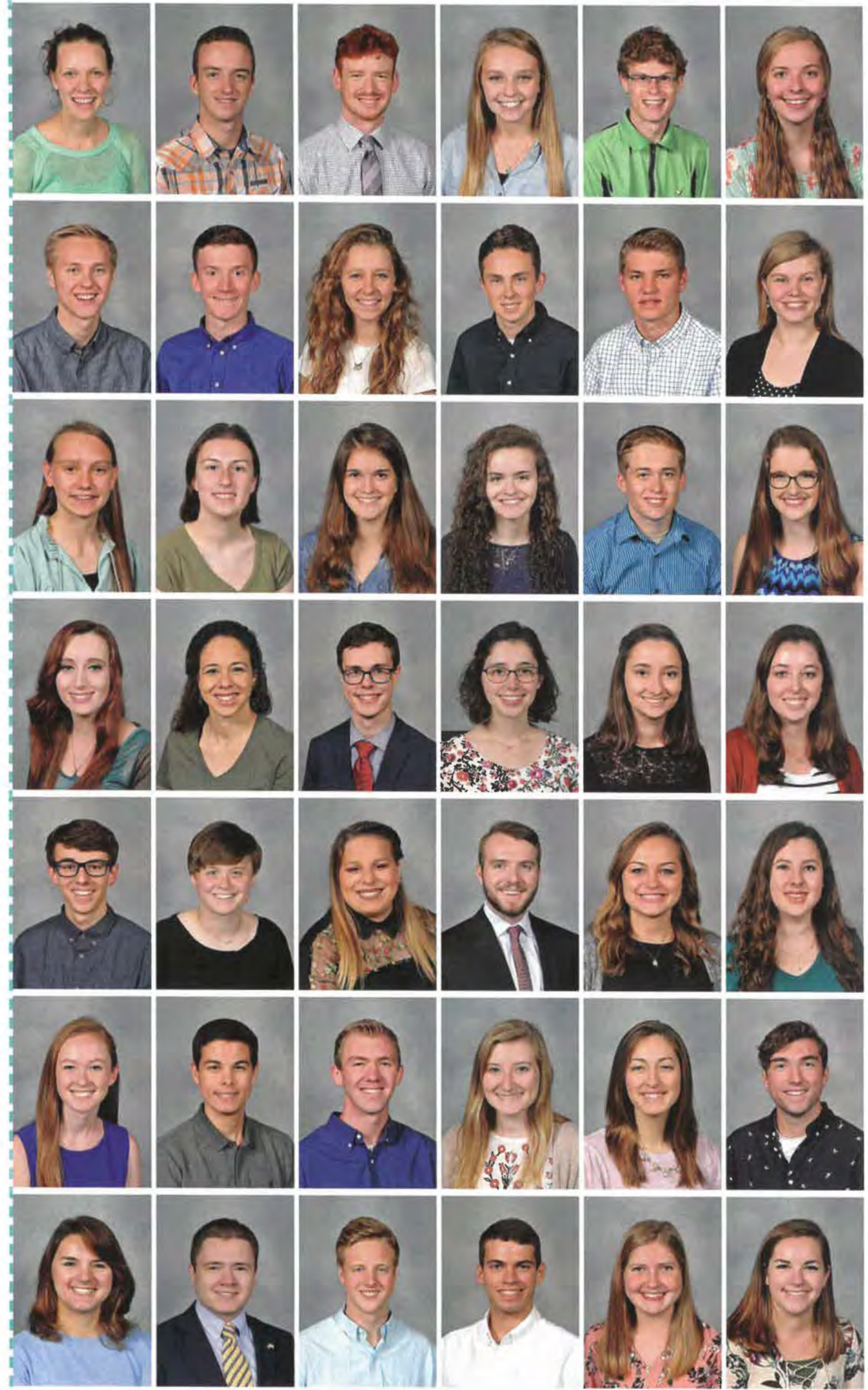
Daniel Urban

David Vance

Olivia Varga

Mikayla Veness

Alexzandrya Vissing

Caroline Wacome

Brienna Weigner

Aaron Weiss

Carina Welker

Jacob Wells

Noel Wilkins

Jack Williamson

Corrin Winsor

Katelyn Winter

Rachel Winters

Natasha Witt

Lydia Wolterman

Laura Woodman

Abigail Woolverton

Hannah Yannie

Timothy Zamora

Emma Zeilenga

Brynna Zellner

Xuecen Zhao
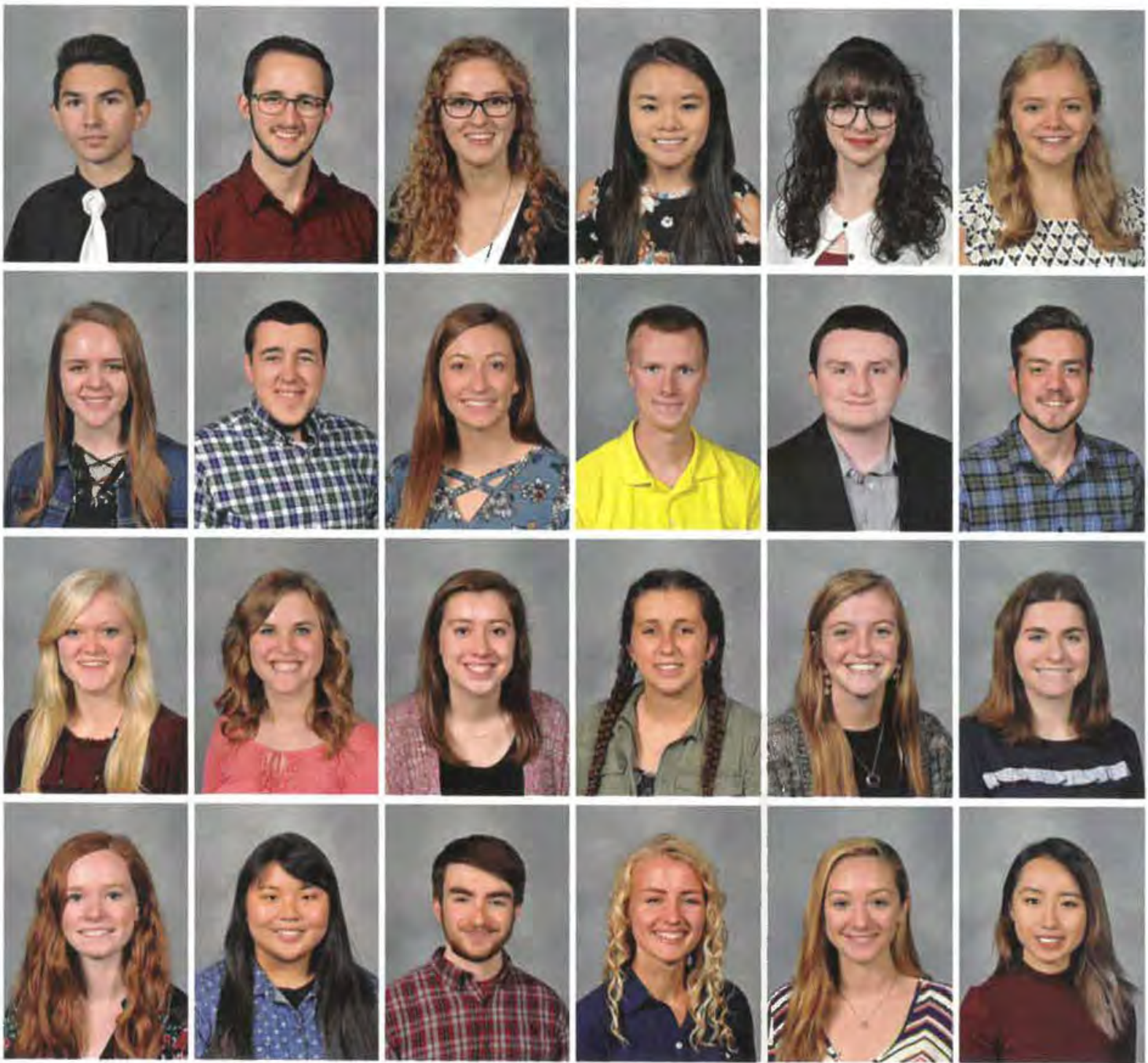


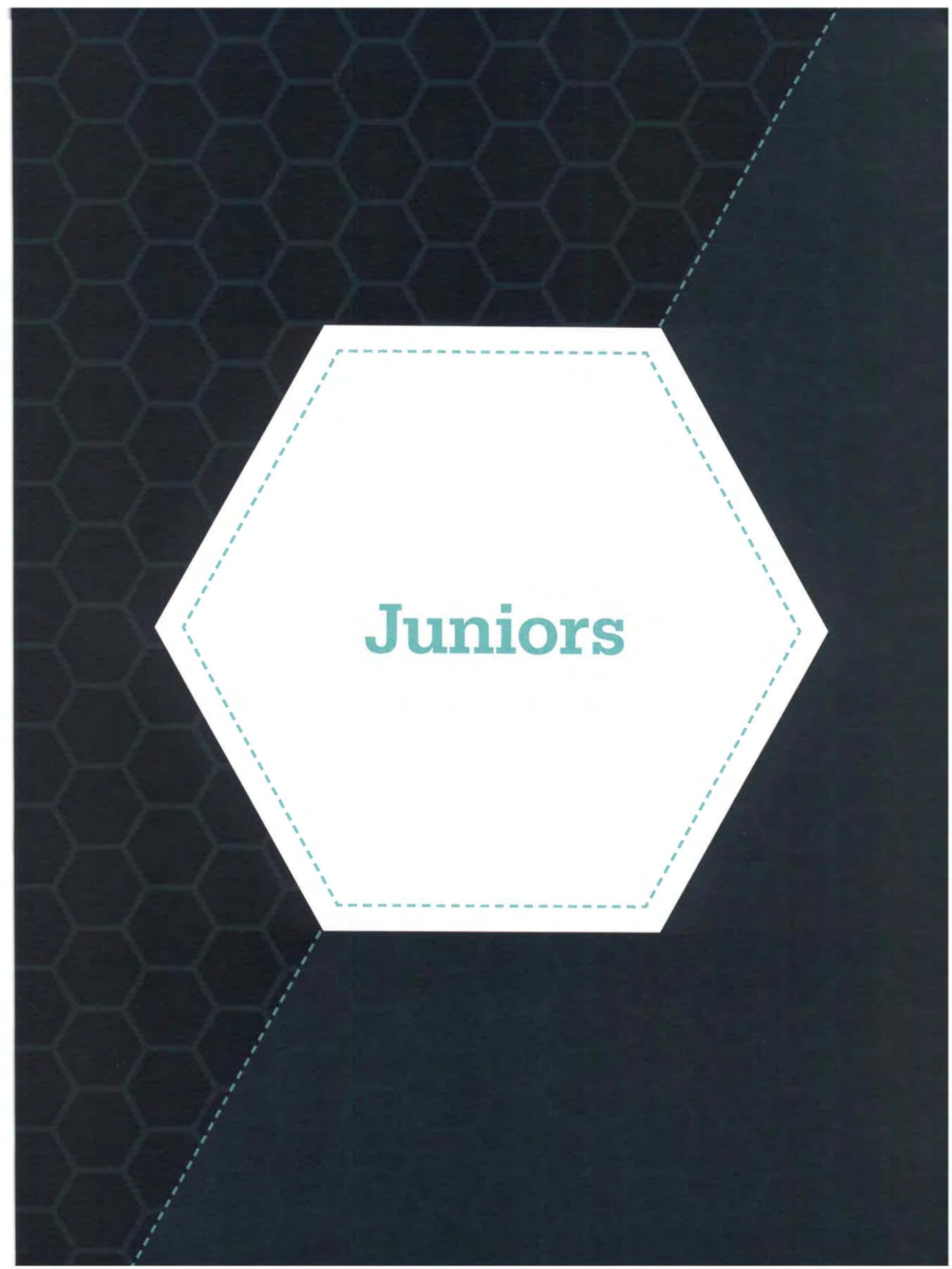




\section{Shelby Ahlborg Matthew Allen Isabelle Armstrong McKenna Armstrong Ryan Ball Kori Beal \\ Caroline Beckman Kylie Beste Jackson Bishop Cassandra Boyer Karina Brady Laurel Bryant}

Claire Burton

Holly Caldwell Grace Christiansen Jordan Clingenpeel Alyssa Cole Olivia Coon

Paul Coviello David Daugherty Benjamin Deeter Carissa Dobson Noelle Doman Ian Downey

Denise Dykema Victoria Ederer Abigail Edsell Elizabeth Ferris Hadley Flener Kaitlyn Flint

Tyler France Stephen Gaynier Melissa Gernert Nickolas Gerwig Kristopher Gibboney Breanna Hamilton

Jacqueline Hansen Sarah Harris Lanissa Hayes Brooke Hieronymus Meredith Hinks Rachel Hostetler
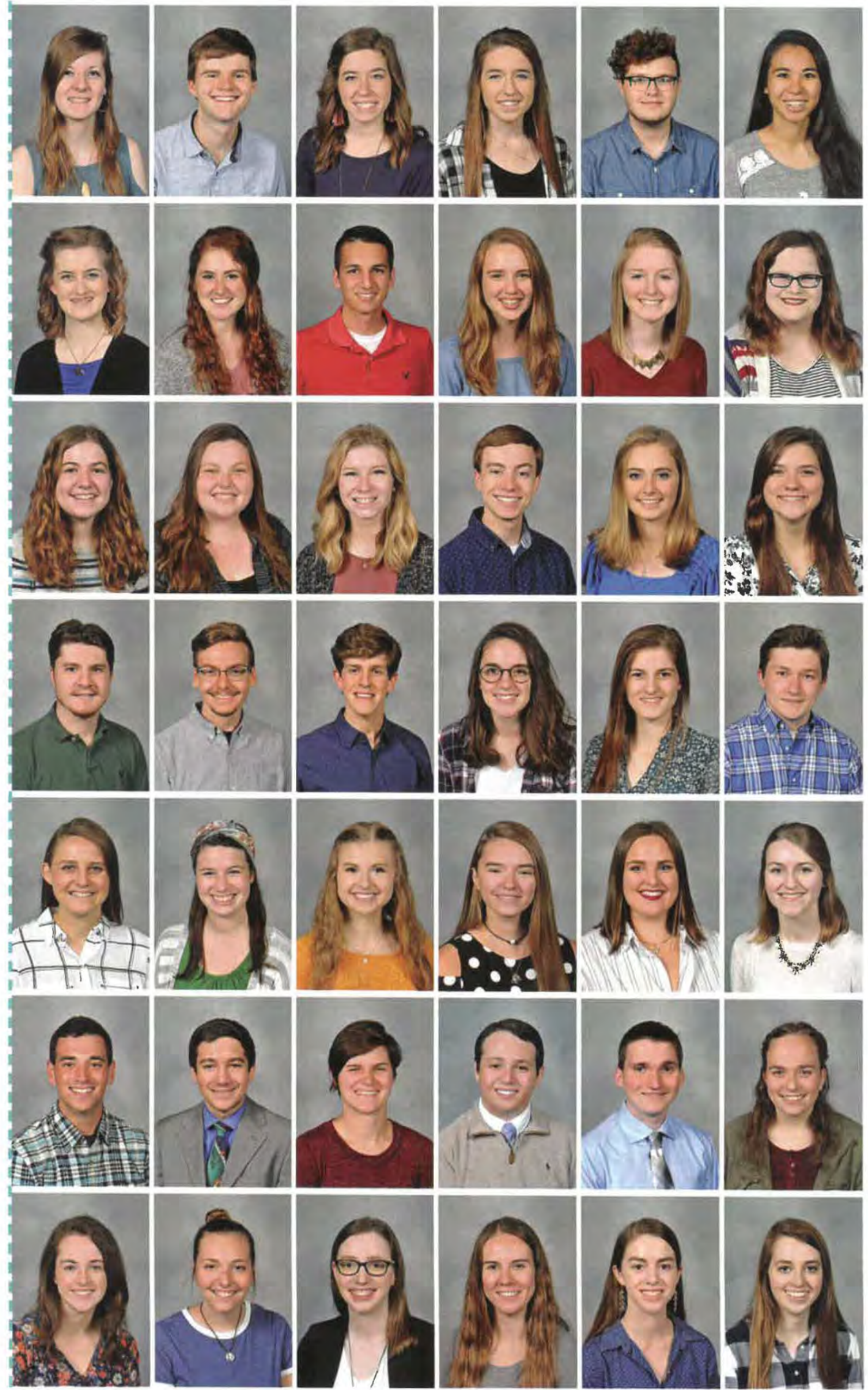
Jonathan Hudson

Elaina Hutton

Christopher Hyde

Audrey lllig

Sarah Imhoff

Lydia Jacobsen

Kaitlin Jarboe

Sarah Jennings

Kathleen Jones

Paul Kempton

Doris King

Mallory King

Abigail Krakora

Julie Krudop

Anna Kurschner

Josiah Lansford

Jacob Lashuay

Andrew Lemesurier

Grant Linville

Anna Luttenegger

Michael McCain

James McElroy

Alexandra McMurray

Halee McPherson

Macy Miller

Aricka Mitchell

Kelton Moore

Benjamin Moses

Jacob Mundell

Taylor Nunan

Logan O'Brien

Ethan Ooms

Caroline Painter

Kristy Parks

Sarah Pennington

Joel Pensworth

Donald Petron

Natalle Phillios

Caroline Phillips

William Plank

Kimberly Powell

Dillon Ragan
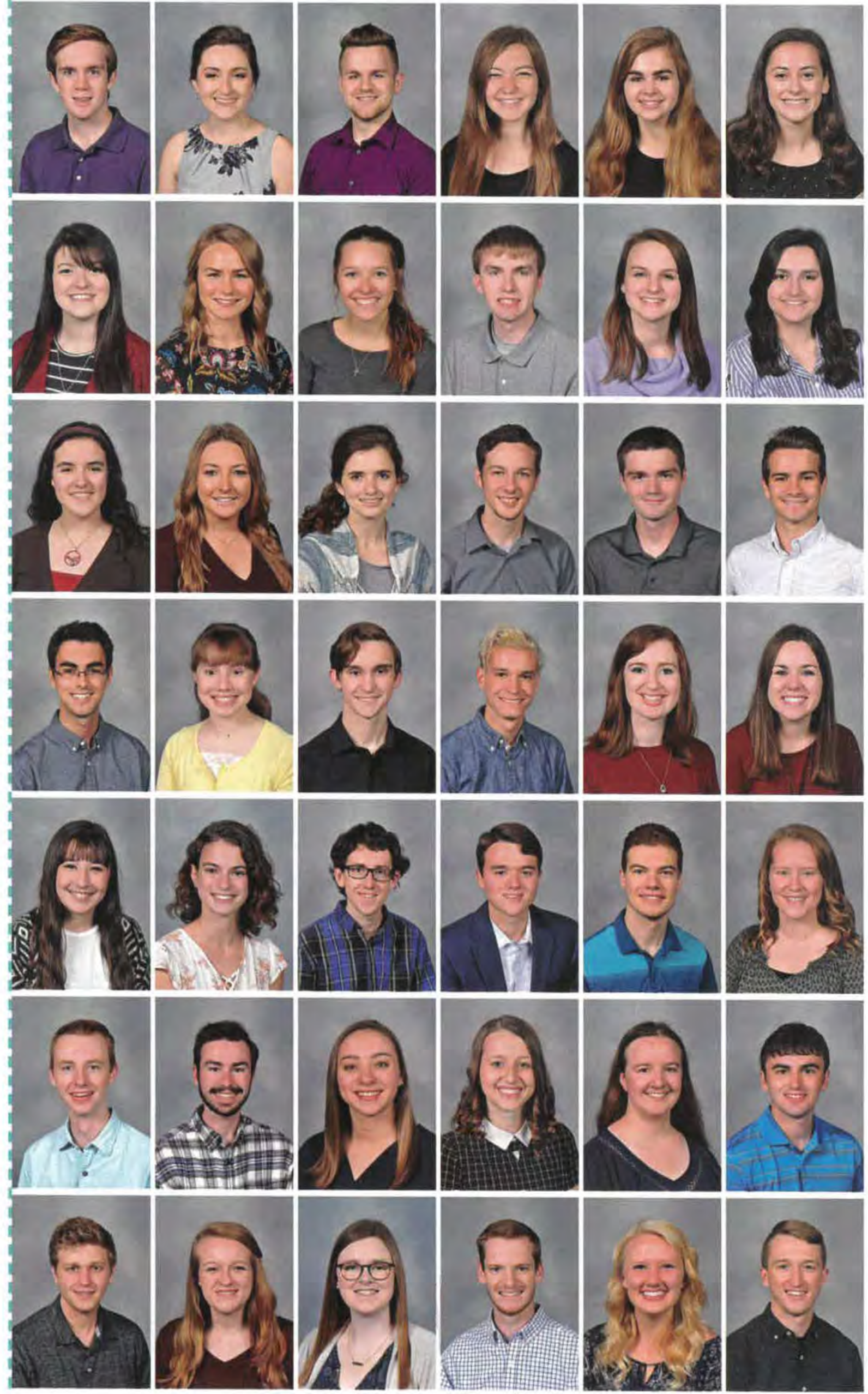
Carolyn Raquet Jacob Ratliff

Keyla Redondo

Trevin Rhoades

Abigail Rivas

Abigail Russell

Sarah Sanders

Amiel Shearer

Presley-Peyton Shemelia

Kelsey Shrum

Brandon Slifer

Haley Spurgeon

Alex St Onge

Natalie Steenwyk

Micah Switzer

Emily Talento

Rachel Terrell

Noah Townsend

Paul Trimble

Chloe Vann

Rebekah Wallace

Marcus Waterman

Max Weimer

Jessica Westenberg

Laura Wright

John Young

Delaney Yutzy

Hannah Zettlemoyer
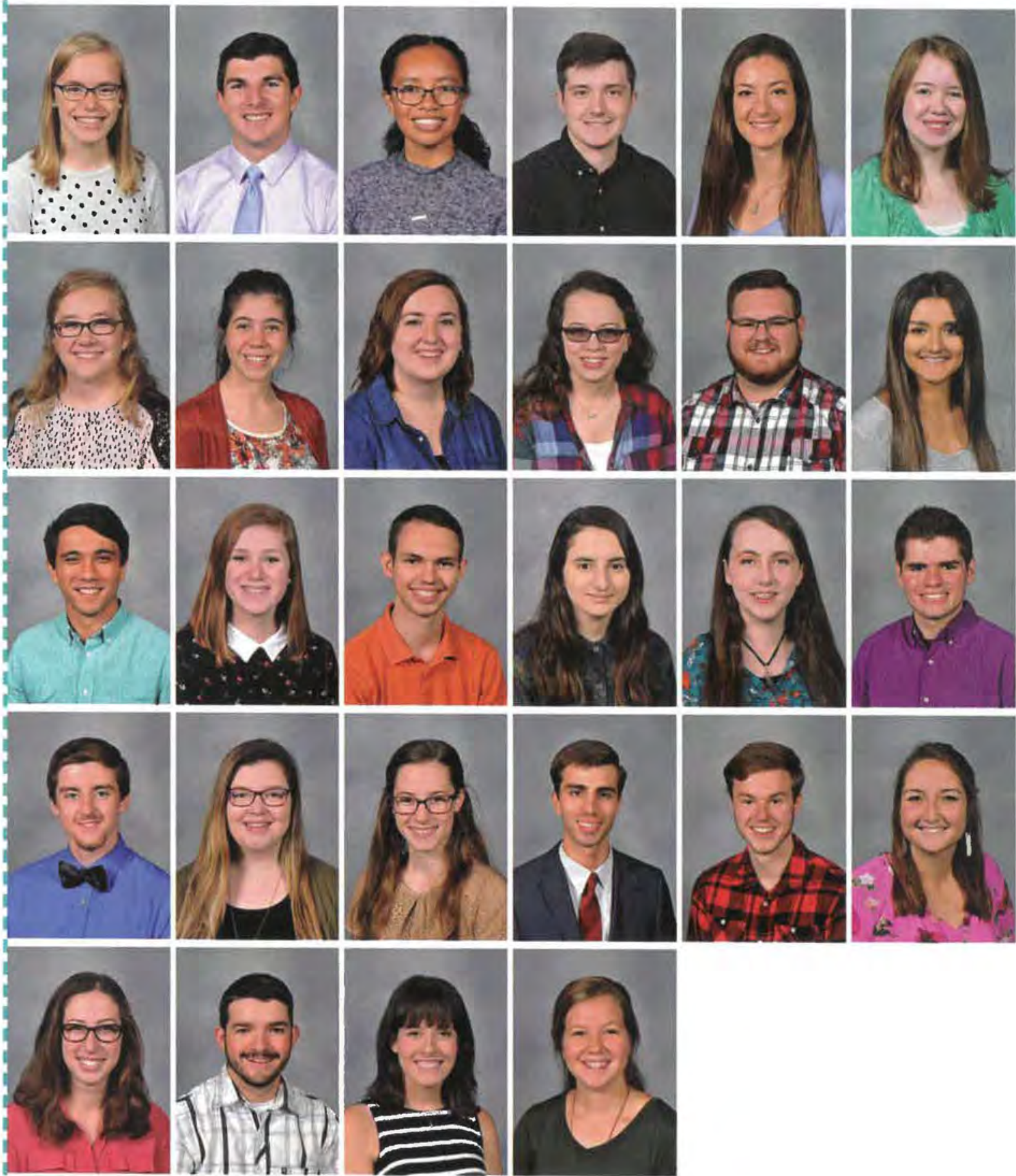


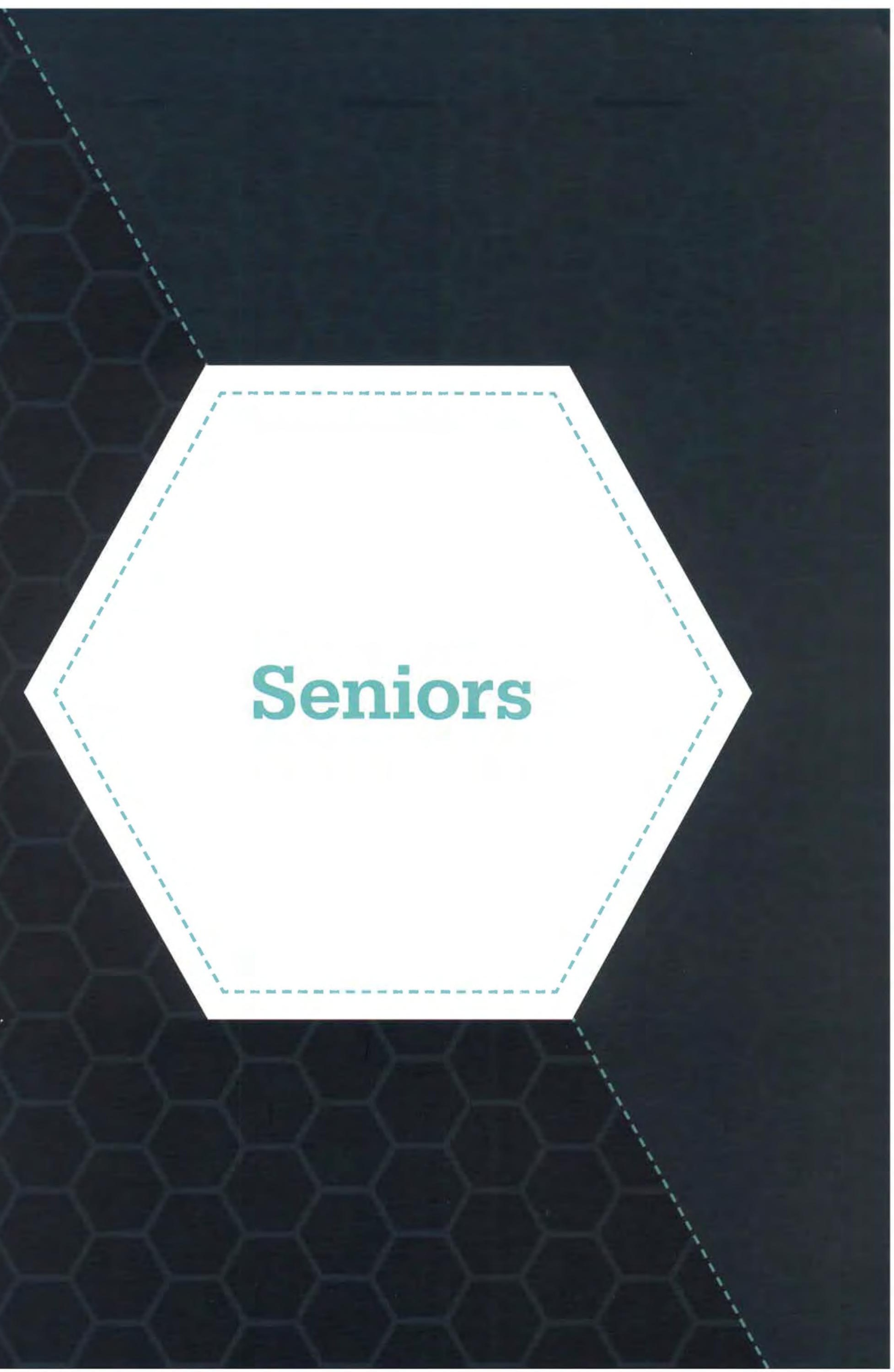


Benjamin Adam

Amy Adams

Emily Akins

Stony Akins

Nathaniel Albrecht

Rebecca Amacher

Olivia Ancil

Timothy Anderson

Abbey Andrews

Alexander Angus

Stephen Anson

Rebekah Athineos

Cara Atienza

Hanna Bahorik

Alexis Baird

Rachael Balentine

Andrew Ballentine

Amanda Barahona Maurer

Julia Barker

Trey Barnes

Janessa Bartlow Elizabeth Bassette

Rebekah Bayle

Alyssa Beals

Sidney Beckman

Alyssa Bergthold Jesse Berkstresser

Stephen Berrill

Charity Best

Brian Billman
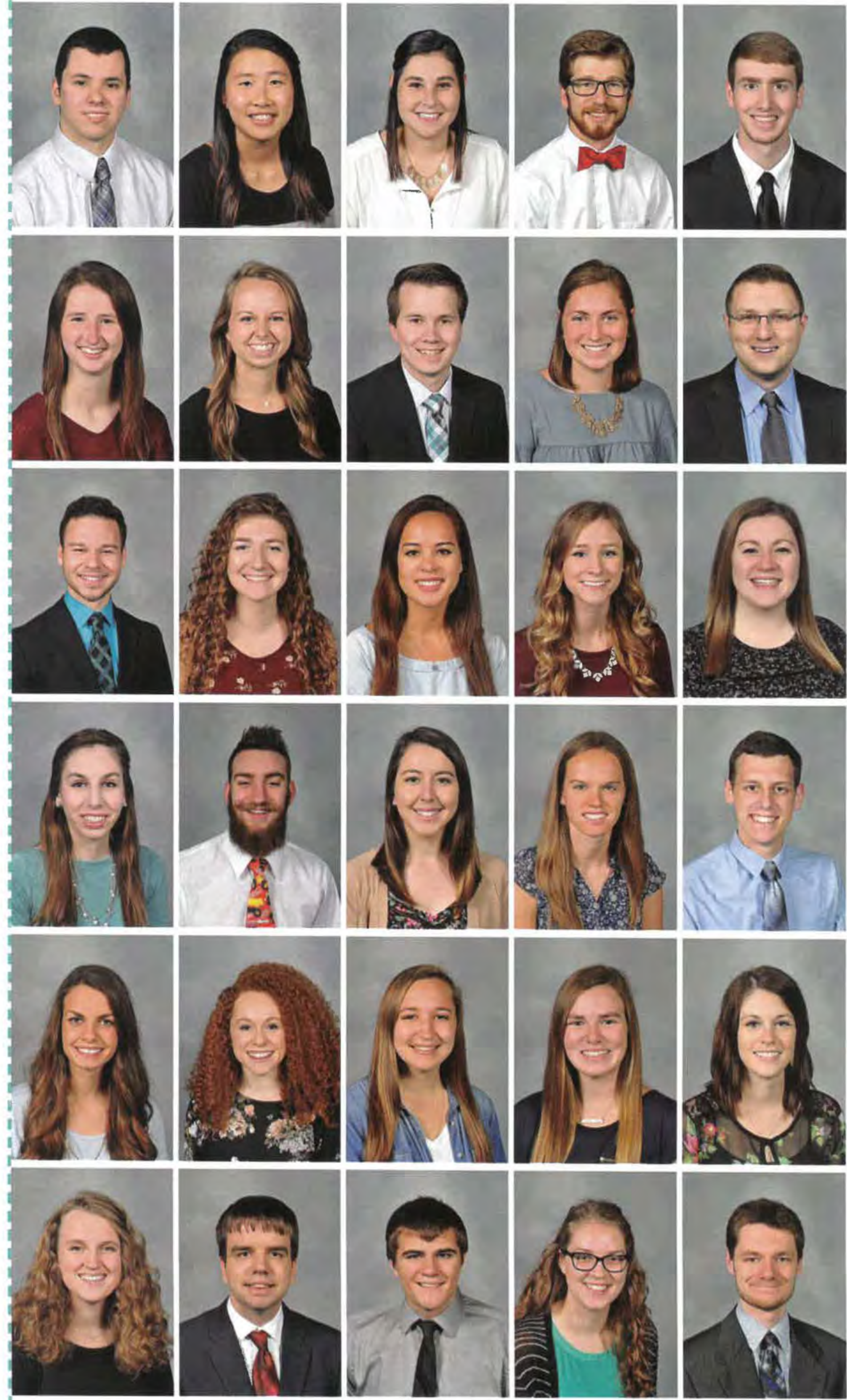
Zachary Bindus

Phillip Birt

Hunter Block

Hannah Boardman

Angela Bobe

Taylor Boeve

Julia Bonifield

Campbell Bortel

Benjamin Bowden

Tirane Bowersock

Christopher Brawley

Abigail Brighton

Stephanie Brimer

Emily Broadwick

Brittney Brown

Ryan Brown

Matthew Brumbaugh

Jonathan Burris

Kelsey Caldwell

Brian Campbell

Timothy Cannata

Aaron Cannon

Sean Carlson

Michaela Carpenter

Lindy Carr

Lindsey Carroll

Kayla Casaletto

Steven Chen

Hannah Clark

Chad Clark
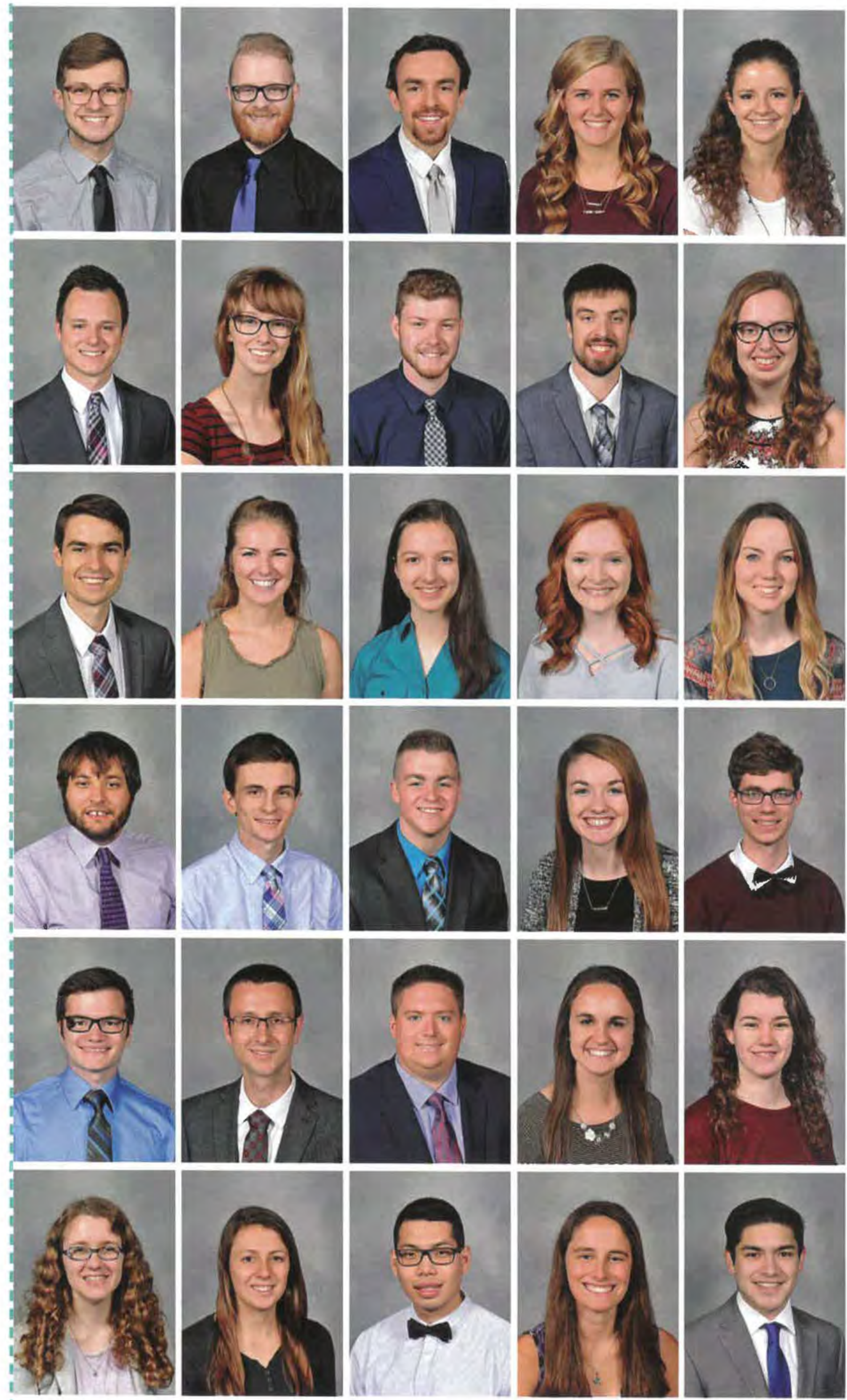
Mackenzi Clemens Catherine Clemons Abigail Cline Jachin Cline Joshua Close

Kristen Cochran Alyssa Cody Natalle Coiro Abigail Cole Olivia Cole

Michael Conner Kenneth Coppens Clara Costello John Costello Micaela Coughlin

Hannah Crane Megan Crawford Noah Cutting Keegan D'Alfonso Kirby Darst

Austin Davidson Emily DeCeglie Colin Dellaperute Tiffany Denen Victoria Denen

Mae Dewhurst Abigail DeWitt Jessica Dodds Gabrielle Drummer Jonathan DuBois
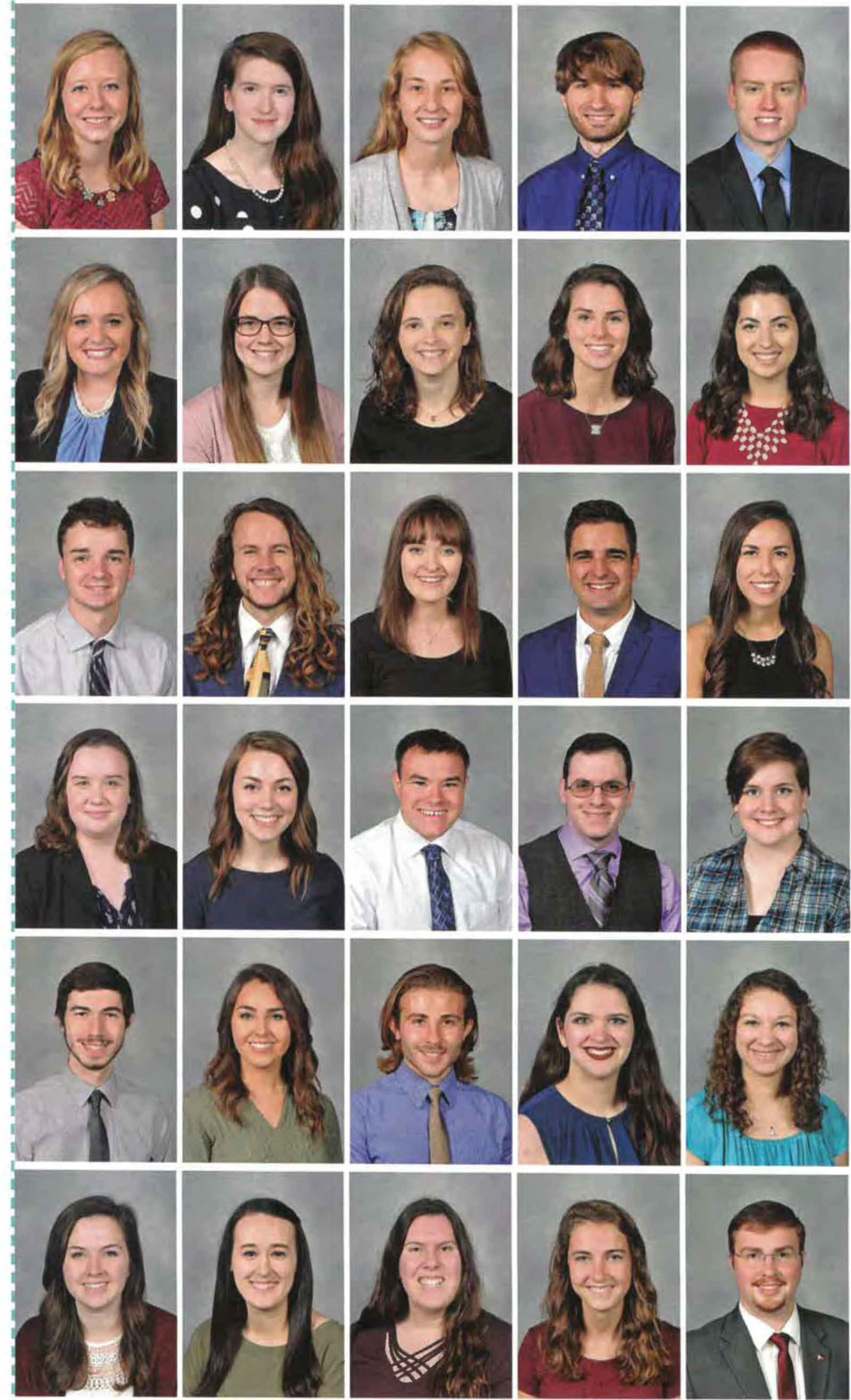
Michaela Duncan
Callie Dunn Danielle Dykema Miranda Dyson Cayla Eckley

Lauren Edmonson Susanna Edwards Vance Ehrlich Christopher Eldred Steven Elizee

Samuel Ellicott Dean English Emily Entner Courtney Eppard Troy Ericson

A J Ervin Kevin Fair Jordan Farley Masie Fedako Madeline Feiser

Hannah Ferris Arielle Feustel Katelyn Fisher Leah Fisher Rachel Fletcher

Grace Flint

Alexis Ford Andrew Foster Jordan Fredericks Rachel Furman
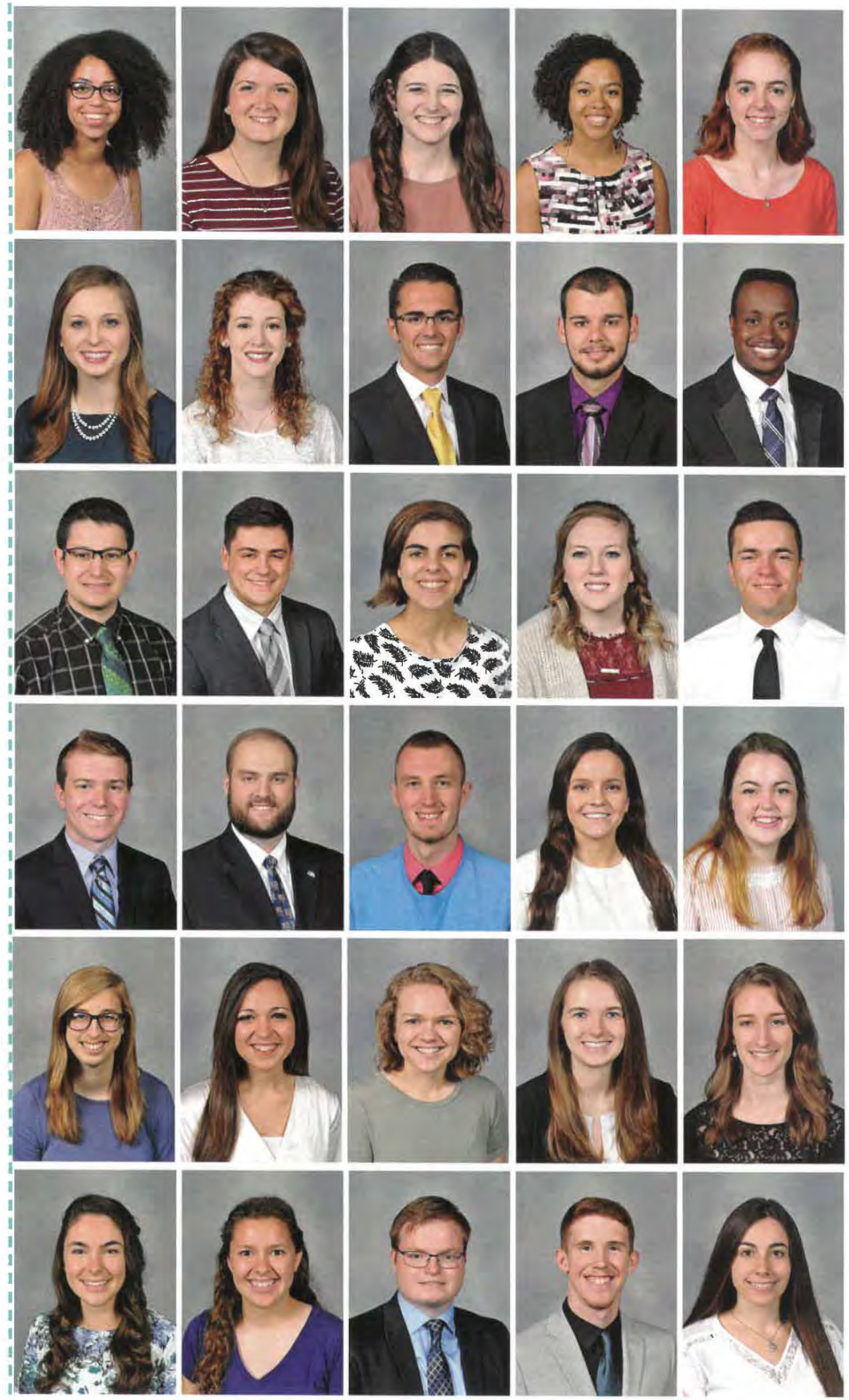
Tristan Galyon

Adam Gardne

Ethan Gatchel

Jonathan Gaunt

Shannon Gebauer

Brennon Gee

Marisa George

Emily Goodwin

Ryan Gordon

Spencer Graffunder

Scott Grimes

Samantha Gross

Chase Gruet

Jared Haas

Pius Halder

Autumn Hankins

Megan Hanley

Abigail Hannay

Eric Hannon

Alan Hardee

Elizabeth Harkness

Nathan Harris

Ashley Harrison

Steven Hart

Savannah Hart

sabelle Harvey

Ranae Haskins

Shelby Hatcher

Rebekah Haught

Aubrey Hauter
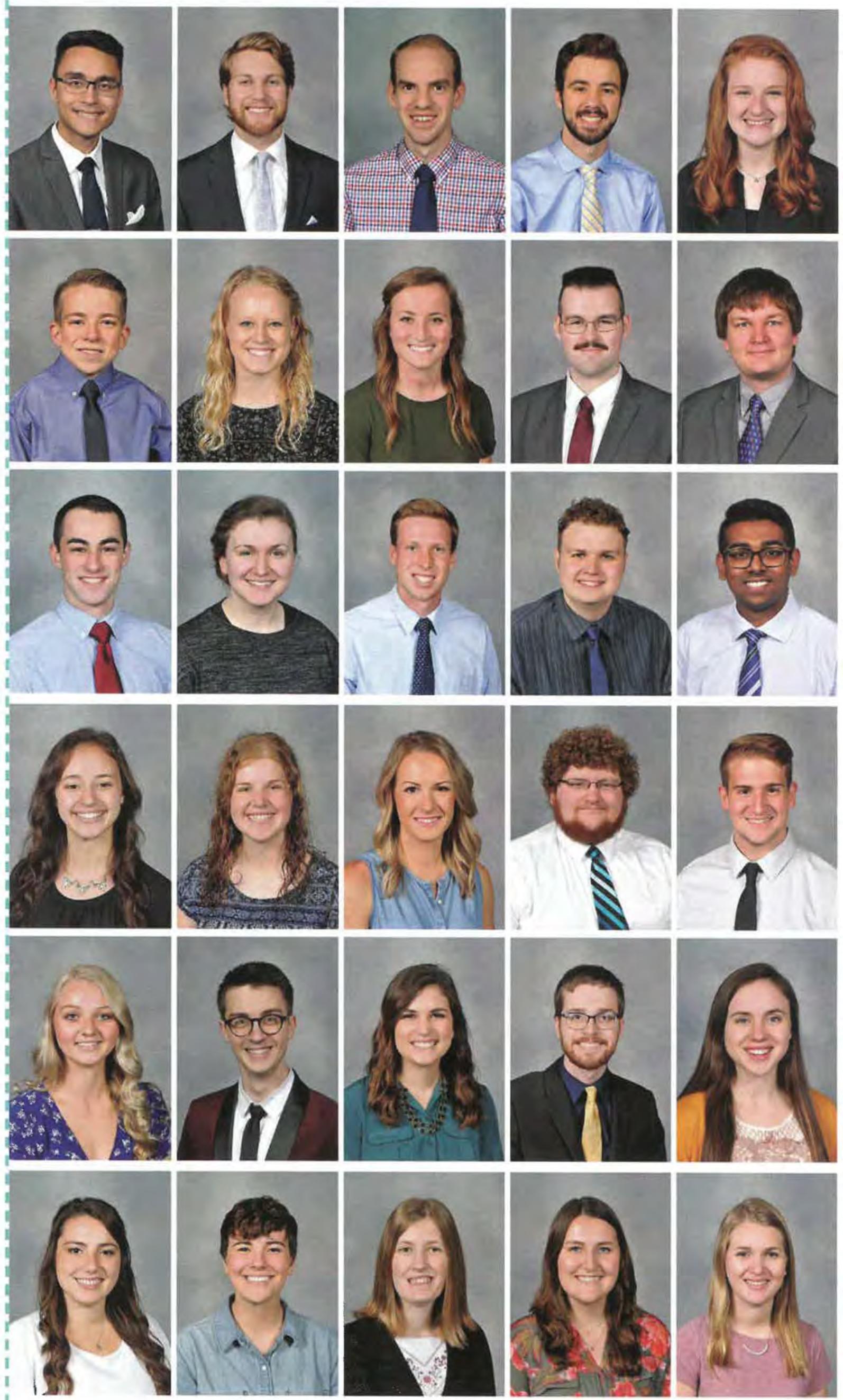
Michael Hayes

Clara Hendrickson

Auston Henninger

Stephanie Hermann

Nathan Herr

Taylor Herr Madison Hertel

Tyler Hess

Jack Higgens

Lane Hluch

Hannah Holbrook

Miranda Holbrook

Cameron Holcomb

Michaela Holloway

Victoria Holmes

Kyle Hooper

Joshua Horne

Zachary Horst

Alexander $\mathrm{Hotz}$

Madison Hultgren

Avary Humes

Emily Hunnemeyer

Luke ingles

Christiana Jackson

Daniel Jaquish

Kristen Jarboe

Amanda Jensen

RaeAnn Jent

Nathan Jessurun

Jodi Johnson
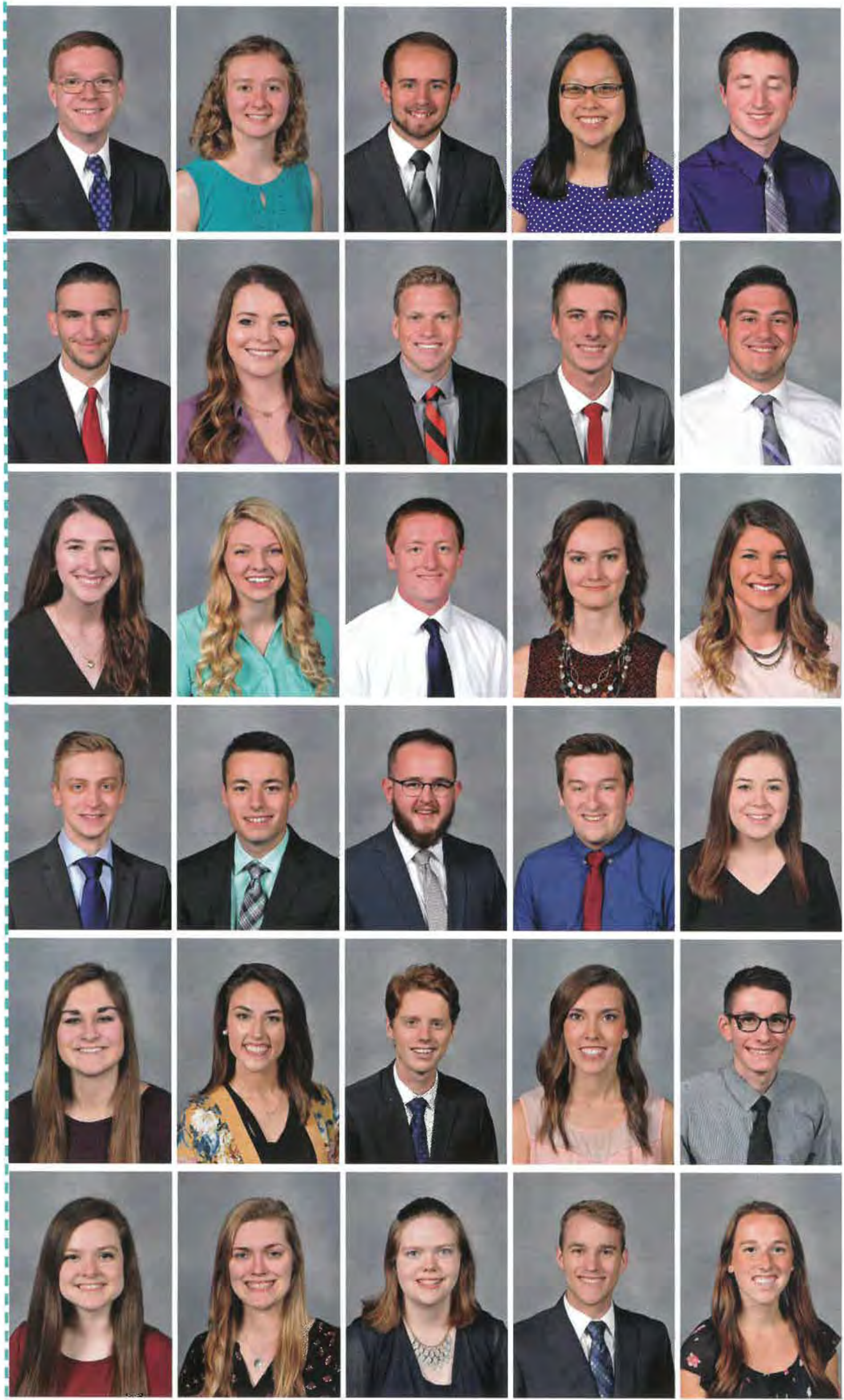
Samuel Johnson

Justus Johnson

Emily Jones

Isaac Jones

Taylor Jones

Theresa Jones

JooHee Jung

Ashtyn Kaptein

Kirstyn Kelley

Peter Kennell

Jared Kick

Syndiana Kim

Katelyn Kime

John Kindig

Sterling King

Rachael Kirby

Natalia Kirychuk

Hannah Klabunde

Emily Klein

Jared Klimek

Jayde Knoerr

Adrienne Krater

Zachary Krauss

Michelle Kropat

John Kuhn

Wade Kyser

Wyatt Kyser

Isaac La Croix

Jaylyn LaFlamme

Luke Lambert
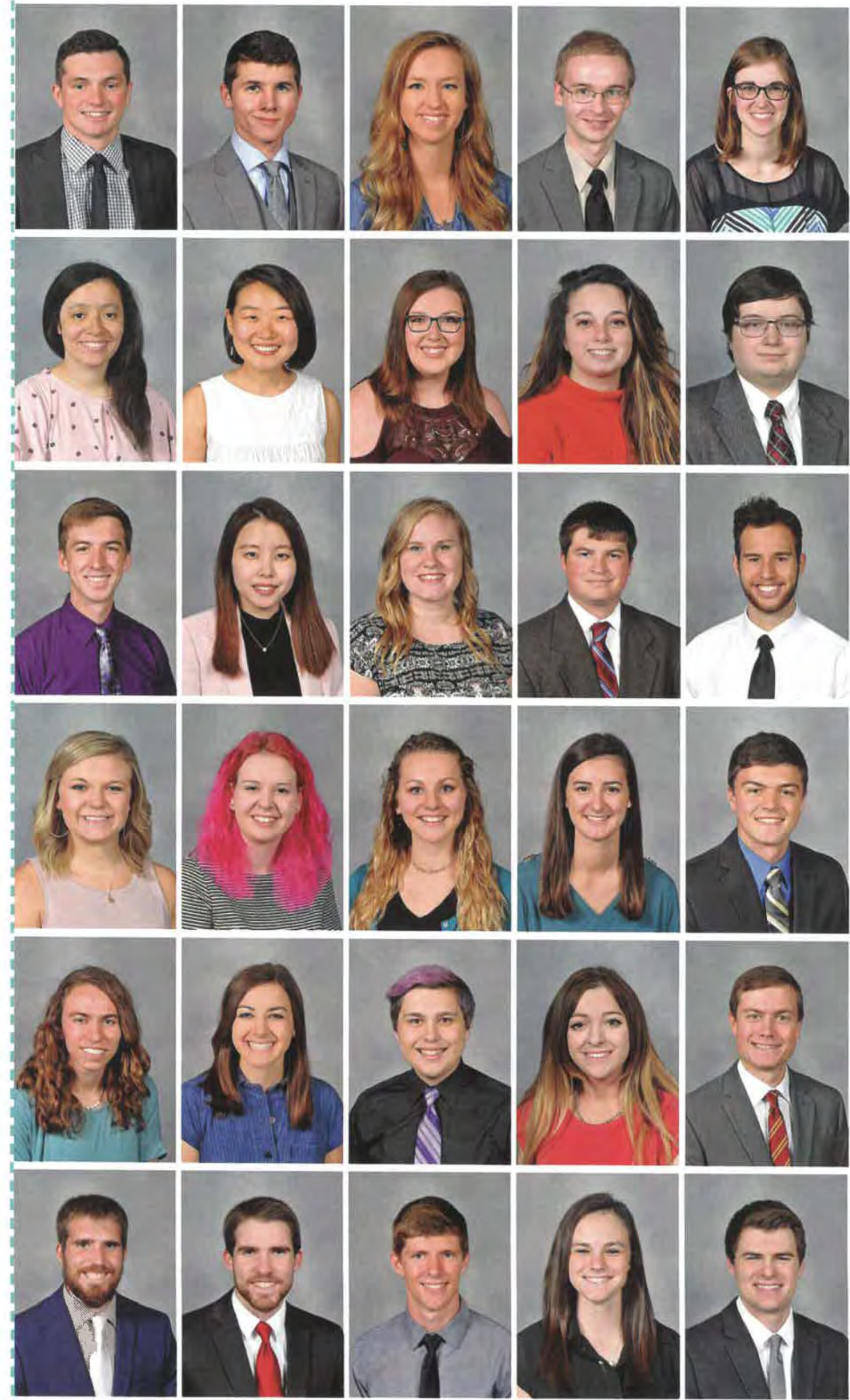
Chloe Lance

Austin Land

Hannah Lankford

Lewis Larsen

Jessica Larson

Jonathan Larson

Charles Learned

Kevin Lee

Georgia Lewis

Nathan Linville

Justin Lough

Addison Love

Aaron Lynn

Alisha Macnamara

Dylan Mangold

Jesse Mangum

Megan Marrie

Malachi Marshall

Sydney Martin

Sean Masiakiewicz

Kelsey McCabe

Thaddeus McClain

Jonathan McDugle

Tad McKanna

Sarah Meisel

Abraham Melnick

Gregg Mendel

Kylee Metzger

Kathryn Meyer
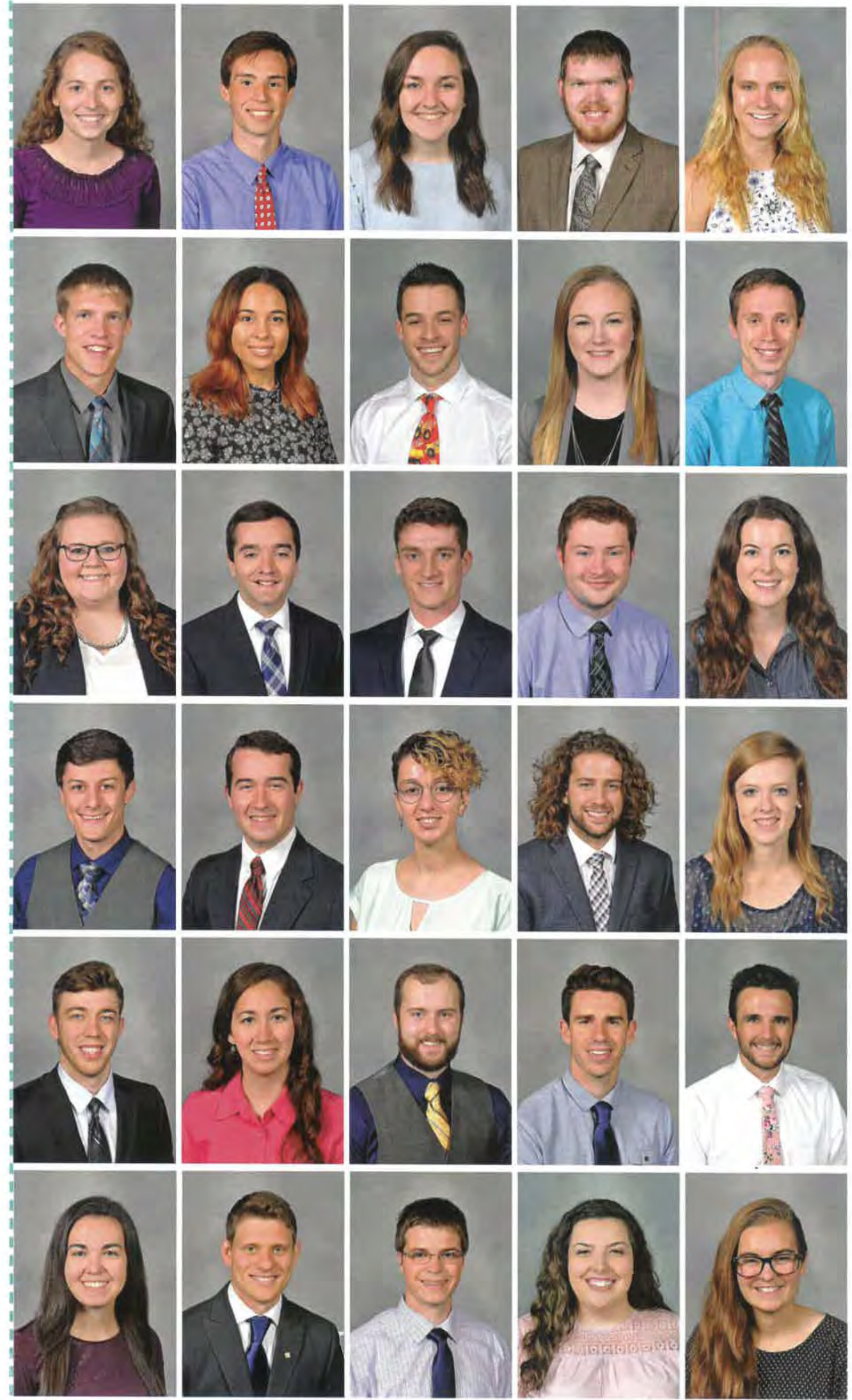
Kristen Mills Joshua Montross

John Morimizu

Taylor Moses

Abigail Mouring

Greta Moyer

Andrew Mrozek

Kelly Murphy

Katie Murray

Austin Myers

Adam Nesmith

Krystal Null

Whitney O'Brien

Timothy O'Donnell

Kaileb O'Neil

James Osborne

Taylor Pace

Molly Paisley

Sorrel Paris

Kayla Parry

Timothy Parsons

Brianna Patricca

Bryan Perschbacher

Hannah Peters

Nicole Peters

Brent Petersen

Tasha Peterson

Cameron Pitstick

David Pitts
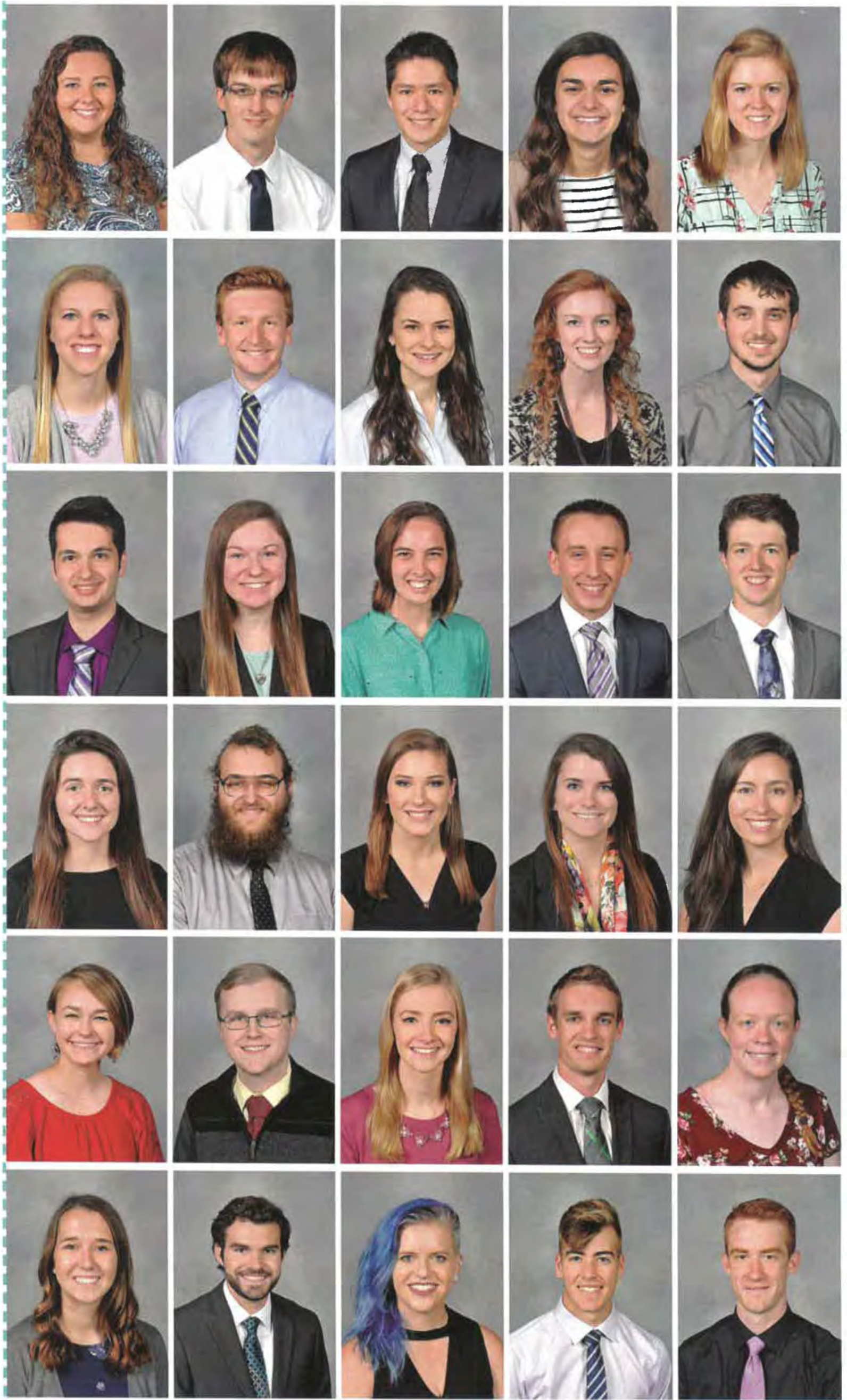
Melanie Poindexter

Gabriel Portillo

Benjamin Posecznick

Jamie Potts

Rachael Potts

Rachel Price

Aria Prichard

Megan Quick

Shruthi Ramachandran

Rachel Ramsey

Benjamin Ratkey

Joshua Ratliff

Katherine Reed

Tyler Reid

Shai Renne

Kaitlyn Ring

Daniel Ringenoldus

Dawn Robbins

Blake Robertson

Cara Robinette

Melissa Robyn

Julianna Ruckersfeldt

Sadie Ruegsegger

Lily Russell

Jessica Rutan

Karis Ryan

James Ryan

Karolyn Sabo

Gabriel Sallstrom

Stephen Samuelsen
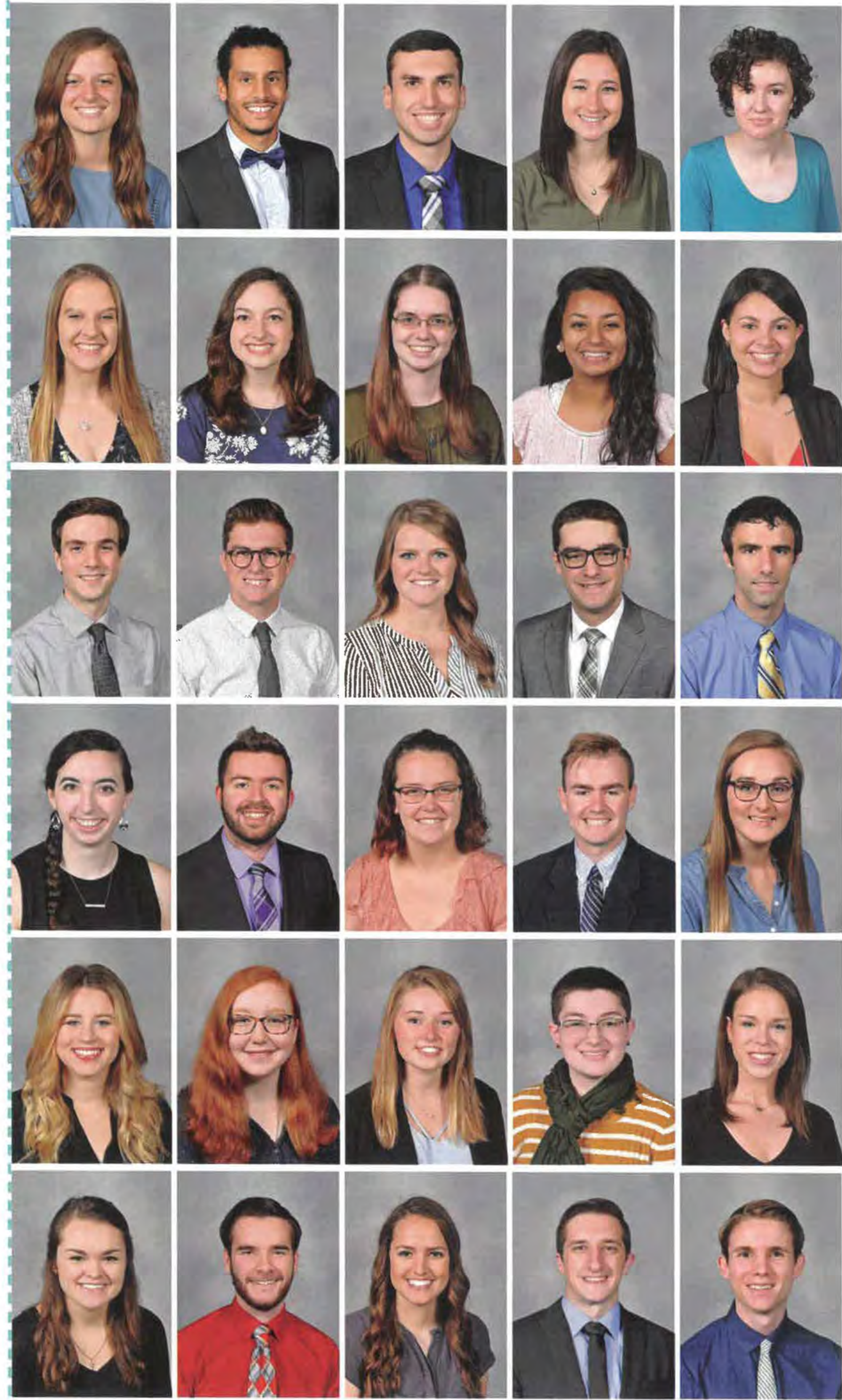
Jacob Sanders

Phoebe Schoeneweis

Jonathan Scouten

Lindsey Seals

Lauren Setzkorn

Emelia Shaffer Sarah Shamburger

Jeremy Sheckler Joshua Sheehan

Anna Simmler

Elizabeth Sizer

Suzanna Slack

Alexis Smith

Jeremy Smith

Kristina Smith

\section{Ryan Smith \\ Carrie Smith \\ Jared Smith \\ Abigail Snow \\ Ablgail Snyder}

Jessica Sohn

Kirsten Sommers

Joshua Southard

Elaina Southwell

Alyssa Spansel

Kyle Spencer

Robert Squier

Kanyapak Sririntrachai

Nathaniel Stahlnecker

Justin Stallard
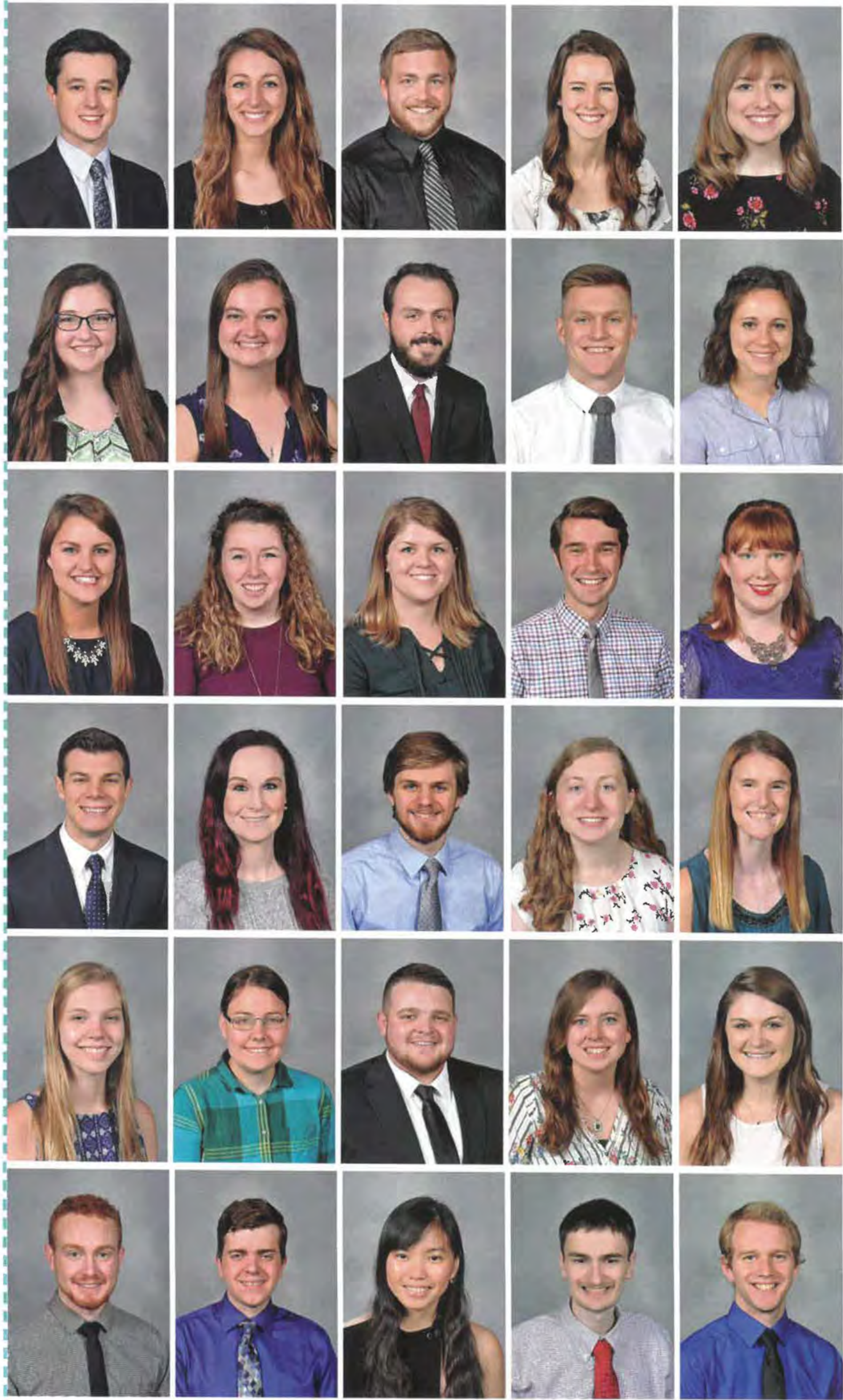
Amanda Staufer

Sarah Staufer

Shelly Steinert

Logan Stringfield

Koinonia Strong

Ethan Sullivan

Alethea Surland

Kevin Symonette

Jessica Tanner

Jonathan Taylor

Lindsey Taylor

Brooke Terracino

RaeAnna Thomas

Jonathan Thong

Jeremy Tiberg

Kelly Tomic

William Tomlinson

Faith Trautmann

Timothy True

Jennifer Tyson

Alison Uhland Michelle Van Strien

Leah Vance

Tyler VanDerMolen

Ashleigh Veltman

Etienne Viaud-Murat Hayden Vroegop Allyson Wagner Nidia Waite Virginia Walker
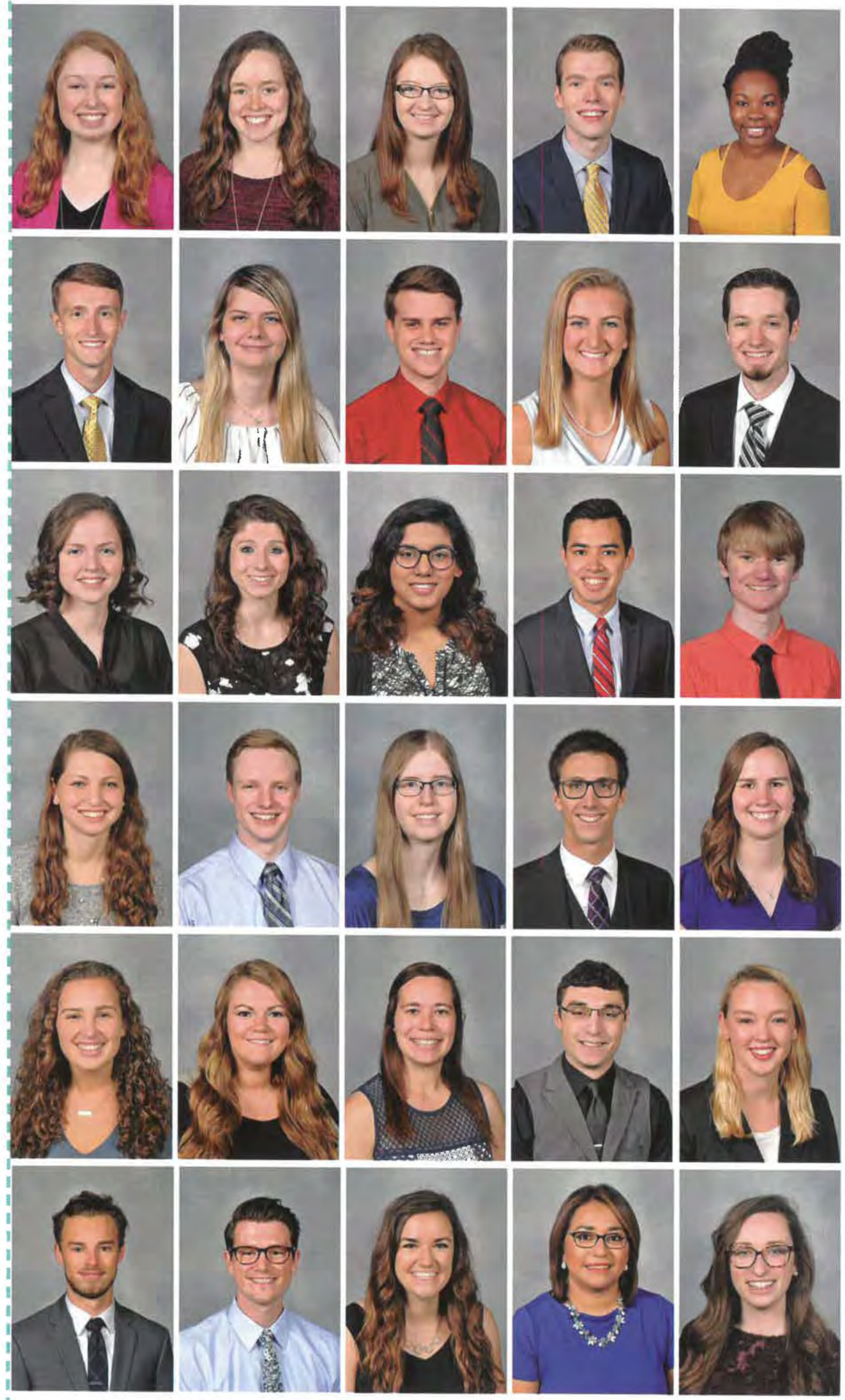
Aaron Waller

Kaitlyn Walters

David Ward

Erica Ware

Joshua Wells

Rosemary Wells

Rachel Wenzinger

Emma Wessels

Allison White

Kimberlyn Wideman

Alicia Williams

Rebekah Williams

Zachary Williams

Kelsey Williamson

Kristen Wilmot

Michael Wilt

Tineka Witt

Joshua Woolverton

Allie Wright

Sabrina Xuereb

Matthew Ysais Jenah Ziegenfus
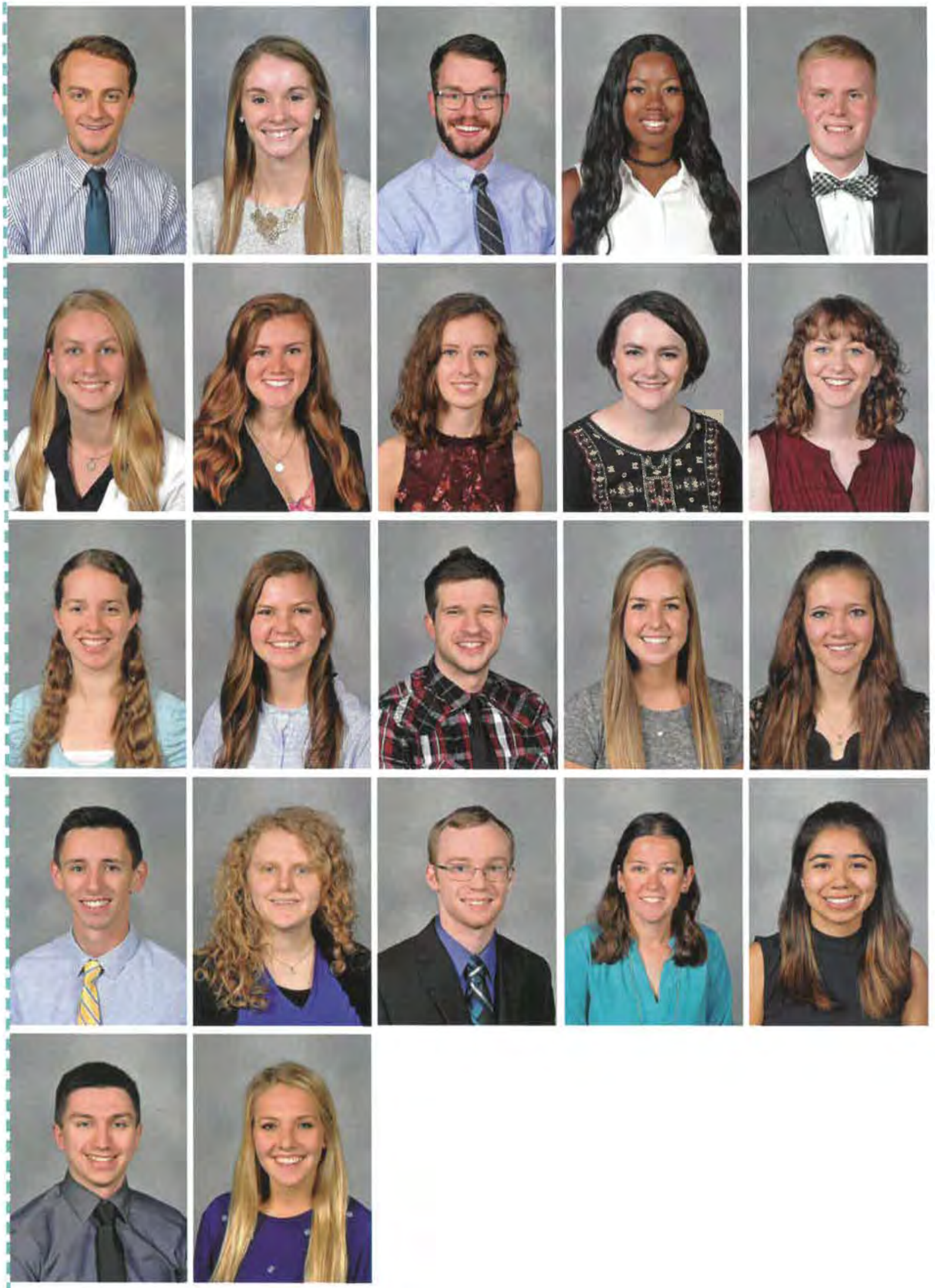


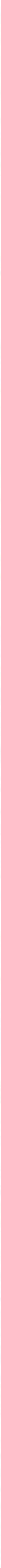




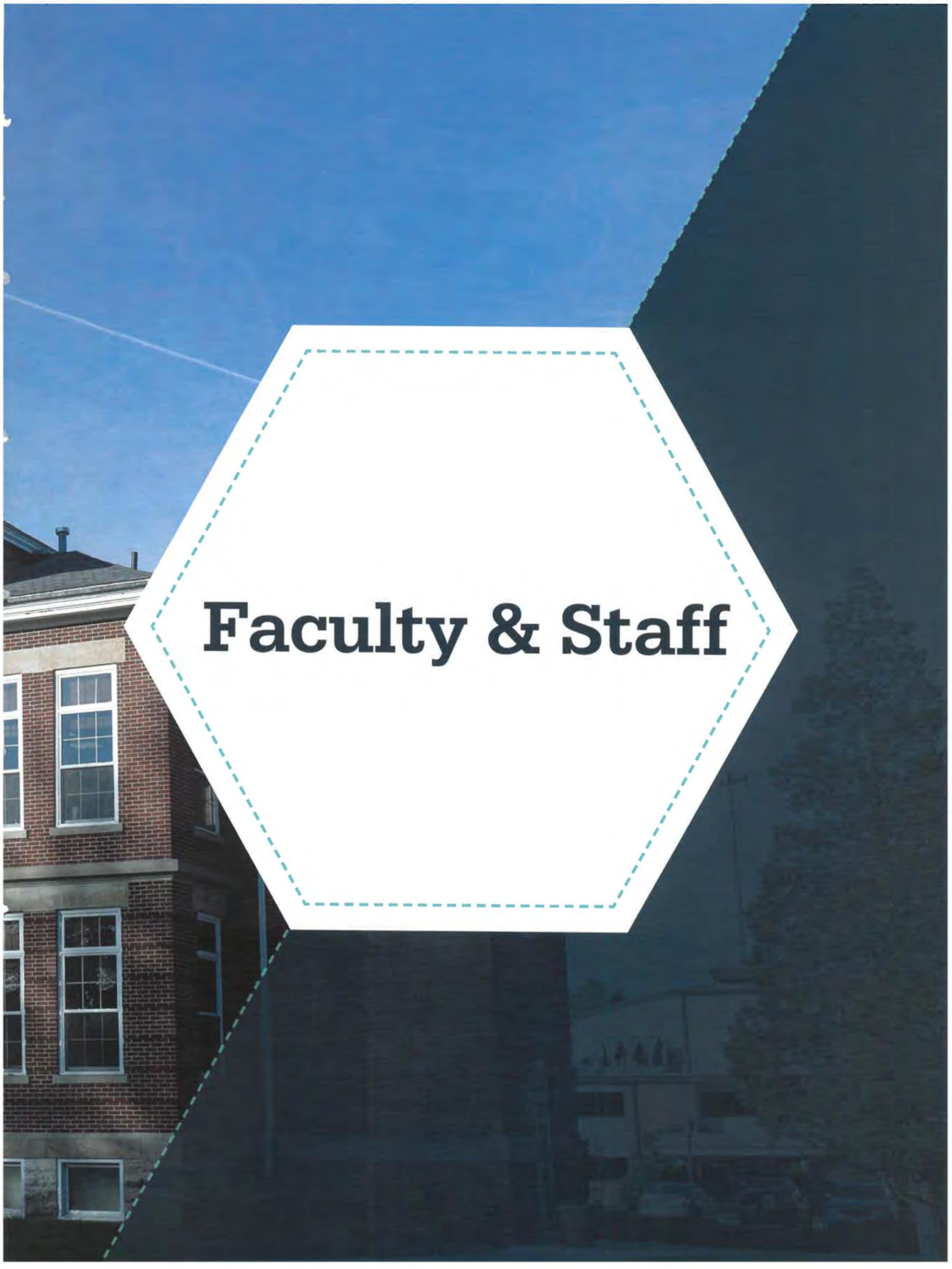




\section{Faculty}

A day in the life of a Cedarville student could be as simple as picking up a latte from Rinnova, or as busy as juggling multiple projects and ministries. One of the primary ways the school participated in students' daily lives was through professor involvement. Dr. DeWitt, an excellent example of this sort of dedication, poured into students outside of class on a weekly basis. Students joined him every Friday at either Stingers or at Beans $n^{\prime}$ Cream for "Mere Caffeination," where they drank coffee together and discussed the book "Mere Christianity"
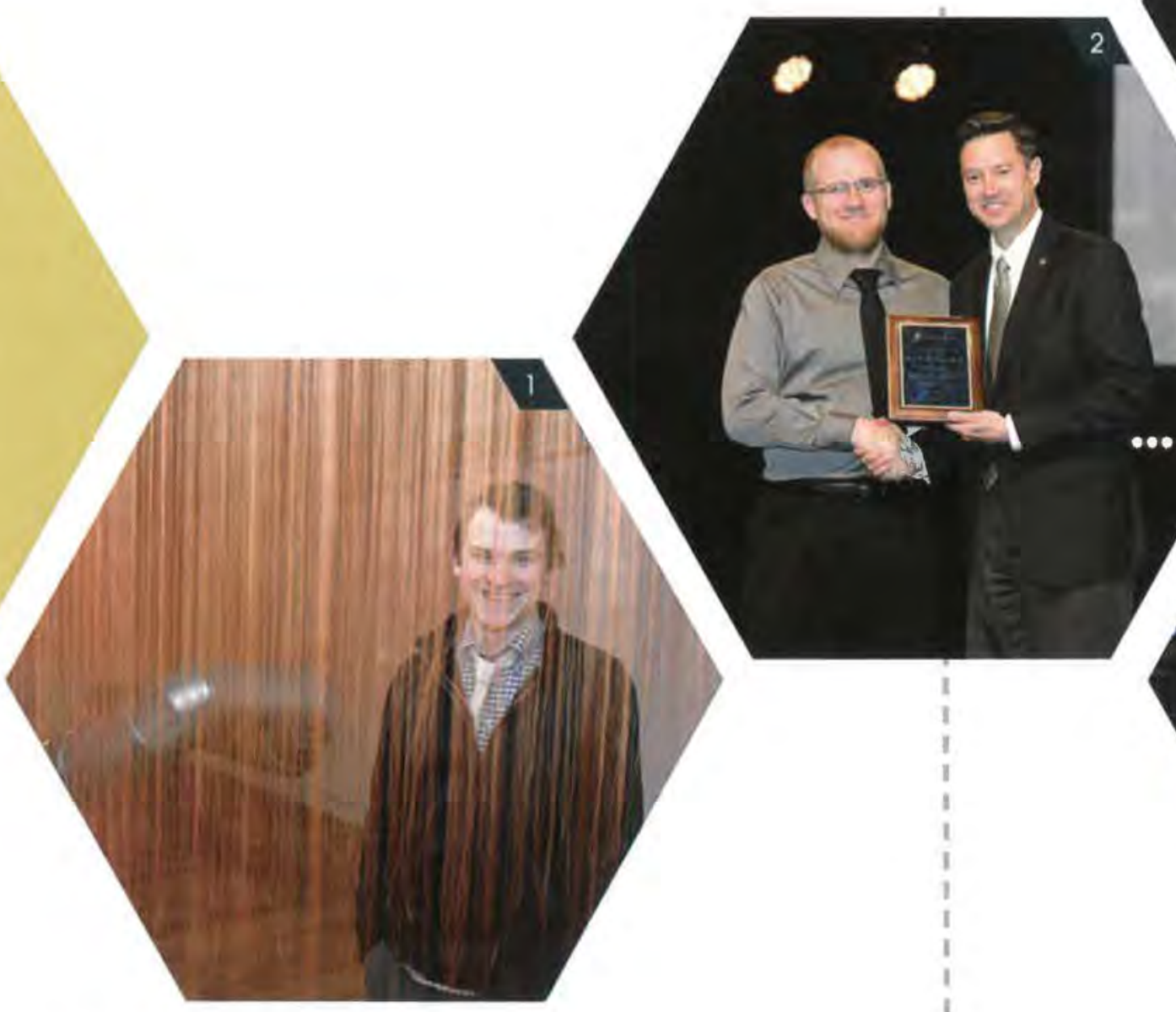

Zac Benson, an assistant professor of studio art,

stands in the middle of one of his installation pleces in the Springfield Museum of Art. This piece was comprised of over 34,000 pieces of orange thread. Each piece of thread represented the life of a refugee who died trying to reach safety.

2: Dr. Ched Speliman becomes an associate professor for the Bible department.

3: Bible professor Dr. Jeremy Kimble speaks in chapel.

4: Dr. Pamela Johnson speaks in the CU Legends panel in chapel.

5: Brian Nester, awarded staff member of the year. and George Huff, awarded faculty member of the year. pose with their awards
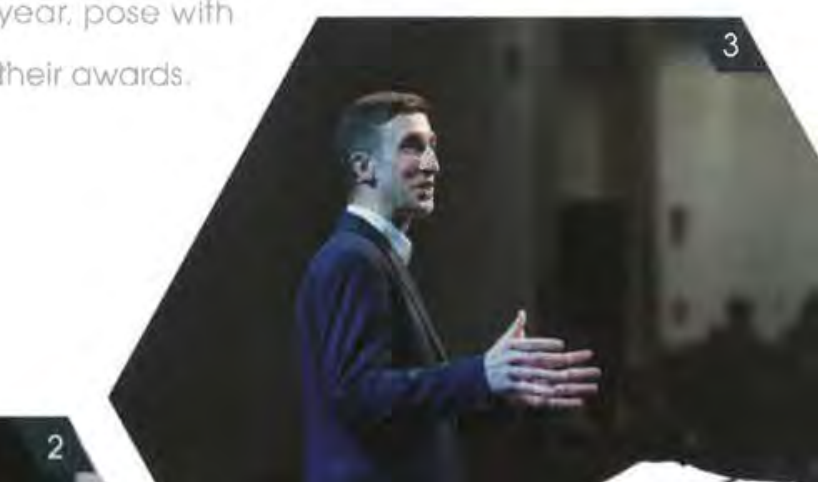


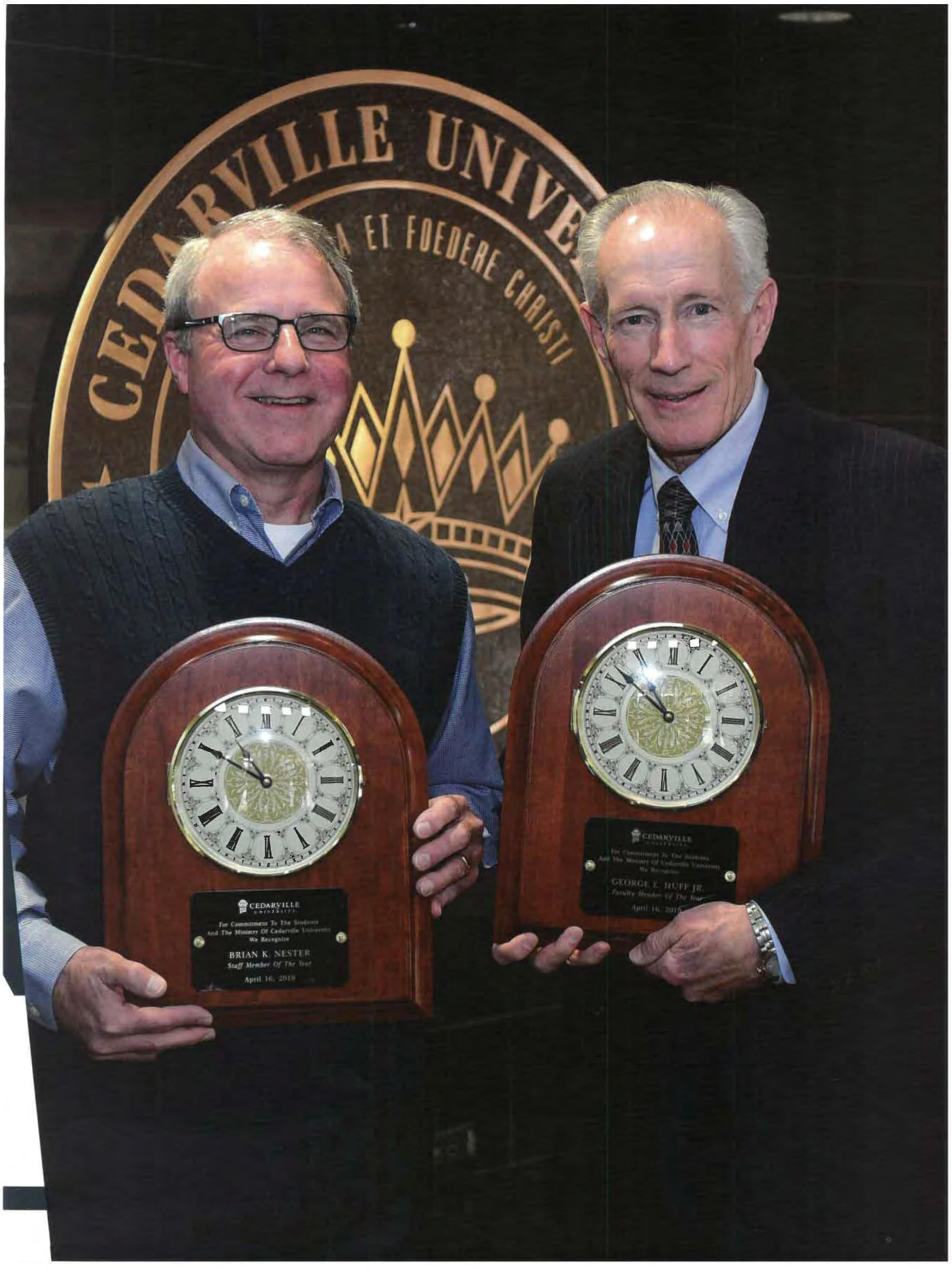




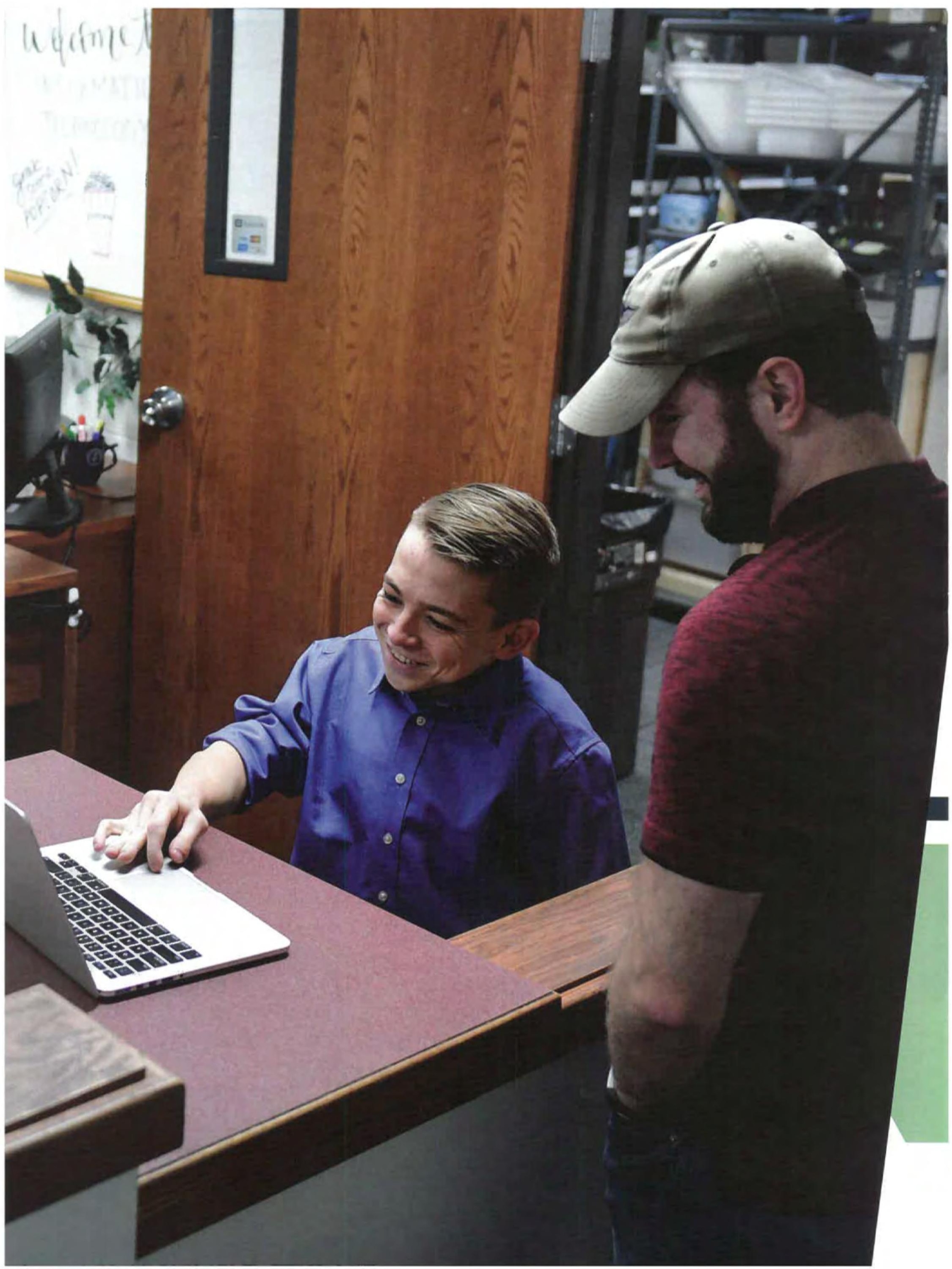




\section{Staff}

1: Brennon Gee assists Gary Wiggins with his computer at Techstop.

2: The counseling statl poses fal a group photo by the lake

3: Dr. Jon Wood speaks at the ribbon-cutting ceremony for Ceciar Falls

4: A staff member from the Cove speaks to a prospective student and his triom of a GU Fiday

5: The Graduate Admisstons stati pose for a group picture

6: The Residence Directors pose for a group picture by the lake

On May 22, Cedar Falls officially reopened after improvements were made in order to enhance Indian Mound Reserve. Dr. Jon Wood, the Vice President for Student Life and Christian Ministries, spoke at the ribbon-cutting ceremony involving many members of the community. "New viewing platforms and picnic areas were built to provide a better viewing experience of the falls," Wood said. "A new bridge was installed, and the trail was extended to allow Cedarville residents to walk from town all the way to the Indian Mound." Because of the park improvements, Wood believes this space will be utilized by the students and the community for years to come. 


\section{Yearbook Staff}

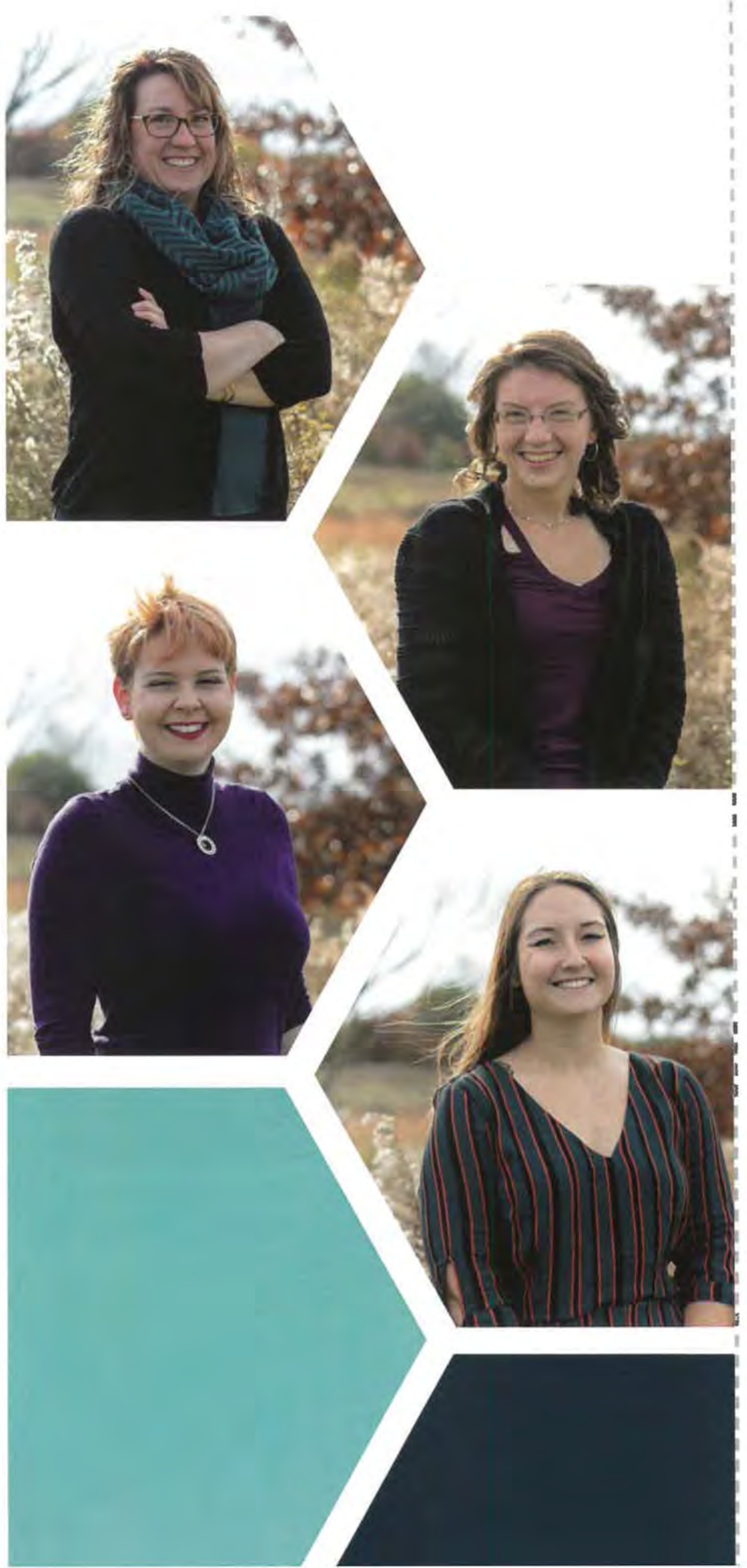

\section{Cynthia Messer}

Cynthia Messer is an Associate Professor of English. She is the Yearbook Faculty Advisor and provides supervision and feedback for the yearbook staff.

\section{Anna King}

Anna is a sophomore Business Management major. She is from St. Augustine, Florida, and is the assistant editor-in-chief. She assists in creating deadlines, proofing the yearbook, and overseeing book production.

\section{Natalia Kirychuk}

Natalia is a senior Theater major with a minor in Public Relations. She is from Glen Burnie, Maryland, and is the editor-in-chief. She creates book deadlines, supervises the proofing process, and is responsible for the final production of the book.

\section{Jessica Westenberg}

Jessica is a senior Social Work major with a minor in Women's Ministry. She is from Laingsburg, Michigan, and is the staff's administrative assistant. She is responsible for correspondence, planning, and communication. 



\section{closing...}

This year at Cedarville was a compilation of millions of moments. We studied, worked, laughed, sang, and endured our way through nine months of school. Then, all the "lasts" came - last dinner in Chucks, last final, last hangout with friends, last chapel as a student body. As the year grinded to a halt, we looked around and realized that our time at Cedarville doesn't last forever, and that soon, all we'd have were memories of what our time here was like.

So, we tried to make the most of the last couple weeks. We contacted all of our friends, hoping to get one last meal with them and take a few more pictures before we left. We danced our hearts out at JS. We brainstormed summer plans while preparing crazy costumes for Elliv. We studied really hard, but we also calculated how well we needed to do on our finals to keep our grades. We teared up in chapel with Dr. White when he told us he was going to miss us and he wanted to see us make an impact for the Lord. We packed up our rooms, and we prayed with our D-groups one last time.

This book captured those moments. If you find yourself fondly remembering your friends or your campus involvement, or saying, "I completely forgot that happened," we have accomplished our goal. This was a chronicle of the student experience, a tribute to all things Cedarville 20182019. Thank you for joining us as we re-lived every second that made Cedarville University our home. 


\section{colophon...}

Publisher: The Miracle Yearbook was published by Jostens, Inc. It was printed at their plant located in State

College, PA.

The Jostens representatlve was Donald Boyd, and the plant coordinator was Crystal Gault.

Cover: The cover is custom screen and is custom art design by Morghan O'Neil. The Miracle was printed with four-color process ink.

Design: The Miracle was designed by Morghan O'Neil, with layout assistance by Ethan Ooms.

Theme: The theme of "moments" was a collaborative brainstorming effort of the editorial staff.

Production: The Miracle was produced on both HP and Apple computers. Layouts were created using Monarch by Jostens. Programs inside Monarch include Adobe InDesign, Adobe Photoshop, and Adobe Bridge.

Typography: The heading font style used in this book was AYT Avalon size 27 pt. The main body text font was also AYT Avalon style at 12 pt size in Book style.

Photography: Photos were primarily taken by Alex St. Onge and his photography assistants. Adrienne Krater and Brady Esper. Several photos were taken by Cedarville University photographer, Scott Huck. Jim McAdams provided senior and underclass portraits, Thank you also for portraits and photos that were individually submitted from our student body.

Inquiries: The Miracle Yearbook office may be contacted for additional information about this book's production at: Miracle, Cedarvllle University

251 N. Main St.

Cedarville, $\mathrm{OH} 45314$

(937) 766-4995 miracle@cedarville,edu

\section{letter from the editor...}

Moments.

From the first day of classes in the Fall to graduation in the Spring is about 250 days. Most students completed about 30 credits, ate in Chuck's over 400 times, and went to chapel over 100 times. Each of these days were made up of moments, and those moments make memories.

This year we made a lot of memories as a class. The moment that Mindy May told us that women were allowed to wear leggings on campus. When the chapel speaker gave out two Apple watches. The introduction of orange soff serve to Chucks. When everyone made Oceans videos with the plastic elephants. When classes were cancelled because of wind chill. The quizzes to find out which dorm you were most like. When Andrew Peterson forgot his lyrics. When that mug fell from the balcony during chapel,

But for each of you, I'm sure there were many more moments that happened more privately that created everlasting memories. For me, I will always remember going to get a tattoo with friends and when a tough professor complimented me.

As you move into the summer and store up vitamin D before another Ohio winter or get geared up for a new environment. I want to give you two verses about what we must remember alongside the memories from this school year:

"Remember the former things of old; for I am God, and there is no other; I am God, and there is none like me." Isaiah 46:9

"But the Helper, the Holy Spirit, whom the Father will send in my name, he will teach you all things and bring to your remembrance all that I have said to you." John 14:26 
Index

Adair, Katie, ...................................................68

Adam, Benjamin.......................................107

Adams, Amy .................................................107

Ahlborg, Shelby.............................................103

Akins, Emily......................................................107

Akins, Stony ....................................................107

Albrecht, Nathanlel...................................107

Aliberry, Sam ........................................... 8, 9

Allen, Matthew..............................................103

Amacher, Rebecca...................................107

Ancll, Olivia........................................73, 107

Anderson, Timothy........................................107

Andrews, Abbey.......................................107

Andrews, Meredith..........................................51

Angus, Alexander.........................................107

Anson, Stephen.........................................107

Antle, Kaitlyn ...................................................

Arango, Ssubi …………............................21

Arbogast, Morgan ............................................77

Armstrong, Isabelle...................................103

Armstrong, McKenna..................................103

Athineos, Rebekah.....................................107

Atienza, Cara ….....................................107

Atkinson, Hannah........................................65

Ausema, Pieter..............................................50

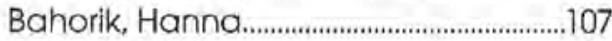

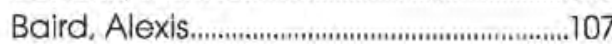

Baker, Chelsea.................................................80

Baker, Wes........................................................3

Balentine, Rachael...................................107

Ball, Ryan ......................................................103

Ballentine, Andrew.....................................107

Barahona, Amanda..................................... 107

Barber, Jennifer..............................................83

Barker, Julia..................................................107

Barnes, Madeline..............................................75

Barnes, Trey..................................................107

Bartlow, Janessa........................................107

Bassett, Elizabeth....................................58, 107

Bauer. McKayla........................................42

Bayle, Rebekah...........................................107

Beal, Kori................................................78, 103

Beals, Alyssa..................................................107

Beaudette, Garett....................................83

Beckman, Caroline......................................103

Beckman, Sidney........................................107

Bennett, Matt..................................................18

Benninger, Chad ............................................82

Benson, Zac............................................122

Bergthold, Alyssa........................................107

Berkstresser, Jesse.......................................107

Berrill, Stephen.................................................107

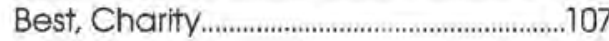

Beste, Kylie...............................................11, 103

Beste, Sara........................................................43

Billman, Brian..............................................107

Bindus, Zachary............................................108

Birt, Phillip.....................................................108

Bishop, Jackson...........................................103

Block, Hunter.................................................108

Boardman, Hannah...............................108

Bobe, Angela................................29, 30, 108

Boeve, Taylor................................................108

Bolender, Isabelle.......................................28
Bolin. Teagan..............................................20

Bonlfield, Julia................................................108

Bortel, Campbell.

25,108

Bowden، Benjamin.......................................108

Bowen, Ryan ...............................................69

Bowersock, Tirane........................................108

Bowles, Cayla..............................................86

Bowser, Mitchell................................................86

Boyer, Cassandra........................................103

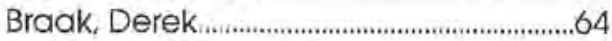

Bradley, Lydia................................................86

Brady، Karina..................................................103

Bragg, Rachel................................................83

Branch, Lia........................................................86

Brandner, Abigail..............................................86 86

Brandt, Christian.............................................28

Branson, Nehemiah........................................86

Brawley, Christopher......................................108

Brennan, Alyssa..............................................86

Brenneman, Isaac.........................................86

Brethauer, William............................................86

Brighton, Abigail............................................108

Brimer, Stephanie ...........................29, 30, 108

Brimner, Kayla...............................................86

Broadwick, Emily...................................37, 108

Brooks, Ariana. ...........................................8, 18

Brosius, Allison...................................................86

Brouwer, Ruth.....................................................8 86

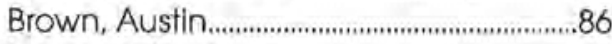

Brown, Brittney..................................................108

Brown, Dana......................................................86

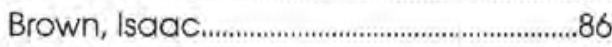

Brown, Josh ........................................................75

Brown, Ryan ...............................................108

Brumbauch, Matthew.......................72, 108

Brumbauch, Phillp...........................................72

Bryant, Laurel...................................29, 30, 103

Bryant, Morgan .................................................86

Burgoon, Sarah..............................................49

Burke, Claire,.................................................

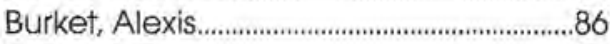

Burns, Brian......................................................52

Burns, Shannon....................................................8 86

Burr, Abigail.......................................................86

Burris, Jonathan ........................................108

Burt, Callie.......................................................86

Burton, Claire........................................29, 103

Bush, Avery.......................................................86

Butaud, Cole ...................................................64

Bynum, Delaney,.............................................86

Byrd, Isabel........................................................86

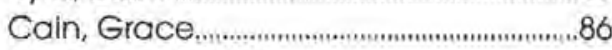

Calderone, Kristin .........................................83

Caldwell. Holly..................................................103

Caldwell, Kelsey............................................108

Callahan, Faith ..............................................86

Campbell, Aaron.........................................86

Campbell, Brian............................................108

Cannata, Timothy.......................................108

Cannon, Aaron.............................................108

Carlson, Sean................................................108

Carmack, Savannah..................................86

Carman, Emily................................................86

Cappenter, Michaela........................ 32, 108

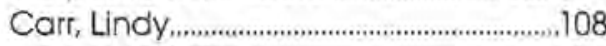

Carraher, Abby..............................................54

Carrico, Caleb............................................74
Carroll, Lindsey... 108

Casaletto, Kayla..

$67,75,108$

Cassidy, DaVonte

20, 21

Castillo Diaz, Mario.............................................86

Chairvolotti, Madeline...................................86

Chapman, Emily...............................................28

Charles, Christa.............................................86

Cheeseman, Alise...........................................86

Chen, Steven.................................................108

Childress, Asia .................................................86

Christansen, Victoria..............................29, 30

Christiansen, Grace ...................................103

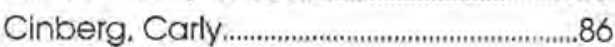

Cinberg, Cole..................................................86

Clark, Cameron................................................86

Clark, Chad..................................................

Clark, Christopher...........................................86

Clark, Hannah.................................................108

Clemens, Kaelin.............................................86

Clemens, Mackenzi......................................109

Clement, Kaylee................................................86

Clemons, Catherine......................................109

Cline, Abigail.................................................109

Cline, Jachin.....................................................109

Clingenpeel, Jordan..................................103

Close, Joshua.................................................109

Coates, Troy .......................................................58

Cochran, Joshua...............................................86

Cochran, Kristen.............................................109

Cochran, Makenzie.......................................86

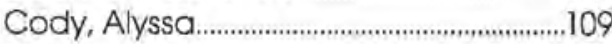

Cogdill, Cody,.................................................69

Coiro, Natalie..................................................109

Cole, Abigail...................................................109

Cole, Alyssa....................................................103

Cole, Olivia...................................................109

Coleman, Ben..................................................11

Concepcion, Cori.........................................83

Conner. Michael...........................................109

Conoboy, Zachary........................................87

Coon, Olivia..................................................103

Cooper, Corinna..........................................87

Cooper, Grace ...............................................87

Coppens, Kenneth.......................................109

Costello, Clara..................................38, 52, 109

Costello, John.................................................109

Coughlin, Micaela....................................109

Counts. Joshua....................................................87

Coviello, Paul.................................................103

Cowell, Braden.....................................................87

Cramer, Colin....................................................87

Crandell, Kameron..........................................87

Crane, Hannah...........................................109

Crawford, Megan........................................109

Creamer, Mitch.............................................69

Creditt, Sarah...................................................87

Curley, Tiana.....................................................87

Curran, Jacob..................................................87

Curran, Joshua................................................87

Cutting, Noah...............................................109

Daghfal, Wilson.............................................87

D'Alfonso, Keegan.....................................109

Darnell, Noah.........................................34, 122

Darst, Kirby....................................................109

Daugherty, David.....................................103

Davidson, Austin..........................................109

Davidson, Noah 
Davidson, Rachel...........................................67

Davidson, Rachel...........................................75

Dawson, MacLaren.........................................87

De Vries, Kathryn ..............................................87

Deane, Hannah...................................................87

Deaton, Natalee..............................................87

DeCeglie, Emily................................32, 49, 109

Decker, Joshua.................................................87

Deeter, Benjamin ...........................................103

Dellaperute, Colin .........................................109

Denen, Tiffany..............................................109

Denen, Victoria..........................................109

Dentel, Nathaniel............................................87

Depinto, Joshua ................................................87

Dewhurst, Mae..........................................81, 109

DeWitt, Abigail................................................109

DeWitt, Dan …………………………......45, 52

Deyaert, Olivia..................................................16

Dibert, Timothy....................................................87

Diller, Bradley........................................................87

Dobson, Carissa.....................................103, 127

Dobson, Natasha..............................................87

Doddrldge, Sarah...........................................87

Dodds. Jessica..............................................109

Doman, Noelle.................................................103

Dowd, Colin......................................................87

Downey, Fiona................................................87

Downey, lan...................................................103

Doyle, Kristen ........................................................ 8

Driver, Brie.......................................................82

Drollinger, Maria..................................................8

Drummer, Gabrielle......................................109

DuBois, Anna....................................................8

DuBois, Jonathan .........................................109

DuBois, Lauren...................................................87

Duncan, Michaela.........................................110

Dunn, Callie.........................................................110

Dupee, Connor.................................................44

Dupler, Grant.....................................................87

Durst, Bryson.........................................................87

Dykema, Danielle............................................110

Dykema, Delaney.............................................87

Dykema, Denise..............................................103

Dyson, Greg.................................................52

Dyson, Miranda..................................................110

Earl, Matthew.......................................................87

Eckley, Cayla...................................................110

Ederer, Victoria.................................................103

Edmonson, Lauren........................................110

Edsell, Abigail..................................................103

Edwards, Susanna......................................110

Eeles, Payton...............................................76, 87

Ehrlich, Vance.................................................110

Eiginger, Kara....................................................77

Eisman, Micah....................................................87

Elam, Jordan......................................................8

Eldred, Christopher......................................110

Elgersma, Rita.......................................................

Elizee, Steven....................................................110

Ellicott, Samuel..................................................110

Ellis, Evan .........................................................27

Ellis, Lauren .........................................................

Ellis, Rebekah..................................................87

Elmers, Julia....................................................8

Emory, Nathaniel............................................87

Emrich, Rory,...................................................83

Engle, Elijah.........................................................8
English, Dean..................................................110

English, Janelle.................................................73

English, Liana .................................................73

Enloe. Abigail...................................................8

Enns, Abraham ................................................8

Entner, Emily....................................................110

Eppard, Courtney .................................78, 710

Ericson, Troy...................................................110

Errichetti, Noah..............................................74

Ervin, A.J............................................................110

Espling, Anna.................................................32

Esselburn, Tanner............................................8

Estepp, Patrick.............................................70

Everhart, Mark .....................................................8

Exline, Cayla .....................................................8

Ezell, Kevin .................................................18, 19

Fair, Kevin ........................................................110

Faison, Erika....................................................8

Farley, Jordan...............................................110

Farrand, Skyler....................................................67

Farrand, Skyler.............................................75

Fasnacht, Caleb............................................8 88

Fauska, Katelyn ..............................................8

Fedako, Masie..................................................110

Feiser, Madeline..............................................110

Ferguson, Kaitlyn ................................................8

Ferris, Cecelia...................................................88

Ferris, Elizabeth..............................................103

Ferris, Faith ...............................................53, 68

Ferris, Hannah................................................. 110

Feustel, Arielle..................................................110

Fierer, Jacob......................................................83

Finley, Jared.....................................................83

Fisher, Brandon................................................8

Fisher, Katelyn .................................................110

Fisher, Leah.....................................................110

Fisher, Stephanie................................................8

Fleming, Anna...................................................4 44

Flener, Hadley...............................................103

Fletcher, Maxwell.............................................88

Fletcher, Rachel.............................................110

Flint, Ethan ..........................................................8

Flint, Grace ...................................................170

Flint, Kaitlyn..........................................29, 103

Folkerts, Thomas......................................21, 88

Ford, Alexis.....................................................110

Fortener, Charley .............................................8

Foss, Joshua ....................................................8

Foster, Andrew.................................................110

Foster, Haley....................................................98

Foust, Autumn ..............................................68

Fox, Abigail................................................8

France, Tyler..................................................103

Franz, Alison........................................................8

Fredericks, Jordan .......................................110

Fretwell, Andrew..............................................17

Fry, Katherine........................................80, 98

Funakoshi, Yuki..............................................8

Funez, Maury....................................................81

Gallardo, Joelle..............................................98

Gallogly, Meghan ..........................................73

Galyon, Tristan .................................................117

Gammie, Philip....................................................8

Gard, Jesse.....................................................8

Gardner, Adam................................32، 38, 111

Gatchell, Ethan ................................................111

Gaunt, Jonathan ..............................................111
Gayman, Jacob............................................88

Gaynier, Stephen..........................................103

Gebauer, Philip............................................98

Gebauer, Shannon.........................................111

Gee, Brennon..................................................111

Gentry, Michaela.............................................8

George, Marisa............................................. Iו

Gerakinis, Jessie..............................................8

Gernert, Melissa.............................................103

Gerwig, Nickolas..........................................103

Gessner, Alex..................................................98

Gibboney, Kristopher..................................103

Gibson, Colin .....................................................

Gifford, Emily..................................................98

Glaze, Wesley.....................................................8

Goodwin, Emily..............................................111

Gordon, Ryan .................................................111

Gosman, Ashley .............................................98

Gosman, Katle.................................................88

Gould, Kurtis...................................................... 88

Gowin, Marcus.................................................82

Graef, Aidan.......................................................88

Graef, Benjamin ...............................................8

Graf, Clara.....................................................8

Graffunder, Spencer......................................111

Graham, Josh................................................28

Greathouse, Madison .....................................8

Green, Derrick...................................................37

Green, Quinton...........................................28, 70

Greene, Krista ..............................................67, 75

Greenhouse, Emily.........................................8

Griffith, Allison....................................................8

Grimes, Scott....................................................111

Gross, Samantha............................................111

Grover, Sarah...................................................8

Gruet, Chase.................................................111

Grunenwald, Jonathon..............................98

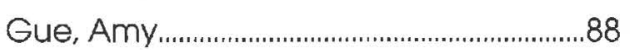

Haas, Jared.........................................................111

Hackler, Andrew................................................8

Halder, Jennifer................................................8

Halder, Pius......................................................111

Hall, Alexis.......................................................98

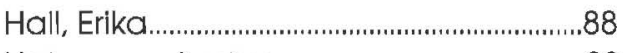

Halverson, Andrew......................................98

Hamilton, Breanna...................................6, 103

Hand, Ethan ......................................................98

Handel, Mark ....................................................98

Haney, Amber..................................................8

Hankins, Autumn......................................32, 111

Hanley, Megan .................................................111

Hannay, Abigail..............................................111

Hannay, Kristin.................................................52

Hannay, Luke...................................................8

Hannon, Eric.....................................................111

Hansen, Jacqueline .....................................103

Hansher, Blake..........................................13, 55

Hanson, Caleb....................................................83

Hanson, Ellen.........................................................60

Hardee, Alan......................................................111

Hardwick, Halie.................................................73

Harkness, Elizabeth ...........................................11

Harmon, Elizabeth..........................................89

Harris, Heidi.........................................................89

Harris, Nathan..........................................30, 11

Harris, Robert..................................................89

Harris, Sarah................................................... 103 
Index

Harrison, Ashley,...................................................111

Harshbarger, Andrew..................................17

Hart Connor....................................................89

Hart, Savannah ..........................................39, 11

Hart, Steven .......................................................111

Harvey, Isabelle............................................... Iו

Harvey, Wright.................................................98

Haskins, Ranae.................13, 34, 39, 111, 122

Haskins, William.................................................82

Hatcher, Shelby...............................................111

Hatfleld, Noah....................................................89

Haught, Rebekah............................................111

Hauter, Aubrey ..................................................111

Hayden, Anita...................................................82

Hayes, Lanissa....................................29, 29, 103

Hayes, Margaret............................................89

Hayes, Michael............................................ 712

Haynes, Brandon............................................18

Haynes, Connor.................................................26

Heeter, Haley.....................................................89

Heideman, Hallie...............................................89

Heist, Nicholas..............................................98

Hendrickson, Clara........................................112

Henig, Luke....................................................82

Henninger, Auston ........................................112

Henninger, Brevin ....................................42, 98

Hentschel, Alex.................................................81

Hermann, Stephanie....................................112

Herr, Nathan ...............................................112

Herr, Taylor........................................................112

Herron, Dalton ................................................89

Hershey, Rachel.............................................89

Hertel, Madison.................................................112

Hess, Joel....................................................89

Hess, Tyler.....................................................112

Hess, Michael.............................................98

Hesterman, Hope................................................ I]

Hicks, Heather...............................................89

Hieronymus, Brooke........................................103

Higgens, Jack .....................................30, 112

HIII, Nicolas...................................................89

Hill, Noah......................................................89

Hines, Vicky...................................................60

Hinks, Meredith...............................................103

Hirschler, Josiah..............................................89

Hluch, Lane...................................................112

Hoffman, Kari..................................................71

Holbrook, Hannah.........................................112

Holbrook, Miranda .................................29, 112

Holcomb, Cameron.......................................112

Holcomb, Kelth............................................60

Holland, Mark...............................................30

Holloway, Michaela....................................112

Holmes, Victoria ............................................112

Holsey, Madison ................................................89

Holsinger, Andrew...........................................89

Holsinger, Gabriel.........................................89

Hooper, Kyle .....................................................112

Hopkins, Avery..............................................89

Hopkins, Morgan ...............................................89

Horn, Shayalay...........................................89

Horne, Joshua................................................112

Horst, Zachary...............................................112

Hostetler, Rachel.......................................103
Hotz, Alexander............................................112

Hotz, Grace................................................45

Hovingh, Savannah.....................................83

Howell, Kaylee..............................................89

Hoyt, Lily.......................................................89

Huck, Emily......................................................45

Hudson, Jonathan ......................................,104

Huelskamp, Trent.............................................89

Huff, George...............................................123

Huffman. Ashlyn ......................................28, 71

Hughes, Connor............................................64

Hultgren, Madison ..........................................112

Humes, Avary,...............................................112

Hunnemeyer. Emily..................26, 27, 55, 112

Hunnemeyer, Evan .........................................78

Hunziker, Aaron............................................89

Hurst, Madeline.................................................98

Hurt, Anna ..........................................................89

Hutton, Andrew...............................................29

Hutton, Elaina...................................................104

Hyde, Christopher....................................... 104

Ice, Brianna ..................................................89

Illig, Audrey .................................................104

Imhoff, Sarah.................................................104

Ingles, Luke,..................................................112

Ingram, Rachel...........................................98

Insko, Jarett....................................................89

Istrate, Alex.............................................98

Jackson, Caleb..............................................81

Jackson, Christiana ...................................112

Jackson, Lauren............................................73

Jackson, Malena............................................89

Jacobs, Lauren..............................................21

Jacobs, Myles................................................89

Jacobsen, Lydia ...........................................104

Jagod, Daniel....................................................98

Jamison، Beka..................................................33

Jaquish, Danie|..............................................112

Jarboe, Kaitlin ...........................................104

Jarboe, Kristen..................................................112

Jarrell, Derek.....................................................89

Jarvis, Cheyanne.......................................89

Jegan, Shamin ..............................................98

Jenks, Abigail...................................................89

Jennings, Sarah ...........................................104

Jensen, Amanda...........................................112

Jent, RaeAnn................................................112

Jeoung, Ye-Chan..........................................8 83

Jepma, Ethan ...................................................89

Jerschina, Tracy..........................................83

Jespersen, Carrie.......................................89

Jesson, Christy ..........................................67, 75

Jessurun, Nathan .........................................112

Jiang, Binyang.............................................89

Jo, Yein .......................................................98

Johnson, Gabby........................................67

Johnson, Gabby...........................................75

Johnson, Hannah........................................75

Johnson. Hunter....................................21, 98

Johnson, Jake.....................................34, 122

Johnson, Jebediah.....................................89

Johnson, Jeremy......................................98

Johnson, Jodi.............................................112

Johnson, Justus .....................................113

Johnson, Micah..........................................89

Johnson, Nathan ................................11, 89

Johnson, Pamela......................................122
Johnson, Samuel...........................................113

Johnson, Savannah......................................44

Johnston, Aaron...............................................78

Johnston, Jenna................................................89

Johnston, Kyrie Eleyson...................................98

Jones, Emily...................................................113

Jones, Grant...................................................42

Jones, Isaac.................................................113

Jones, Kathleen ...............................................104

Jones, Kendall.................................................98

Jones, Marquise..............................................89

Jones, Taylor..................................................113

Jones, Theresa................................................113

Jordan, James.................................................89

Jung, JooHee.............................................173

Kain. Josiah.....................................................90

Kaptein, Ashtyn...........................................113

Keck, Aaron................................................80

Kee, Lydia................................................90

Keener. Brianna.............................................90

Keener, Chris....................................................79

Keller, Sierra....................................................90

Kelley, Kirstyn.................................................113

Kemp, Sadie...............................................98

Kempton, Paul................................................104

Kendall, Joel...................................................90

Kennell, Peter...................................................113

Kenniv, Jake.............................................30, 32

Kern, Elise..................................................90

Kick, Jared................................................113

Kidd. Alexander............................................90

Kijak, Kevin................................................90

Killimann, Sammy..........................................64

Kim, Syndiana ...............................................113

Kim, $Y \in$ Eun......................................................98

Kimble, Jeremy...............................................122

Kime, Katelyn...............................................113

KImmel, Celeste.............................................90

Kindig, John....................................................113

KIng, Anna....................................98, 126

King, Colin .....................................................98

King, Doris........................................................104

King, Maliory...................................................

King, Sterling ..............................................13

Kirby, Rachael...............................................113

Kirychuk, Natalia ........................50, 113, 126

Kitchen, Hannah ............................................90

Klabunde, Hannah......................................173

Klein, Emily ...................................................113

Klimek, Jared............................................58, 113

Klimek, Ryan..............................................98

Klotzbach, Kaylie.............................................98

Kniegge, Elianna........................................90

Knight, Kenneth..................................................90

Knoerr, Jayde ...............................................113

Knowies, Madalyn...........................................90

Knowlton, Nathanael.................................98

Knowiton, Nicolas.........................................90

Koehler, Zachary...........................................98

Kohl, Timothy ...............................................90

Kohler, Kaitlin................................................50

Korwan, Katherine...........................................90

Kosker, Emily ...................................................75

Kovacs, Janelle................................................98

Krakora, Abigail....................................21, 104

Kramer, Eva.................................................98

Krater, Adrienne,...................................113, 127 
Krauss, Zachary..............................................113

Kreiner, Timberly,.............................................17

Kristovitch, Brent...............................................90

Kroger, Sarah..................................................90

Kronk, Mary....................................................90

Kropat, Michelle..............................................113

Krudop, Julie....................................................104

Krueger, Janessa...........................................33

Krupinski, Demichelle.....................................53

Kuczynski, Valerie...........................................90

Kuhn, Emily........................................................... 98

Kuhn, John,......................................................113

Kunz, Tanner.......................................................17

Kurschner, Anna..................................104, 127

Kuzma, Katherine...........................................90

Kyser, Wade.......................................................113

Kyser, Wyatt....................................................113

La Croix, Isaac.................................................113

LaChance, Bert..................................................30

LaFlamme, Jaylyn.......................................113

Laing, Kelsey..................................................98

Laird, Bethany.................................................90

Lambert, Luke..................................................113

Lance, Chloe....................................................114

Land, Austin...............................................42, 114

Lange, Summer..........................................7, 90

Lankford, Hannah........................................ 114

Lansford, Josiah.........................................104

Lantz، Daniel......................................................90

Larsen, Lewis.....................................................114

Larson, Jessica..................................................114

Larson, Jonathan..................................30, 114

Lashuay, Jacob...........................................104

Lasich, Laura.............................................45, 98

Lawless, Jenna.................................................90

Lawrence, Breanna.......................................90

Learned, Charles.........................................114

Lebs, Abigail.......................................................98

Ledford, Alianna............................................. 90

Lee, Kevin................................................................114

Lee, Nathan......................................................90

Leeds, Taylor........................................................37

Leenerts, Braden...............................................83

Lehman, Hannah............................................90

Leightenheimer, Beth.......................................3

Leightenheimer, James..................................3

Leitch, Michael..................................................83

Lemesurier, Andrew.....................................104

Leszczynski, Courtney................................90

Lewis, Georgia..............................................114

Lewis, Karissa...................................................90

Lewis, Sarah.....................................................83

Liang, Yuan........................................................90

Lightbody, Lauren.......................................98

Linville, Grant......................................................104

Linville, Katie........................................................98

Linville, Nathan.............................................114

Litteral, Nathan ...............................................99

Lively, Daniel..................................................99

Lockwood، Grace...........................................90

Loger, Amanda ...............................................90

Lollis, Tyler............................................................90

Lopez, Rafael.....................................................37

Lord, Brinslie........................................................114

Lord, Hannah....................................................77

Lord, MacKenzie,...............................................90

Lough, Justin ..........................................38, 114
Loula, Trevor.....................................................99

Love, Addison..................................................114

Lowry, Thomas................................................99

Lucas, Hannah................................................16

Luckhof, Benjamin.........................................83

Luiken, Andrew..............................................99

Luke, Braylen...................................................90

Lukyanov, Vitaliy ........................................83

Luman, Emma................................................99

Lund, Andrew.................................................90

Luo, Yimiao........................................................90

Luttenegger, Anna.....................................104

Lyall, Timothy....................................................90

Lyford, Kiara....................................................90

Lynch, Naomi.................................................82

Lynn, Aaron .............................................32, 114

Lynn, Danielle...............................................32

Macnamara, Alisha....................................114

Mader, Allison ....................................................71

Magnuson, Jason.........................................90

Mahaffey, Atticus...........................................97

Mahek, Nick.....................................................28

Malashevich, Valeryia.............................99

Mangold, Dylan.............................................114

Mangum, Jesse..............................................114

Manley, Ethan.................................................99

Mantek, Kirsten.................................................97

Markle, Rayna...............................................91

Marks, Katherine............................................9]

Marques, Tamara ..........................................82

Marrie, Megan..........................................48, 114

Marshall, Malachi......................................114

Martin, Ben.....................................................8 82

Martin, Isaiah......................................................91

Martin, Sydney................................................174

Martone, Aleah..............................................91

Marvin, Adam................................................91

Masiakiewicz, Sean....................................114

Mason, Daniel..................................................91

Matej, David....................................................91

Matheson, Cara.............................................83

Mathew, Rufus ..................................52, 53, 91

Matthews, Kelsey .......................................45

Matthews, Makayla.....................................91

Matthias, Corrie ...............................................50

Maue, Sarah .....................................................91

Maughmer, Brandon.................................70

Maurer, Noah.................................................99

May, Allison.......................................................91

Maynard, Madison.....................................91

Mayse, Makenzie.............................................58

Mayse, Mariah..................................................6

Mccabe, Kelsey ..........................................114

McCain, Michael..........................................104

McClain, Elizabeth.........................................91

McClain, Macy................................................11

McClain, Thaddeus....................................114

McClung، Dominic .......................................91

McCormick-Nerlinger, Matthew..............91

McDole, Alexander.........................................97

McDugle, Jonathan ...................................114

McElroy, James...........................................104

McGill, Catherine.........................................99

McGinnis, Katelyn.........................................91

McGuffey, Nathan........................................97

McKanna, Micah.........................................99

McKanna, Tad...............................................114
Mckay, Katherynn.........................................91

McKenna, Laura..............................................99

McMahon, Matthew.....................................99

McMurray, Alexandra................................104

McPherson, Halee.....................................104

Meisel, Sarah ....................................................114

Melchior, Ross..................................................76

Melinger, Ahna...............................................99

Melnick, Abraham.......................................114

Mendel, Gregg...........................................114

Mentzer, Stephen..........................................99

Merk, Ryan.........................................................42

Merkel, Jana....................................................91

Merrick, Justin..................................................91

Messer, Cynthia.........................................126

Messer, Griffin.....................................................91

Metcalf, Micah............................................91

Metzger, Kylee................................................174

Meyer, Kathryn.............................................114

Miedema, Carter...........................................53

Miller, Brooke....................................................... 77

Miller, Caleb.....................................................91

Miller, Chris...................................................11, 10

Miller, Joshua.....................................................91

Miller, Katelyn....................................................99

Miller, Macy......................................................104

Miller, Sarah .......................................................91

Milligan, Katie...........................................45, 99

Mills, Kristen................................................99, 115

Milstead, Gretchen.......................................99

Minier, John......................................................82

Miskimen, Matthew........................................9]

Mitchell, Aricka..............................................104

Mitten, Julianna.................................................31

Mobed, Sarah................................................91

Moldenhauer, Michael................................91

Molinari, Jana.................................................91

Montross, Joshua............................................115

Moore, Kelton.................................................104

Moore, Lexi........................................................28

Moore, Rachel..........................................42, 97

Morimizu, John...............................................115

Morrison, Brooklyn............................................97

Moses, Benjamin..........................................104

Moses, Molly.....................................................99

Moses, Taylor..................................................115

Moss, Cole.........................................................72

Mount, Tallon......................................................91

Mountz, Weston.................................................17

Mouring, Abigail.............................................115

Moyer, Greta...................................................115

Mrowiec, Byron.............................................99

Mrozek, Andrew..............................................115

Mundell, Jacob...........................................104

Mundell, Joshua..............................................91

Munoz, Antonio.........................................45, 50

Munoz, Juan...................................................99

Murch, Rebecca...........................................82

Murphy, Kelly.......................................................115

Murray, Katie......................................................1175

Musgrave, Jesse .............................................91

Myers, Austin.....................................................115

Naegeli, William.............................................99

Naselli, Andy.....................................................25

Naugle, Madison............................................91

Nealis, Joe...........................................................25

Neer, Laura..........................................................9] 
Index

Neikirk, Luke........................................................91

Nelson, Abigail................................................91

Nelson, Ariana................................................99

Nelson, Meredith ................................................99

Nemni, Natalie ................................................91

Nesmith، Adam............................................115

Nester, Brian.............................................60, 123

Neumann, Madeline.....................................99

Nevarez, Elizabeth...........................................92

Nevels, Benjamin............................................92

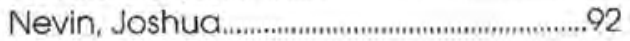

Newman, Rachel...........................................99

Nguyen, Nguyen.............................................92

Nichols, Hannah............................................92

Nichols, Stephen............................................25

Noel, Joshua....................................................99

Nohrer, Hannah............................................ 92

Noll, Taylor............................................................65

Norman, Danielle...........................................92

Norman, Grace...............................................75

Norman, Torrie ..............................................92

Norris, Jillian.....................................................92

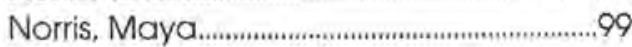

Northcutt. Mackenzle....................................65

Nuil, Krystal.....................................................115

Nunan, Taylor......................................................104

Nussbaumer, Andrew..........................43, 92

Nyquist, Richard..............................................99

Oakley, Erica...................................................92

O'Brien, Logan..................................................104

O'Brien, Lucas................................................92

O'Brien, Madeline..........................................92

O'Brien, Timothy................................................72

O'Brien, Whitney..........................................6. 115

Ochoa, Alicia..................................................92

O'Donnell, Timothy.........................................115

Ogden. Jillilan....................................................92

Olander, Nathanael......................................99

Oldham, Beth........................................13, 21, 99

Oliver, Brittany......................................................99

O'Neel, Caleb...................................18, 34, 122

O'Neil, Kaileb.......................................................

O'Neil, Kaileb....................................................30

O'Neil, Morghan.....................................115, 127

Ooms، Ethan.......................17, 33, 54, 104, 127

Osborne. James.............................................115

Osborne, Nathan......................................33, 82

Osbourne, Samuel..........................................99

Otakasongo, Joyce........................................92

OHo, Nikolas.....................................................92

Ozichukwu, Ojukwu..........................................92

Pace, Taylor.................................................80, 115

Painter, Caroline ..............................................104

Paisley, Molly ...................................................115

Paris, Alexandra.................................................99

Paris, Sorrel,........................................................115

Parker, John........................................................92

Parks, Kristy...................................................104

Parry, Kayla......................................................115

Parschaver, Shelby...........................................99

Parsons, Josiah..................................................83

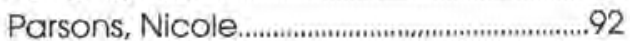

Parsons, Sarah......................................................77

Parsons, Timothy ..........................................115
Pataky, Julianne..........................................92

Patricca, Brianna...........................................115

Patricca, Jeremy.............................................99

Patrick, Jillian................................................92

Patterson, Olivia..............................................81

Patterson, Rebekah....................................92

Paulus, Jason......................................................99

Payton, Amar.....................................................92

Peek, Cameron..............................................71

Pennington, Sarah......................................104

Pensworth, Joel...........................................104

Perschbacher, Bryan..................................115

Pessoa, lan.........................................................92

Peters, Hannah..............................................115

Peters, Nicole..............................................115

Petersen, Andrew........................................50

Petersen, Brent..................................................115

Petersen, Kristina..............................................99

Peterson, Andrew..........................................50

Peterson, Andrew......................................79

Peterson, Gwendolyn....................................44

Peterson, Katriona......................................92

Peterson, Tasha..................................................115

Petrin، Mark...................................................92

Petron, Donald...............................................104

Philipps, Caroline.................................29, 104

Phillips, Natalie..............................................104

Pike, Kaitlynn.............................................79, 92

Pisarsky, Autumn ........................................92

Pitcher, Balley.....................................................58

Pitman, Nicklis..............................................92

Pitstick, Cameron........................................... 115

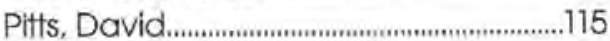

Pizarro, Anna....................................................82

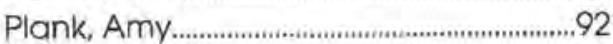

Plank, Monica.................................................. 99

Plank, William...............................................104

Plunkett, Andrew.............................................

Poindexter, Melanle......................................116

Poling, Dawson.........................................72, 92

Pomles, Nathan ..................................................82

Poole, Kelly.......................................................28

Porter, Beth ...........................................................50

Portillo, Gabriel.............................................116

Posecznick, Benjamin...................................116

Posecznick, Daniel......................................92

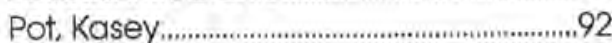

Potts, Breanna.................................................99

Potts, Jamle..........................................................116

Potts, Rachael..............................................116

Powell, Jennifer...........................................92

Powell, Kimberly..............................10, 44, 104

Price, Rachel................................................116

Prichard, Aria...............................................116

Printz, Mia............................................................92

Przypek, Celine,...............................................99

Pullins, Ablgail...........................................................75

Quandt, Hannah........................................92

Quandt, Lydia.............................................100

Quick, Megan............................................116

Quinter, Rebekah........................................92

Quirple, Jocelyn ........................................38, 65

Raczykowski, Deborah...............................92

Raffia, Luciano...............................................92

Ragan, Austin ................................................100

Ragan, Dillon..................................................104

Rager, Ryan..................................................100
Ramachandran, Shruthi.................52, 116

Ramsey, Allison..........................................82

Ramsey, Rachel.....................................116

Raquet, Carolyn.......................................105

Ratkey, Benjamin.......................................116

Ratliff, Jacob.

105

Ratliff, Joshua..............................18, 30, 116

Rea, Silas............................................35, 123

Redondo, Keyla......................................105

Reed, Abby...............................................100

Reed, Katherine .........................................116

Reeder, Zachary.........................................49

Reid, Tyler.......................................................

Reinhard, Nathan....................................92

Reinhard, Tyler...........................................74

Renne, Shai.................................................716

Renner, Andrew.........................................82

Rhoades, Trevin.........................................105

Richmond, Benjamin..............................100

Riddle, Ashley.............................................100

Riley, Catherine,...........................................92

Ring, Kaitlyn......................29, 30, 31, 54, 116

Ring, Rachel..............................................93

Ringendl, Daniel........................................52

Ringstrand. Jake..............................44, 100

Ripperger, Daniel...................................... 100

Rivas, Abigail.............................................105

Rivera, Samantha..................................93

Robbins, Dawn .........................................116

Roberts, Madison.....................................100

Robertson, Blake.....................................116

Robey, Jared...............................................93

Robinette, Cara........................................116

Robyn, Melissa..........................................116

Rockich, Logan........................................93

Rogers, Kamen......................................49, 93

Roseman, Cameron .................................93

Rosenbalm, Madison...............................93

Ross, Aaron ...............................................100

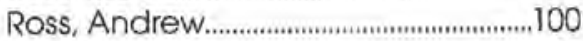

Ross, Shawn .................................................44

Roth, Caroline ..................................................93

Roudebush, Trey.........................................93

Rouland, Mary Ann .................................100

Rowe, Wes..................................................77

Rowell, Anna..........................................100

Rubosky, Zachary........................................49

Ruckersfeldt, Julianna............................116

Ruegsegger, Charity................................52

Ruegsegger, Sadie................................116

Russell. Abigail..............................................105

Russell, Lily...................................................176

Russo, Carolyn ............................................100

Russo, Jake......................................................32

Rutan, Jessica...............................................

Ryan, James,......................................50, 116

Ryan, Karis.................................................116

Sabo, Karolyn.............................................116

Saieg, Robert................................................82

Sallstrom, Gabriel..............................30, 116

Salomon. Abbey...........................................93

Salow, Maria................................................93

Samuelsen, Stephen..................................116

Sanchez, Elijah.........................................76

Sanders, Jacob................................... 58, 117

Sanders, Sarah ...........................................105

Sanderson, Chad.........................................93 
Santavicca, Drayton ...................................83

Sareno, Danielle,............................................93

Sareyka, Hannah........................................65

Saucier, Brianna..............................................100

Scanlan, Blake...............................................83

Schaefer, Lauren...........................................93

Schantz, Julia.......................................100

Schlabach, Justin ..........................................93

Schlichtmann, Jacob..................................100

Schluetz, Dawn...................................................21

Schoeneweis, Phoebe................................117

Schultz, Julia.....................................................45

Schultz, Russell..............................................93

Schulze, Emilie.................................................100

Schuman, Michelle.........................................93

Schweibold, Kimberly..................................

Schweppe, Sarah........................................93

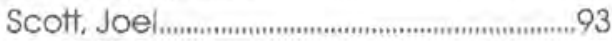

Scott, Katara....................................................100

Scouten, Jonathan.................................74, 117

Seabra, Kayla...............................................100

Seals, Lindsey............................................28, 117

Semmelroth, Kyle...........................................100

Senseman, Blake....................................... 93

Setzkorn, Lauren................................................117

Shade, Steven ..............................................93

Shaffer, Abigail..................................................100

Shaffer, Emelia...............................................117

Shaffer, Hannah.............................................100

Shaffer, Julia......................................................83

Shaffer, Rachel..........................................100

Shamburger, Sarah........................................117

Shearer, Amlel...............................................105

Sheckler, Jeremy........................................117

Sheehan, Joshua.........................................117

Shemelia, Presley-Peyton...........................105

Shepard, Malaya..............................................93

Shepherd, Caleb..........................................100

Shinabery, Trovis .........................................93

Sholl, Andrew....................................................74

Shrum, Kelsey ...................................................105

Siefert, Victoria.................................................93

Simmler, Anna...................................................117

Simmons, Lauren............................................100

Sinkonis,Kristina...............................................93

Sitler, Hannah.....................................................83

Sizer, Elizabeth....................................................

Skaer, Zachary......................................................6

Skidmore, Joseph...........................................93

Skoczen, AnnaMarie..................................100

Slack, Suzanna........................................26, 117

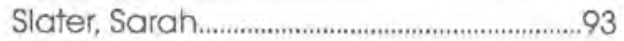

Sllfer, Brandon...................................................105

Slyby, Maggie..................................................45

Smart, Taylor.................................................93

Smid, Benjamin ..............................................93

Smith. Alexis....................................................117

Smlth, Andrew..................................................93

Smith, Benjamin ...........................................100

Smith, Cameron.............................................30

Smith, Carrie......................................................117

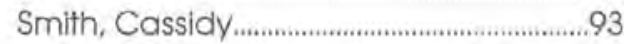

Smith, Greg ........................................................68

Smith, Jared................................................117

Smith, Jeremy........................................13, 117

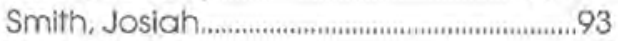

Smith, Kaitlyn...................................................100
Smith, Kristina

Smith, Rebekah. .. .93

Smith, Ryan.

...28, 117

Snow, Abigall.

$29,30,117$

Snow, Sophia.

93

Snyder, Abigall...................................................117

Sodonis, Chloe...............................................100

Sohn, Jessica ...................................................117

Solokha, Timothy.........................................93

Solomon, Krlstina,.............................................93

Sommers, Kirsten.....................................54, 117

Southard, Joshua.............................................117

Southwell, Elaina.............................................117

Spangler, Alex.....................................................83

Spansel, Alyssa.....................................52, 117

Sparks, Isaac...................................................93

Spellman, Ched ,...........................................122

Spencer, Kyle.....................................................117

Spencer, Mark...................................................50

Spencer, Reed .....................................................93

Springmeyer, Chase......................................93

Spurgeon, Haley...........................................105

Squler, Robert......................................................117

Sririntrachai, Kanyapak ..............................117

St. Onge, Alex.......................................105, 127

Stahlhut, Jacy .................................................100

Stahlnecker, Nathaniel.................................117

Stallard, Justin .................................................. 117

Standley, Andrew...............................12, 26, 50

Stanford, Lane ...............................................93

Stanhope, Jonathan......................................93

Staufer, Amanda ............................................118

Staufer, Sarah ................................................118

Steenwyk, Natalie,.....................11, 33, 54, 105

Steger, Jessica, ............................................79

Steigerwald, Zoe......................................79, 94

Steinert, Shelly.......................................................118

Steptoe, lan........................................................100

Stevenson, Grace............................................94

Stieferman, Lauren.....................................33

Stikeleather, Ryan...........................................100

Stimpson, Noah...................................................94

Stokes, BriAnn .....................................................17

Stoneberg, Ethan.............................................94

Stouffer, Madeline..................................................6

Stringfield, Logan.............................................118

Strong, Koinonla............................................118

Stuercke, Hannah...........................................94

Stweart, Morgan ...........................................94

Sullivan, Ethan.........................................74, 118

Sullivan, John..................................................94

Summy, Emmel.............................................94

Surland, Alethea.............................................118

Sutherland, Jonathan...................................94

Sweeney, Steven.......................................10, 94

Swieringa, Abigail..........................................94

Swinford, Leah ...................................................100

Switzer, Lydia.......................................................94

Switzer, Micah ...................................................105

Symonette, Kevin....................................42, 118

Talento, Emily..........................................17, 105

Tan, Elizabeth.................................................94

Tanner, Jessica..................................................118

Taylor, Jonathan............................................118

Taylor, Lindsey.............................................118

Taylor, Mya......................................................100

Taylor, Olivia................................................82
Tenhove, Connor,............................................70

Terhaar, Claire...............................................94

Terracino, Brooke............................................118

Terrell, Rachel...........................................105

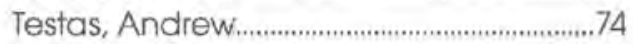

Thomas, Gabriel..............................................94

Thomas, Isaac..................................................82

Thomas, RaeAnna........................................118

Thompson, Rosie.......................................73, 83

Thompson, Samuel..........................................94

Thong, Jonathan...........................................118

Thorsen, Austin ............................................94

Thullen, Max..................................................94

Tiberg, Jeremy.....................................................118

Tiell, Ray..................................................10, 25

Tillinghast, Kyle...........................................100

Timmons, Hannah ........................................100

Tlmmons, Noah.................................................100

Tomic, Anna .................................................94

Tomic, Kelly......................................................118

Tomlinson, Jonathan....................................100

Tomlinson, William............................29, 30, 118

Toth, Caleb.................................................94

Toungate, Brendan.......................................76

Townsend, Noah............................................105

Tracy, Rachel.............................................. 94

Trainer, Megan.....................................................38

Trautmann, Falth..............................................118

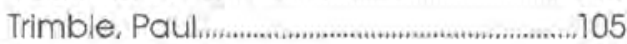

Tsibouris, Christopher...................................100

Tso, Dawson .....................................................10

Tucker, Katrina............................................100

Turnbull. Allison................................................100

Turner, Rachel.................................................94

Tuttle. Andrew...............................................28

Twitchell, Brooke ..............................................94

Tyson, Jennifer..............................................37, 118

Uhland, Alison .................................................118

Urban, Daniel..................................................101

Van Denmark, Craig...................................94

Van Dromme, Alex.........................................94

Van Dyck, Creslyn...........................................65

Van Dyne, Gerrit................................................94

Van Patten, Joshua..........................................94

Van Strien, Michelle........................................118

Van Veldhuizen, Emma................................94

Vance, Caleb............................................94

Vance, David .................................................101

Vance, Leah.................................................118

Vander Have, Tim.........................................33

Vandergrift. Alyssa.........................................94

VanDerMolen, Tyler........................................118

VanHorn, Kollin ................................................70

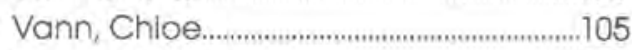

Varga, Olivia .....................................................101

Veltman, Ashleigh..........................................118

Veness, Mikayia.............................................101

Verhey, Brianna...............................................94

VerSchneider, Elise........................................94

Vethanayagam, Keerthi..............................94

Viaud-Murat, Etienne....................................118

Vissing, Alexzandrya........................................101

Vroegop, Hayden.......................................118

Vroegop, Jeremiah.......................................11

Wacome, Carolline....................................101

Wade, Macy....................................................94

Wagner, Allyson............................................118 


\section{Index}

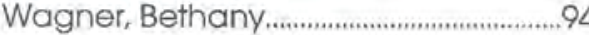

Wagner, Isaac.................................................17

Wagner, Joshua.............................................94

Wagoner, Joseph........................................94

Waite. Nidia.....................................................118

Walker, Emily................................................94

Walker, Virginia..............................................118

Wallace, Leslie..................................................94

Wallace, Michael.......................................94

Wallace, Rebekah.....................................105

Wallenbeck, Jenna.....................................94

Waller, Aaron..............................................119

Walter, Elizabeth ........................................94

Walters, Kaitlyn ..............................................119

Waltz, lan ..........................................................58

Ward, Anna .....................................................

Ward, David....................................................119

Ward, Nicholas...........................................95

Ware, Erica...................................................119

Waterman, Marcus.............................33, 105

Watkins, Samuel............................................95

Watson, David.............................................82

Waywood, Emma..........................................21

Weaver, Carl....................................................95

Webb, Liana..................................................95

Weeks, Kelly......................................................95

Weigner, Brienna...........................................101

Weimer, Max.................................................105

Weinhold, Alec...............................................74

Weiss, Aaron ................................................101

Welch, Kayla............................................18, 52

White, Thomas...............6, $52,24,36,37,38$

Whitney, Megan.........................................17

Whittaker, Kaylynn........................................95

Wideman, Kimberlyn.................................119

Wilfong, Peggy ..............................................45

Wilkerson, Taylor ...........................................68

Wilkins, Noel......................................................101

Welch, Kayla.............................................. 18, 52

Welker, Carina................................................101

Wellin, Hudson...........................................95

Wells Rosemary...........................................119

Wells, Daniel...................................................95

Wells, Jacob..............................................101

Wells, Joshua....................................................119

Wenzinger, Rachel......................................119

Werling, Madison............................................37

Wessels, Emma..............................................119

Westenberg, Jessica........................105, 126

Weston, Mariah ................................................95

White, Allison..................................................119

White, Philip.

Williams, Alicia.............................................179

Williams, Drew..................................................95

Williams, Greg..............................................64

Williams, Rebekah.......................................119

Williams, Zachary.......................................119

Williamson, Jack.........................................101

Williamson, Kelsey.........................................119

Willow, Lauren ..................................................75

Wilmot, Kristen...............................................119

Wilson, Ethan....................................................95

Wilt, Michael...........................................32, 119

Winey, Josiah.
Wingert, Katie..................................................33

Winsor, Corrin .............................................101

Winter, Katelyn.................................................101

Winter, Ken....................................................25

Winter, Tara .....................................................25

Winters, Rachel...........................................101

Witt, Natasha.....................................................101

Witt, Tineka....................................................119

Wolford, Abigail.............................................

Wolterman, Lydia..........................................101

Wong, Chi Hang.........................................95

Wood, Isaac..................................................6, 69

Woodall, lan .....................................................33

Woodall, Moriah.............................................95

Woodard, Abby ...............................................

Woodman, Laura............................................101

Woolverton, Abigail......................................101

Woolverton, Joshua ......................................119

Wormald, Steven..........................................30

Wright, Allie.........................................................119

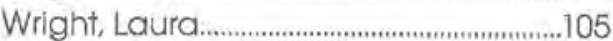

Wright, Natalie.................................................79

Wymer, Macey.................................................95

Xuereb, Sabrina..............................................119

Yannie, Hannah.............................................101

Yeager, Jack........................................................79

Yee, Joshua.......................................................95

Yerkey, Annalynn...........................................95

Yoder, Jeffrey.....................................................95

Yosinski Jennifer..................................................83

Young, John........................................................105

Ysais, Matthew...............................................119

Yutzy, Delaney................................................105

Zahoransky, Sarah..........................................95

Zamora, Timothy...........................................101

Zawadzki, Grant...............................................70

Zell, Micah........................................................95

Zellenga, Emma................................................101

Zellner, Brynna...................................................101

Zettlemoyer, Hannah....................................105

Zhao, Xuecen

Ziamba. Faith...................................................95

Zichi, Emily............................................................95

Zieg, Allison........................................................95

Ziegenfus, Jenah............................................119

Zook، Katelyn 

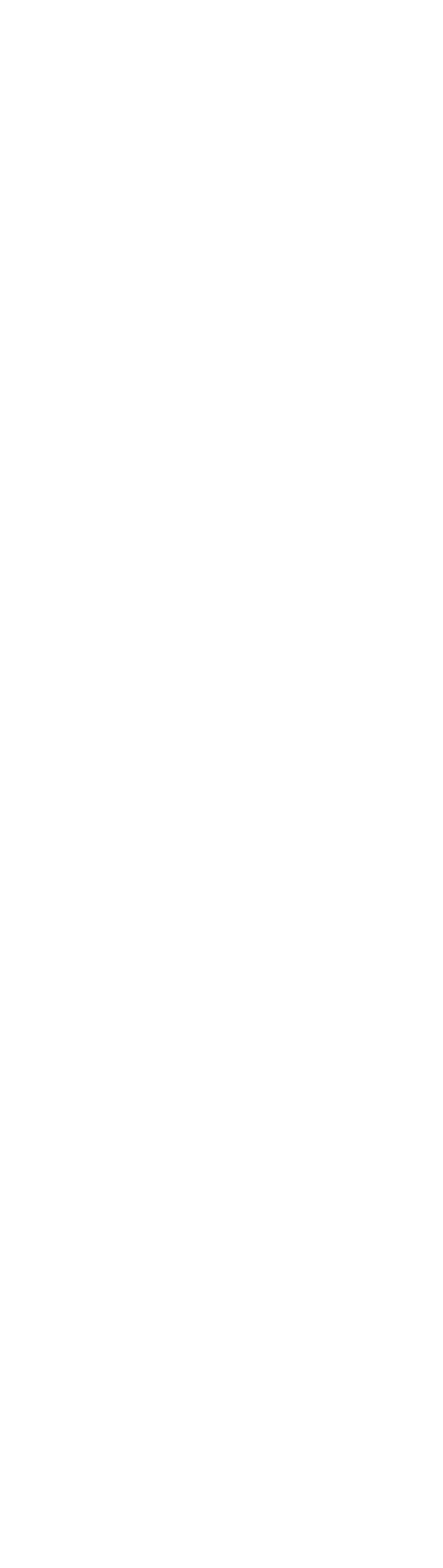



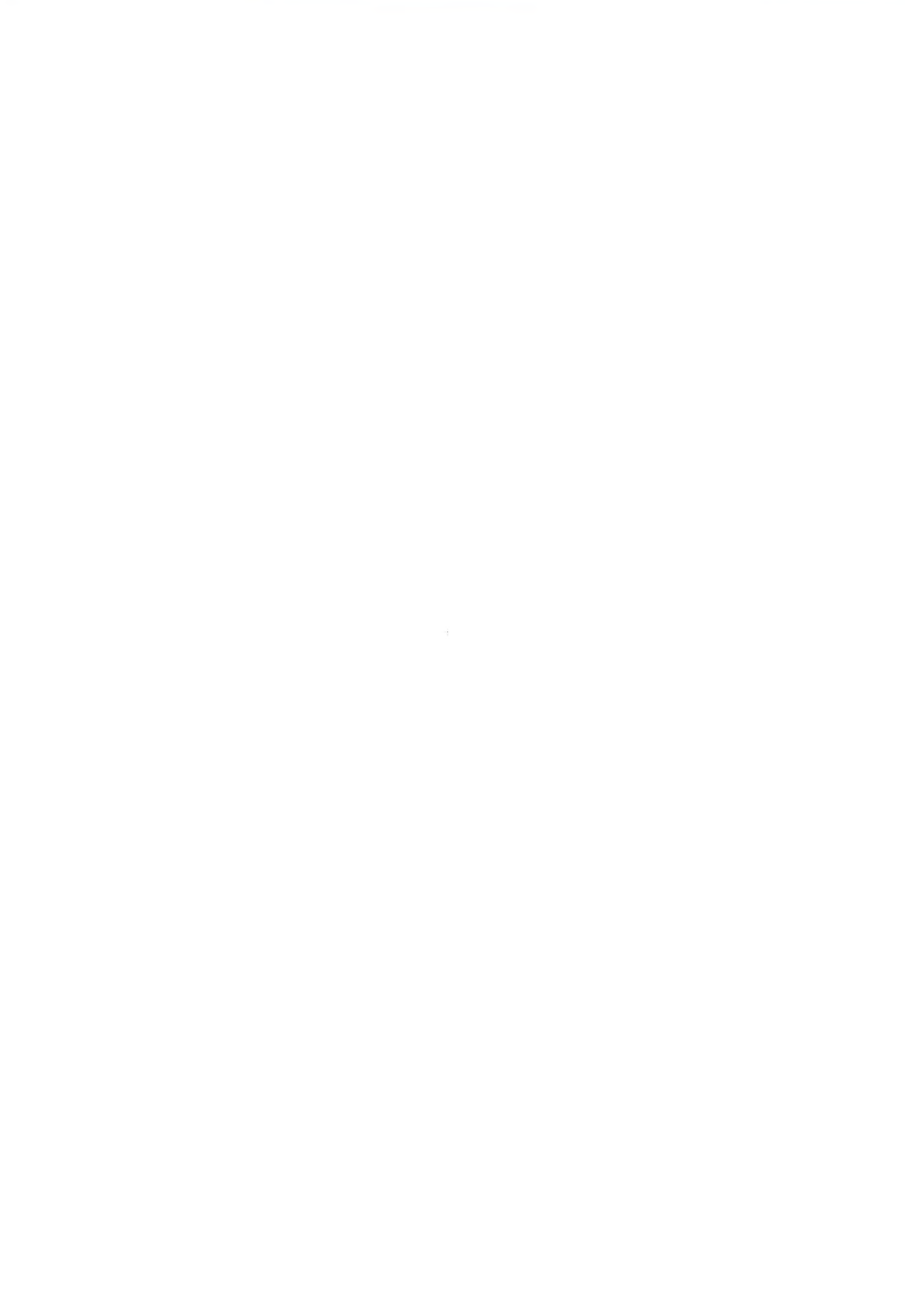


